
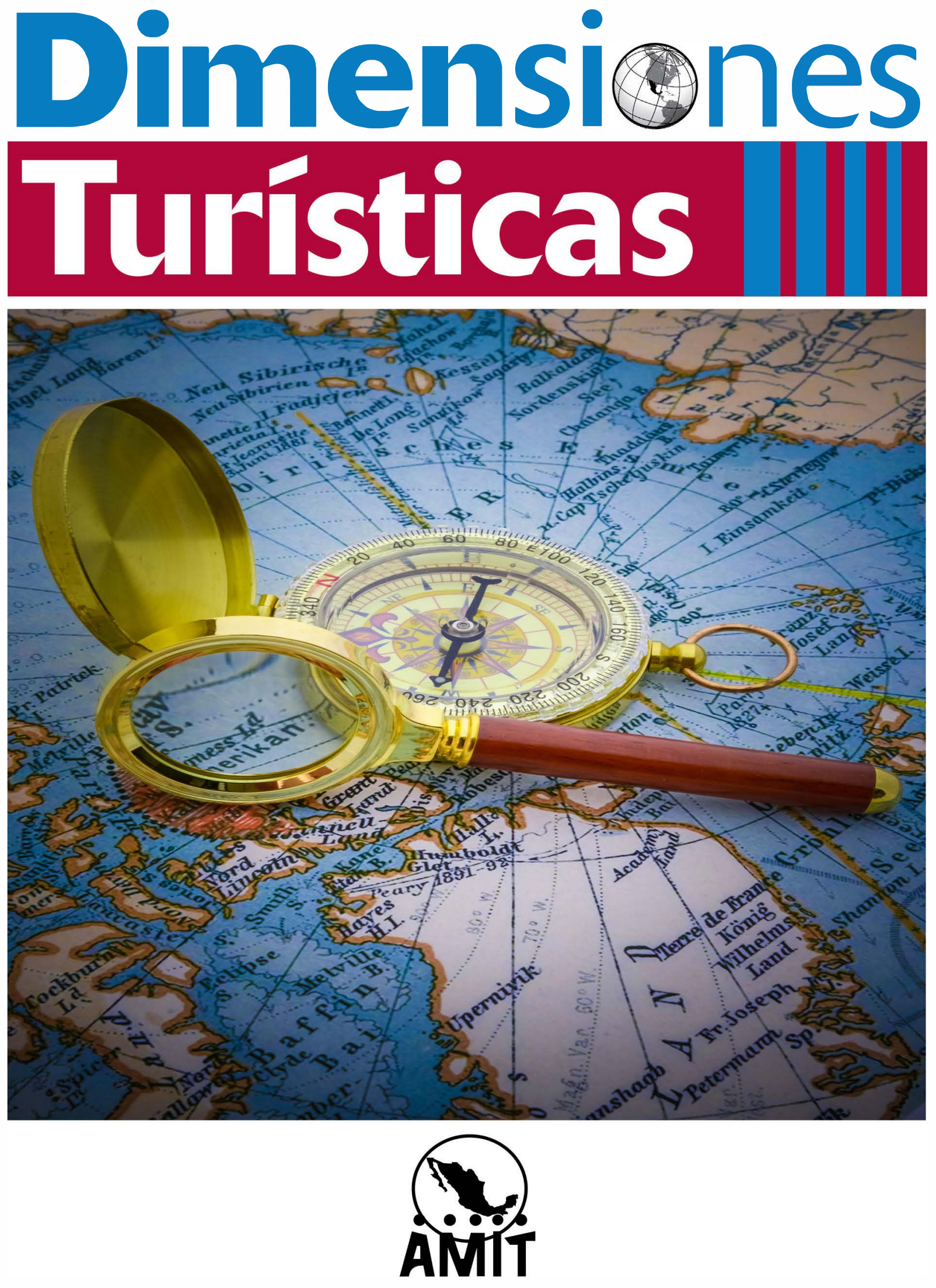

Publicación semestral Vol. 2 Núm. 2 Enero-junio 2018 ISSN: en trámite Academia Mexicana de Investigación Turística, A. C 

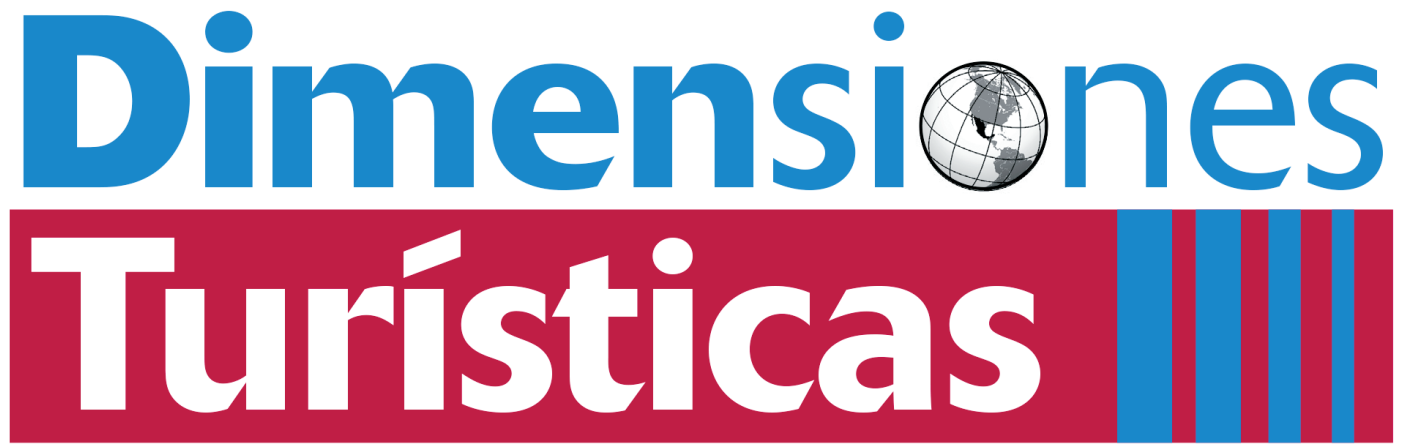

Publicación semestral • Vol. 2 • Núm. 2 • Enero-junio 2018 •ISSN: en trámite https://doi.org/10.47557/NRFB1518

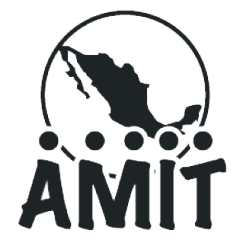

Academia Mexicana de Investigación Turística, A. C. 


\section{Academia Mexicana de Investigación Turística, A. C.}

La Academia Mexicana de Investigación Turística, A.C. (АMIт), de acuerdo con sus estatutos es una sociedad sin fines de lucro cuyos miembros, adscritos a universidades, centros de investigación u otro tipo de entidades públicas y privadas, proceden del campo de estudio del turismo así como de disciplinas como la geografía, economía, sociología, comunicación, antropología, psicología, administración, ciencia política, demografía, ecología, entre otras. La Aміт pretende generar un espacio de trabajo colegiado entre los investigadores(as) dedicados a los estudios del turismo.

Directora de Dimensiones Turísticas

Nora Leticia Bringas Rábago

Teléfono: +52 (664) 6316300 ext. 1306

Correo electrónico: amit.dimentur@gmail.com

Contacto de asistencia

Teresa López Avedoy

Teléfono: +52 (664) 6316300 ext. 1315

Correo electrónico: amit.dimentur@gmail.com

Diseño, formación y cuidado de la edición: Alfa/Zeta

Ma. Eugenia Varela Carlos

zet.alfa@gmail.com

Dimensiones Turísticas, Vol. 2, Núm. 2, año 2, enero-junio 2018, es una publicación semestral, editada por la Academia Mexicana de Investigación Turística, Villa Costa Azul núm. 55, Mediterráneo Club Residencial, Mazatlán, Sinaloa, C. P. 82113, tel.: + 52 (664) 6316300 ext. 1306, https://dimensionesturisticas.amiturismo.org, amit.dimentur@gmail.com. Editora responsable: Nora Leticia Bringas Rábago. Reserva de Derechos al Uso Exclusivo: 04-2018-082217054200-203, ISSN: en trámite, ambos otorgados por el Instituto Nacional de Derechos de Autor. Responsable de la última actualización de este número, administrador web de la Academia Mexicana de Investigación Turística: Carlos Vladimir Ruelas González, Carretera Escénica Tijuana-Ensenada Km 18.5, San Antonio del Mar, Tijuana, Baja California, C. P. 22560, fecha de última modificación, 11 de enero de 2018.

Las opiniones expresadas por los autores no necesariamente reflejan la postura del editor de la publicación. 


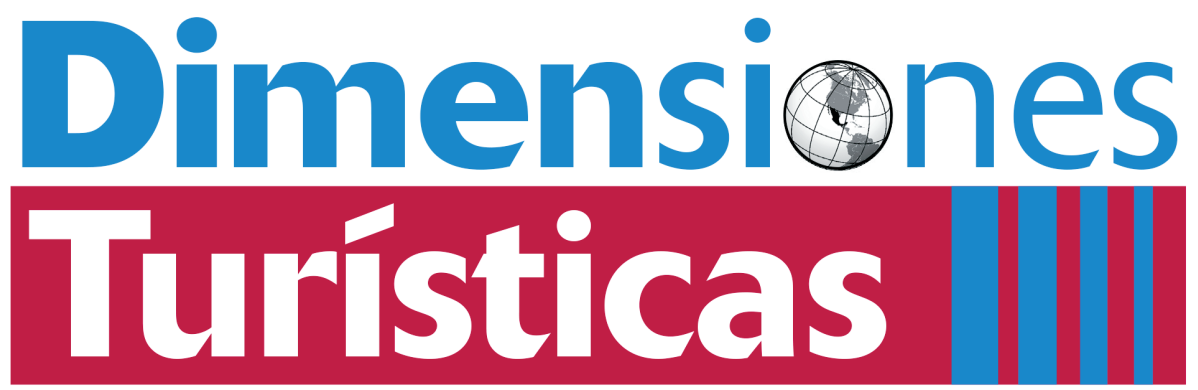

Publicación semestral • Vol. 2 • Núm. 2 • Enero-junio 2018 • ISSN: en trámite

Nora Leticia Bringas Rábago

DiRECTORA

\section{Consejo científico}

Salvador Gómez Nieves • Universidad de Guadalajara, México

Daniel Hiernaux-Nicolas • Universidad Autónoma de Querétaro, México

Raquel Huete Nieves • Universidad de Alicante, España

Antonina Ivanova Boncheva - Universidad Autónoma de Baja California Sur, México

Alfonso de Jesús Jiménez Martínez • Universidad Autónoma de Guerrero, México

Tomás López Guzmán • Universidad de Córdoba, España

Alejandro Palafox Muñoz • Universidad de Quintana Roo, México

Agustín Santana Talavera • Universidad de La Laguna, Canarias, España

Regina G. Schlüter • Centro de Investigación y Estudios Turísticos, Argentina

Rocío del Carmen Serrano Barquín - Universidad Autónoma del Estado de México

Pablo Szmulewicz, Universidad Austral de Chile, Chile

Miguel Ángel Troitiño Vinuesa, Universidad Complutense de Madrid, España

José Fernando Vera Rebollo • Universidad de Alicante, España

\section{COMITÉ EDITORIAL}

Andrea Muñoz Barriga • Pontificia Universidad Católica del Ecuador, Ecuador Alfonso González Damián • Universidad de Quintana Roo, México Maximiliano Korstanje • Universidad de Palermo, Argentina Álvaro López López • Universidad Nacional Autónoma de México Ana Pricila Sosa Ferreira - Universidad del Caribe, Quintana Roo, México Basilio Verduzco Chávez • Universidad de Guadalajara, México Lilia Zizumbo Villarreal • Universidad Autónoma del Estado de México, México 


\section{Dimensiones Turísticas |||}

Publicación semestral

Vol. 2, Núm. 2

Enero-junio 2018

ISSN: en trámite

\section{INDEX}

Nora Leticia Bringas Rábago

Articles

Ismael M. Rodríguez Herrera Astrid Vargas VÁZQueZ

Lucía González ToRreros

Kennedy Obombo Magio Mónica Velarde

Federico Gerardo ZúñIga Bravo

Víctor Manuel Mora Torres

ESSAY

Daniel Hiernaux-Nicolas

\section{BOOK REVIEW}

Rodrigo Espinoza SÁnchez Rosa María Chávez Dagostino

\section{Congress Review}

Irma Magaña Carrillo Maribel Osorio García
9-26 Reticular approach to the scientific production on tourism by mexican researchers

27-52 Geological heritage values of Sierra La Primavera: Proposal of geotourism

53-77 Ecotourism and conservation: Perspectives and practices in Los Tuxtlas Biosphere Reserve, Mexico y Maasai Mara Biosphere Reserve, Kenya

79-101 Patrimonialization and Tourism in Zozocolco de Hidalgo, Veracruz. Ethnicity, Culture, Nature and Putting in Value

103-122 Pilgrimage, Tourism or Religious Tourism? Reinterpretation of Sanctuary of the Lord of the Hill, State of Mexico

123-132 More than three decades of tourism research in Mexico: Some reflections

133-135 González Damián, A. (2017). Social construction of the tourist experience. A coproduction of tourists and hosts based in real facts.

137-143 XI International Congress of the АмІт: "30 years of Tourism Research in Mexico"

Acerca de Dimensiones 144-156

TuRÍSTICAS 


\section{Dimensiones Turísticas |||}

Publicación semestral

Vol. 2, Núm. 2

Enero-junio 2018

ISSN: en trámite

\section{ÍNDICE}

Nora Leticia Bringas Rábago

Artículos

Ismael M. Rodríguez Herrera

Astrid Vargas VázoueZ

Lucía González Torreros

Kennedy Obombo Magio

Mónica Velarde

Federico Gerardo ZúñIga Bravo

Víctor Manuel Mora Torres

\section{NOTA CRÍTICA}

Daniel Hiernaux-Nicolas

\section{ReseñA}

Rodrigo Espinoza SÁnchez

Rosa María Chávez Dagostino

\section{Reseña de CONGRESO}

Irma Magaña Carrillo Maribel Osorio García
7-8 Presentación

9-26 Aproximación reticular a la producción científica sobre turismo realizada por investigadores mexicanos

27-52 Los valores del patrimonio geológico de la Sierra La Primavera: Las oportunidades para el geoturismo

53-77 Ecoturismo y conservación: Perspectivas y prácticas en las reservas de la biósfera de Los Tuxtlas, México y Maasai Mara, Kenia

79-101 Patrimonialización y turismo en Zozocolco de Hidalgo, Veracruz. Etnicidad, cultura, naturaleza y puesta en valor

103-122 ¿Peregrinación, turismo o turismo religioso? La reinterpretación del Santuario del Señor del Cerrito, Estado de México

123-132 Más de tres décadas de investigación turística en México: Algunas reflexiones

$133-135$

González Damián, A. (2017). Construcción social de la experiencia turística. Una cooproducción de turistas y de anfitriones basada en hechos reales.

137-143 XI Congreso Internacional de la AMIT: "30 años de Investigación Turística en México"

Acerca de Dimensiones 144-156

TuRÍSTICAS 


\section{Presentación}

partir de una investigación bibliométrica y con apoyo de la técnica de
análisis de redes, Ismael Rodríguez y Astrid Vargas hacen una revi-
sión de las publicaciones realizadas por especialistas miembros del
Sistema Nacional de Investigadores (sni) durante el periodo 2010-2016, con
la finalidad de identificar la colaboración científica en el campo del turismo,
encontrándose un incremento de la publicaciones -sobre todo en español- en
revistas internacionales y con pares extranjeros, y una escasa o nula coope-
ración entre colegas adscritos al sni, no obstante se observa la presencia de
subredes regionales de publicación mayormente asociadas con los progra-
mas de posgrado.

La sierra La Primavera, cercana al Área Metropolitana de Guadalajara, en Jalisco, presenta una gran biodiversidad basada principalmente en sus recursos geológicos, mismos que Lucía González Torreros se dio a la tarea de inventariar y evaluar con objeto de determinar el potencial que encierran para ser aprovechados con fines turístico-recreativos, no solo por el valor paisajístico de la sierra, sino también por la gran cantidad de geositios que alberga y que son propicios para la práctica de actividades al aire libre como senderismo y ciclismo, entre otras, lo que brinda la oportunidad de promover el desarrollo local de esta región.

Kennedy Magio y Mónica Velarde llevan a cabo un estudio comparativo para detectar la importancia del ecoturismo como estrategia de conservación y la relación que este guarda con las actitudes y prácticas de conservación de cuatro comunidades inmersas en reservas de la biósfera: dos en Los Tuxtlas, en el estado de Veracruz, México, y otras dos en Maasai Mara, Kenia. Apoyándose en el uso de métodos mixtos encuentran que las similitudes y diferencias que existen en las comunidades seleccionadas están condicionadas por el contexto local, los factores sociodemográficos y la cultura, lo que determina en gran medida el éxito o fracaso de la actividad ecoturística.

En una investigación sobre la población indígena totonaca localizada en el municipio de Zozocolco de Hidalgo, en el estado de Veracruz, Federico Gerardo Zúñiga Bravo analiza el proceso de patrimonialización y turistificación de la comunidad, a partir del desarrollo del turismo cultural, ecoturismo y etnoturismo potenciado con las declaratorias de joya de Veracruz y pueblo mágico, otorgadas por los gobiernos estatal y federal. La combinación de métodos cualitativos y el carácter interdisciplinario de su investigación le permiten llegar a originales hallazgos sobre la identidad cultural de esta población y su proceso de autovaloración. 
En un estudio cualitativo en torno al turismo religioso, Víctor Manuel Mora Torres nos ilustra sobre las diferentes interpretaciones que se tienen de la visita al Santuario del Señor del Cerrito, ubicado al norte del Estado de México, en el centro del país. En su investigación logra reconocer que los visitantes interpretan el destino del Santuario con un doble sentido: como un espacio sagrado y como un espacio recreativo, a veces separando ambas concepciones y a veces desdiferenciándolas.

Cabe destacar que los artículos de Mora y de Zúñiga forman parte de los trabajos de tesis que resultaron premiados por la Academia Mexicana de Investigación Turística (AMIT) en 2017 como mejores tesis de Posgrado en sus categorías de Maestría y Doctorado, respectivamente; este último reconocimiento lo recibió también el trabajo de Magio en 2016.

En un interesante recorrido por la línea del tiempo, Daniel Hiernaux-Nicolas -quien se hizo merecedor al Premio Nacional de Investigación Turística 2017 que otorga la AMIT- narra en una nota crítica la aguda visión de quien ha sido un actor fundamental en gran parte del proceso histórico que ha experimentado la investigación turística en México, a lo largo de un sinuoso trayecto de 40 años, relatando el incipiente inicio durante la década de los sesenta y setenta, el quiebre a mitad de la década de los ochenta y su posterior consolidación a partir del nuevo siglo. Declara que es innegable el avance actual de este campo de estudio, pero a la vez señala los retos que aún quedan por enfrentar, como el fortalecimiento del andamiaje teórico-metodológico de las investigaciones y el apuntalamiento de la identidad de este multidisciplinar campo de conocimiento.

Finalmente se presentan dos reseñas, una sobre la reciente publicación del libro de Alfonso González Damián, Construcción social de la experiencia turística (2017). Una coproducción de turistas y anfitriones basada en hechos reales, preparada por Rodrigo Espinoza Sánchez y Rosa María Chávez Dagostino, ambos de la Universidad de Guadalajara, y otra en la que Irma Magaña Carrillo y Maribel Osorio García dan cuenta del XI Congreso Internacional de la AmIT: “30 Años de Investigación Turística en México”, celebrado en las instalaciones de la Universidad de Guadalajara, en Zapopan, en septiembre de 2017, quien fuera también anfitriona del Primer Congreso de Investigación Turística realizado en nuestro país; nuevamente, sus aulas han sido testigo mudo del encuentro de investigadores de todos los puntos cardinales del territorio nacional y más allá de sus fronteras, así como de amplias y ricas discusiones que proclaman por la sólida construcción de puentes entre la docencia, la investigación y la publicación de resultados.

Nora Leticia Bringas Rábago Directora Dimensiones Turísticas 


\title{
APROXIMACIÓN RETICULAR A LA PRODUCCIÓN CIENTÍFICA SOBRE TURISMO REALIZADA POR INVESTIGADORES MEXICANOS
}

\author{
Ismael M. Rodríguez Herrera \\ imrodri@correo.uaa.mx \\ Astrid Vargas VÁzQueZ \\ avargasv@correo.uaa.mx \\ Departamento de Turismo \\ Universidad Autónoma de Aguascalientes
}

\begin{abstract}
Este trabajo presenta la producción de artículos científicos de los académicos mexicanos reconocidos por el Sistema Nacional de Investigadores. Con base en un análisis bibliométrico y con la herramienta que representa el análisis de redes, el estudio se centra en artículos publicados en el periodo 2010-2016. El objetivo fue identificar la colaboración científica en el campo del turismo a partir de la coautoría, calculando indicadores de colaboración simples y examinando redes de colaboración entre investigadores. Para tal efecto, se solicitó a los académicos su producción científica, la cual fue incorporada en una base de datos y después trasladada a los software Ucinet y NetDraw para su examen, lo que permitió visualizar, a través de los grafos, las colaboraciones así como los atributos más importantes de los investigadores. Los resultados dan cuenta del incremento de la producción de los últimos años, motivada en buena parte por las exigencias que establece el propio sistema. Se presenta una red con baja densidad y con claras subredes que condicionan la colaboración entre pares académicos. El trabajo ofrece una perspectiva acerca de la situación que guarda la investigación científica en turismo, además de evidenciar la pertinencia del análisis de redes para este tipo de estudios.
\end{abstract}

Palabras clave: Análisis bibliométrico, análisis de redes, investigación turística, investigadores mexicanos.

\section{Reticular Approach to the Scientific Production on Tourism by MeXican Researchers}

This paper presents the academic production written by Mexican scholars who are recognized by the sni (Sistema Nacional de Investigadores). Based on a bibliometric analysis and using the tool of network analysis, the study is focused on the publication of papers that researchers have written from 2010 to 2016. The purpose of this study is to identify the scientific collaboration in the field of tourism through the co-authorship of papers, by calculating simple collaboration indicators and examining collaborative networks among researchers. To accomplish this, scientific production was requested directly from the scholars, was then entered into a database and analyzed with Ucinet and NetDraw software, thus allowing a visualization, by means of graphs, of the researchers' collaborations and their most important attributes. The results show an increase in scientific production in recent years due largely to the requirements set up by the system itself. Moreover, the study presents a low-density network with clear subnets that condition the collaboration among scholar peers. The study provides a view on the current situation of the scientific research in tourism in recent years, and, furthermore, the evident relevancy of network analysis on such studies.

Keywords: Bibliometric analysis, network analysis, tourism research, Mexican researchers.

Fecha de recepción: 6 de marzo de 2017. Fecha de aceptación: 28 de agosto de 2017

COMO CITAR: Rodríguez, I. y Vargas, A.(2018). Aproximación reticular a la producción científica sobre turismo realizada por investigadores mexicanos. Dimensiones Turísticas, 2(2), 9-26. https://doi.org/10.47557/POPT7335 
os estudios sobre la producción científica a escala mundial en el tema turístico no son abundantes, sin embargo, en los últimos años se han intensificado. Estos varían en metodologías, tópicos, límites territoriales, entre otros aspectos. Algunos de ellos utilizan la bibliometría como parte de sus herramientas de análisis y otros examinan la colaboración en aras de identificar formas de trabajo colectivo.

Para el caso de México, existen estudios relacionados con el análisis de las temáticas turísticas que se investigan en los centros de educación superior principalmente y que luego son presentados en congresos especializados, empero, no se encontró ninguna disertación que abordara la colaboración de coautores usando el análisis de redes sociales (ARS). Ello animó la realización del presente trabajo, el cual tiene como objetivo identificar la colaboración científica a partir de la coautoría de artículos, centrándose en los investigadores vinculados con el turismo y reconocidos por el Consejo Nacional de Ciencia y Tecnología (Conacyt) a través del Sistema Nacional de Investigadores (SNI).

Por otro lado, es menester recordar que los organismos educativos en el nivel federal incentivan la colaboración entre pares académicos, primero entre los integrantes de un Cuerpo Académico y luego a través de proyectos de investigación entre instituciones. Así pues, conocer las redes de colaboración dará un poco de luz sobre las estrategias que emplean los investigadores mejor conectados para proyectar su trabajo y que les ha ayudado para tener el reconocimiento del sNI, lo cual, sin duda, puede apoyar a nuevos talentos a incrementar la producción científica en el tema turístico para fortalecer a las instituciones, así como a los esquemas de trabajo en cada una de ellas, sin olvidar, por supuesto, el papel social que deben cumplir los proyectos de investigación, no solo de divulgación del conocimiento.

Asimismo, es importante mencionar que los resultados aquí presentados forman parte de un proyecto institucional mucho más amplio, relacionado con las diferentes oportunidades que la aplicación del ARS proporciona para estudiar el fenómeno turístico.

El trabajo está dividido en cuatro secciones principales. La primera expone los elementos teóricos vinculados con la problemática a tratar, como la bibliometría, la colaboración y el ARS. La segunda detalla los aspectos metodológicos, describiendo en cada una de las fases las actividades que se llevaron a cabo para realizar la investigación. En la tercera sección se muestran los resultados obtenidos a través de tablas y grafos, así como la discusión correspondiente. Por último, se enlista una serie de conclusiones derivada de los resultados encontrados.

\section{Enfouve teórico}

\subsection{La bibliometría en el turismo}

Estudios científicos sobre turismo se publican en distintas fuentes pero, indiscutiblemente, las revistas científicas o journals son las principales divulgadoras de la literatura en los diferentes campos del conocimiento. Por ende, en los últimos años, diversos autores en el nivel internacional han realizado trabajos relacionados con la investigación del fenómeno 
turístico mediante análisis bibliométricos. Ejemplo de ello es el desarrollado por Palmer, Sesé y Montaño (2005), quienes llevan a cabo un estudio bibliométrico del uso de métodos estadísticos en la investigación turística; el de Hall (2011), quien evalúa la calidad de las revistas a partir de distintos indicadores; el de Corral (2013), que hace un análisis descriptivo de las actas de congresos de una asociación académica española; el de Benckendorff y Zehrer (2013), quienes emplean las redes sociales para conocer los estudios pioneros y los trabajos seminales que han influido en artículos de las más importantes revistas, además de examinar las redes entre académicos a partir de la citación; el de Corral y Cànoves (2013), donde realizan un comparativo entre revistas especializadas en turismo y las no especializadas; o el de Yulan, Ulrike y Tseng (2014), que analizan áreas temáticas y patrones de citas. Otros estudios que se identificaron son los efectuados por Barrios, Borrego, Vilaginés, Ollé y Somoza (2008), Chang y McAleer (2012), Hernández, Campón y Folgado (2011), McKercher, Law y Lam (2006), Sánchez y Marín (2003) y Zhao y Ritchie (2007).

Analizar la producción científica se ha convertido en una nueva disciplina, "la revisión de la literatura representa la base para la investigación en sistemas de información. Como tal, los artículos de revisión son fundamentales para el fortalecimiento de sistemas de información como un campo de estudio" (Webster y Watson, 2002, p. 14). En particular en el área turística, Hall (2011, p. 16) expone que "el análisis bibliométrico es importante en el turismo, como resultado de la evaluación externa de la calidad de la investigación, el interés en los factores de impacto y prestigio, y estudia el desarrollo del área".

Por otro lado, la colaboración científica se refiere a "la interacción entre dos o más científicos que tiene lugar dentro de un contexto social, la cual permite compartir significado y completar tareas con respecto a una meta superior mutuamente compartida" (Sonnenwald, 2007, p. 645).

En el ámbito internacional, existen pocos estudios que tratan la colaboración a partir de las coautorías de artículos utilizando el ARs. Algunos de ellos son los de Ye, Li y Law (2013), Benckendorff (2009, 2010), Racherla y Hu (2010) y Corral y Cànoves (2014).

\subsection{La producción científica sobre turismo en México}

El estudio del turismo en México tiene sus comienzos en los años sesenta con los trabajos del Instituto Mexicano de Investigación Turística (Castillo y Arias, 2012; Monterrubio, 2015), que se orientaron a la planeación, promoción y comportamiento de la demanda. Sin embargo, Castillo y Arias (2012), en su recuento sobre la investigación turística en el país, destacan la década de los ochenta como la que marcó un cambio radical pues se inició un repunte hacia la definición de modelos hipotético-deductivos para el estudio del turismo. Enfatizan además que en la primera década del siglo xxı se fortalecieron las bases del estudio científico del turismo, gracias, en parte, a la participación de instituciones de educación superior y de centros de investigación que abordaron el turismo en México en diversos foros académicos y de investigación. Con referencia a ello, se puede mencionar el trabajo de Espinosa (2007), que identifica siete tendencias de la investigación turística a partir de las ponencias presentadas en los congresos de investigación convocados por 
el Centro de Estudios Superiores en Turismo de 2001 a 2005. Estas tendencias son: el análisis de espacios y planeación de proyectos de turismo; el cuidado y conservación del ambiente, ecoturismo y sustentabilidad; sobre currículum y capacitación; el estado de la investigación turística; la dirección y administración de empresas turísticas; las políticas, reglamentación y normatividad en torno al turismo; y la investigación de diversa vinculación social.

En esa misma década, resalta también la creación de posgrados, aunque los autores mencionan que se estaba produciendo "una gran cantidad de información que no termina por aterrizar el quid de una necesidad añeja del turismo: la construcción seria, rigurosa y sistematizada de su conocimiento que aporte para los fundamentos epistemológicos, teóricos y metodológicos de este objeto de estudio y consecuentemente sirva para una intervención asertiva en la conducción de las actividades vinculadas a esta actividad" (Castillo y Arias, 2012, p. 94). Para los autores, el reto en ese momento radicaba en la formulación de nuevos esquemas para la investigación turística, como la construcción de objetos de estudio desde la inter-, la multi- y la transdisciplina, así como la interactuación en redes de investigación nacionales e internacionales.

A partir de entonces, la producción académica vinculada con el turismo realizada por investigadores mexicanos ha ido incrementándose y, por lo que toca a las publicaciones en revistas especializadas, la coautoría ha sido una estrategia muy socorrida. Existen trabajos que justamente han buscado dimensionar tal aportación; dentro de los que podríamos señalar se encuentra el de Chávez, Andrade y Espinoza (2013), quienes llevan a cabo una revisión de revistas científicas para determinar las aportaciones y tendencias que la academia hispanoamericana ha hecho específicamente en relación con los temas de desarrollo sustentable y turismo. Destaca también el trabajo de Picazo y Moreno (2013), quienes examinan la contribución que los académicos adscritos a instituciones mexicanas han realizado en revistas académicas especializadas en turismo. Asimismo, se identificó el de González y Palafox (2014), quienes se centran en el análisis que sobre sociología del turismo ha hecho la academia de habla hispana. Otros trabajos que hacen una revisión sobre la producción académica del turismo en México son los citados por Osorio y López (2012), de los cuales sobresale el de Castillo (2007) y Castillo, Osorio y Medina (2009), así como el reporte publicado por la Universidad Nacional Autónoma de México (2007) en relación con el diagnóstico del estado de la investigación turística en el país.

Cabe mencionar el reciente trabajo de Monterrubio (2017), en el que, a partir de los avances reportados, se busca reconocer las necesidades de investigación respecto del turismo como objeto de estudio por parte de los académicos mexicanos; una de las cinco necesidades referidas es la identificación del liderazgo de autores y revistas en México.

Pese a lo anterior, no se registraron trabajos específicos sobre la colaboración de los investigadores con reconocimiento en México en cuanto a la publicación de artículos científicos. 


\section{Metodología}

El estudio en cuestión es un análisis exploratorio y descriptivo, debido a que no existe antecedente vinculado con el estudio de las coautorías de la producción científica en turismo en el país. Asimismo, los resultados describen en tiempo y espacio la situación que prevalece respecto a la colaboración entre pares académicos y, por lo tanto, también es un estudio transeccional, dado que la producción científica está en una dinámica constante. En la figura 1 se detalla el proceso metodológico llevado a cabo.

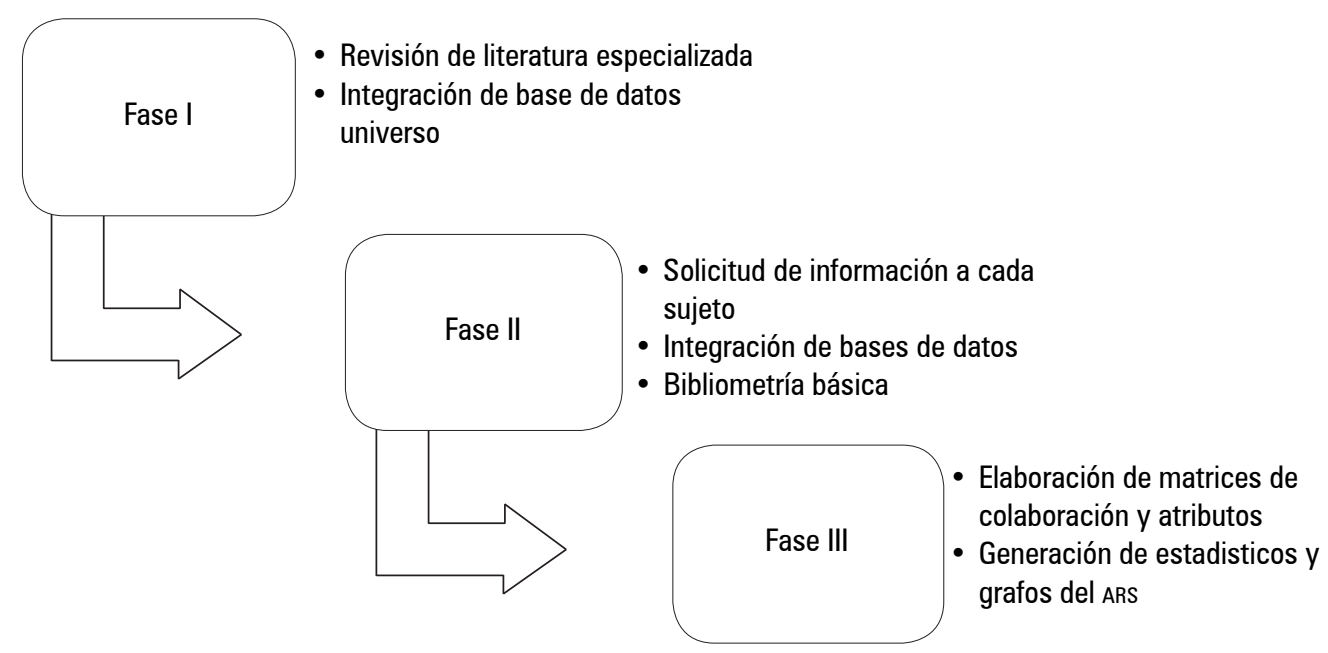

Fuente: Elaboración propia

\section{Figura 1. Fases de la metodología}

La investigación consistió en tres fases. La primera fue revisar la literatura relacionada con los temas abordados, así como delimitar una base de datos, considerando como población objeto de estudio a los investigadores pertenecientes al sNI en el año 2015 y que abordaran el turismo como ámbito de estudio, localizándose 63 en total.

En la segunda etapa se contactó a cada uno de los investigadores a través de correo electrónico o por teléfono solicitándole su currículum que demostrara la producción científica a partir del año 2010, ante lo cual se obtuvo una tasa de respuesta de $57 \%$. Para facilitar el manejo de datos se abreviaron los nombres de los 36 investigadores que respondieron por iniciales, comenzando por los apellidos; para el caso de los coautores, se les asignó un número como código. Con tal información se identificaron los principales indicadores bibliométricos básicos.

En la última fase fueron elaboradas las matrices de colaboración y atributos utilizando como herramienta el ARS, por lo que se recurrió al software Ucinet para generar los estadísticos de medidas de centralidad correspondientes y al NetDraw para los grafos.

Los elementos que se tuvieron en cuenta con base en la propuesta de Rodríguez (2005) para el diseño de la investigación en el ARs hacen referencia a lo siguiente: 
- Nivel de análisis: red egocéntrica, esto es, evaluar a cada actor o nodo con los cuales tiene relación y la red completa, que sirve para describir pautas relacionales de los nodos.

- Forma de las relaciones: propiedad que caracteriza a la intensidad de la unión entre dos actores.

- Contenido relacional: relaciones instrumentales, tienen como objetivo asegurar información a través del trabajo.

\section{Resultados y discusión}

Los resultados se presentan en dos apartados principales, uno referido a la bibliometría básica derivada del análisis de las características de la producción científica en general, y el otro relacionado con la colaboración en la publicación de los artículos. Cabe apuntar que, debido a la tasa de respuesta (36 de 63 investigadores respondieron positivamente), los resultados obtenidos deben ser considerados como parciales.

\subsection{Bibliometría básica}

La bibliometría es una disciplina que permite realizar análisis desde diferentes aristas sobre un tema, por lo cual los siguientes resultados proporcionan una visión general de la situación que guardan los investigadores relacionados con el campo del turismo en la producción científica en el país. De los 63 investigadores que abordan temas turísticos en sus trabajos y que pertenecen al sNı, destaca significativamente que 11 de ellos se encuentran adscritos a la Universidad Autónoma del Estado de México (UAEM), encabezando el ranking con el mayor número de investigadores en el sistema. Le siguen la Universidad de Guadalajara (UdG) y el Instituto Politécnico Nacional (IPN) (véase cuadro 1).

Como ya se ha mencionado, solo respondieron 36 investigadores, los cuales de 2010 a la fecha produjeron un total de 297 artículos, es decir, un promedio de 8.25 artículos por sujeto.

En el análisis de firmas por artículo destaca que solamente un investigador publicó en solitario un artículo, mientras que el resto colabora de manera significativa, pues más de $70 \%$ de las publicaciones fueron firmadas entre dos o tres autores y el índice de coautorías es de 2.96 dado que en total se registraron 880 firmas (véase cuadro 2).

En el ranking por producción científica, los primeros cinco lugares están ocupados por académicos adscritos a la UAEM, lo que proyecta su liderazgo en el nivel nacional, además de que avala la larga trayectoria de la institución en la formación de capital humano en el sector turístico (véase cuadro 3).

En promedio, los investigadores produjeron casi 50 artículos por año, sin embargo, el 2015 destaca como el más productivo, en tanto que del 2010 al 2014 la cantidad de artículos publicados se mantuvo casi en los mismos niveles, según puede observarse en la figura 2. 
CuADRo 1. Ranking de instituciones en el SNI (campo de estudio: turismo)

\begin{tabular}{|rlc}
\hline Lugar & \multicolumn{1}{c}{ Institución de adscripción } & Número de investigadores \\
\hline 1 & Universidad Autónoma del Estado de México (UAEM) & 11 \\
\hline 3 & Universidad de Guadalajara (UdG) & 7 \\
\hline 4 & Unstituto Politécnico Nacional (IPN) & 4 \\
\hline 5 & Universidad Autónoma de Sinaloa (UAS) & 3 \\
\hline 6 & Universidad Nacional Autónoma de México (UNAM) & 3 \\
\hline 7 & Universidad Anáhuac del Norte (UA Norte) & 3 \\
\hline 8 & Universidad Autónoma de Baja California (UABC) & 2 \\
\hline 9 & Universidad Autónoma de Chiapas (Unach) & 2 \\
\hline 10 & Universidad de Colima (UCol) & 2 \\
\hline 11 & Universidad de Occidente (Uo) & 2 \\
\hline 12 & Universidad de Ouintana Roo (Uaroo) & 2 \\
\hline 13 & Universidad Intercultural de Chiapas (Unich) & 2 \\
\hline & Resto de instituciones & 2 \\
\hline
\end{tabular}

Fuente. Elaboración propia.

Cuadro 2. Firmas por artículo

\begin{tabular}{cccc}
$\begin{array}{c}\text { Número de } \\
\text { firmas }\end{array}$ & $\begin{array}{c}\text { Número de } \\
\text { artículos }\end{array}$ & $\%$ & \% acumulado \\
\hline 1 & 1 & 0.3 & 0.3 \\
\hline 2 & 119 & 40.1 & 40.4 \\
\hline 3 & 94 & 31.6 & 72.1 \\
\hline 4 & 58 & 19.5 & 91.6 \\
\hline 5 & 21 & 7.1 & 98.7 \\
\hline 6 & 4 & 1.3 & 100.0 \\
\hline Total & 297 & 100.0 & \\
\hline
\end{tabular}

Fuente. Elaboración propia. 
CuAdro 3. Ranking de 36 investigadores por producción científica (artículos)

\begin{tabular}{|cllc|}
\hline Lugar & Investigador & \multicolumn{1}{c}{ Institución de adscripción } & Número de artículos \\
\hline 1 & ZVL & Universidad Autónoma del Estado de México & 30 \\
\hline 2 & SBR & Universidad Autónoma del Estado de México & 27 \\
\hline 3 & CJG & Universidad Autónoma del Estado de México & 26 \\
\hline 4 & VMEE & Universidad Autónoma del Estado de México & 26 \\
\hline 5 & MCJC & Universidad Autónoma del Estado de México Texcoco & 24 \\
\hline 6 & CCTJ & Universidad Autónoma de Ciudad Juárez & 22 \\
\hline 7 & PMA & Universidad de Quintana Roo & 21 \\
\hline 8 & CDRM & Universidad de Guadalajara (Centro Universitario de la & 19 \\
\hline 9 & CNM & Costa) & 15 \\
\hline 10 & AMCM & Universidad Autónoma del Estado de México & 10 \\
\hline
\end{tabular}

Fuente. Elaboración propia.

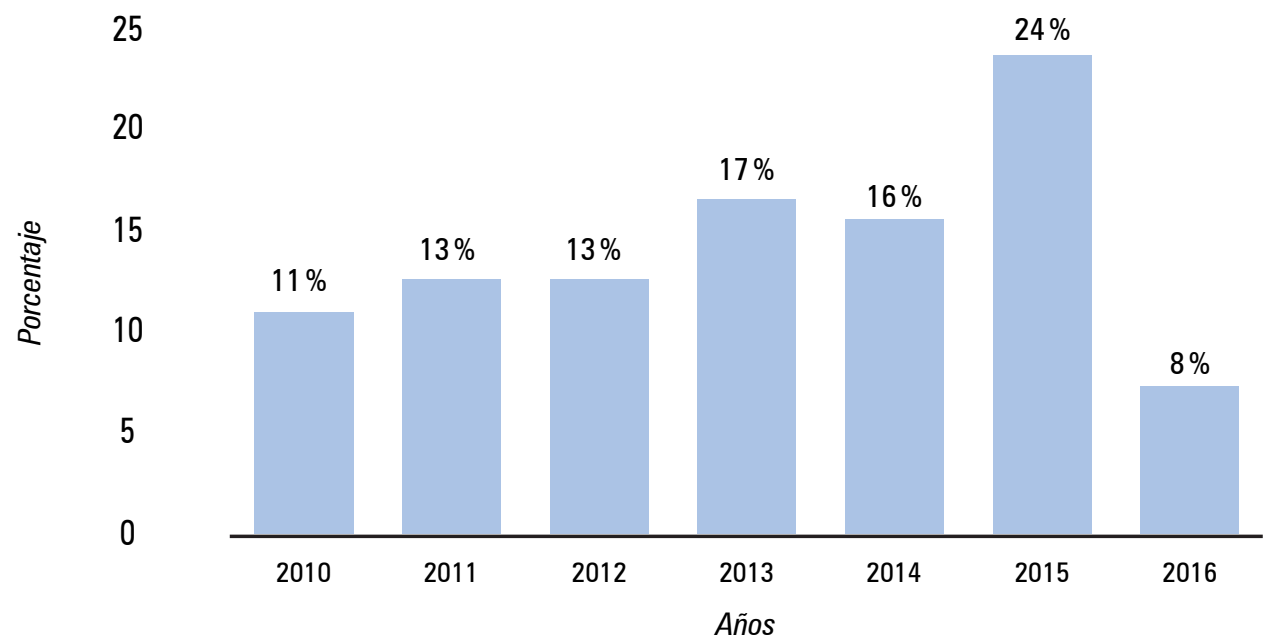

Fuente: Elaboración propia.

Figura 2. Producción científica anual 
En el estudio se identificaron 153 revistas en las que los 36 investigadores publicaron sus artículos. De estas, 41 son nacionales y 112 internacionales, o sea, casi tres cuartas partes de los trabajos de investigación se divulgaron en el extranjero (véase figura 3).

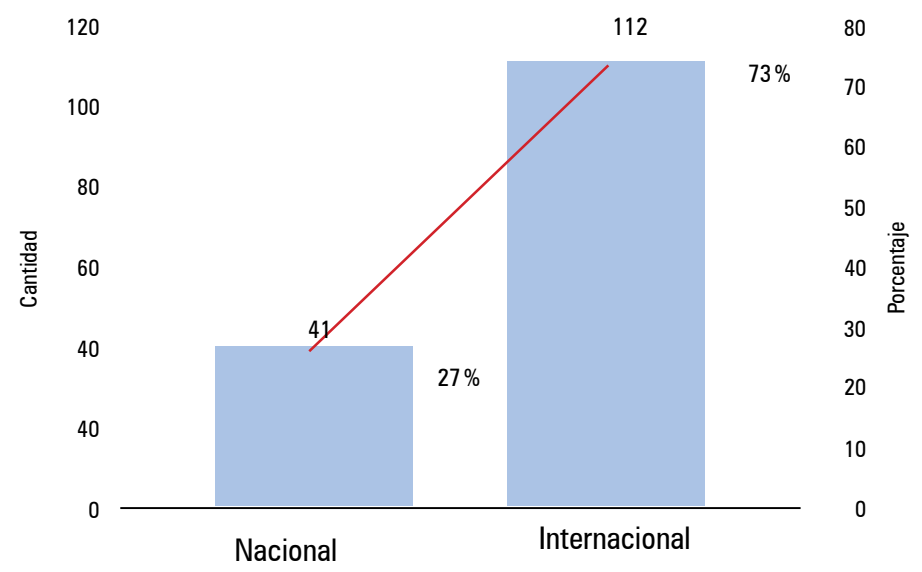

Fuente. Elaboración propia

FIGURA 3. Origen de las revistas donde 36 investigadores del sNI publicaron

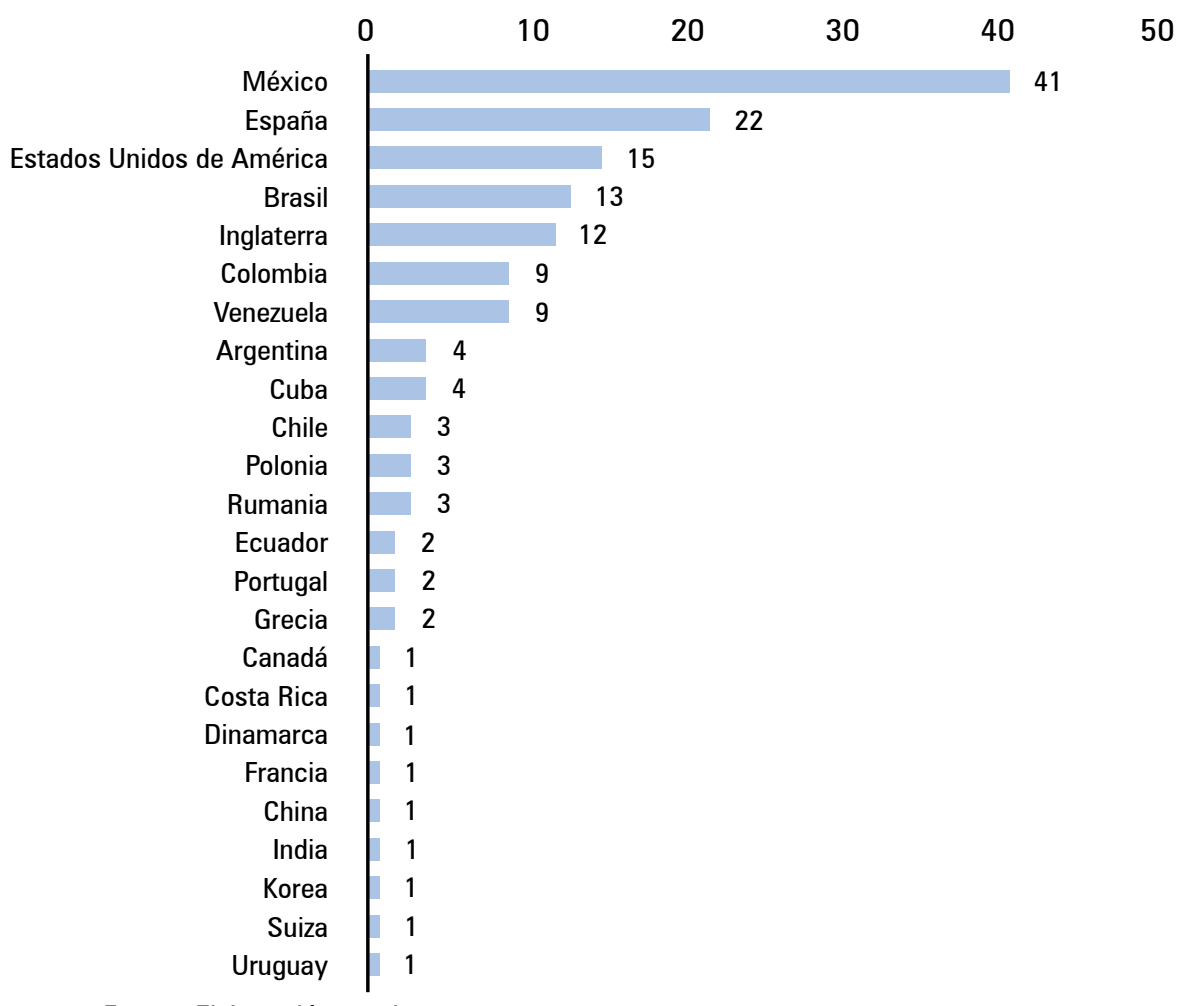

Fuente. Elaboración propia.

Figura 4. Número de revistas por país 
Los países de origen de las revistas que destacan después de México son España, Estados Unidos de América, Brasil e Inglaterra; les siguen países latinoamericanos y otros de Europa y Asia (figura 4).

La lista de las diez revistas con el mayor número de artículos publicados está integrada por tres mexicanas, tres españolas, dos brasileñas, una argentina y una chilena. Se puede apreciar en la figura 5 que las ediciones nacionales como Teoría y Praxis y El Periplo Sustentable ocupan un lugar importante del ranking y son especializadas en temas turísticos. Llama la atención que la revista Topofilia tiene como ámbito de divulgación aspectos relacionados con arquitectura, urbanismo y territorios y también se encuentra dentro de las diez primeras.

Por otro lado, las revistas extranjeras cuentan con prestigio internacional, sin embargo todas ellas, a excepción de las brasileñas, se publican en español, por lo que puede deducirse que los investigadores mexicanos publican muy poco en revistas donde se requiere el idioma inglés o algún otro distinto de la lengua materna.

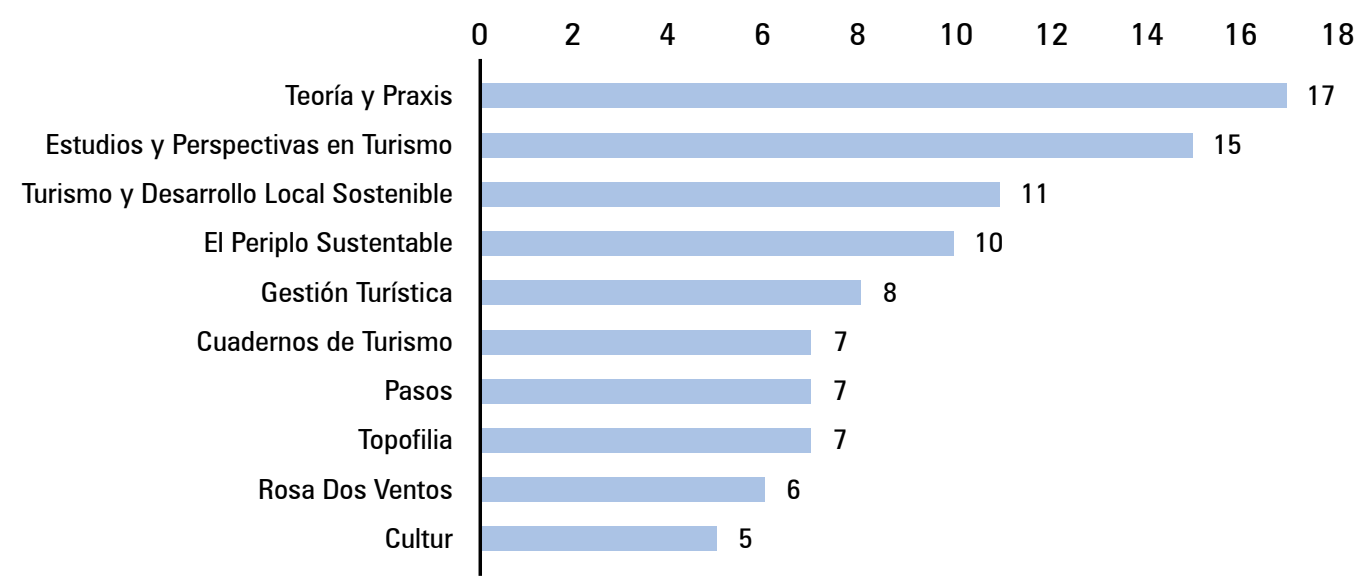

Fuente: Elaboración propia.

FiguRA 5. Ranking de revistas con mayor número de artículos publicados

Por último, dentro de este apartado se analizan las temáticas tratadas en los artículos publicados y, como se evidencia en el cuadro 4, destacan aquellos que versan sobre impactos sociales del turismo, seguidos de temas ambientales y sobre áreas naturales protegidas, aspectos vinculados con el desarrollo social y la gestión de destinos. Por el contrario, pocos trabajos abordaron cuestiones de educación y patrimonio cultural, además de que existe un porcentaje elevado (10.3\%) de artículos que no se refieren específicamente a temáticas turísticas. 


\section{CuAdro 4. Temas}

\begin{tabular}{lc}
\multicolumn{1}{c}{ Tema abordado } & $\%$ \\
\hline Impactos sociales & 15.4 \\
\hline Ambientales y ANP & 13.4 \\
\hline Desarrollo local & 9.9 \\
\hline Gestión de destinos & 9.2 \\
\hline Empresariales & 8.6 \\
\hline Epistemología, metodología & 7.9 \\
\hline Mercadotecnia, segmentación de mercado & 7.2 \\
\hline Política, gobernanza y participación & 6.8 \\
\hline Económico financieros & 3.4 \\
\hline Turismo transfronterizo & 2.4 \\
\hline Tecnología & 2.1 \\
\hline Gastronomía & 1.4 \\
\hline Educación & 1.0 \\
\hline Patrimonio & 1.0 \\
\hline Otros temas & 10.3 \\
\hline Total & 100.0 \\
\hline
\end{tabular}

Fuente. Elaboración propia.

\subsection{Redes de colaboración en la producción científica en turismo}

Respecto a la colaboración entre los académicos para la producción científica, el ARs permite observar de una manera gráfica y clara los diferentes subgrupos formados por los 36 investigadores que se dieron la oportunidad de participar en este análisis.

Para elaborar la red de colaboración, primero se vació la información de la producción científica de los investigadores a una base de datos donde se identificó por cada una de las publicaciones a los coautores, lo que proporcionó dos tipos de nodos: por un lado, los académicos pertenecientes al SNI (identificados por las iniciales de su nombre y un círculo rojo), y por el otro, los coautores (codificados a través de números y un cuadrado azul), resultando 36 nodos del SNI y 300 coautores. De estos últimos, 18 \% fueron reconocidos como extranjeros y el resto nacionales, y sobresalieron las siguientes instituciones por el número de coautores: UAEM, con 66; UdG, 14; Universidad de Quintana Roo (UaROo), 12; Universidad Autónoma de Baja California (UABC), 11; Universidad Autónoma de Ciudad Juárez (UACJ), 10; y Universidad de Colima (UCol), 10.

El análisis en el nivel de instituciones arrojó que fueron 78 las organizaciones de adscripción de los autores, dentro de las que se encuentran universidades públicas y privadas, nacionales y extranjeras, colegios y centros de investigación, e incluso alguna dependencia de gobierno (véase cuadro 5). Dentro de las instituciones del extranjero se registraron adscripciones a universidades latinoamericanas (en Brasil, Cuba, Colombia, Paraguay y Puerto 
Rico), europeas (destacando ocho en España, además de Reino Unido, Alemania, Noruega y Dinamarca), así como dos universidades de Kenia.

CuAdRo 5. Instituciones de adquisición de los autores

\begin{tabular}{lr}
\multicolumn{1}{c}{ Tipo de institución } & Núm. \\
\hline Universidades públicas nacionales & 27 \\
\hline Universidades privadas nacionales & 3 \\
\hline Centros de investigación nacionales & 8 \\
\hline Dependencias de gobierno & 1 \\
\hline Universidades de Norteamérica & 6 \\
\hline Universidades de Latinoamérica & 13 \\
\hline Universidades europeas & 18 \\
\hline Universidades africanas & 2 \\
\hline Total & 78 \\
\hline Fuente. Elaboración propia.
\end{tabular}

Para manejar los datos en el software Ucinet se integró una matriz adyacente, es decir, una matriz cuadrada con el mismo número de filas y de columnas y las relaciones se codificaron de manera binaria: 1 si existía colaboración y 0 si no se presentaba.

En la figura 6 se aprecia una red general poco cohesionada ya que su densidad alcanza solamente $11.58 \%$, esto es, que entre los integrantes del sNI existe muy poca colaboración, y lo mismo sucede con los coautores; incluso, se observa un nodo solitario, así como 16 académicos del SNI que trabajan con un número reducido de coautores y sin ninguna vinculación entre ellos.

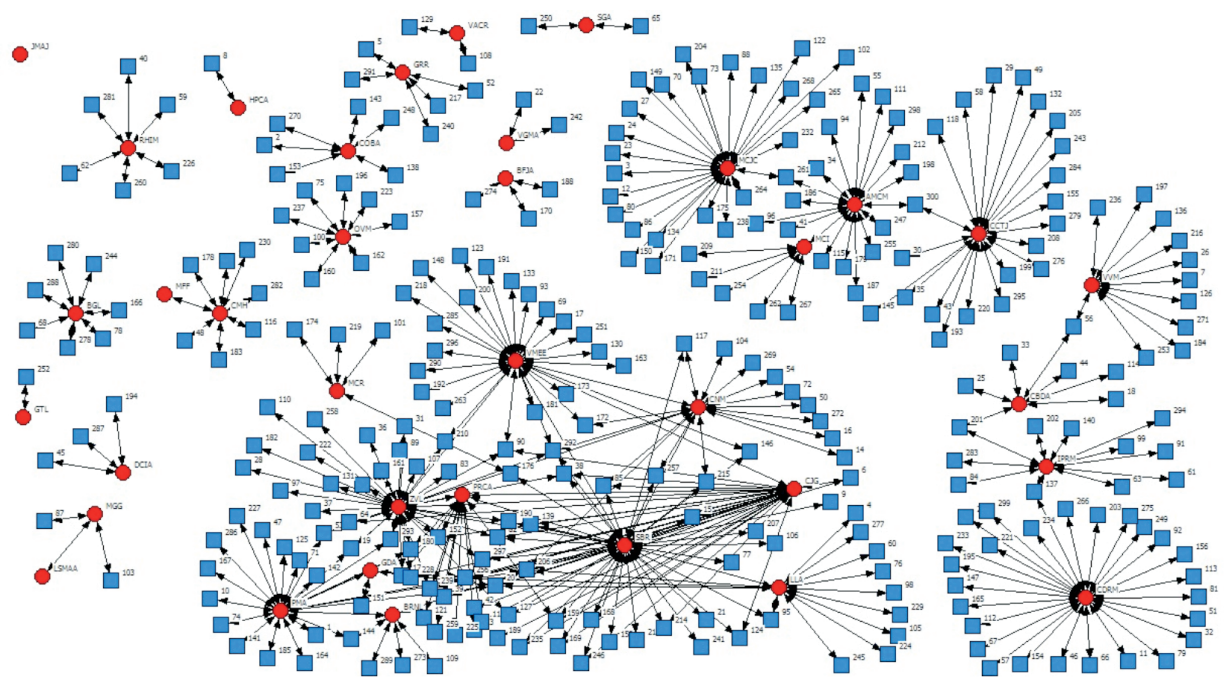

Fuente: Elaboración propia mediante NetDraw.

FIGURA 6. Red de colaboración entre investigadores del SNI (36) y sus coautores 
A pesar de lo anterior, es importante destacar a los nodos mejor conectados, según se observa en el cuadro 6. Para el caso de la centralidad, los primeros cuatro académicos que mayor colaboración tienen con otros autores en su producción científica están adscritos a la UAEM y el quinto se ubica en la UdG. Hay que aclarar que el valor arrojado por Ucinet indica el número de relaciones que un nodo presenta y no se refiere al número de artículos publicados.

Tres de los investigadores anteriores repiten el siguiente indicador asociado con la intermediación, es decir, nodos que trabajan además con otros pares académicos y que estos a su vez colaboran con otros investigadores. Se agregan los dos últimos que se encuentran actualmente laborando con la UaROo y con la UCol. Este indicador alude a que el nodo en cuestión es un puente entre colaboradores.

CuAdro 6. Indicadores de la red de colaboración

\begin{tabular}{|c|c|c|}
\hline Indicador & Nodo & Valor \\
\hline \multirow{5}{*}{ Centralidad } & SBRL & 41 \\
\hline & zVL & 38 \\
\hline & CJG & 30 \\
\hline & VMEE & 28 \\
\hline & CDRM & 27 \\
\hline \multirow{5}{*}{ Intermediación } & SBRL & 6.598 \\
\hline & ZVL & 6.153 \\
\hline & VMEE & 4.503 \\
\hline & PMA & 3.720 \\
\hline & AMCM & 3.173 \\
\hline
\end{tabular}

Fuente. Elaboración propia con base en estadísticos del Unicet

Los atributos también forman parte importante del grafo. A partir de la figura 7, se observa el tamaño del nodo en función del número de artículos publicados, los círculos rojos representan a los investigadores del sNi, los cuadrados azules a los coautores y, por último, se otorgó valor a las líneas, esto es, el número de veces que han colaborado los pares académicos. Se puede advertir claramente que los investigadores que integran el subgrupo de mayor tamaño también tuvieron una mayor colaboración entre ellos, sobre todo el nodo ZVL, el cual tiene 38 coautores, con un promedio de producción con cada uno de 2.6 artículos, le sigue SBRL con 41 relaciones y solo dos trabajos publicados en promedio, a diferencia de CJG, que con 30 coautores publicó 2.4 investigaciones en promedio; pero lo más importante es el trabajo conjunto entre estos tres académicos, que va de siete a 15 artículos entre ellos. 


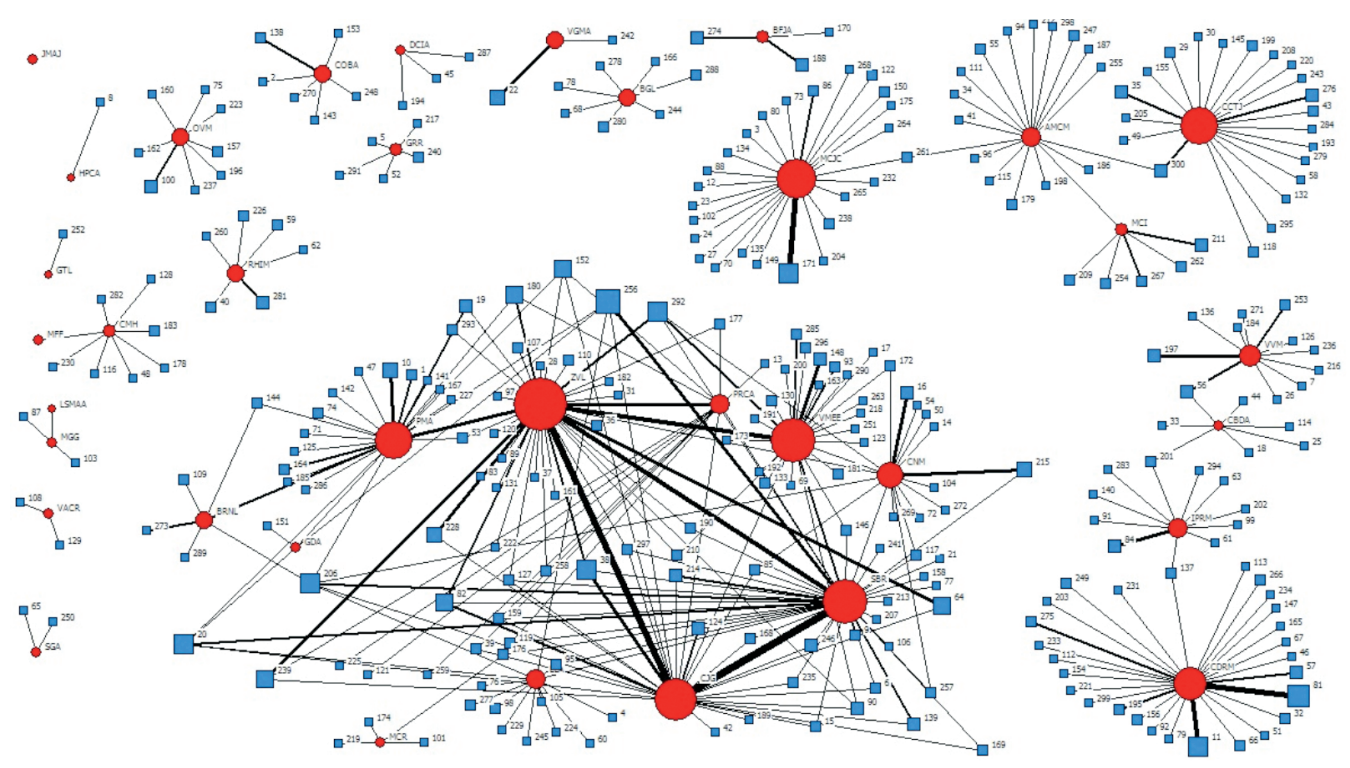

Fuente: Elaboración propia mediante NetDraw.

Figura 7. Atributos de los nodos: producción científica e intensidad

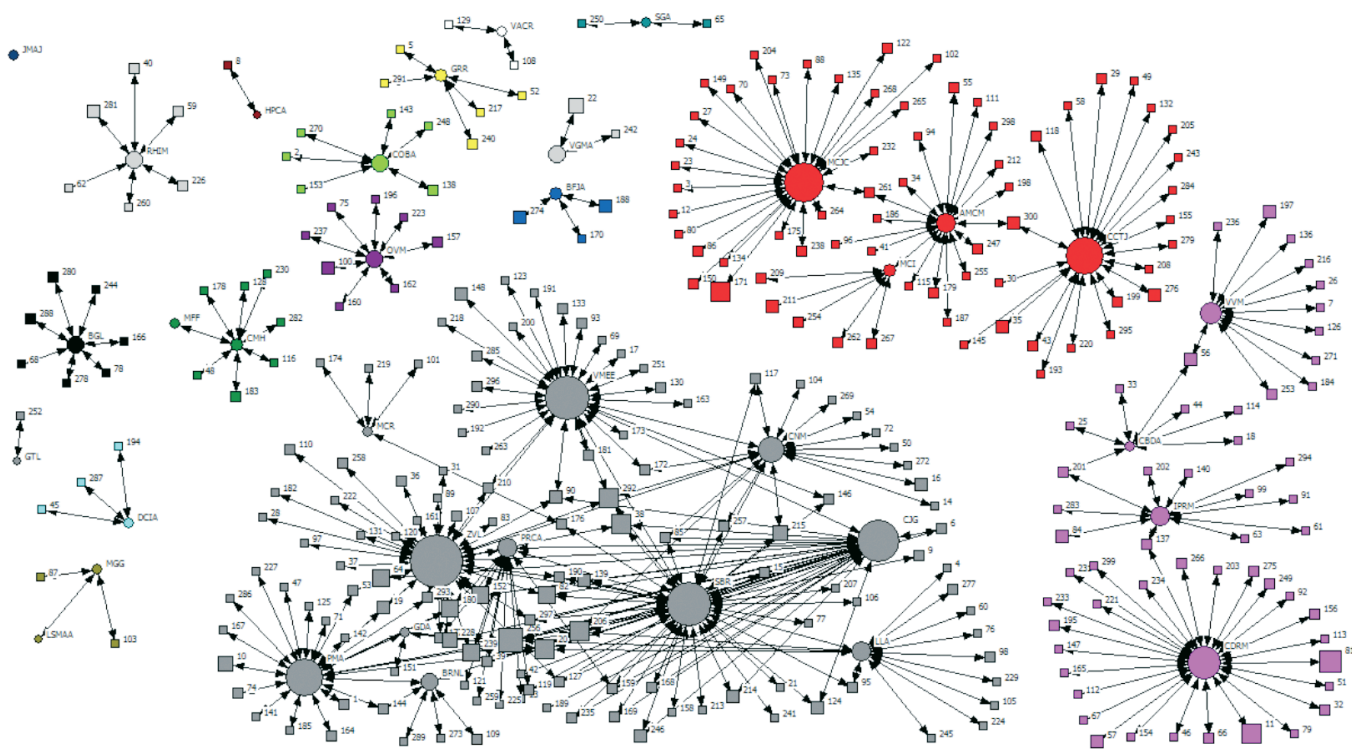

Fuente: Elaboración propia mediante NetDraw.

FIGURA 8. Subgrupos de colaboración entre los miembros del SNI (36) 
En la figura 8 se observan algunos subgrupos donde el trabajo colectivo es un poco más evidente. Al centro de la red general se establece claramente una subred (en color gris) que es la de mayor tamaño, en ella se localizan los investigadores del sNI que pertenecen a la UAEM. Sin embargo, el grupo no es exclusivo, ya que otros académicos relevantes por su producción significativa y número de coautores también participan en él, tal es el caso de PMA de la varoo, BRNL de El Colegio de la Frontera Norte (Colef) y LLA de la Universidad Nacional Autónoma de México (UNAM), y se evidencia por una serie de conexiones, incluso coautores no pertenecientes al SNI que operan como nodos puente.

Del lado derecho y en la parte superior del grafo se ubican otros dos subgrupos (color violeta y rojo) que están integrados por cuatro investigadores del SNI de diferentes adscripciones cada uno y que están unidos por un solo coautor. Por último, se identifican 14 pequeños subgrupos en los cuales participan 16 investigadores del SNI donde se muestra su red egocéntrica y ninguna relación con otros nodos, además de presentar un bajo número de coautorías y de producción científica.

En la figura 9 se observa la colaboración de los investigadores del SNI (color verde) con pares extranjeros (color azul marino). Se registró, por ejemplo, a $\mathrm{MCl}$ de la UCol, que ha trabajado con cinco extranjeros de seis colaboradores, BGL de la Universidad Autónoma Metropolitana (UAM) con cuatro de siete, COBA de la UAEM con cuatro de seis y RHIM de la Universidad Autónoma de Aguascalientes (UAA) con tres de seis. Estos tres últimos académicos aislados en sus subgrupos. El nodo 215 adscrito a la Universidad de São Paulo de Brasil se identifica como uno con producción científica significativa y que por lo menos ha colaborado con dos investigadores del SNI dentro del subgrupo de la UAEM.

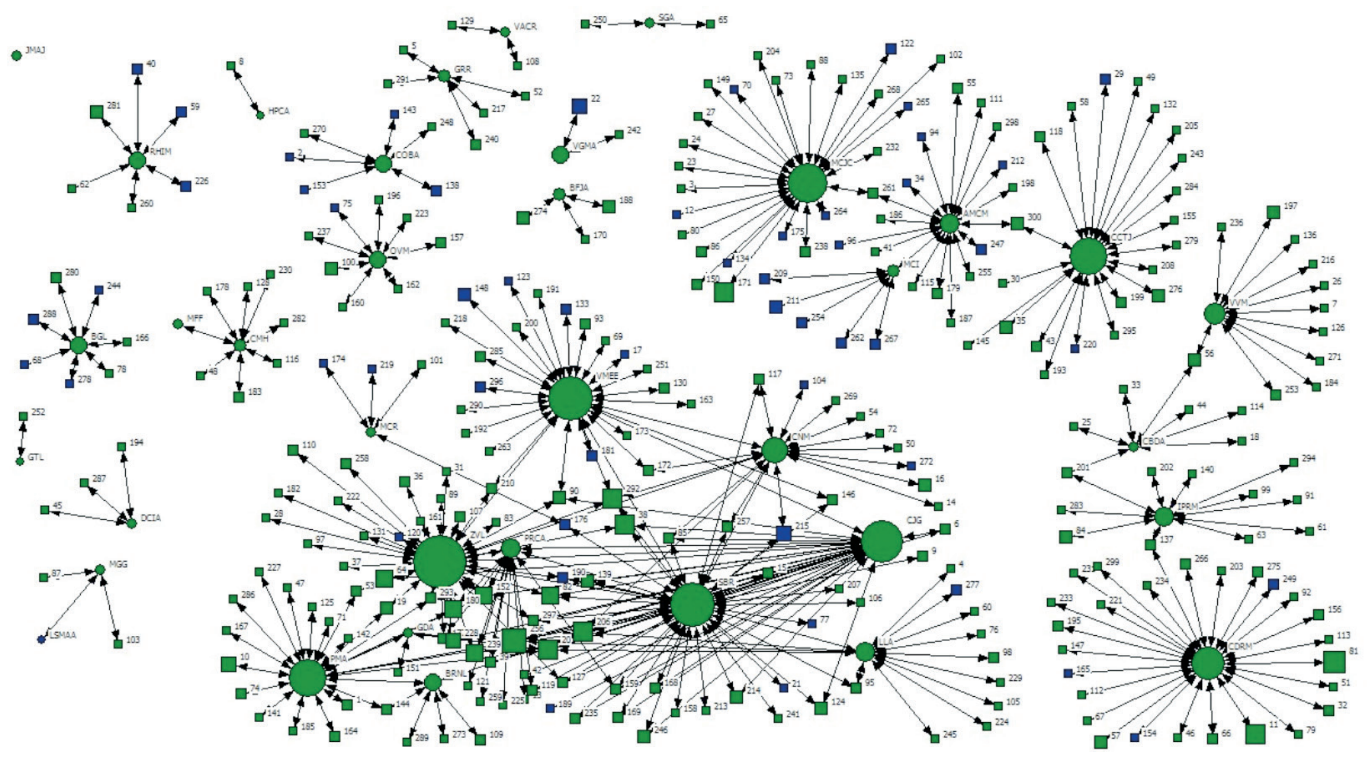

Fuente: Elaboración propia mediante NetDraw.

FIGURA 9. Colaboración entre investigadores mexicanos y extranjeros 
De acuerdo con estos resultados, la colaboración entre investigadores del SNI con campo de estudio en turismo es muy baja, sin embargo, resalta la fortaleza de la UAEM como entidad académica de mayor antigüedad en la educación turística y en la formación de capital humano no solo a través de sus programas de pregrado, sino también de posgrado, como la maestría y el doctorado, proporcionando una oportunidad a los académicos de contar con una mayor producción científica.

\section{Conclusiones}

La realización de este estudio permite generar algunas conclusiones, si bien preliminares, en torno a la producción académica y más específicamente a la colaboración de los investigadores pertenecientes al SNI del Conacyt.

En primer lugar, se observa un interés por publicar en revistas extranjeras, debido tal vez al prestigio de las propias revistas y a las recomendaciones de instancias nacionales como la Secretaría de Educación Pública (SEP) o el Conacyt. Sin embargo, es claro que la producción en revistas que publican en español es más frecuente, a pesar del reducido número de publicaciones en este idioma que se encuentran dentro de los índices más prestigiosos (JCR y Scopus).

No existe una colaboración significativa entre pares académicos reconocidos por el SNI. En cambio, es frecuente distinguir redes egocéntricas de cada investigador. Sería conveniente ahondar en el estudio y verificar si esas redes responden a algún tipo de lógica en la colaboración, como la pertenencia a un cuerpo académico reconocido por el Programa para el Desarrollo Profesional Docente (Prodep).

Se identifica que la producción científica esta directamente relacionada con los programas de posgrado en primer lugar, y de pregrado, en caso de que los alumnos realicen tesis o trabajos de grado. Esto se refleja en el mayor número de publicaciones de investigadores vinculados con este tipo de programas.

Por último, se podría deducir que los investigadores mexicanos utilizan la colaboración con pares académicos extranjeros como estrategia para incrementar el número de publicaciones en revistas de prestigio internacional.

\section{Fuentes CONSUltadAs}

Barrios, M., Borrego, Á., Vilaginés, A., Ollé, C. y Somoza, M. (2008). A bibliometric study of psychological research on tourism. Scientometrics, 77(3), 453-467.

Benckendorff, P. (2009). Themes and trends in Australian and New Zealand tourism research: A social network analysis of citations in two leading journals (1994-2007). Journal of Hospitality and Tourism Management, 16(1), 1-15.

Benckendorff, P. (2010). Exploring the limits of tourism research collaboration: A social network analysis of co-authorship patterns in Australian and New Zealand tourism research. Proceedings of the 20th Annual CAUTHE Conference. Hobart, Tasmania. 
Benckendorff, P. y Zehrer, A. (2013). A network analyses of tourism research. Annals of Tourism Research, 43, 121-149.

Castillo, M. (2007). Aportes y retos de la investigación turística. En M. Osorio (coord.), Entorno del Turismo, Perspectivas, vol. 3. Toluca: Universidad Autónoma del Estado de México.

Castillo, M. y Arias, A. (2012). Orientaciones de la investigación turística en cuerpos académicos de instituciones de educación superior en México. Homo Aviator, 3, 84-100.

Castillo, M., Osorio, M. y Medina, L. (2009). Reporte final de la investigación del proyecto Investigación y Conocimiento Turístico en México: Instituciones de Educación Superior y Centros de Investigación. Toluca: Universidad Autónoma del Estado de México.

Chang, Ch.-L. y McAleer, M. (2012). Citations and impact of ISI tourism and hospitality journals. Tourism Management Perspectives, 1, 2-8.

Chávez, R. M., Andrade, E. y Espinoza, R. (2013). Turismo y desarrollo sustentable: contribución de Hispanoamérica. Teoría y Praxis, 13, 9-33.

Corral, J. A. (2013). Estudio bibliométrico de las actas del Congreso de la Asociación Española de Expertos Científicos en Turismo (Aecit, 1994-2012). Revista de Análisis Turístico, 16, 33-44.

Corral, J. A. y Cànoves, G. (2013). La investigación turística publicada en revistas turísticas y no turísticas: análisis bibliométrico de la producción de las universidades catalanas. Cuadernos de Turismo, 33, 55-81.

Corral, J. A. y Cànoves, G. (2014). La colaboración científica en turismo: grupos y redes de investigación en Cataluña. Documents d’Anàlisi Geogràfica, 60(1), 57-86.

Espinosa, M. (2007). Tendencias de investigación turística a principios del sig/o XXI. México: Instituto Politécnico Nacional.

González, A. y Palafox, A. (2014). Sociología del turismo en español. Revisión exploratoria de artículos publicados en revistas iberoamericanas 2003-2013. Estudios y Perspectivas en Turismo, 23, 805-819.

Hall, M. (2011). Publish and perish? Bibliometric analysis, journal ranking and the assessment of research quality in tourism. Tourism Management, 32, 16-27.

Hernández, J. M., Campón, A. M. y Folgado, J. A. (2011). La investigación en turismo en España a través de las revistas de dirección de empresas. Revista de Análisis Turístico, 12, 1-9.

McKercher, B., Law, R. y Lam, T. (2006). Rating tourism and hospitality journals. Tourism Management, 27(6), 1235-1252.

Monterrubio, C. (2017). Necesidades de la investigación turística en México. Dimensiones Turísticas, 1, 31-52.

Monterrubio, J. C. (2015). El turismo como campo de estudio. México: Trillas.

Osorio, M. y López, A. (2012). Introducción: producción académica reciente en la investigación turística. En M. Osorio y Á. López (coords.), Investigación turística. Hallazgos y aportaciones (pp. 15-21). Toluca: Universidad Autónoma del Estado de México/ Universidad Nacional Autónoma de México/Academia Mexicana de Investigación Turística/Secretaría de Turismo.

Palmer, A. L., Sesé, A. y Montaño, J. J. (2005). Tourism and statistics. Bibliometric study 1998-2002. Annals of Tourism Research, 32(1), 167-178. 
Picazo, P. y Moreno, S. (2013). Difusión de la investigación científica en turismo. El caso de México. El Periplo Sustentable, 24, 7-40.

Racherla, P. y Hu, C. (2010). A social network perspective of tourism research collaborations. Annals of Tourism Research, 37(4), 1012-1034.

Rodríguez, J. A. (2005). Análisis estructural y de redes (Cuadernos Metodológicos, 16). (2a. ed.). Madrid: Centro de Investigaciones Sociológicas.

Sánchez, M. y Marín, B. (2003). La investigación en turismo y economía de la empresa publicada en revistas especializadas españolas: 1996-2001. Papers de turisme, 33, 6-39.

Sonnenwald, D. H. (2007). Scientific collaboration. Annual Review of Information Science and Technology, 41(1), 643-681.

Universidad Nacional Autónoma de México. (2007). Asesoría Técnica: elaboración de un Diagnóstico del Estado de la Investigación Turística en el país y generación de un Programa de Investigación Nacional para el Sector Turismo. México: Autor.

Webster, J. y Watson, R. T. (2002). Analizar el pasado para prepararse para el futuro: escribiendo una revisión de la literatura. MIS Quarterly, 26(2), 13-23.

Ye, Q., Li, T. y Law, R. (2013). A coauthorship network analysis of tourism and hospitality research collaboration. Journal of Hospitality \& Tourism Research, 37(1), 51-76.

Yulan, Y., Ulrike, G. y Tseng, Y.-H. (2014). Revealing the nature of contemporary tourism research: Extracting common subject areas through bibliographic coupling. International Journal of Tourism Research, 17(5), 417-431.

Zhao, W. y Ritchie, B. (2007). An investigation of academic leadership in tourism research: 1985-2004. Tourism Management, 28(2), 476-490. 


\title{
LOS VALORES DEL PATRIMONIO GEOLÓGICO DE LA SIERRA La PrimaVera: las oportunidades para el geoturismo
}

\author{
Lucía González Torreros \\ Universidad de Guadalajara \\ lucia_torreros@yahoo.es
}

No obstante que se ha ignorado el valor geológico de la sierra La Primavera (SLP), adyacente al Área Metropolitana de Guadalajara, Jalisco, el potencial recreativo de las aguas termales y del bosque ha despertado el interés desde hace varias décadas, aunque ya se le apreciaba incluso desde el siglo xIx. Tomando como referencia el trabajo coordinado por González, Valdivia y Gómez en 2018, Geodiversidad volcánica y geopatrimonio en la sierra La Primavera, fue posible identificar, documentar y evaluar la geodiversidad y su potencial para ser calificada como patrimonio, en particular aquellos geositios que pueden ser considerados para el geoturismo, un recurso importante para el desarrollo local. Esta geodiversidad es resultado de una evolución volcano-lacustre de 140000 años, que ha acondicionado el paisaje; sus recursos ahora poseen gran valor recreativo para la creación de balnearios, delimitación de espacios para pícnic o camping, práctica de ciclismo, senderismo, cabalgata, ecoturismo, así como turismo interpretativo y rural.

Palabras clave: SLP, patrimonio, geoturismo.

\section{Geological Heritage Values of Sierra La Primavera: Proposal of Geotourism}

The geological value of the Sierra La Primavera (SLP), adjacent to Guadalajara's Metropolitan Area, Jalisco, has remained ignored for many years. However, in the past few decades, -ever since the 19th century-, the thermal waters, -being a geohydrothermal element-, and the forest, have gained attention for recreational activities. Taking as a reference the study coordinated by González, Valdivia and Gómez in 2018, -Volcanic Geodiversity and geological heritage of Sierra La Primavera (Geodiversidad volcánica y geopatrimonio en la Sierra La Primavera)-, it has been possible to identify, document and evaluate the geodiversity and its potential to be considered heritage, focusing on those that can be considered important for geoturism practices, which are an important resource for local development. This geodiversity is the result of a 140-thousand-year volcano-lacustrine evolution that has determined the actual landscape and its worth for activities such as health resorts, picnic, camping, cycling, trekking, horseback riding, ecotourism, as well as interpretative and rural tourism.

Keywords: sLP, heritage, geoturism.

Fecha de recepción: 18 de abril de 2017. Fecha de aceptación: 3 de octubre de 2017

CÓMO CITAR: González, L. (2018). Los valores del patrimonio geológico de la sierra La Primavera: las oportunidades para el geoturismo. Dimensiones Turísticas, 2(2), 27-52. https://doi.org/10.47557/RGNK7688 
as contribuciones de este estudio se orientan a otorgar un inventario y localización de los elementos que fueron valorados como patrimonio geológico-geomorfológico, puntos de observación del paisaje volcánico y su relación con otras actividades de naturaleza turístico-recreativas, entre las que se encuentran senderos, rutas ciclistas y el equipamiento tradicional que basa su oferta en recursos geohidrotermales (balnearios), respecto al área natural protegida (ANP) sierra La Primavera, adyacente al Área Metropolitana de Guadalajara, Jalisco, México. Esta información se ha sistematizado y georreferenciado, abriendo la posibilidad de poner sobre la mesa las oportunidades para la práctica del geoturismo, un insumo para la gestión del ANP que no se ha destacado anteriormente.

En esta investigación se retoman las reflexiones vertidas en un trabajo previo y de mayor alcance titulado Geodiversidad volcánica y geopatrimonio en la sierra La Primavera, coordinado por González, Valdivia y Gómez (2018), particularmente respecto de los conceptos geodiversidad, geoconservación (capítulo ॥) y patrimonio geológico, así como su potencial para la práctica del geoturismo y sus contribuciones al desarrollo local (capítulo III).

Se debe aclarar primero que, para efectos de este estudio, el bosque La Primavera será referido como sierra La Primavera (SLP), en función de que dentro del concepto de "bosque" se encuentra limitado el relieve. La justificación que lleva a esta denominación se basa en el origen de esta entidad; supone la formación de domos y estructuras de naturaleza riolítica, que fueron formando cúpulas, frentes marcados, barrancas y valles; se acude a una referencia topográfica diversa que ha sido objeto de una apropiación sociohistórica. ${ }^{1}$ Asimismo, resalta el contraste paisajístico que se produce por la convivencia de planicies y elevaciones que le confieren esa complejidad que sobrepasa el imaginario construido -limitada y recientemente- como bosque. Con esta simplicidad, que se observa con claridad en los distintos intentos de protección oficial, se ha perdido de vista el componente geológico-geomorfológico y se ha circunscrito su importancia al componente forestal. Posteriormente, esto se enlaza a una reflexión sobre las dinámicas turístico-recreativas actuales que se desarrollan sobre todo dentro del perímetro del ANP, de donde resulta el énfasis en el potencial para la práctica del geoturismo.

\section{Antecedentes}

La referencia más frecuente cuando se habla sobre el tema de patrimonio suele destacar el construido (material): se piensa en catedrales, palacios, casonas, caseríos y edificios prehispánicos, incluso sin considerar que gran parte de ellos tuvieron como insumo materia prima de origen geológico de la región donde se levantaron y que ahora son los elementos

\footnotetext{
${ }^{1}$ Ha de señalarse que, aunque de forma general, una sierra se refiere a un conjunto topográfico lineal, de montañas en pliegue (material sedimentario), formas metamórficas y eruptivas; en el caso de La Primavera, la topografía alineada se asocia con fallas anulares que conforman líneas curvas (Arco Sur y Arco Norte). Si bien es cierto que en sentido estricto no conforma una sierra, ya que no se trata de una configuración lineal, sí se reconoce su complejidad topográfica, uno de los rasgos históricos distintivos de La Primavera. (Cap. El contexto del territorio. Una forma de introducción a la sierra La Primavera, en González, Valdivia y Gómez, 2018).
} 
que le dan carácter (por ejemplo, mármoles, canteras, granitos, tobas), y le sigue, por supuesto, el inmaterial. Luego, toma posición el natural (biótico) en forma de cascada, lago, bosque o selva (consumadas muchas de ellas en ANP), o algunas de las numerosas especies animales o florísticas que lo habitan.

Todos esos elementos que hoy se relacionan con el patrimonio natural o cultural son reconocidos por ser auténticos, originales, poco comunes, singulares o espectaculares, pero es inusual que un conjunto de rocas, una pared de un cerro o el mismo suelo tienda a ser considerado patrimonio, pasa desapercibido, aunque con frecuencia forme parte del paisaje cotidiano. Sin embargo, si se piensa en estos elementos con base en explicaciones originadas en la geología, comienzan a surgir distintas interpretaciones, nuevas imágenes de lo que también es sujeto de considerarse patrimonio.

En el ámbito mundial se observa una tendencia creciente que reconoce la importancia del conocimiento geológico, lo cual ha llevado a su vez a la sistematización y valoración de los elementos geológicos que contribuyen a reescribir la historia de la Tierra. Cada vez más, tal revaloración lleva a la creación de propuestas que abrazan el conocimiento geológico con distintas funciones sociales, ambientales y económicas, como las prácticas turísticas, vinculadas con propuestas que abonan al desarrollo local.

\section{Geodiversidad, geoconservación y geopatrimonio²}

Es común que, al hablar sobre patrimonio, surjan de inmediato imágenes relacionadas con lo que recibimos del pasado y estamos obligados a conservar y proteger para el futuro. Pero ¿es posible fijar un horizonte temporal para posar la mirada y determinar qué es lo que debe considerarse patrimonio o cuántos años deben haber transcurrido desde su creación? ¿Es suficiente la existencia de un elemento geológico en un territorio para que sea considerado patrimonio? El referente temporal para el ser humano suele ser muy corto, se habla de siglos e incluso un par de milenios. De manera automática, se podría pensar que por el simple hecho de que un elemento natural o cultural exista, ya forma parte del patrimonio, pero no siempre ocurre así. En principio, un elemento tiene que ser identificado, valorado y reconocido por los grupos humanos con los que cohabita, debe tener un significado para ellos, ahí comienza el proceso de patrimonialización. De este modo, y aunque no ha sido habitual pensarlo bajo esta idea, la concepción básica del patrimonio se encuentra ligada intrínsecamente con la perspectiva de la sustentabilidad. Por ello es importante destacar algunos pilares conceptuales como geodiversidad y geoconservación, antes de continuar con el tema de patrimonio geológico.

2 Este apartado resulta de una investigación exhaustiva de más de dos años de trabajo de campo en la SLP, de reconocimiento y apropiación de conceptos y métodos, de una mirada integral que se propone en el libro Geodiversidad volcánica y geopatrimonio en la sierra La Primavera (González, Valdivia y Gómez, 2018), particularmente los capítulos II y III, de los cuales la autora de este artículo es coautora. 


\subsection{Un acercamiento al concepto de geodiversidad}

La década de 1990 y las reflexiones acerca del tema de la sustentabilidad, enmarcadas principalmente en la Cumbre de Río, establecieron un nuevo entorno académico sobre cuestiones ambientales y el tema de la diversidad geológica, sobre la cual han surgido distintos debates conceptuales. En el año 2000, el Consejo de Ministros Nórdicos destacó que ambas, biodiversidad y geodiversidad, influyen en el desarrollo económico del territorio, afectan los usos del suelo y la práctica de actividades recreativas, por lo que se debe asumir una responsabilidad y no dejarla solo en manos del gobierno (Guillén cit. en González, Valdivia, Gómez y Castillo, 2018).

CuAdro 1. Distintos conceptos y componentes conceptuales de la Geodiversidad

- Variedad de elementos geológicos (incluidos rocas, minerales, fósiles, suelos, formas del relieve, formaciones y unidades geológicas y paisajes) presentes en un territorio y que son el producto y registro de la evolución de la Tierra.

- Abreviación de diversidad geológica.

- La evolución geológica de una región y los elementos geológicos resultantes, son los que determinan su geodiversidad.

- La geodiversidad, en muchos casos, condiciona el paisaje. Investigar la relación entre geodiversidad y paisaje puede ser muy útil, en especial para la ordenación territorial.

- La geodiversidad condiciona en gran medida la biodiversidad de un territorio...

Fuente: Elaboración propia a partir de Carcavilla, L., López, J. y Durán, J. (2007, 2008 y 2014)

La geodiversidad, entendida como la diversidad de elementos abióticos, incluye la necesidad de cuantificar la abundancia, frecuencia y distribución con objeto de valorar el gradiente geodiverso. Por ello, la geodiversidad es una propiedad del territorio que puede ser cuantificable y, aunque guarda relación con el patrimonio geológico, son conceptos diferentes. Un territorio puede ser poco diverso pero puede tener un alto valor patrimonial y viceversa. Mientras que la geodiversidad lleva a considerar una cantidad y variedad de elementos, el valor como patrimonio se referirá a su valor intrínseco (Carcavilla, López y Durán, 2007).

\subsubsection{La valoración de la geodiversidad}

La perspectiva de la geodiversidad que aquí se retoma se basa principalmente en los trabajos de Carcavilla, López y Durán, 2007, 2008 y 2014 (referidos en Serrano, 2014, p. 70), los cuales realizan una propuesta de valoración que tiene su base en tres aspectos: la diversidad de los elementos que muestran la evolución de la Tierra, sean estos geológicos, geomorfológicos o del paisaje; la frecuencia con la que aparecen en un territorio; y la distribución de las entidades geológicas. En todo ello cobra relevancia la litología, sus acomodos y relaciones, así como las consecuencias de los procesos erosivos. Para Serrano (2014), el objetivo es delimitar áreas con características similares en las cuales estos 
componentes tienen un eminente carácter sintético, que define, delimita y correlaciona espacios homogéneos desde un enfoque abiótico.

Se eligió la metodología de Walter Medina Importancia de la geodiversidad. Método para el inventario y valoración del patrimonio geológico, publicada en $2015 .{ }^{3}$ En una primera etapa, los geositios inventariados y seleccionados se sometieron a una serie de criterios asignándoles valores de acuerdo con sus características intrínsecas; este hecho parte de la idea básica de que no es posible conservar todo lo que se ha inventariado, lo que obliga a una revisión y evaluación exhaustivas que lleven a seleccionar los lugares más representativos de la geodiversidad, consiguiendo de este modo explicar mejor la evolución geológica del área de estudio. ${ }^{4}$ La segunda etapa corresponde al porcentaje de aprobación (PA), para lo cual la suma del puntaje otorgado a cada parámetro de valoración (escala de valoración individual) debería alcanzar un mínimo de 44 puntos, lo que corresponde a 50 \% de aprobación; los lugares que obtuvieron este porcentaje fueron considerados como geositio y, en etapas posteriores, alimentarán una propuesta de geoconservación.

\subsection{La geoconservación}

Cuando se habla de rocas u otros materiales geológicos o geomorfológicos, el imaginario común dicta que son de alta resistencia/durabilidad, lo cual constituye una gran amenaza para este tipo de recursos. Brilha (2005) indica que buena parte de esa amenaza tiene como origen la actividad humana en escalas diversas: desde la paisajística, hasta la de un afloramiento. La geoconservación y sus estrategias deben considerar algunos elementos, como los suelos y la geomorfología, el valor ecológico y su importancia como parte de los ecosistemas, las relaciones y dinámicas sociales y económicas que detonan en su entorno, no solo el valor científico. La geoconservación es, por lo tanto, un concepto más integrador.

Carcavilla, López y Durán (2007, p. 173) determinan que la geoconservación se asienta fundamentalmente sobre dos principios: su valor intrínseco y su fragilidad/vulnerabilidad, es decir, el valor y las amenazas (tal como se presentan en los criterios de evaluación). Estos autores definen a la geoconservación como: "el conjunto de técnicas y medidas encaminadas a asegurar la conservación (incluyendo la rehabilitación) del patrimonio geológico y de la geodiversidad, basada en el análisis de sus valores intrínsecos, su vulnerabilidad y en el riesgo de degradación" (Carcavilla et al., 2007, p. 174). De todo esto surgen las bases para el diseño de estrategias y pautas de manejo, la geoconservación, del área que se intenta poner en valor.

\footnotetext{
${ }^{3}$ Aunque hubo necesidad de hacer algunos ajustes considerando condiciones particulares de la sLP, como el tema de la tenencia de la tierra, que ya presenta condiciones importantes de vulnerabilidad, o la accesibilidad en los criterios del valor turístico.

${ }^{4}$ En las categorías resultantes se agrupan: sitios de interés geológico, geomorfológico, geohidrotermal, observación del paisaje, alteración antrópica y turístico-recreativos, es decir, los elementos, lugares o paisajes potencialmente de interés que puedan entrar en el concepto de patrimonio, ya sea por su rareza, singularidad, excepcionalidad o interés científico o educativo.
} 

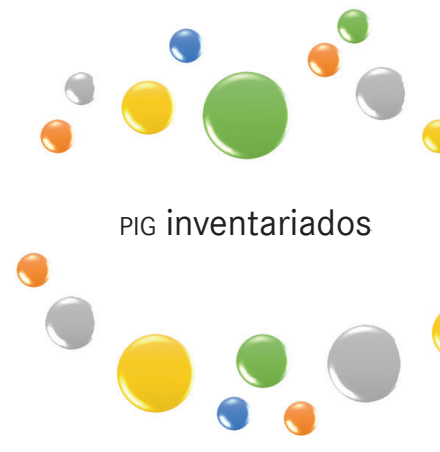

Inventario sistemático de puntos de interés geológicogeomorfológico

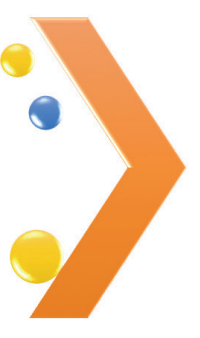

Potenciales Geositios

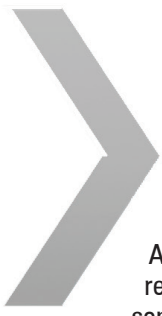

artir de la valoración que da como resultado los potenciales geositios, se someten a dos nuevos cálculos de valor:

- Valor de relevancia del geositio (VRG) - Valor de Uso Científico / Educativo (vuce) Turístico (VUT)

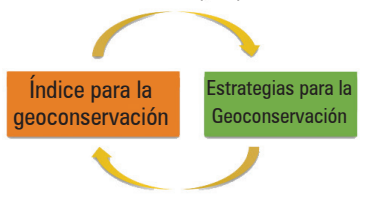

\begin{abstract}
Los PIG inventariados se valoran a partir de cuatro criterios: intrínseco, científico, turístico y de vulnerabilidad, obteniendo como resultado un porcentaje de aprobación ( $+50 \%$ para ser seleccionado como geositio)
\end{abstract}

\section{Geositios definitivos}

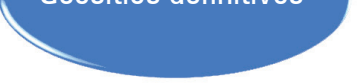

Fuente: Elaboración propia a partir de Medina, 2015, pp. 64-67.

\section{Figura 1. Esquema del proceso de evaluación y selección de geotipos}

\section{- Formaciones rocosas y estructuras geológicas \\ - Composición del suelo y acumulaciones sedimentarias \\ - Formas del terreno y paisajes \\ - Yacimientos minerales, petrológicos o paleontológicos (fósiles), meteoritos \\ - Colecciones museísticas (público-privadas) \\ - Estudios e investigaciones científicas \\ - Recreaciones tecnológicas de los procesos geológicos}




\subsection{El patrimonio geológico y el geoturismo}

El concepto patrimonio geológico llama la atención hacia los procesos y manifestaciones que permiten estudiar y comprender el origen y evolución de la Tierra, climas y paisajes resultantes; es un conjunto de recursos geológicos de valor científico, educativo y patrimonial. Derivado de las reflexiones del VI Congreso Geológico de España, en Zaragoza en 2004, se acuerda que:

El patrimonio geológico es el conjunto de recursos naturales geológicos de valor científico, cultural y/o educativo, ya sean formaciones y estructuras geológicas, formas del terreno, minerales, rocas fósiles, suelos y otras manifestaciones geológicas que permiten conocer, estudiar e interpretar:

a) El origen y evolución de la Tierra

b) Los procesos que la han modelado

c) Los climas y paisajes del pasado y presente

d) El origen y evolución de la vida (cit. en Carcavilla et al., 2007, p. 17).

En la figura 2 también se observan algunos de los elementos que forman parte de este patrimonio y las condiciones que dan paso al proceso de patrimonialización, interpretación y valoración otorgada por el ser humano.

\subsection{Geoturismo como estrategia para el impulso al desarrollo local}

Desde las primeras discusiones que llamaron la atención sobre el uso turístico del patrimonio geológico, hacia la última década del siglo xx, su orientación principal estuvo encaminada a la puesta en valor y la difusión de las evidencias que contaban la historia de la Tierra. Se trataba de una propuesta de turismo que tenía su cuna en la geología, la geomorfología, la paleontología e, incluso, parte de la arqueología.

No obstante, National Geographic ${ }^{5}$ realiza una propuesta que, aunque no excluye literalmente al geoturismo -en su forma original-, no lo incluye de manera explícita, por lo que no se trata específicamente de lo mismo. El objetivo de ese geoturismo es destacar todas las condiciones naturales y culturales, incluidas las intangibles, que expresan la integridad de un lugar, se entiende, por lo tanto, todos los elementos del territorio. En este sentido se apunta que: "El Geoturismo en su mejor expresión debe beneficiar a los habitantes locales. Los habitantes locales, por su parte, deben velar por lo que atrae al turista, que sea un bosque lluvioso, una calle histórica o simplemente un paisaje bello". ${ }^{6}$ Todo ello con soporte de la tecnología para el desarrollo de aplicaciones para mejor conocimiento y uso del territorio.

\footnotetext{
${ }^{5}$ La fecha de la publicación suponemos ronda cerca del año 2005, debido a que en el texto se hace referencia a un evento ocurrido en octubre de 2004. En el documento se presenta a J. Tourtellot como creador del concepto geoturismo. Geoturismo para su comunidad. National Geographic. World Tourism Organization/World Travel and Tourism Council. Recuperado de http://travel.nationalgeographic.com/travel/sustainable/pdf/geotourism_community_espanol.pdf [2017, 15 de marzo].

${ }^{6}$ Geoturismo para su comunidad. National Geographic. World Tourism Organization/World Travel and Tourism Council, p. 3. Recuperado de http://travel.nationalgeographic.com/travel/sustainable/pdf/geotourism_community_espanol.pdf [2017, 15 de marzo].
} 
Ese geoturismo que estaría relacionado, en el mejor de los casos, con una forma de turismo responsable o de un desarrollo sustentable del turismo, o bien con un turismo con enfoque local, al que definimos como la orientación de un proceso de desarrollo de un territorio en el cual tiene lugar un conjunto de relaciones económicas, sociales, ambientales y políticas detonadas por la actividad turística, orientadas a movilizar los recursos naturales y culturales que se poseen en la búsqueda de generar iniciativas y proyectos territoriales, liderados por actores locales a fin de mejorar la calidad de vida de los habitantes del destino turístico. Sin embargo, pese a que es muy positiva esta forma de pensar el turismo, no es nada nueva; estos enfoques nacen en un contexto de reflexión sobre el desarrollo alrededor de los años setenta del siglo pasado y han venido madurando y evolucionando durante las últimas décadas integrando, entre otras, a la práctica turística. En realidad, todo turismo así debe ser: sustentabilidad, responsabilidad, enfoque local como elementos transversales a las prácticas y territorios turísticos y no tipologías turísticas.?

Aunque se comparte esta manera de promover y comunicar el valor del territorio convertido en destino turístico, en términos conceptuales se encuentra un tanto disociada de la forma propuesta original para el geoturismo, es decir, desde la geología. Por ello, en el Congreso Internacional de Arouca “Geotourism in Action", celebrado en Portugal en 2011, ${ }^{8}$ se tuvo como tarea central definir el concepto. Como resultado, se obtuvieron las siguientes precisiones:

- [El] Geoturismo debe ser definido como un turismo que sustenta y mejora la identidad de un territorio, considerando su geología, medio ambiente, cultura, valores estéticos, patrimonio y bienestar de sus residentes. El turismo geológico se asume como uno de los diversos componentes del Geoturismo.

- El turismo geológico es una herramienta fundamental para la conservación, la divulgación y la valorización del pasado de la Tierra y de la Vida, incluyendo su dinámica y sus mecanismos, y permitiendo al visitante entender un pasado de 4600 millones de años para analizar el presente con otra perspectiva y proyectar los posibles escenarios futuros comunes para la Tierra y la Humanidad.

- La valorización del patrimonio geológico debe intentar ser innovadora y privilegiar la utilización preferente de las nuevas tecnologías de la información para mejorar el contenido transmitido.

- El formato de la información deberá ser accesible e inteligible para el público en general, centrado en unos pocos conceptos básicos y presentado de una manera clara, como resultado

${ }^{7}$ En Jalisco, por ejemplo, hacia finales del año 2015, se anuncia el Programa de Geoturismo para el Tequila que ha diseñado The National Geographic Society, Mundo Cuervo y el Consejo de Desarrollo Integral de Tequila (CoDIT), cuya finalidad es convertir a este municipio y a la bebida en un destino turístico cultural, inteligente y sustentable. La propuesta se encuentra más relacionada con el tema de la georreferenciación-geolocalización de los puntos considerados como de interés turístico, particularmente una plataforma interactiva que es operada por National Geographic (NatGeo). Recuperado de https://www.forbes.com.mx/forbes-life/tequila-jalisco/\#gs.Ihci51w [2017, 23 de enero]. Aunque resulta interesante el esfuerzo de comunicación y puesta en valor de los sitios de interés que ofrece Tequila, así como los servicios que integra, no se trata de un geoturismo en los términos que se intentan exponer en este caso.

${ }^{8}$ Congreso Internacional de Geoturismo-“Geotourism in Action-Arouca, 2011”, Unesco, Arouca Geopark (Portugal), del 9 al 13 de noviembre de 2011. Recuperado de http://viajealasostenibilidad.org/documentos/declaracion-de-arouca/ [2017, 13 de marzo]. 
de la colaboración de científicos, comunicadores y diseñadores... es el momento de rememorar los principios básicos de interpretación propuestos en 1957 por Freeman Tilden y de aplicarlos al patrimonio geológico:

- Resulta estéril cualquier valorización del patrimonio geológico que no se adecúe, de un modo o de otro, a la personalidad o a la experiencia de vida del visitante.

- La información no es interpretación. La interpretación es una revelación basada en la información. Ambos conceptos son completamente diferentes pero toda interpretación contiene información.

- Cada punto de interpretación debe provocar y despertar curiosidad, así como emocionar, en lugar de pretender enseñar.

- Animamos a los territorios a desarrollar el Geoturismo, enfocado no sólo al medio ambiente y al patrimonio geológico sino también a los valores culturales, históricos o escénicos. En este sentido, recomendamos que la población local y los visitantes se involucren de un modo eficaz y no se limiten al simple papel de espectadores, contribuyendo así a construir una identidad local, promoviendo los valores auténticos y únicos del territorio. De este modo, conseguiremos que el territorio y sus habitantes alcancen integridad medioambiental, justicia social y desarrollo económico sostenible (cursivas propias).

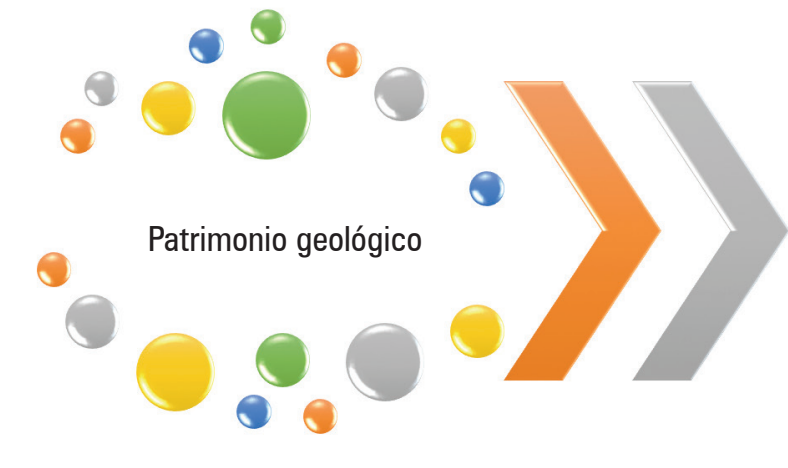

\footnotetext{
*Turismo geológico + tecnologías de la información + interpretación con participción científica, de la población local y de los visitantes.

*Herramientas para el desarrollo.
}

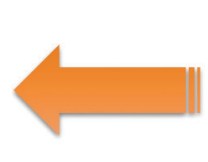

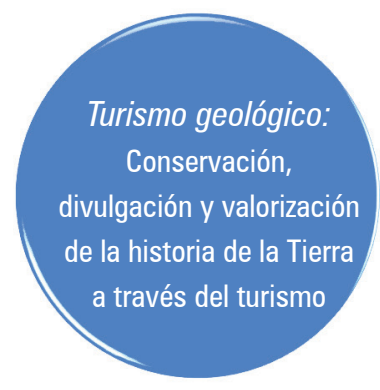

Uso de tecnologías que contribuyen a la valorización de dicho patrimonio. Una tarea de interpretación es mas compleja que el simple hecho de localizar u otorgar información.

Fuente: Elaboración propia a partir de la Declaración de Arouca, 2011.

FiguRA 3. Relación patrimonio geológico y turismo

En este contexto de revaloración y protección del patrimonio geológico, aparecen distintos elementos que enlazan conceptual y operativamente al turismo con el desarrollo local. La participación y el involucramiento de la población local en la operación y gestión de la actividad turística proveen a la perspectiva de la sustentabilidad en el turismo de mejores prospectivas. Cuando se adapta un modelo de desarrollo turístico al territorio y no el territorio al modelo y se cuenta con la participación de la sociedad local, se adosa 
de contenido a las prácticas turísticas, se le da sentido al patrimonio natural y cultural, se ofrece una garantía de uso responsable de los activos del patrimonio territorial: la comunidad toma el control de las prácticas que se desarrollan en su territorio.

Las estrategias turísticas deben buscar activar el capital social mediante una gestión conjunta que involucre la participación de la población local en forma de cooperativas, patronatos y asociaciones, así como estrechar los vínculos con las instituciones educativas, la administración pública y la iniciativa privada. De este modo, el geoturismo, concebido como proyecto territorial, deberá asentarse sobre una estrategia que integre la conservación del patrimonio geológico con el uso turístico, orientado a establecer nuevas rutas para el desarrollo económico y social del ámbito local; es decir, un proyecto territorial cuya gestión surja y se realice desde abajo, de manera que sea posible visualizar cambios cualitativos favorables en la calidad de vida de las personas. La búsqueda del desarrollo local requiere descubrir las relaciones de la sociedad con el territorio sobre el cual interactúa y del que depende.

\section{Sierra la Primavera \\ Caracterización y complejidad territorial}

La SLP ofrece la oportunidad de desarrollar distintas lecturas -temáticas, funcionales y de escala-, pero al mismo tiempo, de innovar en términos de gestión y ordenamiento al poner los valores geológicos-geomorfológicos como algunos de los primeros referentes para la lectura de este territorio. Se parte de la consideración de que la sLP está formada por un conjunto de relieves singulares acompañado de rasgos únicos resultantes de la actividad volcánica y lacustre, que envuelven desde escalas territoriales mayores a esta entidad geográfica.

Las 30500 ha de superficie protegida quedan distribuidas en tres municipios del centro del estado de Jalisco: Zapopan, Tala y Tlajomulco de Zúñiga. Otra importante situación es haber sido reconocida desde 2006 como una de las 40 reservas de la biósfera (Programa sobre el Hombre y la Biósfera -Man and the Biosphere Programme, MAB-) que se encuentran en México y una de las 122 reservas reconocidas en América Latina y el Caribe. ${ }^{9}$ El reconocimiento se sustenta en la rica biodiversidad de los ecosistemas presentes en la reserva, la cual recibe la influencia geográfica de dos provincias florísticas: la Sierra Madre Occidental y su pertenencia a la Faja Neovolcánica Transversal.

A pesar de tratarse de un ámbito complejo, las distintas declaratorias y sus respectivos objetivos de protección y de manejo están enmarcados exclusivamente en el patrimonio natural; más aún, dejan de lado los procesos que determinan la configuración de los elementos, no solo bióticos, sino también los relacionados con la presencia humana y referidos a la impronta urbana, que permiten la comprensión integral de este territorio, aunque sí se

\footnotetext{
${ }^{9}$ Organización de las Nacionales Unidas para la Educación, la Ciencia y la Cultura/Programa sobre el Hombre y la Biósfera (Unesco-mAв Biosphere Reserves Directory, 2011). En su declaración, la Unesco reconoce la existencia en esta zona de hábitats singulares para especies de flora y fauna únicos en el nivel regional, que actúan como reserva genética y corredores biológicos entre los sistemas naturales de la región.
} 


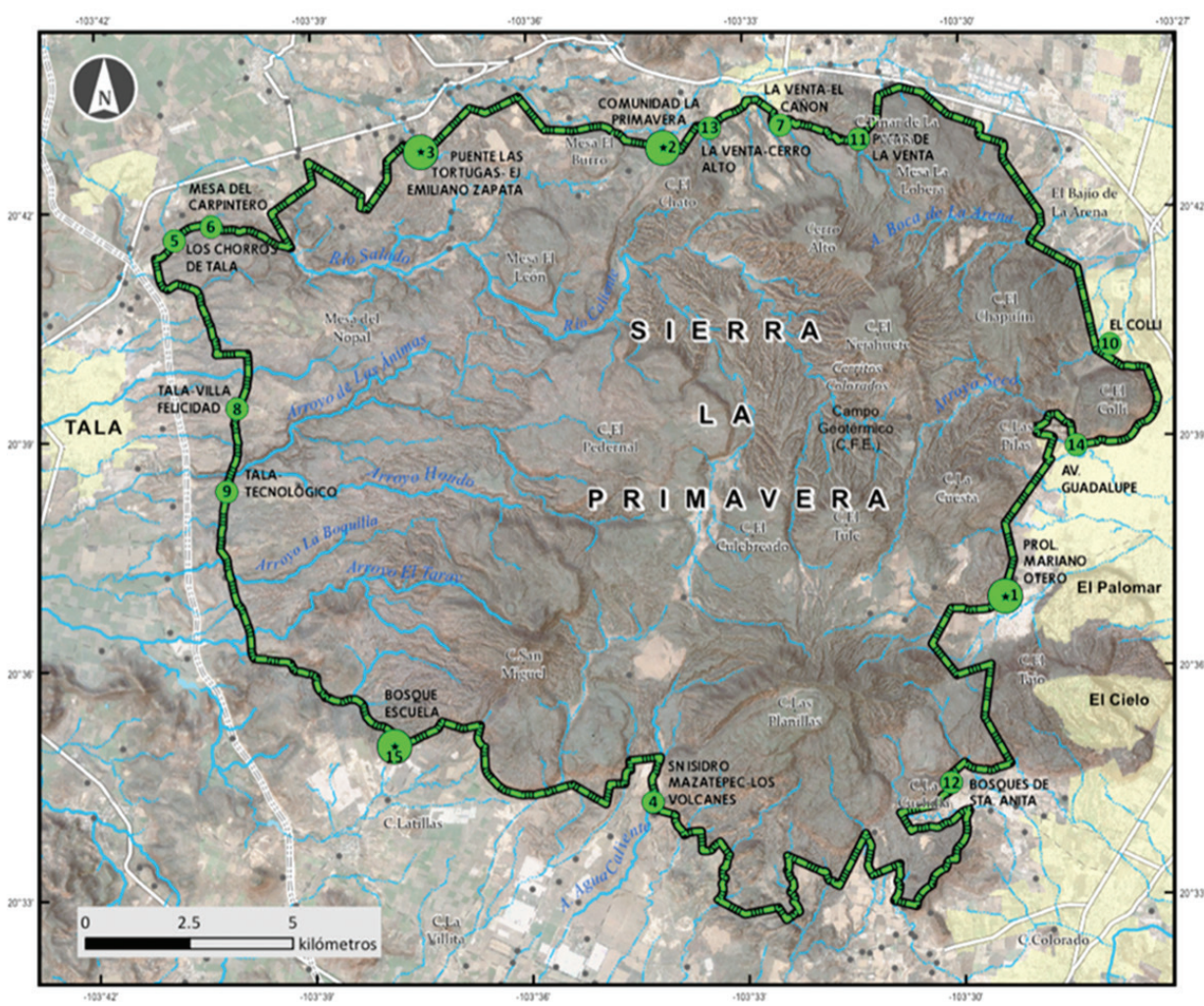

Fuente mapa base: Elaboración propia a partir de INEGI (2002) Conjunto de Datos Vectoriales de la Carta Topográfica F13D64 Tala; INEGI (2003) Conjunto de Datos Vectoriales de la Carta Topográfica F13D65 Guadalajara Oeste; INEGI (2010) Marco Geoestadístico. Localidades Rurales y Urbanas; INEGI (s/f) Red Hidrográfica escala 1:50 000 versión 2.0; Gobierno del Estado de Jalisco (2011) Atlas Estatal de Carreteras y Caminos Rurales. El trazo del libramiento fue construido a partir de Google Earth. conanP (2016). Áreas Naturales Protegidas Federales de la República Mexicana. 2016, edición; 1. Comisión Nacional de Áreas Naturales Protegidas. Actualización de las Áreas Naturales Protegidas Federales. Ciudad de México, México. Polígono de Área Protegida La Primavera. Los accesos fueron levantados en campo (2015). Imagen Google Earth (2017)

Coordenadas geográficas. Proyección utm 13N. Datum wgs84

Localización

Simbología

ACCESO

Principal

Secundario

$\star \quad$ Control de ingreso

CuRSO DE AGUA

Intermitente
Perenne
-

Fuente: González, Valdivia y Gómez (2018).

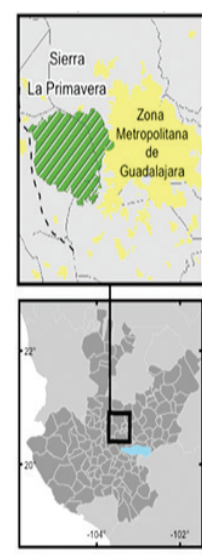

Autores: María del Rocío Castillo Aja, Luis Valdivia Ornelas, Lucia González Torreros

REDACCIÓN CARTOGRÁFICA, DISEÑO Y MAQUETACIÓN: María del Rocío Castillo Aja

\section{Figura 4. Mapa de localización de la Sierra La Primavera en el contexto del Área Metropolitana de Guadalajara y sus principales accesos}


destaca la práctica turística en uno de los cinco ejes de manejo. Las diversas instancias que intervienen en la gestión de este territorio reconocen que uno de los problemas que más aquejan a esta ANP es la tenencia de la tierra. Este asunto se encuentra asociado directamente con las diferentes funciones que se realizan dentro y en los márgenes del perímetro de protección.

La presión inmobiliaria toma fuerza día con día y con ello se incrementa la vulnerabilidad del bosque hacia los incendios forestales. El crecimiento de la mancha urbana amenaza con nuevas vías de comunicación que no solo ponen en peligro a la flora y fauna del lugar y fragmentan la conectividad del ecosistema, lo que conlleva la pérdida de biodiversidad, sino también afectan el patrimonio geológico que ha permanecido enterrado, por no decir olvidado. Se trata de miradas parciales de nacen desde adentro y circunscritas al perímetro del ANP.

\subsection{Un poco de la historia geológica de la SLP}

En términos geológicos, la estructura de la sLP se relaciona principalmente con una evolución volcano-lacustre asociada con la Faja Volcánica Transmexicana cuya manifestación se observa en los niveles estructural y paisajístico.

De acuerdo con expertos como Mahood, Truesdell, Templos y Halliday (cit. en Valdivia, 2018), la historia geológica de La Primavera da comienzo hace unos 140000 años ${ }^{10}$ y concluye apenas unos 27 000-30 000 años atrás. Distintas etapas produjeron los elementos más significativos del patrimonio geológico y las particularidades geológicas-geomorfológicas y paisajísticas de mayor importancia actual.

En las etapas más tempranas, surgen las primeras evidencias de la actividad magmática: los domos precaldéricos. Hacia los 95000 años atrás, emisiones masivas de lava y gases y piroclastos dieron origen a la Toba Tala. ${ }^{11}$ Entre los 70000 y 50000 años se emplazan los domos caldéricos, que al interactuar con el agua, generan un inusual Horizonte de piedra pómez gigante; al colapsar las paredes de la cámara magmática, se formó una caldera que alcanzó $11 \mathrm{~km}$ de diámetro, con lo cual surge el lago que durante los siguientes 50000 años fue depositario de material lacustre; simultáneamente y como resultado de distintos eventos volcánicos y telúricos, el paisaje tomó la forma de sierra-serranía.

El primer momento da origen a los edificios de piroclastos del Anillo Caldérico Sur y Norte que, al colapsarse, provocaron un desbordamiento por los puntos más bajos. La obsidiana resulta del súbito enfriamiento de roca, dejando evidencias dispersas por prácticamente toda la región, siendo partícipe en el desarrollo cultural de los habitantes prehispánicos. Un segundo momento da origen a los cerros - domos- del Arco Sur así como a los hummocks. El último evento sucedido entre los 30000 y 27000 años atrás condiciona la

\footnotetext{
${ }^{10}$ Pónganse como referencia una línea que mide $14 \mathrm{~cm}$. Cada centímetro equivale a 10000 años en la evolución de la sierra La Primavera, y cada milímetro supone un lapso de 1000 años. En este sentido, la etapa más intensiva se produce durante 110000 años, periodo en el cual sucedió la producción del material que hoy constituye el patrimonio geológicogeomorfológico. En el último milímetro se manifiesta la mayor intensidad de sucesos sociales y ambientales, determinada por la presencia de los grupos humanos, quienes han influido en su evolución, uso (entre el que se encuentra el turismo y la recreación), deterioro, protección e invasión.

${ }^{11}$ Su volumen alcanzó $40 \mathrm{~km}^{3}$ y su extensión, 700 km².
} 
formación de El Colli y se rejuvenecen las depresiones de El Bajío y del valle de Atemajac con una potente capa de piedra pómez. Esta breve referencia fue la base del conocimiento que llevó al trabajo de campo, en el cual se identificaron distintos elementos entre los que se han de destacar aquellos que detentan un potencial para la práctica del geoturismo.

\subsubsection{Algunas evidencias}

Para el caso que se expone, en el tema de la geodiversidad se obtuvo un total de 80 unidades distribuidas de la siguiente manera: seis con un valor muy alto, 20 con un valor alto, 32 con una valoración media, 18 con calificación baja y las cuatro restantes, con un valor muy bajo. Las unidades con valoraciones más altas se ubican con relación a los domos: Cerritos Colorados y su entorno geotérmico, Las Planillas y San Miguel, receptores principales de las prácticas ciclistas.

Una vez realizado el ejercicio de inventario y clasificación, resultaron 123 puntos en la SLP. ${ }^{12}$ De ellos se consideraron en una primera evaluación 16 puntos, áreas y corredores que podrían ser calificados como geositios (valor potencial); estos fueron sometidos a la evaluación a partir de los criterios de valor intrínseco, científico/educativo, turístico y vulnerabilidad. Las ponderaciones bajo los criterios metodológicos propuestos arrojaron 13 geositios (GS\#) para la SLP. Los elementos resultantes se agruparon en siete macrozonas con características que facilitaron una descripción puntual de su contenido patrimonial. ${ }^{13}$ La información anterior alimentó el cuadro 2.

La situación actual en la sLP remite a zonas de camping, ciclismo, balnearios, senderos y, de forma general, a tipologías como turismo rural, ecoturismo o turismo interpretativo, turismo de aventura o extremo; sin embargo, en todas las propuestas de uso y gestión, así como en los emprendimientos económicos, no se tiene previsto (en sentido puntual y estricto) el valor geológico de la sLP.

\footnotetext{
${ }_{12}$ Para evitar duplicidad, de los 179 puntos del inventario realizado, se restan 28 puntos de alteración antrópica y 28 estrictamente turístico-recreativos.

${ }^{13}$ En esta lectura, conviene aclarar que algunos de los puntos de observación del paisaje están contenidos en otras clasificaciones, por tener un componente de origen geológico, geomorfológico o geohidrotermal, pero se contabilizan de este modo debido a que presentan una oportunidad para la observación-interpretación del proceso evolutivo de la SLP (geoturismo). De la misma manera, es importante apuntar que entre los 39 puntos ligados a la clasificación geohidrotermal se encuentran los pozos 13 del proyecto federal de la Geotérmica, por lo que podrían resultar restringidos para un uso turístico-recreativo, aunque en la actualidad ya reciben una carga, particularmente de parte de ciclistas; de igual forma, en esta categoría se cuentan algunos pozos (afluentes) de agua caliente que alimentan a los emprendimientos recreativos (balnearios).

En las figuras que se ofrecen relacionadas con el ciclismo y senderismo páginas adelante, se observa la localización de los geositios obtenidos del inventario y la evaluación respectiva, incluidos aquellos que ya cuentan con una orientación económica para la práctica del turismo y la recreación (balnearios y ranchos turísticos - picnic y camping-) como los que se identifican que pueden articular una propuesta para el geoturismo, incluidos puntos de observación del paisaje. Se muestra la dispersión espacial de los recursos geológicos - geomorfológicos relacionándose la información con el acceso a los mismos.
} 
CuAdro 2. Lista de geositios (potenciales y reales) definidos en función de su valor para representar rasgos distintivos de la evolución geológica de la SLP

\begin{tabular}{|c|c|c|c|}
\hline ID & Nombre & $\begin{array}{l}\text { Macrozona en la } \\
\text { que se encuentra }\end{array}$ & Rasgos relevantes del origen o evolución \\
\hline \multicolumn{4}{|r|}{ GEOTÉRMICOS } \\
\hline GS1 & $\begin{array}{l}\text { Nacimiento y cuenca } \\
\text { del Río Caliente }\end{array}$ & Río Caliente & \multirow{2}{*}{$\begin{array}{l}\text { Relacionadas con sistema geotérmico, constituyen una evi- } \\
\text { dencia real de la evolución volcánica con manifestaciones } \\
\text { actuales. }\end{array}$} \\
\hline GS2 & $\begin{array}{l}\text { Colina de precipitacio- } \\
\text { nes de azufre }\end{array}$ & Geotérmica & \\
\hline \multicolumn{4}{|r|}{ MuRos } \\
\hline GS3 & $\begin{array}{l}\text { Pared de } \\
\text { Los Cuervos }\end{array}$ & $\begin{array}{l}\text { Tala-Los } \\
\text { Chorros }\end{array}$ & $\begin{array}{l}\text { Concentración de } 1000 \text { chimeneas -aprox.- fosilizadas } \\
\text { de distinto tamaño acomodadas de forma horizontales, } \\
\text { incrustadas en el muro. Dispuestas principalmente en capas } \\
\text { sobre puestas, en líneas apiladas. }\end{array}$ \\
\hline GS4 & $\begin{array}{l}\text { Muro de las } \\
\text { Chimeneas } \\
\text { Gigantes }\end{array}$ & $\begin{array}{l}\text { Macrozona } \\
\text { Tala-Villa } \\
\text { Felicidad }\end{array}$ & $\begin{array}{l}\text { Muro del cual han aflorado las chimeneas de mayor tamaño } \\
\text { identificadas en el trabajo de campo. En la actualidad han } \\
\text { tomado distintas formas debido a la erosión, pero aún se } \\
\text { mantienen íntegras, incrustadas diagonalmente a la pared. }\end{array}$ \\
\hline \multicolumn{4}{|r|}{ CORTES } \\
\hline \multicolumn{4}{|c|}{ Por Arroyo Seco (rumbo a la geotérmica) } \\
\hline GS5 & $\begin{array}{l}\text { Corte de } \\
\text { sedimentos } \\
\text { subaéreos }\end{array}$ & Geotérmica & $\begin{array}{l}\text { Originado por la construcción de un camino hacia el campo } \\
\text { geotérmico, presenta evidencias de los sedimentos subaé- } \\
\text { reos descansando sobre sedimentos lacustres en contacto } \\
\text { angular. }\end{array}$ \\
\hline GS6 & Corte Slumps & & $\begin{array}{l}\text { Originado por la construcción de un camino hacia el campo } \\
\text { geotérmico, se puede observar una secuencia lacustre defor- } \\
\text { mada con pómez flotante, slump y contacto en orlas lamini- } \\
\text { llas lacustre deformadas. }\end{array}$ \\
\hline GS7 & $\begin{array}{l}\text { Horizonte de Piedra } \\
\text { Pómez Gigante } \\
\text { (Corte) }\end{array}$ & & $\begin{array}{l}\text { Constituye uno de los rasgos de mayor importancia, el que } \\
\text { otorga un mejor ejemplo de la existencia del Horizonte de } \\
\text { Piedra Pómez Gigante (incrustadas en el muro). }\end{array}$ \\
\hline \multicolumn{4}{|c|}{ Por el Macrolibramiento } \\
\hline $\mathrm{GS}^{2}$ & $\begin{array}{l}\text { Corte geológico de } \\
\text { pómez de caída y flujo } \\
\text { ignimbrita del domo } \\
\text { San Miguel (corte } \\
\text { Arcoíris) }\end{array}$ & $\begin{array}{l}\text { Macrolibra- } \\
\text { miento }\end{array}$ & $\begin{array}{l}\text { Todos los cortes que se incluyen como geositios, ligados } \\
\text { al macro libramiento, han quedado expuestos por la } \\
\text { creación de infraestructura carretera. Otorgan un sentido } \\
\text { más amplio de riesgo para los recursos geológicos, pero } \\
\text { a la vez, ofrecen oportunidades para la investigación y } \\
\text { ambientes didácticos. Ofrecen una importante oportunidad }\end{array}$ \\
\hline $\mathrm{GS}^{1,2}$ & Corte Obsidiana & & $\begin{array}{l}\text { para encontrar explicaciones sobre los procesos que dieron } \\
\text { origen al Domo San Miguel, a procesos de desvitrificación- }\end{array}$ \\
\hline GS10 & $\begin{array}{l}\text { Corte estructura inter- } \\
\text { na de una chimenena }\end{array}$ & & $\begin{array}{l}\text { enfriamiento, la estructura sedimentaria de la тт y la } \\
\text { naturaleza de las chimeneas fosilizadas. }\end{array}$ \\
\hline GS $11^{1,2}$ & $\begin{array}{l}\text { Corte de chimeneas } \\
\text { estampadas }\end{array}$ & & \\
\hline
\end{tabular}


CuAdro 2. Lista de geositios (potenciales y reales) definidos en función de su valor para representar rasgos distintivos de la evolución geológica de la SLP

(finaliza)

\begin{tabular}{|c|c|c|c|}
\hline ID & Nombre & $\begin{array}{l}\text { Macrozona en la } \\
\text { que se encuentra }\end{array}$ & Rasgos relevantes del origen o evolución \\
\hline \multicolumn{4}{|c|}{ Por Pinar de La Venta } \\
\hline GS12 & $\begin{array}{l}\text { Corte Pómez Gigante } \\
\text { (individual) }\end{array}$ & Río Caliente & $\begin{array}{l}\text { Corte originado por la incisión del escurrimiento La Cuartilla, } \\
\text { presenta otra evidencia del horizonte de Piedra Pómez (la de } \\
\text { mayor tamaño identificada al momento), así mismo, deja ver } \\
\text { un sistema de fallas poscaldéricas normales, relevantes en el } \\
\text { contexto evolutivo de la sLP. }\end{array}$ \\
\hline \multirow[t]{2}{*}{ GS13 } & Cañón El Carbón & Río Caliente & $\begin{array}{l}\text { Esta zona, que presenta distintos cortes, cuenta con las } \\
\text { condiciones para observar parte de la columna geológica } \\
\text { (de origen tectónico-volcano-lacustre), se manifiesta la } \\
\text { importancia de la tectónica poscaldérica, originada por la } \\
\text { resurgencia de la sLP. }\end{array}$ \\
\hline & & & CoLINAS \\
\hline GS14 & $\begin{array}{l}\text { Colina de las } \\
\text { chimeneas } \\
\text { recostadas }\end{array}$ & $\begin{array}{l}\text { Emiliano Zapata } \\
\text { La Primavera }\end{array}$ & $\begin{array}{l}\text { Constituye el clúster más importante identificado de chime- } \\
\text { neas fosilizadas de gran tamaño. Se trata de un agrupamiento } \\
\text { de alrededor de } 30 \text { unidades, emplazados de forma inclinada } \\
\text { sobre la colina, de entre dos y siete metros de largo. }\end{array}$ \\
\hline GS15 & $\begin{array}{l}\text { Colina de las } \\
\text { chimeneas en forma } \\
\text { de pétalo y muro } \\
\text { crestado }\end{array}$ & $\begin{array}{l}\text { Tala-Villa } \\
\text { Felicidad }\end{array}$ & $\begin{array}{l}\text { Constituye el clúster más importante identificado de chime- } \\
\text { neas fosilizadas verticales aunque de tamaño pequeño. Su } \\
\text { singularidad radica en la forma deformada, orlas onduladas } \\
\text { que se han denominado de pétalo. Una sección contigua, pre- } \\
\text { senta una serie de muros ondulados característicos de la Tा, } \\
\text { uno en particular, presenta un relieve crestado, lo que lo hace } \\
\text { único en el contexto geológico de la sLP. }\end{array}$ \\
\hline GS16 & $\begin{array}{l}\text { Colina el Caballero } \\
\text { Águila }\end{array}$ & $\begin{array}{l}\text { Tala-Los } \\
\text { Chorros }\end{array}$ & $\begin{array}{l}\text { Presenta distintos elementos, principalmente ligados con la } \\
\text { geomorfología resultante de los afloramientos de } \pi \text { : chime- } \\
\text { neas verticales de gran tamaño, pequeños racimos de chime- } \\
\text { neas apiladas, estructuras rocosas caprichosas y muros de } \pi \text {. }\end{array}$ \\
\hline
\end{tabular}

${ }^{1}$ No cumple con escala de referencia. No fue considerado geositio.

${ }^{2}$ No cumple con el porcentaje mínimo de aprobación establecido por la metodología: $44=50 \%$. No fue considerado geositio.

Fuente: González, Valdivia, Gómez y Castillo, 2018. Capítulo II.

\section{Discusión: La geOdiversidad y el geOpatrimonio en El CONTEXTO DE LA UTILIZACIÓN TURÍSTICO-RECREATIVA}

\subsection{La dinámica de las actividades turístico-recreativas en la SLP: una mirada a los últimos años}

Desde mediados del siglo xIx, la sLP ha permitido a los habitantes del Área Metropolitana de Guadalajara y a los pobladores de los municipios aledaños el desarrollo de actividades con fines turístico-recreativos, en particular relacionadas con los recursos geohidrotermales. Su localización justo al lado de una ciudad de gran tamaño sugiere que el destino turístico es el Área Metropolitana de Guadalajara (actúa como centro de estadía y distribución) y desde aquí se realizan desplazamientos de corta estancia, apenas de cuatro a cinco horas hacia la SLP. La motivación tradicional se centra en tres elementos: el recurso geohidrotermal, 
el bosque y, más recientemente, la topografía y el paisaje (el relieve), que llaman la atención para el ciclismo y el senderismo. Quienes desarrollan la práctica son, en términos generales, los habitantes de esta metrópoli y de los municipios aledaños, por lo que el territorio en cuestión no desempeña por sí mismo, al menos en sentido estricto y por el momento, una sólida función turística pero sí recreativa. Los movimientos ligados al ciclismo, camping-pícnic y senderismo tienen diversos actores, pocos de ellos relacionados, específicamente, con un interés geológico.

A la fecha, el Organismo Público Descentralizado (OPD) Bosque La Primavera tiene un registro de automóviles y personas que ingresan por las dos casetas principales - de más de 15 identificadas-: la ubicada por la prolongación Mariano Otero y la que se localiza en el ejido La Primavera (\#1 y \#2, respectivamente; véase figura 4). Los conteos de los últimos años indican que, en promedio, ingresan 3.3 personas por vehículo; ${ }^{14}$ la relación personas / vehículo es más o menos constante.

En este contexto de usos turístico-recreativos se propone el geoturismo, una actividad ordenada, a realizarse en zonas muy específicas del ANP, con guías especializados que ofrecerían la información bajo esquemas de interpretación del patrimonio geológico. Las formas y trayectos de acceso, así como los horarios de visita, pueden ser acordados entre los propietarios y las autoridades del OPD. En este tenor, la producción de material informativo e incluso el desarrollo de aplicaciones móviles es pertinente.

\subsubsection{Balnearios, campings y áreas de pícnic}

La mayoría de los balnearios que operan actualmente, y que fueron identificados en el trabajo de campo como unidades económicas activas, abrieron sus puertas entre las décadas de los setenta y ochenta. Todos tienen entre 35 y 40 años de funcionamiento continuo, con altibajos causados por la afluente (gasto) de agua termal y por algunos incendios forestales. La temporada alta de demanda para las actividades ligadas con el bosque y los recursos hidrotermales inicia a partir de la Semana Santa (con fechas variables) -con una pretemporada que da comienzo en el puente del 5 de febrero- y continúa hasta mediados o finales de octubre, cuando desciende la demanda.

Como resultado del inventario inicial otorgado por el OPD y validado en trabajo de campo, se identificaron 28 sitios ya con una práctica turístico-recreativa: 16 de ecoturismo/ turismo vinculado con la naturaleza y la educación ambiental (incluye dos empresas no registradas por el OPD), 11 balnearios (dos no inventariados por el oPD por localizarse fuera del perímetro de protección) y un restaurante. La mayoría son empresas de carácter privado con origen en la propiedad ejidal..$^{15}$

${ }^{14}$ Los registros expresan altibajos en la afluencia que pueden explicarse por incendios forestales, momentos de conciencia ambiental, eventos deportivos, o simplemente moda. Llama la atención que tanto el punto más alto (2006) como el más bajo (2012), coinciden con la ocurrencia de dos de los incendios más importantes de los últimos años, los cuales afectaron el ambiente regional. Como ya se indicó, el registro más bajo corresponde al año 2012, con apenas poco más de 38000 personas y 11795 vehículos. Se intuye que el ingreso puede ser mayor a las cifras registradas debido a que solo se controla la entrada en dos de los 15 accesos inventariados. En el Plan de Manejo se cuentan 22 accesos al AnP.

${ }^{15}$ Un punto importante para el acceso hacia los balnearios y el camping es por los ejidos La Primavera, San Isidro 

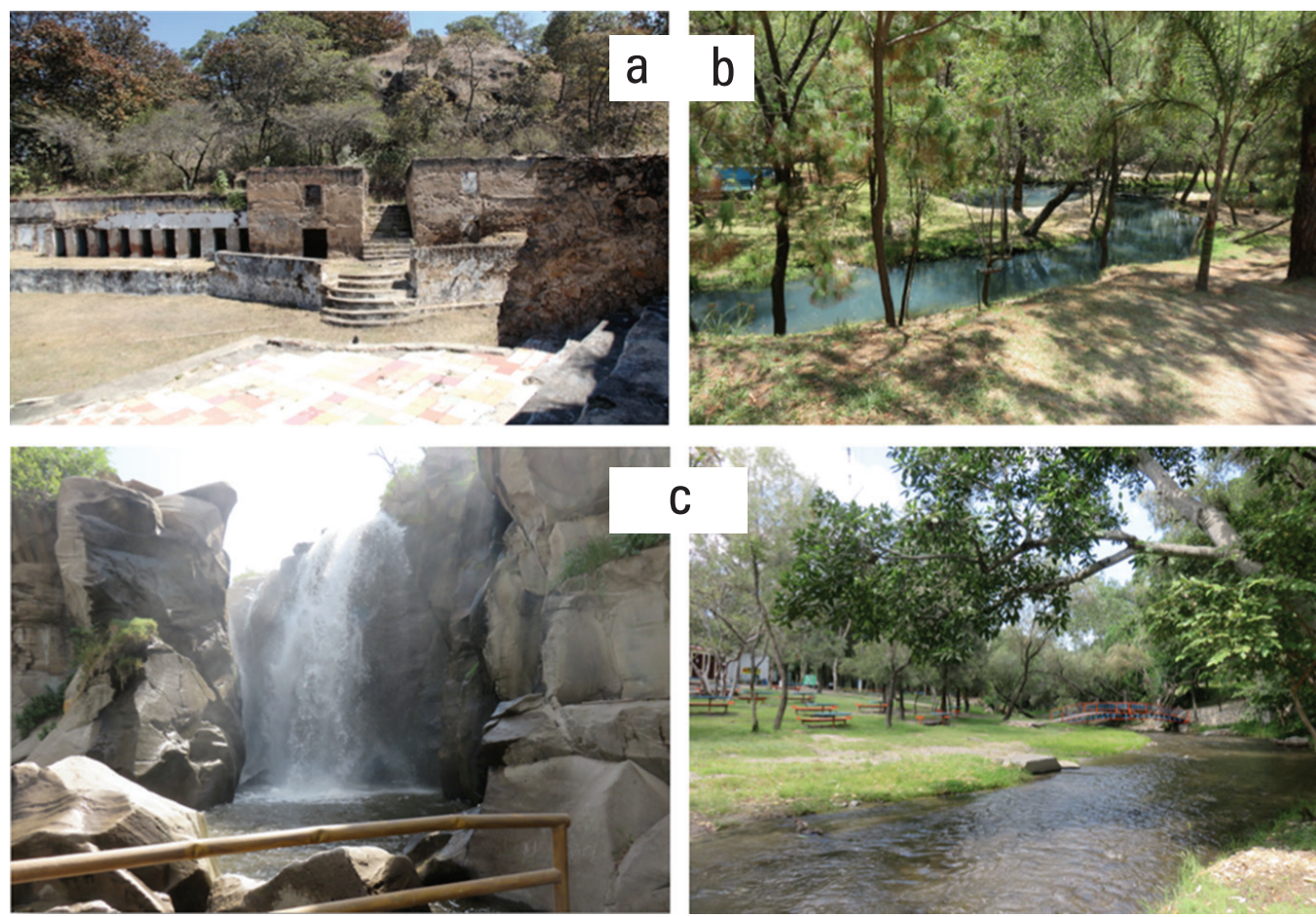

Archivo personal: Trabajo de campo febrero-noviembre de 2015.

FiguRA 5. Recursos localizados en el área de la sLP con función turístico-recreativa: a) Vestigios de la Hacienda La Primavera, pionera de las prácticas turístico-recreativas; b) Rancho-Camping Agua Dulce; y

c) Balneario Los Chorros de Tala.

A los emprendimientos económicos señalados es necesario sumar otras actividades de importancia, primero, en términos de las acciones emprendidas en el marco de la educación ambiental y el turismo de naturaleza, y segundo, por tratarse de actividades que generan un mayor impacto en el ANP. Se trata del ciclismo y el senderismo.

\subsubsection{Las rutas ciclistas}

La actividad de los ciclistas cada vez presenta mayores niveles de consolidación. Con el común denominador de la bicicleta, existen actividades relativamente moderadas, como el ciclismo de recreo, pero también algunas más intensas, como a campo traviesa y downhill, que ya comienzan a impactar ambiental y socialmente distintas áreas de la SLP. ${ }^{16}$

De acuerdo con los informantes, pero sin existir un número oficial, se estiman alrededor de 2500 ciclistas cada fin de semana; 90 \% del ingreso de ciclistas al ANP se realiza por la

Mazatepec y Emiliano Zapata, seguido por la zona de Mariano Otero. En el juego de escalas, en el nivel municipal Tala tiene una afluencia a la zona que se relaciona fuertemente con actividades de día de campo y senderismo.

${ }^{16}$ Las fuentes principales son: Puraventura (Agencia de Ecoturismo-Mauricio Margules); John Pint (Senderista); Wikilock (registro de internet); Marcelino Villavicencio, miembro clave del Club de Exploraciones de México; Jorge Gabriel Ruiz Cortés, del colectivo Mountain Bike A. C.; el opd Bosque La Primavera y, en menor medida, Colectivo Cámara Rodante (Edgar Fidalgo). 
entrada de Mariano Otero. Esta afluencia ha detonado distintos procesos en la escala del medio físico, pero también en la escena social, fundamentalmente porque la mayoría de las rutas son reportadas como "no oficiales", ya que no tienen el seguimiento apropiado para evitar erosión y desgaste del suelo, ni para llevar a cabo acciones de restauración de las mismas. La parte social se ve afectada debido a que son rutas que pasan por predios que no están destinados al uso público, lo que supone una invasión constante a la propiedad privada.

La actividad ciclista se concentra sobre todo en la parte sureste y en la oeste del ANP. La red de rutas se ramifica hacia la ladera norte del cerro Las Planillas y al noroeste del cerro San Miguel. También se aprecian algunos segmentos de las rutas que involucran los cerros El Culebreado y El Madroño y otras que se dirigen hacia el cerro Nejahuete, donde se localiza la Torre 2, así como otra ramificación menor que se distribuye por el lado de Tala. ${ }^{17}$

El potencial del ciclismo es alto y la demanda de este espacio, creciente. Con mayor frecuencia se ofertan carreras organizadas por distintos colectivos y asociaciones locales, nacionales e internacionales. Páginas de ciclismo especializadas, como la de MTBProject, considera miles de rutas en el ámbito mundial (principalmente en Estados Unidos), entre ellas 56 rutas en México, de las cuales 35 se ubican en el estado de Jalisco y tres de ellas se promueven en La Primavera: Espinazo-Pinitos, Torre de observación \# 2 y La Cebada. ${ }^{18}$ La información que se ofrece sobre las rutas tiene que ver con longitud, pendiente, clima, grado de dificultad e interés; además se mencionan en blogs y en páginas web de pequeñas empresas que ofrecen un turismo alternativo. Sin embargo, las quejas de los dueños de los predios también van en aumento. En la figura 6 se presentan las distintas rutas ciclistas, según el punto de acceso; se han relacionado con la localización de los geositios para evaluar su coincidencia espacial. Como se observa, los puntos de mayor riesgo son nacimientos de agua caliente y algunas zonas de chimeneas fósiles apiladas, pero en particular los domos de San Miguel y Las Planillas. La figura también muestra el tipo de propiedad de los predios en los cuales se manifiestan estas prácticas, así como la localización de sitios con actividad turístico-recreativa actual.

${ }^{17}$ El Programa de Manejo Área de Protección de Flora y Fauna La Primavera, México (Comisión Nacional de Áreas Naturales Protegidas, 2000) establece a Las Planillas, el cerro San Miguel y la mesa El León como "Zonas de Protección", las rutas ciclistas identificadas transitan por terrenos clasificados en el mismo programa como "Zonas de Uso Restringido" y, en menor medida, por la zona de La Cebada y el cauce del Río Caliente, identificadas como "Zonas de Uso Público"; asimismo, algunos ramos de las rutas se registran sobre áreas calificadas como "Zonas de Recuperación"; estas áreas constituyen los escenarios más frecuentes para la práctica del ciclismo de montaña, cuestión que implica una ligereza en la aplicación rigurosa del Plan por falta de recursos o capacidad institucional, o desconocimiento o falta de interés de parte de los usuarios, o quizá las dos cosas.

18 Recuperado de https://www.mtbproject.com/trail/7002267/espinazo-conectando-con-pinitos; https://www. mtbproject.com/trail/7000794/watchtower-number-2; https://www.mtbproject.com/trail/7002268/la-cebada [2017, 20 de diciembre]. 


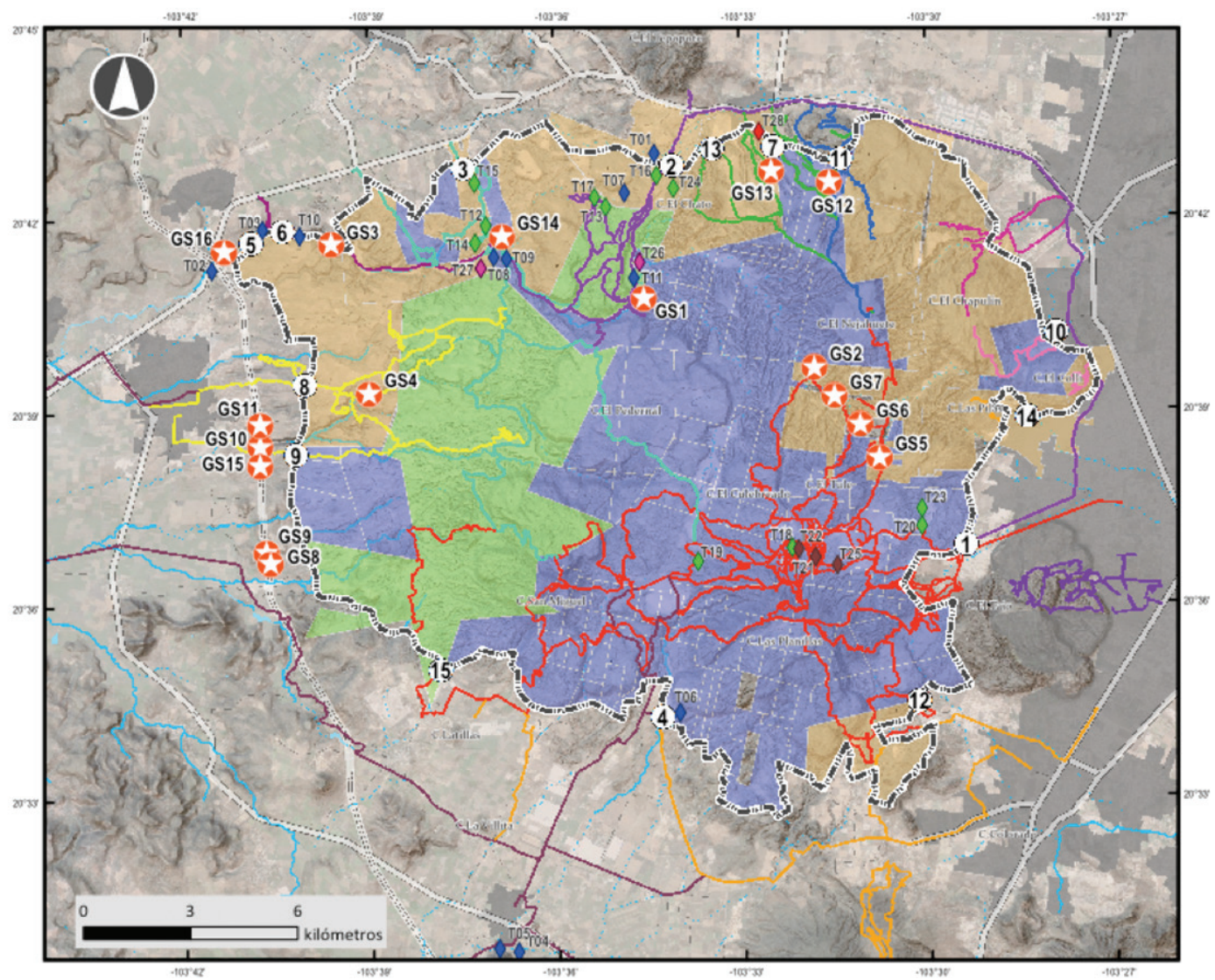

Fuente: Elaboración propia a partir del Mapa de Localización, Mapa de Tenencia de la Tierra, Levantamiento en campo e información proporcionada por Mauricio Margules de la empresa Puraventura, Edgar Fidalgo del Colectivo Cámara Rodante, OPD Bosque La Primavera, Colectivo Mountain Bike y distintos usuarios que agregaron tracks! a Wikiloc. Febrero de 2015 Marzo de 2016.

Coordenadas geográficas en grados. Proyección UTM 13N Datum wGS84

\section{RUTAS CICLISTAS}

Simbología

- Geositio (GS\#)

RUTA CICLISTA POR ACCESO

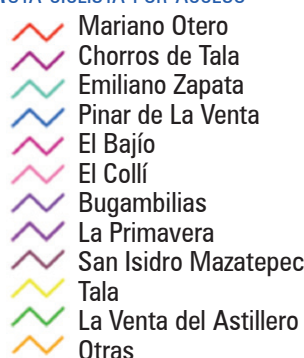

Fuente: González, Valdivia y Gómez (2018).
TuRístico RECREATIVO ACTUAL

$$
\begin{aligned}
& \text { Restaurante } \\
& \text { Educación ambiental y/o } \\
& \text { campamento ecoturístico } \\
& \text { Spa } \\
& \text { Ciclismo y otros } \\
& \text { Balneario }
\end{aligned}
$$

TIPO DE PROPIEDAD

\section{Estatal}

Ejidal

Pequeña propiedad

Punto de acceso
CURSO DE AGUA

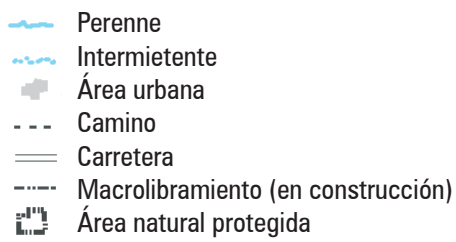

Autores: Lucía González Torreros, Roberto Torres Leos Redacción cartográfica, diseño y maquetación: María del Rocío Castillo Aja.

Figura 6. Mapa de rutas ciclistas con la distribución de los geositios 


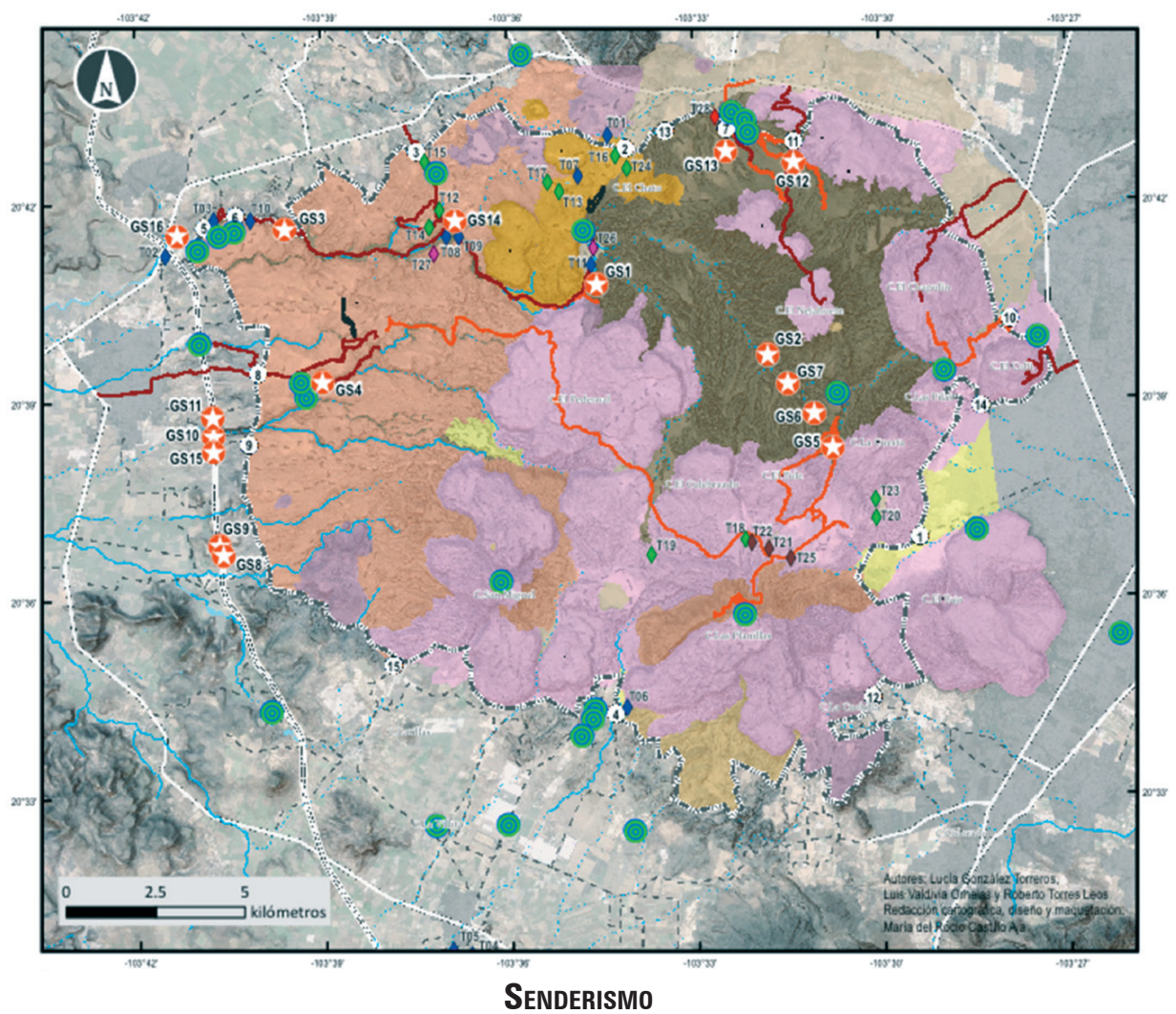

Simbología

- Geositio (gs\#)

( ) Punto para observar el paisaje

TuRísTICO RECREATIVO ACTUAL

Restaurante

Educación ambiental y/o campamento ecoturístico

$\checkmark$ Spa

Ciclismo y otros

- Balneario

TIPO DE RUTA

$\simeq$ Sendero interpretativo
Mixto: Senderismo
y ruta ciclista
$\simeq$ Senderismo

UNIDAD DE RELIEVE

Lomeríos y cerros precaldéricos

Cerros y mesas caldéricas

Barrancas y mesas por procesos de resurgencia

Depresiones generadas por movimientos tectónicos deferenciales (levantamiento/hundimiento)

Chimeneas y paredes; lomas, mesas y barrancas asociadas con el enfriamiento de la Toba Tala Cráteres mayores y menores y lomeríos cónicos asociados con colapsos gravitacionales y actividad freatomagmática

Rampa ligeramente inclinada formada en Toba Tala con una capa de conglomerados fluviales

Lomeríos y cerros volcánicos pre-Primavera
Curso de Agua

_. Perenne

.... Intermitente

4. Área urbana

= Carretera

-..-. Macrolibramiento (en construcción)

. . Camino

- Acceso

: Área natural protegida

Fuente: Elaboración propia a partir de información proporcionada por John Pint, Marcelo Villacencio (miembro del Club de Exploraciones México A.C.), oPD Bosque La Primavera y distintos usuarios que agregaron tracks a Wkiloc. La información proporcionada por el oPD sobre los emprendimientos turísticos - recreativos, fue verificada y enriquecida en trabajo de campo, junto con los sitios de interés geológico, geomorfológico, geohidrotermal y de observación del paisaje.

Febrero de 2015 - Marzo de 2016.

Coordenadas geográficas en grados. Proyección uTM 13N. Datum wGs84

Fuente: González, Valdivia y Gómez (2018).

Figura 7. Mapa rutas de senderismo con geositios y puntos de observación del paisaje 


\subsubsection{Los senderos}

En el caso de los senderos, se cuentan 44 y solo dos son interpetativos, los que gestiona el OPD: Sentidos y Toba Tala. Su distribución se concentra principalmente en la parte norte del ANP; no obstante, la mayoría de las rutas tienen origen en la parte norte y se prolongan hacia el centro de la SLP.

Los senderos se visualizan como una oportunidad real para el geoturismo y, al mismo tiempo, como una estrategia para la educación ambiental. ${ }^{19}$ Es común que las rutas que trazan los senderistas, que avanzan a un ritmo más lento y espaciado sobre el territorio, sean también para quienes desean hacer recorridos a trote; incluso, hay trayectos que son para senderistas, corredores y ciclistas, lo cual implica un riesgo para quienes realizan actividades de bajo impacto o que llevan a cabo su visita con menores de edad.

Con la creciente demanda como espacio recreativo, la afluencia a La Primavera se ha intensificado, lo que provoca una problemática mayor y la necesidad de establecer líneas de acción orientadas a generar las condiciones para un control más eficiente de los flujos temporales. Por ejemplo, el acceso desde el poblado de Tala no cuenta con un ingreso controlado ni un conteo, pero resulta de gran importancia para actividades como el camping y el pícnic. ${ }^{20}$ En cuestión del patrimonio geológico, este es uno de los accesos de mayor relevancia por la localización de puntos de interés geológico identificados en campo. En la figura 7 se exponen los trazos de los senderos, combinándose con la localización de geositios y de puntos de observación del paisaje así como con los emprendimientos turísticos y con la capa de unidades de relieve, entre las que destacan los lomeríos, las barrancas y las zonas de chimeneas fosilizadas, coincidentes con buen número de geositios.

Todo ello permite reconocer un gran potencial para la práctica del geoturismo. De las cinco macrozonas identificadas, la número 1 (Macrozona del Río Caliente) es la que cuenta con una actividad recreativa vinculada con los balnearios, la cual se desarrolla a partir del recurso geohidrotermal de manera formal desde las décadas de los setenta y ochenta. Es la manifestación más clara de una actividad (aunque leve) volcánica.

La Macrozona 2 (Geotérmica) tiene la limitación de configurarse, dentro del Programa de Manejo (Comisión Nacional de Áreas Naturales Protegidas, 2000) del área protegida, como "Zona de Aprovechamiento Especial”. Esta situación, pese al potencial que ostenta la zona por sus valores geotérmicos y paisajísticos, presenta restricciones legales -debido al proyecto de la Geotérmica recientemente reactivado- para el uso turístico recreativo. Se trata de una zona frecuentada por ciclistas.

La Macrozona 3 representa uno de los valores más importantes para la interpretación de la evolución volcánica a través del paisaje. Además, aquí se localizan dos elementos vinculados culturalmente con la región: la piedra de San Isidro (Mazatepec) y las minas de

\footnotetext{
19 Los tracks de las rutas identificadas fueron proporcionados por John Pint y Marcelo Villavicencio y obtenidos mediante los registros de diferentes usuarios de Wikiloc.

${ }^{20}$ Con poca presencia, en el ANP se identificaron además paseos a caballo y, en otro extremo, motocross y vehículos $4 \times 4$, los cuales provocan el mayor impacto erosivo.
} 

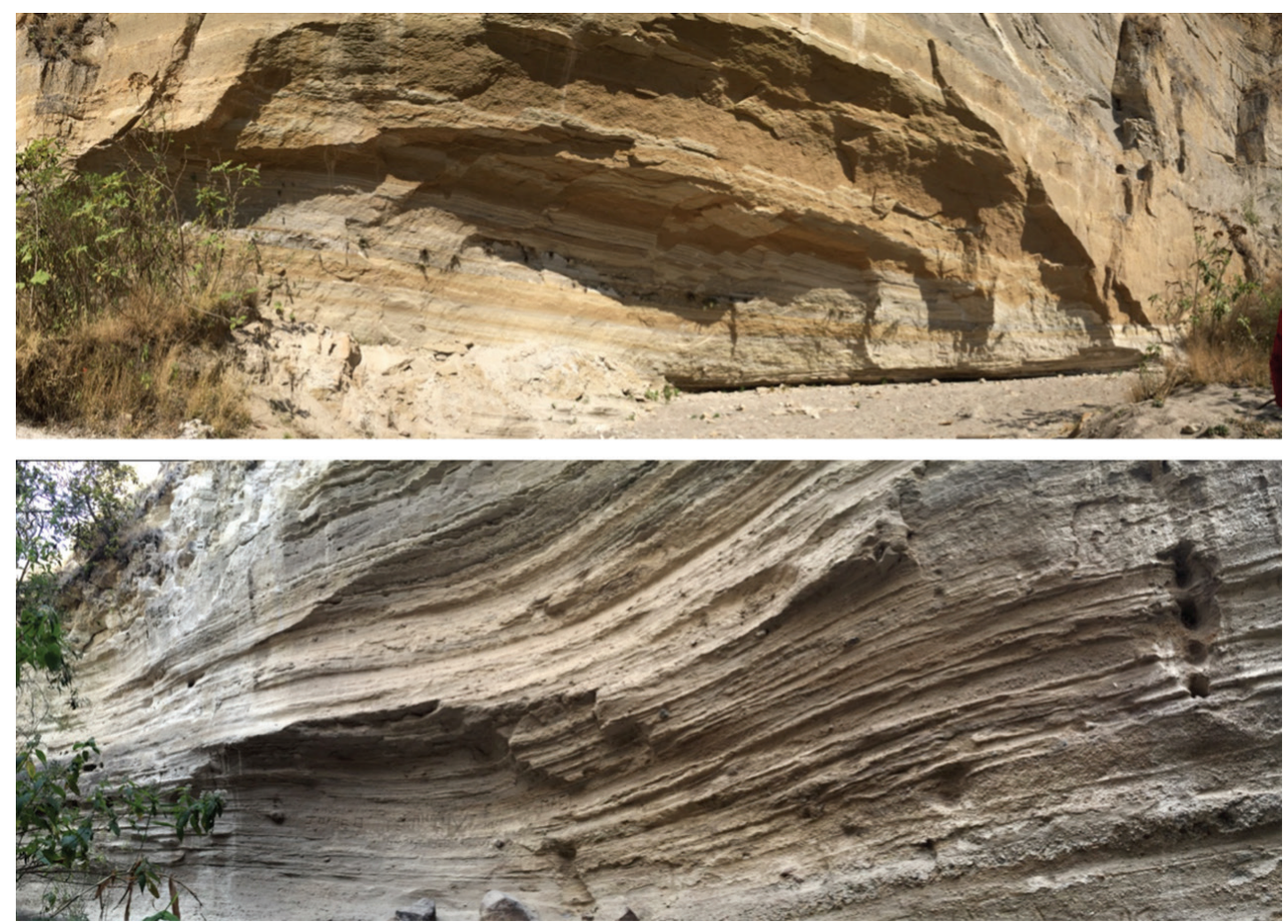

Archivo personal: Trabajo de campo. Enero - marzo 2016.

Figura 8. Estructuras geológicas Corredor El Carbón.

Los muros muestran distintos procesos de la evolución lacustre.

obsidiana, estas últimas ligadas con un aprovechamiento por parte de la población que ha habitado en su entorno.

Las mejores evidencias de las chimeneas fosilizadas se ubican en las macrozonas 4 y 5 (Tala-Villa Felicidad y Tala-Los Chorros). Aquí se inventariaron las aglomeraciones más relevantes de chimeneas fósiles (clústeres) pero además las de mayor tamaño: se cuentan numerosos racimos de chimeneas adosadas en muros, muros ondulantes y rocas de formas caprichosas. Estas se combinan con cuerpos de agua (fría) y con lecturas importantes del paisaje. Sin embargo, estas zonas reciben la impronta urbana más significativa. El trazo del macrolibramiento, en el perfil oriente del ANP, ha dejado expuesto material que permite un mayor conocimiento del proceso volcánico, pero al mismo tiempo ha significado la pérdida de elementos que se suponen valiosos por lo que se ha encontrado en el contexto, pero que no estaban inventariados por la falta de interés y la desprotección legal del patrimonio geológico.

De esta manera, la organización del patrimonio geológico-geomorfológico identificado en la SLP admite distintas lecturas para asociarlo con prácticas que ya se realizan. Los balnearios se valen desde antaño de un recurso geohidrotermal, los ciclistas buscan los puntos más encumbrados (incluso, las zonas de mayor vulnerabilidad, como Las Planillas), 
no obstante, poco se relaciona la práctica con la observación del paisaje. Son los grupos de senderistas los que mayor potencial presentan para vincularlos con la propuesta de geoturismo: el ritmo al que se desarrolla su práctica les permite introducirse en un paisaje volcánico con la posibilidad de realizar una lectura más detenida, incluso especializada, y con menor impacto que las prácticas de los ciclistas, motos y cuatrimotos que también se identificaron en algunas zonas de la sierra La Primavera.
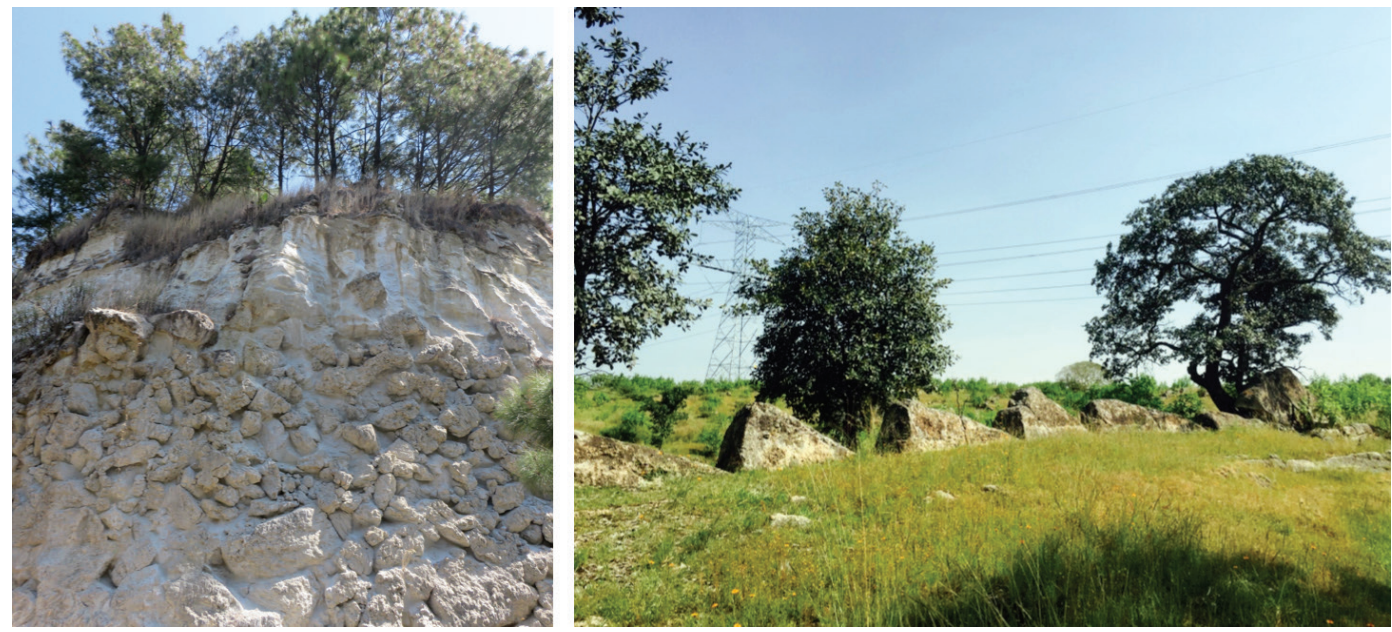

Archivo personal: Trabajo de campo febrero-noviembre de 2015.

Figura 9. Muro de Horizonte Pómez Gigante y muro ondulante dentado.

Vista de dos de los muros más interesantes: izquierda, el muro muestra el horizonte de Piedra Pómez Gigante y a la derecha, el muro tt en forma dentada, llamado para efectos de atracción Muro de Quetzalcóatl.

El OPD tiene en su haber información y programas de educación ambiental, institucionalizados entre algunos organismos públicos y privados de educación básica y media. Salvo la información que uno puede consultar en la red, el trazo de los senderos no cuenta con oficialidad desde el OPD, no existe ninguna aplicación, mucho menos material impreso que le permita al senderista afrontar los vaivenes de internet, la conectividad suele ser poco eficiente debido a las condiciones topográficas. Se requiere de un trabajo multidisciplinario y de mediano-largo plazo. Es importante la comunicación entre los distintos grupos de interés que inciden en la investigación, gestión, uso y derechos de propiedad del área nacional protegida.

\section{Conclusiones}

El ANP bosque La Primavera (SLP) resulta de una impronta volcánica que le otorga un valor añadido a la ciudad de Guadalajara y a su área metropolitana, no solo en términos ambientales, sino también económicos, turístico-recreativos y paisajísticos. El valor geológico del patri- 
monio ligado a la SLP ha permanecido olvidado, salvo por aquellas manifestaciones secundarias que hacen visible el potencial geológico y la actividad turístico-recreativa que se basa en el aprovechamiento de los recursos geohidrotermales, así como la emoción del senderismo y el ciclismo de montaña. Su geodiversidad es amplia y significativa.

Dispersos por el territorio circunscrito a la declaratoria se identificaron elementos únicos, representativos de procesos volcano-lacustres: toba tala; pómez gigantes; chimeneas en formas, tamaños y disposiciones varias; cortes que muestran la actividad tectónica y los procesos de sedimentación lacustre, así como perfiles topográficos que muestran las cicatrices de la evolución: fallas, barrancas y domos, muchos de ellos en una situación de alta vulnerabilidad por su exposición al crecimiento urbano, a trazos de vías de comunicación y al reciente nuevo impulso a la Geotérmica.

Todos estos elementos son sumamente vulnerables; existe un hueco legal (en distintas escalas) que olvida que el patrimonio geológico merece una protección explícita, no solo implícita en el marco del patrimonio natural; incluso, la biodiversidad depende en gran medida de los sustratos geológico y geomorfológico. Una actualización reciente al plan de manejo propone considerar estos activos geológicos-geomorfológicos inventariados.

La riqueza geológica identificada hasta el momento, las dinámicas sociales entre usuarios, autoridades y propietarios, así como los problemas ambientales recurrentes, son factores que motivan seguir construyendo una estrategia para impulsar nuevas prácticas más sostenibles. Considerar el patrimonio que ofrece la SLP bajo lecturas de patrimonio territorial y asociadas con un proceso de patrimonialización en distintos niveles, el cual da comienzo con estudios orientados a identificar y evaluar la geodiversidad.

El geoturismo, basado en el reconocimiento de los valores del patrimonio geológico -desde la geología, como se propone en la Declaración de Arouca-, es perfectamente compatible con la perspectiva propuesta por NatGeo: el apego al significado del territorio con enfoque local y al uso de nuevas tecnologías para su disfrute, pero con mayor énfasis en los activos que ofrece todo el proceso evolutivo de La Primavera.

Conviene dejar claro que promover el geoturismo no implica nuevas restricciones de uso en esta ANP; se trata de una estrategia de doble vía: la geoconservación y la promoción del desarrollo local, a través del impulso de iniciativas económicas derivadas de esta práctica; es decir, dar fortaleza a los emprendimientos turístico-recreativos ya existentes y que tienen más de 40 años de funcionamiento, así como a las nuevas propuestas que surgen asociadas con los movimientos ciclistas y senderistas, cuyo potencial cada vez es mayor, tanto en sentido positivo como destructivo.

Por ello, una de las tareas más urgentes es la de establecer acuerdos para el diseño de rutas y miradores interpretativos que sean de poco impacto ambiental, teniendo en cuenta los esfuerzos de geoconservación, los intereses de los propietarios y las opiniones de los grupos de ciclistas y senderistas, donde se considere el valor geológico y los límites de carga del territorio. Las gestiones que se realizan dentro del ANP corresponden a unos límites marcados por decreto, pero las evidencias de la dinámica evolutiva se presentan no solo al interior de sus bordes, también pudieron identificarse hacia el exterior del perímetro elementos de gran valor que se encuentran vulnerables ante la impronta urbana. 
El futuro de la SLP y las actividades de recreación y, por qué no, turísticas, depende de la estrategia que los distintos grupos de interés definan; a mayor consideración de la premisa del enfoque local-sustentable, mayores oportunidades de desarrollo tiene a futuro. La constante generación de conocimiento científico sobre el patrimonio cultural y natural (entre el que se ubica el geológico-geomorfológico), así como la apropiación cultural de los valores que ofrece la SLP, abonan al proceso de patrimonialización. De esta manera, tras conocer los valores con los que se cuenta, se despierta el interés por su conservación y por el geoturismo.

\section{Fuentes consultadas}

Brilha, J. (2005). Patrimonio geológico e Geoconservação. A Conservação da natureza na sua verte geológica. Braga: Palimage.

Carcavilla, L., Durán, J. y López, J. (2008). Geodiversidad: concepto y relación con el patrimonio geológico. Geo-Temas, 10, 1299-1303. VII Congreso Geológico de España.

Las Palmas de Gran Canaria. Recuperado de http://www.igme.es/patrimonio/ descargas/concepto_Geodiversidad.pdf [2016, 21 de noviembre].

Carcavilla, L., López, J. y Durán, J. (2007). Patrimonio geológico y geodiversidad: Investigación, conservación, gestión y relación con los espacios naturales protegidos (Cuadernos del Museo Geominero, 7). Madrid: Instituto Geológico y Minero de España.

Carcavilla, L., Delvene, G., Díaz-Martínez, E., García, A., Lozano, G., Rábano, I., ... Vegas, J. (2014). Geodiversidad y patrimonio geológico (Edición Parques Nacionales). Madrid: Instituto Geológico y Minero de España. Recuperado de http://www.igme. es/patrimonio/novedades/FolletoPatrimonio_Nov2014.pdf [2015, 22 de junio].

Comisión Nacional de Áreas Naturales Protegidas. (2000). Programa de Manejo Área de Protección de Flora y Fauna La Primavera. México: Secretaría de Medio Ambiente y Recursos Naturales. Recuperado de http://www.conanp.gob.mx/que_hacemos/ pdf/programas_manejo/primavera.pdf [2015, 14 de abril].

González, L., Valdivia, L. y Gómez, J. (coords.). (2018). Geodiversidad volcánica y geopatrimonio en la sierra La Primavera. México: Universidad de Guadalajara-Centro Universitario de Ciencias Sociales y Humanidades/Gobierno del Estado de Jalisco-Secretaría de Medio Ambiente y Desarrollo Territorial.

González, L., Valdivia, L., Gómez, J. y Castillo, M. (2018). La geodiversidad y su valoración. En L. González, L. Valdivia y J. Gómez (coords.), Geodiversidad volcánica y geopatrimonio en la sierra La Primavera (capítulo II). México: Universidad de Guadalajara-Centro Universitario de Ciencias Sociales y Humanidades/Gobierno del Estado de Jalisco-Secretaría de Medio Ambiente y Desarrollo Territorial.

Medina, W. (2015). Importancia de la geodiversidad. Método para el inventario y valoración del patrimonio geológico (Correlación Geológica, 31). San Miguel de Tucumán: Instituto Superior de Correlación Geológica.

Serrano, D. (2014). Valoración de la geodiversidad. Validación metodológica en escalas detallada. Revista de Geografía Norte Grande, 59, 65-82. 
Valdivia, L. (2018). Caracterización de los procesos geológico-geomorfológicos y la clasificación del relieve. En L. González, L. Valdivia y J. Gómez (coords.), Geodiversidad volcánica y geopatrimonio en la sierra La Primavera (capítulo I). México: Universidad de Guadalajara-Centro Universitario de Ciencias Sociales y Humanidades/Gobierno del Estado de Jalisco-Secretaría de Medio Ambiente y Desarrollo Territorial. 


\title{
Ecoturismo y CONSERVAción: Perspectivas y PRÁcticas EN LAS RESERVAS DE LA BIÓSFERA DE LOS TUXTLAS, México y Maasai Mara, Kenia
}

\author{
Kennedy Obombo Magio \\ Programa Cátedras Conacyt \\ Instituto Tecnológico de Cancún \\ magiobom@yahoo.com·kmagio@conacyt.mx \\ Mónica Velarde Valadez \\ Universidad de Occidente \\ mvelardemx@yahoo.com·monica.velarde@udo.mx
}

\begin{abstract}
En este estudio se analiza la relación entre el ecoturismo y las actitudes de las comunidades locales hacia la conservación en dos reservas de la biósfera: Los Tuxtlas, México, y Maasai Mara, Kenia. La información se recopiló a través de una encuesta cuantitativa, entrevistas abiertas, cuatro grupos focales, así como la observación y participación directa. Se encontró que las actitudes y prácticas hacia la conservación se determinan por diferentes factores, entre ellos, beneficios directos e indirectos del ecoturismo, las costumbres, leyes y restricciones. También se advirtió que el ecoturismo puede generar impactos negativos como resultado de acciones involuntarias o equivocadas.
\end{abstract}

Palabras clave: Ecoturismo, conservación, desarrollo socioeconómico, reserva de la biósfera de Los Tuxtlas (México), reserva de la biósfera de Maasai Mara (Kenia).

\section{Ecotourism and conservation: Perspectives and practices in Los Tuxtlas Biosphere Reserve, Mexico y Maasai Mara Biosphere Reserve, Kenya}

The study presents an analysis of the relationship between ecotourism and conservation attitudes held by local community in two biosphere reserves: Los Tuxtlas, Mexico and Maasai Mara, Kenya. Information was collected through a quantitative survey administered by the researcher, open interviews, four focus group discussions, as well as direct observation and participation. It was found that conservation attitudes are determined by different factors, among them, direct and indirect benefits of ecotourism, customs, laws and restrictions. It was also found that ecotourism can generate negative impacts as a result of unintended or wrong actions.

Keywords: Ecotourism; Conservation; Socioeconomic Development; Los Tuxtlas Biosphere Reserve, Mexico; Maasai Mara Biosphere Reserve, Kenya.

Fecha de recepción: 8 de marzo de 2017. Fecha de aceptación: 7 de julio de 2017

CÓMO CITAR: Obombo, K. y Velarde, M. (2018). Ecoturismo y conservación: Perspectivas y prácticas en las reservas de la biósfera de Los Tuxtlas, México y Maasai Mara, Kenia. Dimensiones Turísticas, 2(2), 53-77. https://doi.org/10.47557/PMQQ9256 
- I surgimiento en todo el mundo de áreas naturales protegidas (ANP) es resultado de las políticas conservacionistas de los siglos xx y xxI (Toledo, 2005) y responde a un intento de la humanidad para proteger, conservar y mantener sitios de relevancia natural, cultural y ecológica. Según la Unión Internacional para la Conservación de la Naturaleza y los Recursos Naturales (International Union for the Conservation of Nature, 1994), son espacios terrestres o marinos dedicados a la protección y preservación de la diversidad biológica, y de los recursos naturales y culturales asociados con ella, y cuentan con instrumentos legales que definen su manejo. Se ha criticado la gestión tradicional de las ANP basada en la conservación estricta de la biodiversidad (Palomo et al., 2014), y muchas veces se limita la participación de las comunidades locales (véanse los trabajos de Hvenegaard, 1994; Vargas del Río y Brenner, 2013). Esto genera las siguientes preguntas fundamentales: ¿Para quién se crean estas unidades de conservación y a qué costo? Desdoblando este cuestionamiento, se señala que cualquier estilo de gestión ambiental que ignora la participación de las comunidades locales y les niega beneficios directos e indirectos, no contribuye a los principios de la sustentabilidad y está destinado a fracasar inevitablemente (Magio, Velarde, Santillán y Ríos, 2013).

Aún así, la gestión de las ANP ha evolucionado hacia el paradigma de uso múltiple en el cual se busca conciliar la conservación con el desarrollo local, reconociendo que la conservación es un acontecimiento social donde se interrelacionan diversas herramientas jurídicas, legales, jurisdiccionales, de ordenamiento territorial, educativas (Barriga, 2017). En este contexto, se destaca el concepto de reservas de la biósfera (RB), una subcategoría del grupo VI de las ANP planteada en el marco del Programa sobre el Hombre y la Biósfera (MAB, Man and the Biosphere Programme) de la Organización de las Naciones Unidas para la Educación, la Ciencia y la Cultura (Unesco) en 1970 y abarca una red mundial de paisajes representativos que se manejan como espacios de aprendizaje para el intercambio de información sobre conservación y desarrollo sustentable (Unesco, 1995). Este se ha convertido, dentro del paradigma del desarrollo sustentable, en uno de los conceptos dominantes en las políticas de conservación en el nivel internacional (Unesco, 2005).

Por su enfoque holístico, las RB han sido el escenario ideal para el establecimiento de actividades alternativas con el fin de disminuir la presión sobre los recursos naturales bajo el supuesto del desarrollo sustentable, las cuales incluyen turismo de naturaleza, ecoturismo, turismo de aventura, etc. (Barriga, 2015). El ecoturismo se ha reconocido como un instrumento tanto para conservar el patrimonio natural y cultural, como para promover un desarrollo sustentable. En diversos casos, se plantea como una alternativa económica que automáticamente cambia la manera en que los miembros de la comunidad local ven, perciben e interactúan con la biodiversidad, para apoyar las iniciativas de conservación (Honey, 2008). Este condicionamiento por enfoques y estímulos económicos produce fuertes impactos sociales, aumenta la inequidad, provoca trastornos ecológicos, entre otras cosas (Marín, García y Daltabuit, 2012). Por lo tanto, son relativamente raros los escenarios donde el desarrollo del ecoturismo en las áreas protegidas resulta tanto en la generación de bienestar económico y social como en la conservación ambiental (Agüera y Morales, 2015). 
CuAdro 1. Categorías analíticas (dimensiones e indicadores) del desarrollo ecoturístico sustentable en las áreas naturales protegidas

\begin{tabular}{|c|c|}
\hline DIMENSIONES & INDICADORES \\
\hline $\begin{array}{l}\text { 1. Estrategias } \\
\text { del desarrollo } \\
\text { ecoturístico }\end{array}$ & $\begin{array}{l}\text { i. ¿Quién controla las actividades de ecoturismo? } \\
\text { ii. La propiedad de las empresas/proyectos de ecoturismo (porcentajes de propiedad } \\
\text { local y de fuera). } \\
\text { iii. La distribución de los beneficios. ¿Qué porcentaje se queda en la comunidad? } \\
\text { iv. Son significativos estos beneficios para incentivar actitudes, perspectivas y } \\
\text { prácticas positivas hacia la conservación. } \\
\text { v. Gobernanza del ecoturismo: el papel del gobierno, las asociaciones locales de } \\
\text { ecoturismo. } \\
\text { vi. Política y planificación del ecoturismo. ¿Quién la desarrolla, quiénes participan? } \\
\text { vii. Participación y empoderamiento de la comunidad. } \\
\text { viii. ¿Quiénes gestionan los proyectos de ecoturismo? ¿Son personas de la comunidad } \\
\text { local o de fuera? } \\
\text { ix. ¿Cómo se realiza la actividad ecoturística? ¿Se realiza de manera que no perjudica } \\
\text { el bienestar de la reserva? }\end{array}$ \\
\hline 2. Conservación & $\begin{array}{l}\text { i. Actitudes y comportamientos de las comunidades hacia la conservación. } \\
\text { ii. Protección de los hábitats. } \\
\text { iii. Participación en la protección de las reservas. } \\
\text { iv. Restauración del hábitat (con fines ecoturísticos, iniciativas individuales o } \\
\text { colectivas de las comunidades locales, iniciativa pública o de las ONG Organización } \\
\text { no gubernamental). } \\
\text { v. Uso sustentable de los recursos naturales. } \\
\text { vi. Iniciativas de conservación privadas. } \\
\text { vii. Apoyo a la conservación de la flora, fauna y sus hábitats. } \\
\text { viii. Amenazas a la biodiversidad (como la caza de animales; comportamiento de los } \\
\text { ecoturistas). } \\
\text { ix. Concientización sobre conservación/educación ambiental (operadores, ecoturistas } \\
\text { y las comunidades locales). }\end{array}$ \\
\hline $\begin{array}{l}\text { 3. Desarrollo } \\
\text { socioeconómico de } \\
\text { las comunidades } \\
\text { locales }\end{array}$ & $\begin{array}{l}\text { i. Acceso al empleo. } \\
\text { ii. Nivel de ingresos. } \\
\text { iii. El acceso a la educación básica (primaria y secundaria). } \\
\text { iv. Sobrevivencia económica. } \\
\text { v. Estándares de la vida. } \\
\text { vi. Accesibilidad a la vivienda adecuada y digna. } \\
\text { vii. Estándares de salud. } \\
\text { viii. Acceso al crédito. } \\
\text { ix. Seguridad social y de empleo. } \\
\text { x. Beneficios indirectos del ecoturismo. }\end{array}$ \\
\hline
\end{tabular}
4. Factores que
i. Los factores legales (leyes y restricciones).
influyen en la
ii. Los factores económicos (la distribución de los costos y beneficios).
conservación
y desarrollo
iii. Los factores culturales (tradiciones y conductas culturales).
socioeconómico
iv. Los factores políticos (nivel de involucramiento y participación de las comunidades locales, vínculos y relación entre partes interesadas).
v. Los factores ecológicos (creación de las reservas).
vi. Los factores sociales (conductas sociales, características sociodemográficas).

Fuente: Elaboración propia, con base en Honey (2002), Picard (2015) y Weaver $(1998,2006)$. 
Ante esta situación, académicos y políticos están proponiendo investigaciones que mejoren la eficacia de las estrategias de conservación a través del desarrollo local (véase por ejemplo Honey, 2008; Eric et al., 2011; Brenner y Job, 2012; Vargas del Río y Brenner, 2013). Además, Guerrero Rodríguez (2010: 43) señala que es evidente "la falta de investigación acerca de las realidades existentes en los proyectos de ecoturismo", por lo que sugiere indagar sobre las diferentes estrategias empleadas en la implementación del concepto y evaluar si los proyectos mantienen una orientación hacia la conservación de los recursos naturales y si consideran la sustentabilidad social y cultural en los espacios donde se desarrolla. El cuadro 1 resume las categorías analíticas (dimensiones e indicadores) del desarrollo ecoturístico sustentable en las ANP, que se han utilizado en diversas investigaciones en este campo para determinar criterios de evaluación (Honey, 2002; Picard, 2015; Weaver, 1998, 2006).

Los objetivos fundamentales de la presente investigación fueron, por una lado, caracterizar el ecoturismo como una estrategia de conservación y, por el otro, analizar la relación entre los beneficios del ecoturismo y las actitudes de las comunidades involucradas hacia la conservación. Se plantearon tres hipótesis principales: 1. Los incentivos económicos por sí solos no son suficientes para transformar las actitudes y prácticas de las comunidades sobre la conservación; 2. Una mayor participación de las comunidades locales y la distribución equitativa de los costos y beneficios pueden generar actitudes y prácticas positivas que apoyen a la conservación; y 3. El ecoturismo puede influir negativamente en la conservación como resultado de acciones involuntarias o equivocadas.

\section{Fundamentos teóricos del eCoturismo, la CONSERVACión Y EL DESARROLLO SUSTENTABLE}

La sustentabilidad surgió durante la década de los ochenta como el enlace integral e inevitable entre el sistema natural y el desarrollo (Cardoso-Jiménez, 2006). El término fue utilizado por primera vez en 1987, dentro de un estudio realizado por la Comisión Mundial para el Medio Ambiente de la Organización de las Naciones Unidas, en donde, entre otras cosas, se llegó a la conclusión de que era necesario un cambio de fondo en el enfoque del desarrollo, ya que el planeta y todos sus sistemas ecológicos estaban sufriendo daños graves e irreversibles, debido a que los modelos tradicionales de desarrollo están basados en buena medida en visiones de corto plazo y de recursos ilimitados (Vargas del Río y Brenner, 2013). Pocos años después, se convertió en un término popular y de moda para la gestión de los recursos naturales (Gómez, 2011). De igual manera, el origen y la adopción del concepto turismo sustentable se ha vinculado con la evolución semántica del término desarrollo sustentable (Barriga, 2015). Adams y McShane (1992) afirman que la idea de integrar el turismo con la conservación probablemente ha existido desde los primeros días de safaris en África, y la creación de los parques nacionales en el siglo xIx. 
La relación entre turismo y sustentabilidad ofrece un panorama en el que aquel pudiera constituirse en una de las vías más eficaces para detonar procesos de desarrollo, enfatizando la participación de las poblaciones locales; específicamente, lo anterior se refiere al aprovechamiento de los recursos naturales y culturales por parte de las mencionadas poblaciones locales, mediante un turismo de corte alternativo (Laven, Wall-Reinius y Fredman, 2015).

En este tenor, Lawton y Weaver (2015) describen al turismo sustentable como "una forma humana de turismo a pequeña escala, que busca desarrollar y promover nuevas formas de turismo, las cuales generan beneficios para todos los participantes -viajeros, poblaciones locales y empresas turísticas- sin causar daño ecológico y social intolerable". El turismo sustentable, por lo tanto, responde al paradigma del desarrollo sustentable, buscando conciliar objetivos ambientales, económicos, sociales y culturales, mediante criterios como la planeación y gestión, la preservación ecológica, y la protección del patrimonio cultural y de la biodiversidad, para así lograr una producción sostenida a largo plazo y con equidad (Picard, 2015).

En el ámbito mundial, el turismo sustentable se ha ligado fuertemente con el diseño y manejo de ANP (Castillo, Baltazar, Lugo y Piñera, 2016). En especial, se destaca la creación de las RB, consideradas por Barriga (2017) como espacios de reconciliación entre conservación y desarrollo. Para cumplir con los objetivos de conservación, estas reservas se constituyen por zonas núcleo, donde se llevan a cabo actividades que están estrictamente vinculadas con la conservación, por ejemplo, educativas y de investigación; luego siguen las zonas tampón o de amortiguamiento, que por lo general rodean a las zonas núcleo, donde se establecen actividades compatibles, como educación ambiental, recreación, ecoturismo e investigación aplicada básica; y por último se encuentran las zonas de transición flexible, que comprenden variadas actividades (Primack y Ros, 2002).

Particularmente en las zonas de amortiguamiento y en las de transición flexible, las comunidades locales, los organismos de gestión, los científicos, las organizaciones no gubernamentales, los grupos culturales, el sector económico y otros interesados trabajan conjuntamente en la administración y el desarrollo sustentable del área (Unesco, 1995). En ese sentido, las principales funciones de las RB son: 1) conservación in situ, 2) desarrollo de áreas de demostración para uso sustentable y 3) apoyo logístico para los proyectos experimentales en investigación, monitoreo, educación ambiental y entrenamiento de las comunidades locales (Unesco-MAB, 1996 cit. en Barriga, 2017).

Se promueven modalidades sustentables del turismo en las ANP como alternativa de desarrollo por proveer beneficios ambientales, socioeconómicos y culturales (Castillo et al., 2016). El ecoturismo es una de las actividades económicas alternativas permitidas en la zona de amortiguamiento, ya que implica el desarrollo local con fines de conservar los recursos naturales; se considera esencialmente como un ejemplo de las estrategias de conservación contempladas en las RB. Más aún, una característica propia del ecoturismo es que, al ser una de las actividades alternativas, su desarrollo y aplicación no debe sustituir a aquellas que tradicionalmente realizan los pobladores de las comunidades en las que se realiza, sino constituir una actividad adicional o alternativa. 
Si bien se han documentado resultados satisfactorios derivados del turismo en ANP (como son los casos de Australia, Nueva Zelanda, Zanzíbar y Costa Rica), tanto en materia de conservación como en el empoderamiento de las comunidades y el fortalecimiento de la organización social (Barriga, 2015), la interacción de elementos ecológicos y sociales del turismo en áreas protegidas vuelve compleja su gestión y manejo; existen retos fundamentales que limitan la conciliación del desarrollo socioeconómico con la conservación de los recursos naturales. Por ejemplo, con frecuencia, los estudios han mostrado una desarticulación entre las acciones de las comunidades locales y las efectuadas por las instituciones gubernamentales (Castillo et al., 2016). Otro reto identificado es el menor peso asignado a la escala de la participación local; se ha revelado que solo un grupo selecto, por lo general las élites de la comunidad, participa o gestiona las actividades del desarrollo alternativo (Bello, Lovelock y Carr, 2017).

Estas cuestiones generan varias preguntas fundamentales, algunas de las cuales fueron respondidas en el presente estudio: ¿la participación de solo unas pocas personas garantiza beneficios para toda la comunidad? ¿Cómo influye la ecología política y la relación entre los actores en las iniciativas de conservación y desarrollo local? Si la comunidad no se beneficia, ¿es probable que cambien sus valores, creencias y prácticas de conservación? ¿Existen otros costos asociados con el ecoturismo (o cualquier otra actividad del desarrollo local compatible con la conservación) que las partes interesadas o los académicos ignoran? ¿Existen programas de distribución de costos y beneficios en empresas de ecoturismo basados en la comunidad, así como estrategias de gobernanza apropiadas que pueden contribuir de manera eficiente a la integración de conservación y desarrollo local? ¿Qué enfoques de gobernanza pueden reforzar la capacidad de organización local y mejorar las relaciones de las partes interesadas?

En general, cuando la participación de las comunidades locales es escasa y los beneficios mínimos, se originan actitudes negativas, como enojo, apatía y desconfianza de los pobladores, rechazo de las actividades de conservación y turismo, amenazas a la biodiversidad -por ejemplo, la caza furtiva-, conflicto entre seres humanos y vida silvestre, etc., lo que se convierte en un reto de gestión ambiental en las ANP. Al contrario, cuando las comunidades participan y perciben beneficios del turismo, emergen actitudes positivas: buena voluntad de los habitantes, apoyo a las actividades de conservación y turismo, custodia local de la biodiversidad, conservación de especies y hábitats en peligro de extinción, etcétera.

En el marco conceptual expuesto en la figura 1 se presenta una relación precisa de los factores que influyen en el turismo y las actitudes hacia la conservación en las ANP. Como se observa, las actividades turísticas en las ANP pueden generar dos tipos de actitudes hacia la conservación: positivas o negativas, dando lugar al éxito o al fracaso en su gestión.

En resumen, "lograr el éxito de integrar conservación y desarrollo socioeconómico a través del ecoturismo ha sido difícil” (Björk, 2007, p. 24), y los resultados varían de un caso a otro; esa valoración constituye una parte esencial del problema teórico y empírico de la presente investigación. Según Björk (2007, p. 24), existen diversos factores que influyen 


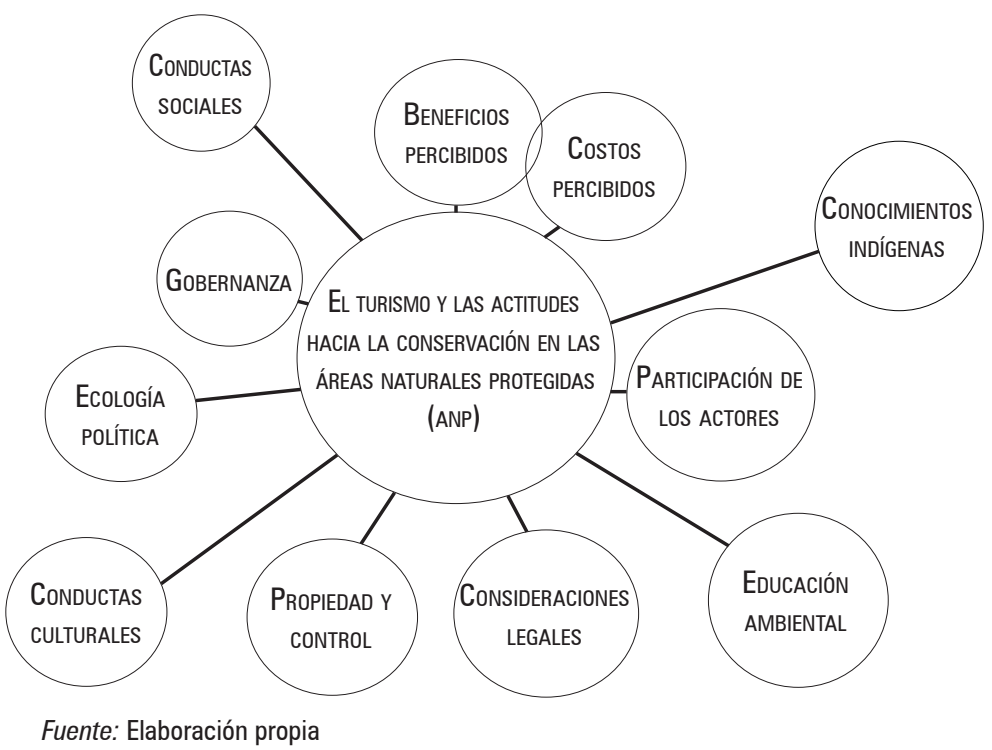

Figura 1. Marco conceptual de los factores que influyen en el turismo y las actitudes hacia la conservación en las Áreas Naturales Protegidas (ANP)

de manera significativa en el desempeño de los proyectos ecoturísticos en las RB, entre ellos, la escasa coordinación entre los actores, la propiedad de los negocios ecoturísticos, la participación local, la infraestructura existente, el estilo de gobernanza, así como las herramientas para gestionar el comportamiento de los turistas a fin de minimizar el impacto ecológico y fomentar la conservación (Brenner y Job, 2012).

\section{Metodología}

La investigación se desarrolló en cuatro grupos ejidales: los ejidos Adolfo López Mateos y Ruiz Cortines, ubicados en la reserva de la biósfera de Los Tuxtlas (RBLT), en el estado de Veracruz, México, y los ejidos Koiyaki (Koiyaki Group Ranch) y Lemek/Ol Chorro (Lemek Group Ranch), en la reserva de la biósfera de Maasai Mara (RBMM), en Kenia. Las cuatro comunidades se encuentran involucradas en las iniciativas de conservación y recientemente se han visto impactadas por proyectos ecoturísticos.

Es importante mencionar por qué se escogieron estos cuatro casos. Patton (1990) argumenta que no cualquier caso permite generar suficiente información para contestar las preguntas de investigación, por lo que se determinó un criterio en el cual se aseguró de que: 1. Existe el ecoturismo basado en la comunidad y que la comunidad participa en los proyectos ecoturísticos; 2. Los proyectos ecoturísticos incluidos en el estudio hayan sido establecidos hace al menos cinco años (el tiempo fue importante para evaluar los 
CuAdro 2. Criterios para la selección de los casos de estudio

\begin{tabular}{|c|c|c|c|c|}
\hline \multirow[b]{2}{*}{ CRITERIO de SELECCIÓN } & \multicolumn{2}{|c|}{ Casos de México } & \multicolumn{2}{|c|}{ Casos de Kenya } \\
\hline & $\begin{array}{c}\text { Ejido Adolfo López } \\
\text { Mateos }\end{array}$ & $\begin{array}{l}\text { Ejido Ruiz } \\
\text { Cortines }\end{array}$ & $\begin{array}{c}\text { Ejido Koiyaki } \\
\text { (Koiyaki Group } \\
\text { Ranch) }\end{array}$ & $\begin{array}{l}\text { Ejido Lemek/ OI chorro } \\
\text { (Lemek Group Ranch) }\end{array}$ \\
\hline $\begin{array}{l}\text { Éxito reportado en la } \\
\text { literatura }\end{array}$ & Sí & Pocos datos & Sí & Sí \\
\hline $\begin{array}{l}\text { Influencia de centro } \\
\text { turístico masivo }\end{array}$ & Sí & Bastante & Sí & Sí \\
\hline Región & $\begin{array}{l}\text { Sierra de Santa } \\
\text { Marta al este del } \\
\text { Municipio de } \\
\text { Catemaco }\end{array}$ & $\begin{array}{l}\text { Sur del Volcán de } \\
\text { San Martín Tuxtla } \\
\text { en el municipio de } \\
\text { San Andrés Tuxtla }\end{array}$ & $\begin{array}{l}\text { Condado de Narok } \\
\text { Oeste }\end{array}$ & $\begin{array}{l}\text { Condado de Narok } \\
\text { Norte }\end{array}$ \\
\hline $\begin{array}{l}\text { Sistema de gestión } \\
\text { ambiental de } \\
\text { acuerdo con la Unión } \\
\text { Internacional para } \\
\text { la Conservación de } \\
\text { la Naturaleza y los } \\
\text { Recursos Naturales } \\
\text { (IUCN, por sus siglas } \\
\text { en inglés) }\end{array}$ & $\begin{array}{l}\text { Reserva de la } \\
\text { Biósfera-Los } \\
\text { Tuxtlas (RBLT) }\end{array}$ & $\begin{array}{l}\text { Reserva de la } \\
\text { Biósfera-Los } \\
\text { Tuxtlas (RBLT) }\end{array}$ & $\begin{array}{l}\text { Reserva de la } \\
\text { Biósfera-Maasai } \\
\text { Mara (RBMM) }\end{array}$ & $\begin{array}{l}\text { Reserva de la } \\
\text { Biósfera-Maasai } \\
\text { Mara (RBMM) }\end{array}$ \\
\hline $\begin{array}{l}\text { Existencia de } \\
\text { turismo basado en la } \\
\text { naturaleza }\end{array}$ & Sí & Sí & Sí & Sí \\
\hline $\begin{array}{l}\text { Alta participación } \\
\text { de las comunida- } \\
\text { des locales en las } \\
\text { actividades del } \\
\text { ecoturismo }\end{array}$ & Sí & Sí & Sí & Sí \\
\hline $\begin{array}{l}\text { Sistema de tenen- } \\
\text { cia, ambiental y } \\
\text { participación en } \\
\text { ecoturismo }\end{array}$ & Comunitario & Comunitario & Comunitario & Comunitario \\
\hline $\begin{array}{l}\text { Año de implemen- } \\
\text { tación formal del } \\
\text { proyecto de TBN a } \\
\text { nivel local }\end{array}$ & 1999 & 2008 & 1992 & 1996 \\
\hline $\begin{array}{l}\text { Número } \\
\text { de habitantes }\left({ }^{*}\right)\end{array}$ & $424(536)$ & $305(422)$ & $630(716)$ & $548(603)$ \\
\hline
\end{tabular}

${ }^{*}$ ) Estimación basada en el Instituto Nacional de Estadística Geográfica e Informática (INEGI, 2010) y Kenya Bureau of Statistics (KBS, 2012) - entre paréntesis, estimación después de los últimos censos. 
cambios en las prácticas y la distribución de beneficios); ${ }^{1} 3$. Que estos hayan sido desarrollados para fines de conservación, además de que incluyan los objetivos de desarrollo; 4. Que estén situados en o cerca de las RB; 5. Las comunidades involucradas demuestren la dependencia histórica de los recursos locales para sus necesidades de subsistencia; y 6. Se demuestre interés por parte de las comunidades y los actores de participar en la presente investigación.

Las seis consideraciones se investigaron por medio de un análisis de datos secundarios y una visita de exploración que se llevó a cabo durante noviembre de 2013 en Veracruz, México, y diciembre del mismo año en Maasai Mara, Kenia. Como se muestra en el cuadro 2, la investigación no solo se enfocó en la existencia de actividades turísticas basadas en la naturaleza, sino en la presencia de una amplia participación de la comunidad local en las actividades ecoturísticas o alguna estrategia de gestión que responde a los objetivos de conservación y desarrollo dentro del MAB, y que se considera como suficiente en la literatura académica (Honey, 2002, 2008; Higham, 2007; Adams y Hutton, 2007; Brenner y Job, 2012; Vargas del Río y Brenner, 2013).

Todos coinciden en un momento histórico, cuando el conflicto que surge de las necesidades de conservar o de utilizar los recursos naturales con fines turísticos es mediado por el discurso de la sustentabilidad, que busca incluir un cierto grado de participación social. Además, todas son localidades que poseen sistemas de manejo comunitario, y donde los habitantes han modificado en unos cuantos años su economía, pasando de la producción primaria y el autoconsumo, a una economía cada vez más enfocada en ofrecer servicios del turismo basado en la naturaleza y específicamente de ecoturismo. Las muestras se tomaron de las poblaciones que viven contiguas a las RB.

En el caso de la RBLT, se tomó como población meta cuatro municipios que rodean la reserva: San Andrés Tuxtla: 157364 habitantes y 39976 hogares; Catemaco: 48593 habitantes y 10470 hogares; Santiago Tuxtla: 56427 habitantes y 13840 hogares; y Hueyapan de Ocampo: 41649 habitantes y 9315 hogares; el total es de 304033 habitantes y 73601 hogares (Instituto Nacional de Estadística y Geografía, 2010). En cuanto a Kenia, se consideraron dos condados como población meta: Narok Oeste, con 196015 habitantes y 28002 hogares, y Narok Norte, con 242325 habitantes y 35617 hogares, cuyo total es de 438340 habitantes y 63619 hogares.

Del número total de hogares, se estima que solo 3900 y 2997 se encuentran contiguos a la RBLT y a la RBMM, respectivamente, y participan en actividades ecoturísticas. El tamaño de la muestra para la parte cuantitativa fue bastante grande (nRBLT=77 y nRB$\mathrm{MM}=69$ ) (véase cuadro 3). Este tamaño de muestra se calculó de acuerdo con la fórmula propuesta por Morse (2003), con una precisión de 5 \%, y 95 \% de nivel de confianza:

Donde: $\quad n=\frac{z^{2}(p \times q)}{e^{2}}$

1 Con base en el modelo de ciclos de vida de un destino (Butler, 1980), se puede argumentar que el ecoturismo en las dos reservas (la reserva de la biósfera de Los Tuxtlas y la reserva de la biósfera de Maasai Mara) se encuentra en la etapa de consolidación. 
$\mathrm{n}=$ tamaño de la muestra

$z=$ constante estadística que representa el nivel de confianza de $95 \%$ (1.96)

$p=$ proporción de éxito (3 900 $\div 33601$ para el caso de México, y $2997 \div 63619$ para el caso de Kenia); es decir, el número aproximado de los hogares involucrados de alguna manera en las actividades de ecoturismo dividido por el total de hogares en el área de estudio

$p=0.0530$ para el caso de la RBLT y 0.0471 para el caso de la RBMM

$q=$ proporción de fracaso $(1-p)=0.9470$ para el caso de la rblt y 0.9529 para el caso de la RBMM

e = error aceptable/precisión (5 \% o 0.05)

Se adoptó un enfoque de estudio de caso, lo que incluyó un examen profundo de las actividades de ecoturismo y conservación. La naturaleza del tema, los objetivos y la estrategia a través de la que se llevó a cabo esta investigación aglutinan componentes de la investigación aplicada, la evaluación sumativa y, en menor medida, la investigación básica. El componente de evaluación sumativa surgió en el esfuerzo por entender cómo el ecoturismo y sus supuestos beneficios influyen sobre las perspectivas y prácticas hacia la conservación. Por lo tanto, se examinó el grado en que el ecoturismo puede ser una intervención eficaz para estimular comportamientos relacionados con este concepto.

El diseño metodológico implicó la aplicación de métodos mixtos (cuantitativo y cualitativo), basándose en un paradigma interpretativo (Patton, 1990). Los métodos clave incluyeron una encuesta cuantitativa ( $n=138,95 \%$ de la muestra establecida), entrevistas abiertas ( $n=22,11$ en cada caso de estudio), cuatro grupos de enfoque, así como la participación y observación directa. Se aplicaron los instrumentos a los residentes locales y líderes de opinión en la comunidad. El cuestionario utilizado en la parte cuantitativa se estructuró de manera que respondiera al objetivo principal de la investigación: caracterizar el ecoturismo como una estrategia de conservación en las RB. En el diseño del instrumento (una escala de Likert), así como en la selección de los indicadores e ítems, se tuvieron en cuenta reflexiones de estudios previos sobre el tema (Vargas del Río y Brenner, 2013; Honey, 2008; Brenner y Job, 2012).

En las primeras dos secciones (A. Prácticas de conservación y B. Actitudes hacia la conservación) se incluyeron ítems (afirmaciones) sobre el impacto del ecoturismo y la conservación para detectar las actitudes de la comunidad local. En la última sección de la encuesta se buscó identificar los factores que influyen en el ecoturismo como estrategia de conservación. Es importante mencionar que la conceptualización del ecoturismo abarca una amplia variedad de dimensiones y criterios analíticos, por lo tanto, la selección de los indicadores e ítems incluidos en el análisis no es conclusiva. Sin embargo, permite dar un entendimiento global de los beneficios del ecoturismo y su influencia en las actitudes hacia la conservación.

El análisis cuantitativo fue descriptivo e inferencial, utilizando el paquete estadístico para ciencias sociales (sPSs versión 18). Para cada afirmación, los encuestados indicaron su nivel de concordancia (si estuvieron de acuerdo, en desacuerdo, o si el comentario les fue indiferente). A través de un análisis cuidadoso, se eligió una serie de afirmaciones 
CuAdro 3. El cálculo del tamaño de la muestra para la encuesta cuantitativa

\begin{tabular}{|c|c|c|c|c|c|c|}
\hline \multirow{3}{*}{$\begin{array}{l}\text { Caso de } \\
\text { estudio } \\
\text { Población } \\
\text { Meta } \\
\text { (Número de } \\
\text { habitantes en } \\
\text { los municipios } \\
\text { que abarcan } \\
\text { las Reservas } \\
\text { de la Biósfera) }\end{array}$} & \multirow{2}{*}{\multicolumn{4}{|c|}{ La reserva de la Biósfera de Los Tuxtlas (RBLT) }} & \multirow{2}{*}{\multicolumn{2}{|c|}{$\begin{array}{l}\text { La reserva de la Biósfera de Maasai } \\
\text { Mara (RBMM) } \\
\end{array}$}} \\
\hline & & & & & & \\
\hline & $\begin{array}{c}\text { San Andrés } \\
\text { Tuxtla }\end{array}$ & $\begin{array}{l}\text { Catemaco } \\
\\
48593\end{array}$ & $\begin{array}{c}\text { de Santiago } \\
\quad 56427\end{array}$ & $\begin{array}{l}\text { Hueyapan } \\
\text { de Ocampo }\end{array}$ & Narok Oeste & Narok Norte \\
\hline $\begin{array}{l}\text { Número de } \\
\text { hogares }\end{array}$ & 39976 & 10470 & 13840 & 9315 & 28002 & 35617 \\
\hline $\begin{array}{l}\text { Cálculo de la } \\
\text { muestra }\end{array}$ & \multicolumn{4}{|c|}{$\begin{array}{c}n=\frac{\underline{z}^{2}(p \times q)}{e^{2}} \\
.96^{2} \frac{(0.0530 \times(1-0.0530)}{0.05^{2}} \\
\frac{3.8416 \times(0.0530 \times 0.9470)}{0.0025} \\
\text { BLT }=\frac{0.1928137456}{0.0025} \\
n_{\text {RBLT }}=77.1255 \\
n_{\text {RВLT }}=77\end{array}$} & \multicolumn{2}{|c|}{$\begin{array}{c}\mathrm{n}=\underline{\mathrm{z}^{2}} \underline{(\mathrm{p} \times \mathrm{q})} \\
\mathrm{e}^{2} \\
\mathrm{n}_{\text {RBMM }}=\frac{1.96^{2}}{\mathrm{n}_{\mathrm{RBMM}}=\frac{(0.0471 \times(1-0.0471)}{0.05^{2}}} \\
\mathrm{n}_{\text {RBMM }}=\underline{3.8416 \times(0.0471 \times 0.9529)} \\
0.0025 \\
0.0025 \\
\mathrm{n}_{\text {RBMM }}=68.96685 \\
\mathrm{n}_{\text {RBMM }}=69\end{array}$} \\
\hline $\begin{array}{l}\text { Número total } \\
\text { de habitantes } \\
\text { en cada grupo } \\
\text { ejidal }\left(^{*}\right)\end{array}$ & \multicolumn{2}{|c|}{ Ejido Adolfo López Mateos } & \multicolumn{2}{|c|}{ Ejido Ruiz Cortines } & $\begin{array}{l}\text { Ejido Koiyaki } \\
\text { (Koiyaki Group } \\
\text { Ranch) } \\
\quad 630(716)\end{array}$ & $\begin{array}{l}\text { Ejido Lemek/ 0I } \\
\text { Chorro (Lemek } \\
\text { Group Ranch) } \\
548 \text { (603) }\end{array}$ \\
\hline $\begin{array}{l}\text { Proporción } \\
\text { que repre- } \\
\text { senta de la } \\
\text { muestra }\end{array}$ & \multicolumn{2}{|c|}{$(424 \div 729 \times 100) 58 \%$} & \multicolumn{2}{|c|}{$(305 \div 729 \times 100) 42 \%$} & $\begin{array}{c}(630 \div 1178 \times 100) \\
53 \%\end{array}$ & $\begin{array}{c}(548 \div 1178 \times 100) \\
47 \%\end{array}$ \\
\hline $\begin{array}{l}\text { Número de } \\
\text { encuestas } \\
\text { previsto }\end{array}$ & \multicolumn{2}{|c|}{$\begin{array}{c}58 \% \text { de }\left(\mathrm{n}_{\text {RBLT }}\right)= \\
45\end{array}$} & \multicolumn{2}{|c|}{$\begin{array}{c}42 \% \text { de }\left(\mathrm{n}_{\mathrm{RBLT}}\right)= \\
32\end{array}$} & $\begin{array}{c}53 \% \text { de }\left(\mathrm{n}_{\text {RBMM }}\right)= \\
37\end{array}$ & $\begin{array}{c}47 \% \text { de }\left(\mathrm{n}_{\text {RBMM }}\right)= \\
32\end{array}$ \\
\hline
\end{tabular}

$\left({ }^{*}\right)$ Se tomaron los datos oficiales de INEGI, 2010 y KBS, 2012 como base para el cálculo de la proporción de representación de la muestra

Fuente. Elaboración propia. 
que patentemente refleja las tendencias de conservación (actitudes y prácticas) en los cuatro grupos ejidales. Las afirmaciones escogidas para el análisis fueron las más claras y representativas, y se seleccionaron meticulosamente para reflejar las experiencias y conciencia general de los encuestados acerca de la relación entre ecoturismo y conservación. Además, se identificaron las afirmaciones cuyas respuestas difirieron de manera sustancial, donde la distribución de respuestas fue diferente de un grupo a otro; esta variación fue importante porque permitió el análisis estadístico adecuado (correlaciones) entre las variables dependientes (actitudes y prácticas de conservación) y las independientes (costos y beneficios del ecoturismo). Se utilizaron pruebas de Chi-cuadrado para determinar las asociaciones entre las actitudes hacia la conservación y posibles variables predictoras o explicativas, que en este caso fueron las variables independientes.

En cuanto a la parte cualitativa, se empleó la técnica llamada análisis de contenido o temático. Primero, se llevaron a cabo entrevistas que fueron grabadas, transcritas y analizadas junto con fuentes de información secundaria; también se realizaron otras entrevistas no grabadas y notas de campo mediante un proceso de asignación de códigos y recuperación de la información, mediado por una clasificación en categorías analíticas. Luego se organizaron las respuestas siguiendo los temas emergentes de los datos generados como resultado de las entrevistas. Como parte del análisis cualitativo, se identificaron patrones comunes de las respuestas y el desarrollo de temas que los reflejan. Para facilitar el análisis de la información cualitativa, se usó un programa de cómputo (ATLAS.ti) basado en la organización de la información mediante asignación de códigos y categorías de análisis. Se presentan citas textuales para apreciar mejor la variedad de las opiniones de los encuestados sobre los temas identificados. Por último, el estudio también incluyó una amplia revisión y análisis de documentos para complementar los datos primarios. Se utilizó una variedad de métodos de investigación y fuentes de datos para aumentar la triangulación, fortaleciendo de esta manera el diseño del estudio a través de controles de validez (véase Patton, 1990). Adicionalmente, mezclar herramientas cualitativas y cuantitativas en el presente estudio enriqueció la comprensión del trabajo final.

\section{Resultados de la investigación}

En la siguiente sección, se describen las actitudes y prácticas de las comunidades locales hacia la conservación, y las estrategias que aplican para usar y manejar los recursos naturales. Respondiendo a los dos objetivos de la investigación, esta sección proporciona una visión general de las actitudes y prácticas de conservación, que resume algunas similitudes y diferencias principales en las tendencias entre los cuatro grupos ejidales (se examina si el ecoturismo en las cuatro comunidades ha sido una alternativa económica/ herramienta/estrategia adecuada para incentivar actitudes y prácticas que favorecen la conservación en las reservas adyacentes). 


\subsection{Actitudes y prácticas de las comunidades hacia la conservación}

Uno de los principales hallazgos de los diferentes grupos ejidales es que los miembros de las comunidades consideran a la biodiversidad (flora y fauna) como parte importante de su sobrevivencia, por lo que reconocen la trascendencia de proteger los recursos naturales para las generaciones futuras. Sin embargo, ha sido difícil conciliar sus necesidades económicas con las de conservación. Respecto a los resultados del cuadro 4, se puede observar que miembros de la comunidad local en distintos grupos ejidales consideran ciertas prácticas como aceptables y otras no, dependiendo de la forma en que interpretan el concepto de conservación. El cuadro muestra una comparación de las actitudes hacia la conservación entre las cuatro comunidades, notándose que hay seis casos en los cuales las comunidades difieren de manera significativa en lo referente a las prácticas hacia la conservación. En general, los encuestados cuyas comunidades presentan actividad ecoturística disminuida (especialmente Ruiz Cortines y Lemek/OI Chorro) demostraron actitudes más negativas hacia la conservación, mientras que los de comunidades que experimentan mayor actividad ecoturística (Koiyaki y López Mateos) manifestaron actitudes más positivas (véase cuadro 4).

CuAdRo 4. Las actitudes y prácticas hacia la conservación en los cuatro grupos ejidales

\begin{tabular}{|c|c|c|c|c|c|c|}
\hline $\begin{array}{l}\text { Afirmaciones sobre } \\
\text { la conservación }\end{array}$ & $\begin{array}{c}\text { Nivel de } \\
\text { concordancia }\end{array}$ & $\begin{array}{c}\text { Ruiz Cortinez- } \\
\text { Tuxtlas (\%) }\end{array}$ & $\begin{array}{c}\text { Koiyaki- } \\
\text { Maasai } \\
(\%)\end{array}$ & $\begin{array}{c}\text { Adolfo López } \\
\text { Mateos- } \\
\text { Tuxtlas (\%) }\end{array}$ & $\begin{array}{c}\text { Lemek Ol } \\
\text { Chorro- } \\
\text { Maasai (\%) }\end{array}$ & $\begin{array}{l}\text { Nivel de } \\
\text { significan- } \\
\text { cia }\end{array}$ \\
\hline \multirow{2}{*}{$\begin{array}{l}\text { Más que para otra } \\
\text { cosa, los recursos } \\
\text { naturales (flora y } \\
\text { fauna) existen para } \\
\text { ser aprovechados } \\
\text { (leña, madera, } \\
\text { carne, etcétera). }\end{array}$} & De acuerdo & 22 & 12 & 28 & 47 & \multirow[t]{2}{*}{$*$} \\
\hline & En desacuerdo & 76 & 82 & 64 & 45 & \\
\hline \multirow{2}{*}{$\begin{array}{l}\text { A veces es nece- } \\
\text { sario cortar árboles } \\
\text { para fines econó- } \\
\text { micos cuando uno } \\
\text { no tiene empleo. }\end{array}$} & De acuerdo & 30 & 46 & 58 & 74 & \multirow[b]{2}{*}{$*$} \\
\hline & En desacuerdo & 54 & 42 & 34 & 21 & \\
\hline \multirow{2}{*}{$\begin{array}{l}\text { A veces es nece- } \\
\text { sariocazar anima- } \\
\text { les cuando uno no } \\
\text { tiene empleo. }\end{array}$} & De acuerdo & 14 & 26 & 52 & 44 & \multirow{2}{*}{ ** } \\
\hline & En desacuerdo & 80 & 69 & 46 & 55 & \\
\hline \multirow{2}{*}{$\begin{array}{l}\text { Debería ser } \\
\text { permitido para los } \\
\text { miembos de la } \\
\text { comunidad local } \\
\text { cortar árboles para } \\
\text { cultivar o practicar } \\
\text { la ganadería sin } \\
\text { ninguna restricción } \\
\text { de las autoridades. }\end{array}$} & De acuerdo & 22 & 2 & 17 & 31 & \multirow[t]{2}{*}{ 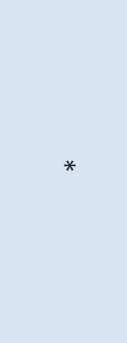 } \\
\hline & En desacuerdo & 54 & 86 & 81 & 57 & \\
\hline
\end{tabular}


CUADRo 4. Las actitudes y prácticas hacia la conservación en los cuatro grupos ejidales (finaliza)

\begin{tabular}{|c|c|c|c|c|c|c|}
\hline $\begin{array}{l}\text { Afirmaciones sobre } \\
\text { la conservación }\end{array}$ & $\begin{array}{c}\text { Nivel de } \\
\text { concordancia }\end{array}$ & $\begin{array}{l}\text { Ruiz Cortinez- } \\
\text { Tuxtlas (\%) }\end{array}$ & $\begin{array}{l}\text { Koiyaki- } \\
\text { Maasai } \\
(\%)\end{array}$ & $\begin{array}{l}\text { Adolfo López } \\
\text { Mateos- } \\
\text { Tuxtlas (\%) }\end{array}$ & $\begin{array}{c}\text { Lemek Ol } \\
\text { Chorro- } \\
\text { Maasai (\%) }\end{array}$ & $\begin{array}{l}\text { Nivel de } \\
\text { significan- } \\
\text { cia }\end{array}$ \\
\hline \multirow{2}{*}{$\begin{array}{l}\text { Si no fuera por la } \\
\text { conservación de } \\
\text { la reserva, habría } \\
\text { más oportunida- } \\
\text { des de generar } \\
\text { ingresos. }\end{array}$} & De acuerdo & 34 & 9 & 40 & 47 & \\
\hline & En desacuerdo & 57 & 76 & 58 & 41 & \\
\hline \multirow{2}{*}{$\begin{array}{l}\text { La caza de anima- } \\
\text { les silvestres se } \\
\text { considera buena } \\
\text { cuando uno ne- } \\
\text { cesita usarla para } \\
\text { generar ingresos. }\end{array}$} & De acuerdo & 2 & 16 & 11 & 23 & \\
\hline & En desacuerdo & 93 & 76 & 87 & 73 & \\
\hline \multirow{2}{*}{$\begin{array}{l}\text { Se involucraría } \\
\text { en prácticas de } \\
\text { uso intensivo de } \\
\text { recursos, en caso } \\
\text { de ganar más } \\
\text { dinero, sea de la } \\
\text { actividad turística } \\
\text { u otra actividad } \\
\text { económica. }\end{array}$} & De acuerdo & 73 & 56 & 75 & 99 & \\
\hline & En desacuerdo & 25 & 42 & 23 & 1 & $* * *$ \\
\hline \multirow{2}{*}{$\begin{array}{l}\text { El gobierno no } \\
\text { debe preocuparse } \\
\text { más por la con- } \\
\text { servación porque } \\
\text { los seres humanos } \\
\text { tienen más dere- } \\
\text { cho de vivir que los } \\
\text { animales. }\end{array}$} & De acuerdo & 34 & 42 & 28 & 31 & \\
\hline & En desacuerdo & 64 & 52 & 70 & 65 & \\
\hline \multirow{2}{*}{$\begin{array}{l}\text { Si la población de } \\
\text { animales fuera } \\
\text { alta, estaría bien } \\
\text { la caza. }\end{array}$} & De acuerdo & 38 & 42 & 40 & 71 & \multirow{2}{*}{$* *$} \\
\hline & En desacuerdo & 57 & 56 & 46 & 27 & \\
\hline \multirow{2}{*}{$\begin{array}{l}\text { No es bueno cazar } \\
\text { animales salvajes. }\end{array}$} & De acuerdo & 67 & 59 & 70 & 73 & \\
\hline & En desacuerdo & 18 & 26 & 23 & 21 & \\
\hline \multirow{2}{*}{$\begin{array}{l}\text { Los bosques exis- } \\
\text { ten únicamente } \\
\text { para ser aprove- } \\
\text { chados económi- } \\
\text { camente }\end{array}$} & De acuerdo & 35 & 12 & 28 & 44 & \\
\hline & En desacuerdo & 58 & 79 & 64 & 51 & \\
\hline
\end{tabular}


En el cuadro 4 se encontraron seis respuestas que difirieron significativamente. Para determinar las relaciones específicas que contribuyeron a las significativas diferencias entre las comunidades, se realizaron pruebas de Chi-cuadrado comparando dos comunidades a la vez (véase cuadro 5). La primera línea de cada afirmación se refiere a la prueba entre las dos comunidades cuyas diferencias fueron las más claras.

Cuadro 5: La significación estadística de las asociaciones en el cuadro 4

\begin{tabular}{|c|c|c|c|c|c|c|}
\hline $\begin{array}{l}\text { Afirmaciones que muestran } \\
\text { asociaciones (diferencias) } \\
\text { significativas entre las comu- } \\
\text { nidades }\end{array}$ & $\begin{array}{l}\text { Grupo } \\
\text { ejidal }\end{array}$ & $\begin{array}{l}\text { En desacuerdo } \\
(\%)\end{array}$ & $\begin{array}{l}\text { Grupo } \\
\text { ejidal }\end{array}$ & $\begin{array}{l}\text { En desacuerdo } \\
(\%)\end{array}$ & $\begin{array}{l}\text { Valores } \\
p\end{array}$ & $\begin{array}{l}\text { Niveles de } \\
\text { significancia }\end{array}$ \\
\hline \multirow{4}{*}{$\begin{array}{l}\text { Más que para otra cosa, los } \\
\text { recursos recursos naturales } \\
\text { (flora y fauna)existenpara ser } \\
\text { aprovechados (leña, madera, } \\
\text { carne, etcétera). }\end{array}$} & $\mathrm{KY}$ & 82 & LOC & 45 & 0.0409 & $*$ \\
\hline & KY & 82 & ALM & 64 & 0.0829 & \\
\hline & $\mathrm{RC}$ & 76 & LOC & 45 & 0.0307 & * \\
\hline & ALM & 64 & LOC & 45 & 0.7772 & \\
\hline \multirow{3}{*}{$\begin{array}{l}\text { A veces es necesario cortar } \\
\text { árboles para fines económicos } \\
\text { cuando uno no tiene empleo. }\end{array}$} & $\mathrm{RC}$ & 54 & LOC & 21 & 0.0241 & * \\
\hline & $\mathrm{KY}$ & 42 & LOC & 21 & 0.0421 & * \\
\hline & $\mathrm{RC}$ & 54 & ALM & 34 & 0.1955 & \\
\hline \multirow{3}{*}{$\begin{array}{l}\text { A veces es necesario cazar } \\
\text { animales cuando uno no tiene } \\
\text { empleo. }\end{array}$} & $\mathrm{RC}$ & 80 & ALM & 46 & 0.0038 & $* *$ \\
\hline & $\mathrm{RC}$ & 80 & LOC & 55 & 0.0011 & $* *$ \\
\hline & $\mathrm{KY}$ & 69 & ALM & 46 & 0.1674 & \\
\hline \multirow{4}{*}{$\begin{array}{l}\text { Debería ser permitido para los } \\
\text { miembros de la comunidad } \\
\text { local cortar árboles para cul- } \\
\text { tivar o practicar la ganadería } \\
\text { sin ninguna restricción de las } \\
\text { autoridades. }\end{array}$} & $\mathrm{KY}$ & 86 & $\mathrm{RC}$ & 54 & 0.0110 & * \\
\hline & $\mathrm{KY}$ & 86 & LOC & 57 & 0.0251 & * \\
\hline & $\mathrm{KY}$ & 86 & ALM & 81 & 0.3422 & \\
\hline & ALM & 81 & LOC & 57 & 0.1510 & \\
\hline \multirow{4}{*}{$\begin{array}{l}\text { Se involucraría en prácticas de } \\
\text { uso intensivo de recursos, en } \\
\text { caso de ganar más dinero, sea } \\
\text { de la actividad turística u otra } \\
\text { actividad económica }\end{array}$} & $\mathrm{KY}$ & 56 & LOC & 99 & 0.0001 & $* * *$ \\
\hline & $\mathrm{RC}$ & 73 & LOC & 99 & 0.0004 & $* * *$ \\
\hline & ALM & 76 & LOC & 99 & 0.0011 & ** \\
\hline & $\mathrm{KY}$ & 56 & ALM & 76 & 0.3481 & \\
\hline \multirow{3}{*}{$\begin{array}{l}\text { Si la población de animales } \\
\text { fuera alta, estaría bien la caza. }\end{array}$} & $\mathrm{RC}$ & 57 & LOC & 27 & 0.0035 & $* *$ \\
\hline & ALM & 46 & LOC & 27 & 0.0206 & * \\
\hline & $\mathrm{KY}$ & 56 & LOC & 27 & 0.0216 & * \\
\hline
\end{tabular}

$\mathrm{RC}=$ Ejido Ruiz Cortines- Tuxtlas; ALM = Ejido Adolfo López Mateos- Tuxtlas; $\mathrm{KY}=$ Ejido Koiyaki- Maasai Mara; LOC = Ejido Lemek OI Chorro.

Los niveles de significación se representan de la manera siguiente: "**" se refiere a $p<.05$, "*" se refiere a $\mathrm{p}<.01 \mathrm{y}$ "***" se refiere a $\mathrm{p}<.001$.

Fuente. Elaboración propia. 
Con base en los resultados de los cuadros 4 y 5 , se demuestra que las actitudes y prácticas de conservación se determinan por diferentes factores: oportunidades del ecoturismo, situación económica de los residentes, costumbres y circunstancias de diferentes comunidades. Por ejemplo, la comunidad de Lemek/Ol Chorro tuvo el mayor porcentaje (75\%) de las personas que consideran que "a veces es necesario cortar árboles para fines económicos cuando uno no tiene empleo". Los miembros de este grupo ejidal no están involucrados activamente en las actividades de ecoturismo como en otras comunidades, las tasas de desempleo son bastante altas en la zona y los miembros de la comunidad dependen en gran medida de la madera y la ganadería. Al contrario, la comunidad de Ruiz Cortines, que está más involucrada en actividades ecoturísticas y no depende de la madera, generó el porcentaje más bajo $(31$ \%) de las personas que están de acuerdo con la afirmación anterior (la diferencia en las respuestas de las dos comunidades fue estadísticamente significativa en $\mathrm{p}<0.05$ ).

Los encuestados de la comunidad Koiyaki, donde el ecoturismo es dominante, estuvieron en desacuerdo en que "debería ser permitido para los miembros de la comunidad local cortar árboles para cultivar o practicar la ganadería sin ninguna restricción de las autoridades", mientras que comunidades como Lemek/OI Chorro están a favor de la tala de árboles sin restricciones por parte del gobierno. Estas actitudes negativas pueden deberse a su dependencia de la agricultura y la ganadería. Además, han tenido experiencias negativas (conflictos) en el pasado con las autoridades del gobierno y gestores de la reserva en cuanto a las restricciones (la diferencia en las respuestas de Koiyaki y Lemek/OI Chorro fueron estadísticamente significativas en $p<0.05$ ). Asimismo, se destaca la variación en las prácticas de los residentes y su impacto sobre el medio ambiente. Por ejemplo, en Ruiz Cortines, 89 \% de los encuestados está de acuerdo en lo referente a los controles de la cacería, pero solo 28 \% está de acuerdo en cuanto a los controles relacionados con la escala de agricultura. Uno de los entrevistados comentó: "Los gestores de la reserva no entienden que ganamos la vida principalmente a través de la agricultura (...) el ecoturismo no es suficiente para todos nosotros (...) y los que ganan del ecoturismo, el ingreso no les alcanza para nada".

En términos generales, los encuestados de los cuatro grupos fueron casi unánimes en dos aspectos: primero, es de gran importancia que las generaciones futuras tengan la posibilidad de disfrutar de los bosques y los animales silvestres, y segundo, que los árboles clasificados entre las especies en peligro de extinción nunca se deberían de cortar. Estos resultados muestran que los miembros de las comunidades locales adyacentes a áreas protegidas por lo menos reconocen el delicado vínculo entre la conservación y las necesidades de las generaciones futuras.

Se buscó saber si había disminuido la tala de árboles y la cacería en los diferentes grupos ejidales y cuáles fueron las causas. En general, los encuestados estuvieron de acuerdo en que la tala de árboles y la caza de animales había disminuido (79 y $90 \%$ de los encuestados, respectivamente). El resultado más sorprendente es que lo atribuyen principalmente a las leyes y restricciones impuestas por los gestores de la reserva y no tanto al desarrollo del ecoturismo. Aún así, estuvieron de acuerdo en que tanto el ecoturismo como 
el aumento de la conciencia ambiental han tenido un impacto significativo (aunque sea mínimo) en el cambio de las actitudes y prácticas de conservación.

Estos resultados coinciden con lo que encontraron Siewe, Vadjunec y Caniglia (2017) y Ghimire (1994): que la gestión de las áreas protegidas a través de restricciones estrictas ha logrado disminuir la cacería y la deforestación. Durante las entrevistas, se identificaron fuertes sentimientos de animosidad entre los miembros de la comunidad y los gestores de las reservas; los encuestados atribuyen tales conflictos a la aplicación estricta de las normas y reglamentos dentro y fuera de las reservas. Sin embargo, esta consideración no debe ser malinterpretada; no se trata de defender el uso ilimitado de los recursos naturales, sino un cambio de la estrategia que busca influenciar las actitudes y percepciones de las comunidades locales a través de incentivos, más que el uso de la fuerza.

\subsection{Los impactos del ecoturismo y la conservación}

Con referencia a los hallazgos, queda claro que las prácticas de conservación en las cuatro comunidades tienen una fuerte asociación con el empleo del ecoturismo; por ejemplo, se manifestó que las familias que cuentan con empleo o las que participan en la actividad ecoturística tienen el mayor porcentaje de tierras con pastos en recuperación (80 \%) o en reforestación (75\%). El análisis determinó una asociación estadísticamente significativa $(p<0.001)$ entre participación o beneficios del ecoturismo y las prácticas de conservación. Sin embargo, se localizó una relación menos clara entre empleo, exposición y participación en la actividad ecoturística y las actitudes hacia la conservación.

Se encontraron asociaciones en únicamente cinco de las 12 correlaciones realizadas (pruebas de Chi-cuadrado) entre empleo o participación y las actitudes hacia la conservación, y solo una de las cinco asociaciones fue estadísticamente significativa en $p<.05$ (los encuestados que cuentan con empleo en comercios ecoturísticos y los que no); la afirmación de conservación en donde difirieron fue: “debería ser permitido para los miembros de la comunidad local cortar árboles para cultivar o practicar la ganadería sin ninguna restricción de las autoridades".

Por otro lado, hay varias afirmaciones que muestran tendencias inesperadas en cuanto a las actitudes hacia la conservación. Por ejemplo, se esperaba que los residentes beneficiados del ecoturismo mostraran el mayor porcentaje de respuestas positivas (demostrando actitudes positivas para la conservación) en comparación con los que generan pocos beneficios; sin embargo, es sorprendente que los encuestados del ejido Ruiz Cortinez, cuya participación y beneficios de las actividades ecoturísticas son mínimos, exhiben el mayor porcentaje de respuesta en desacuerdo con la afirmación "a veces es necesario cazar animales cuando uno no tiene empleo". Tomando la afirmación anterior como variable dependiente, la prueba Chi-cuadrado generó una asociación estadísticamente significativa en $p<0.001$ al comparar la respuesta de Ruiz Cortinez y Koiyaki.

No está claro por qué los encuestados de Ruiz Cortinez, una comunidad que recibe beneficios mínimos, dieron respuestas más opuestas a la cacería que los residentes de 
Koiyaki, un centro ecoturístico más establecido y que evidentemente produce mayor derrama económica que el anterior. Una de las razones puede ser la escasez general de animales salvajes en la RBLT, así como el aumento de la conciencia ambiental en la comunidad, y especialmente entre los líderes del grupo ejidal.

Aunque el empleo de la familia como un predictor de actitudes manifestó una tendencia inesperada, otras variables predictoras (como niveles de responsabilidad en la actividad ecoturística, ingresos indirectos, interacción e intercambio de ideas con ecoturistas, así como mejoras en la infraestructura) revelaron tendencias orientadas a la conservación (así se esperaba). Sin embargo, de todas las variables predictoras antes mencionadas, se halló significancia estadística únicamente en dos de las respuestas: intercambio de ideas con turistas y mejoras en la infraestructura.

Con base en las pruebas de Chi-cuadrado, se señala que la asociación entre el empleo y las actitudes hacia la conservación no mostró una tendencia clara (a pesar de que esta misma relación es más evidente en los hallazgos de las entrevistas); de hecho, las variables vinculadas con el beneficio indirecto del ecoturismo -por ejemplo, mejoras en la infraestructura e intercambio de ideas con turistas- expresaron una relación más fuerte y clara con las actitudes hacia la conservación que el empleo.

Hubo otras sorpresas similares; por ejemplo, la asociación entre niveles de responsabilidad en la actividad ecoturística y las actitudes hacia la conservación: se esperaba que los encuestados cuyos familiares tenían niveles más altos de responsabilidad en el ecoturismo manifestaran actitudes positivas, orientadas a la conservación, en comparación con los que manejaban bajos niveles de responsabilidad; empero, tal escenario fue evidente únicamente en seis de las 12 afirmaciones sobre la conservación, además, solo un caso de las seis asociaciones fue estadísticamente significativo.

A pesar de que los resultados no demuestran una fuerte asociación entre responsabilidad en la actividad ecoturística y actitudes hacia la conservación, no se descarta esta posibilidad; se aclara que sí existe una relación positiva entre diferentes niveles de responsabilidad y las actitudes hacia la conservación; se enfatiza también que todos los otros beneficios del ecoturismo, salvo el empleo directo, mostraron una asociación positiva como predictoras de las actitudes hacia la conservación; sin embargo, tales asociaciones no fueron claras o estadísticamente significativas.

También se encontró que la magnitud en la cual se opera el ecoturismo genera diferentes niveles de beneficios e impactos (cuando la escala es grande, se producen más beneficios y viceversa). Honey (2008) obtuvo resultados semejantes cuando realizó un estudio comparativo que abarcó casos de dos países para examinar los beneficios e inconvenientes del ecoturismo.

En Lemek/OI Chorro y Ruiz Cortines, donde el ecoturismo ocupa un papel secundario en la economía local, se encontraron pocos residentes que generan beneficios de la actividad ecoturística. Asimismo, la mayoría no experimenta efectos negativos del ecoturismo (de hecho, algunos de los encuestados quedaron sorprendidos cuando se les preguntó sobre 


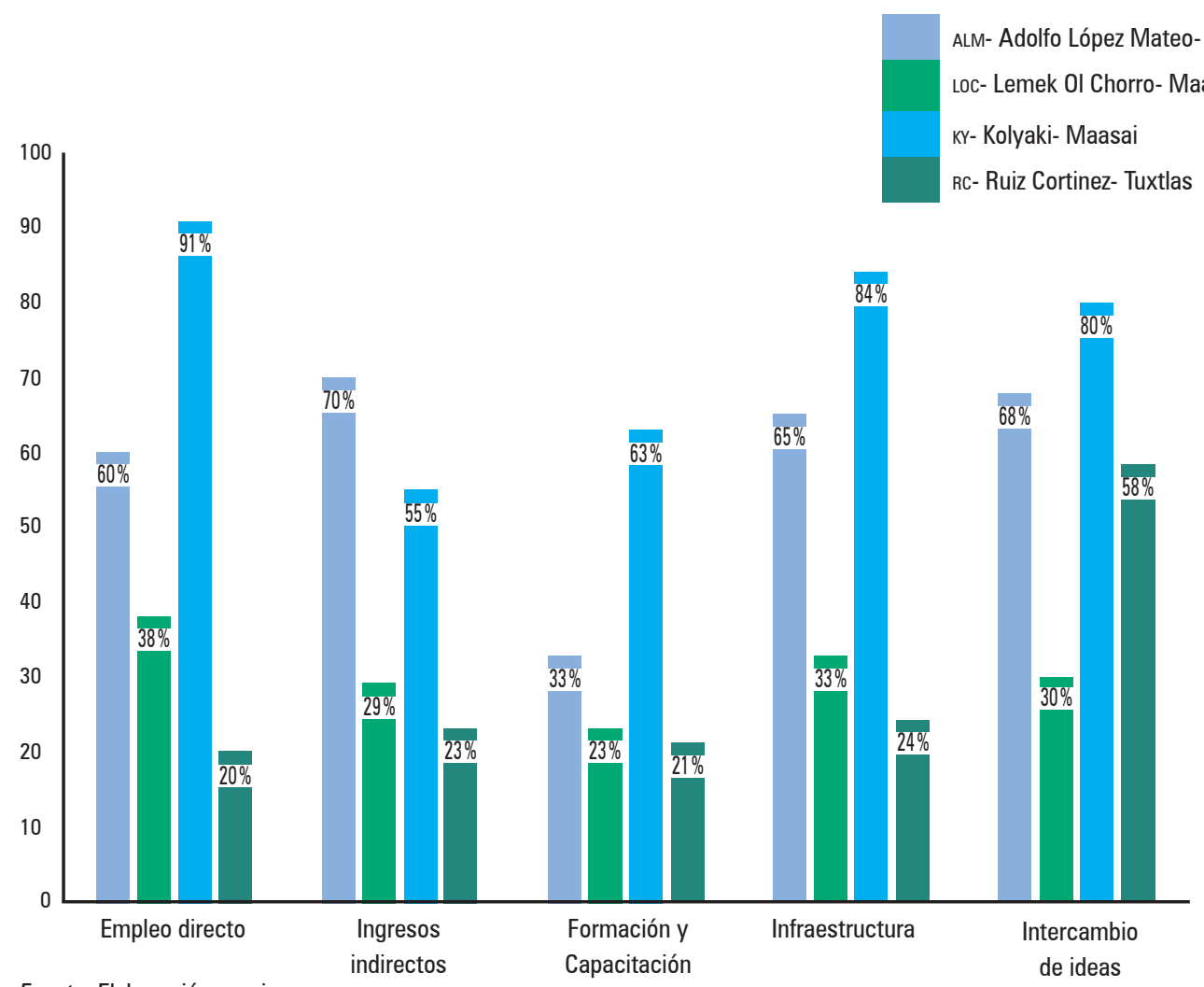

Fuente: Elaboración propia.

FiguRA 2. Distribución de beneficios en los cuatro grupos ejidales

el impacto del ecoturismo). Al contrario, las economías locales de Koiyaki y Adolfo López Mateos dependen en gran medida del ecoturismo.

Como se observa en las figuras 2 y 3 , estas dos comunidades se han beneficiado más del ecoturismo que Lemek/OI Chorro y Ruiz Cortines. De igual manera, se han generado más impactos (socioculturales, económicos y ambientales) en esas comunidades, como resultado de una mayor actividad ecoturística.

Aunque la mayoría de esos impactos se refieren específicamente al ecoturismo, cabe reconocer que representan una amenaza potencial al desarrollo económico alternativo en las comunidades y, por consecuencia, al bienestar de los residentes a largo plazo. Un buen ejemplo se encuentra en el ejido Koiyaki: los habitantes dependen tanto del ecoturismo que cualquier disminución de la demanda, por ejemplo de las llegadas de ecoturistas, tendría efectos adversos en cuanto a su sobrevivencia (conclusión basada principalmente en las encuestas). En caso de haber una reducción significativa de la actividad ecoturística, casi todos los encuestados indicaron que volverían a sus antiguas actividades económicas (la mayoría de las cuales no son compatibles con los objetivos de conservación, por ejemplo, la agricultura masiva). 
En Adolfo López Mateos, la comunidad se ha quedado sin ningún tipo de diversidad económica que actúe como una alternativa si disminuye el ecoturismo. Los resultados del presente estudio concuerdan con los planteamientos de Brasileiro y Tovar (2017) que destacan las limitaciones o desventajas de la dependencia excesiva del turismo. Según ellos, la economía local queda vulnerable durante temporadas bajas. Además de la dependencia excesiva, la mayoría de los encuestados en Koiyaki y Adolfo López Mateos considera que la comunidad ha perdido el control sobre los precios de bienes y servicios esenciales, y argumenta que el ecoturismo ha causado un enorme aumento de los precios.

En Koiyaki, los miembros de la comunidad no pueden permitirse el lujo de pagar precios exorbitantes que se cobran en los centros comerciales locales por productos básicos como agua mineral. Brasileiro y Tovar (2017) abordan esta cuestión de forma detallada, y señalan que la excesiva dependencia del turismo puede llevar a la comunidad a una especie de desastre económico, en el cual sus miembros ya no pueden comprar comodidades y servicios básicos; con el tiempo se convierten en comunidades pobres que sirven a una industria rica. Es importante aclarar que ninguna de las dos comunidades (Koiyaki y Adolfo López Mateos) ha llegado a este estado (y, probablemente, nunca lo harán), sin embargo, se debe reconocer que sus economías se han transformado de manera significativa, llegando a ser bastante dependientes de la industria ecoturística.

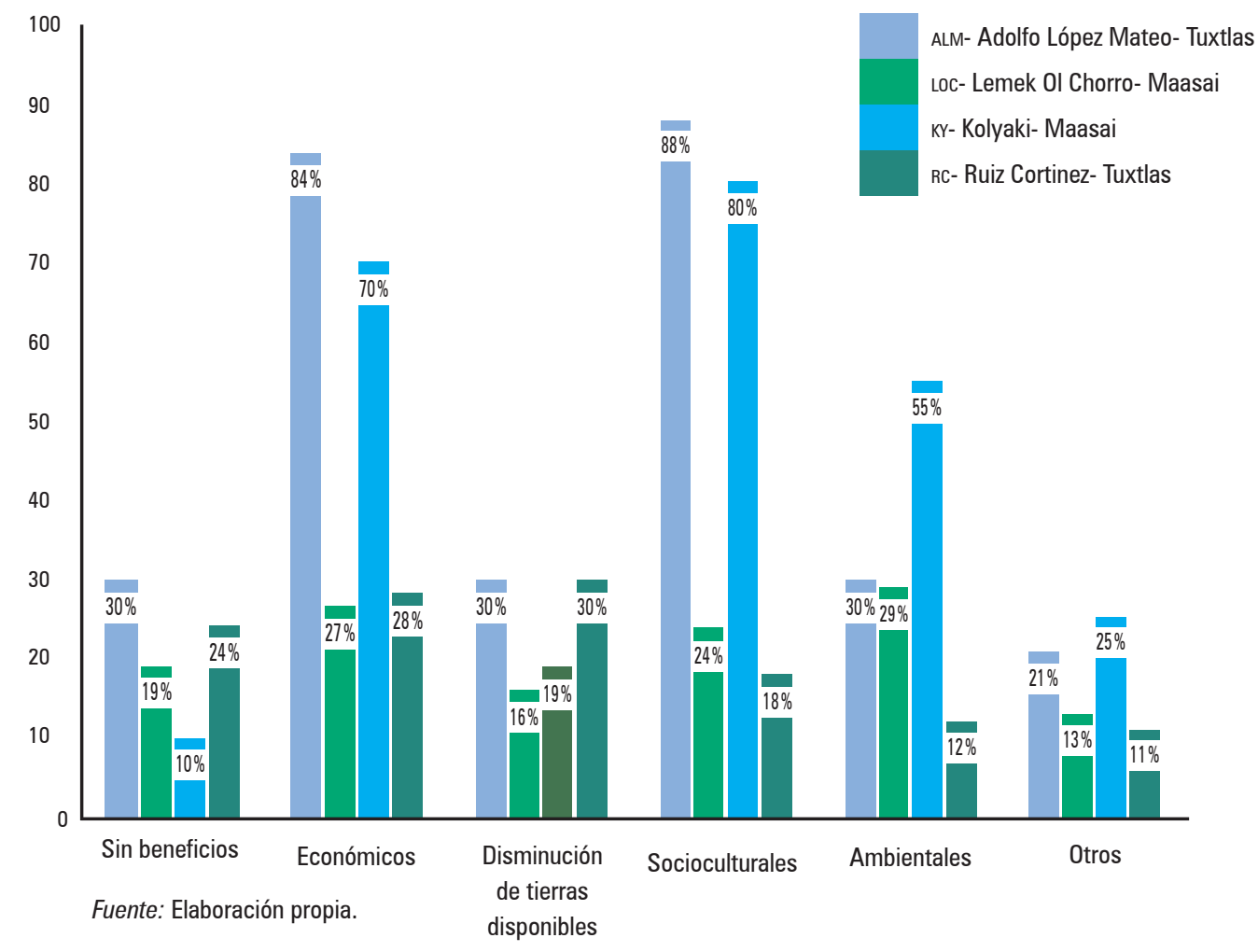

Figura 3. Los impactos del ecoturismo en los cuatro grupos ejidales 
Con relación a los impactos generales del ecoturismo, la figura 3 ilustra claramente que el aumento de la actividad ecoturística ha originado diversos efectos negativos, sobre todo en las comunidades donde la actividad se realiza a una escala más amplia. Los encuestados de Lemek/OI Chorro y Ruiz Cortines refieren menos impactos negativos (por ejemplo, consideran que su participación en el ecoturismo es mínima y no les permite generar beneficios), mientras los de Koiyaki y Adolfo López Mateos indican los diversos impactos negativos del ecoturismo: un aumento de los problemas ambientales como la contaminación, e impactos socioculturales como la pérdida de culturas indígenas y desintegración general de la comunidad (en el caso de Koiyaki).

Existen diversos estudios que examinan los impactos del ecoturismo. Poudel y Nyaupane (2017) exploran impactos ambientales causados por el comportamiento de los turistas, como la contaminación. Por otro lado, Karst (2017) aborda los efectos socioeconómicos y culturales, por ejemplo, escasez de beneficios para la comunidad local, conflictos entre sus miembros cuando tratan de competir por los beneficios del ecoturismo, vulnerabilidad de la economía local cuando se depende demasiado del ecoturismo, desintegración de las comunidades y familias debido a los conflictos relacionados con el uso de los recursos y distribución de beneficios. Asimismo, Honey (2008) presenta diversos puntos de vista, con ejemplos empíricos generados de estudios comparativos que abarcan proyectos de ecoturismo en diferentes países, y es común entre sus resultados la afirmación de que el ecoturismo produce impactos negativos, los cuales se deben controlar para que la actividad logre objetivos de sustentabilidad.

\section{Conclusiones}

La presente investigación consolida el acervo de conocimientos sobre el ecoturismo y la conservación; se generaron aportaciones teóricas y prácticas para conciliar la conservación con el desarrollo local. Siendo el estudio de caso comparativo, que abarcó cuatro casos en dos países, se tiene importancia metodológica; a través de la comparación se logró esclarecer las similitudes y diferencias entre las cuatro comunidades, y las condiciones en que ocurren, lo que permite comprender mejor cómo se relaciona el ecoturismo y la conservación bajo las circunstancias contextuales de cada una.

Se concluye que el ecoturismo puede engendrar importantes beneficios económicos para las comunidades locales e incentivar su participación en iniciativas de conservación, evitando prácticas destructivas, como la tala de árboles, la cacería o actividades que implican uso intensivo de los recursos naturales, como la agricultura. Los resultados demuestran una asociación significativa entre empleo en la actividad ecoturística y las prácticas de conservación; aún así, la relación entre el ecoturismo y las actitudes hacia la conservación parece ser estadísticamente insignificante. Tambien se concluye que los incentivos económicos directos no son los únicos factores que influyen en las actitudes y prácticas de conservación; los beneficios indirectos del ecoturismo, como la interacción e intercambio de ideas con ecoturistas, la participación local, la distribución de ingresos y la formación 
y capacitación, mostraron asociaciones o tendencias claras y positivas con las actitudes hacia la conservación, por lo tanto, se reconoce su importancia como factores determinantes. Es decir, los beneficios del ecoturismo van más allá del ingreso económico directo. Se deben contemplar estrategias para asegurar ambos beneficios (directos e indirectos).

El análisis del ecoturismo como factor predictor de las actitudes y prácticas de conservación comprueba las tres hipótesis planteadas al inicio del estudio: 1. Incentivos económicos por sí solos no son suficientes para que las comunidades locales abandonen sus prácticas económicas tradicionales a favor de la conservación. Otros factores, como las leyes y restricciones, la distribución de los beneficios, el involucramiento y empoderamiento, motivan e influyen en las actitudes y prácticas hacia la conservación; 2. Una mayor participación de las comunidades locales en las actividades del ecoturismo y la distribución equitativa de los costos y beneficios pueden generar actitudes y prácticas positivas que apoyan a la conservación; y 3 . El ecoturismo puede influir negativamente en la conservación como resultado de acciones involuntarias o equivocadas.

Con base en los resultados obtenidos en esta investigación, se puede concluir que no existe un nivel de la actividad ecoturística ideal que no se considera excesivo, y ofrece máximos beneficios con mínimos impactos. Así pues, el éxito o fracaso de la actividad ecoturística puede variar en diferentes casos y depende del contexto local, además de los factores sociodemográficos, como la cultura.

Por otro lado, se distingue un caso de otro por los enfoques y estrategias empleados principalmente por los operadores ecoturísticos para integrar la conservación y el desarroIlo de las comunidades. Cuando el ecoturismo ocupa un papel importante en la economía local, y ofrece beneficios sin perjudicar los recursos naturales que son la base económica de la comunidad, existen posibilidades de integrar la conservación y el desarrollo socioeconómico. Sin embargo, se recomiendan estudios más críticos y profundos para evaluar las relaciones de poder entre los diferentes actores y las comunidades. El ecoturismo puede generar impactos negativos cuando no se maneja de manera apropiada. Se debería ir más allá de la suposición de que el ecoturismo es una alternativa económica absolutamente segura que contribuye al bienestar de los recursos naturales y de las comunidades locales; en contextos ideales, lo afirmado sería cierto. 


\section{Fuentes CONSULtadas}

Adams, J. S. y McShane, T. O. (1992). The Myth of Wild Africa: Conservation without Illusion. Berkely y Los Ángeles: University of California Press.

Adams, W. M. y Hutton, J. (2007). People, parks and poverty: Political ecology and biodiversity conservation. Conservation and Society, 5(2), 147-183.

Agüera, F. O. y Morales, P. C. (2015). Ecoturismo y desarrollo sostenible. Un estudio de caso en comunidades rurales de República Dominicana. PASOS. Revista de Turismo y Patrimonio Cultural, 13(6), 1425-1435.

Barriga, A. M. (2015). La contradicción del turismo en la conservación y el desarrollo en Galápagos-Ecuador. Estudios y Perspectivas en Turismo, 24(2), 399-413.

Barriga, A. M. (2017). Percepciones de la gestión del turismo en dos reservas de biosfera ecuatorianas: Galápagos y Sumaco. Investigaciones Geográficas, Boletín del Instituto de Geografía, 93, 110-125.

Bello, F. G., Lovelock, B. y Carr, N. (2017). Constraints of community participation in protected area-based tourism planning: The case of Malawi. Journal of Ecotourism, 16(2), 131-151.

Björk, P. (2007). Definition paradoxes: From concept to definition. En J. E. Higham (ed.), Critical Issues in Ecotourism: Understanding a Complex Phenomenon (pp. 23-45). Oxford: Butterworth-Heinemann.

Brasileiro, M. S. y Tovar, L. S. (2017). Actividad turística y empleo. Una realidad entendidad desde los actores. Paradigma, 24(2), 87-111.

Brenner, L. y Job, H. (2012). Challenges to actor-oriented environmental governance: Examples from three Mexican biosphere reserves. Tijdschrift voor economische en sociale geografie, 103(1), 1-19.

Butler, R. (1980). The concept of a tourist area cycle of evolution. Implications for management of resources. Canadian Geographer, 24(1), 5-12.

Cardoso-Jiménez, C. (2006). Turismo sostenible: una revisión conceptual aplicada. El Periplo Sustentable, 11, 5-21.

Castillo, S. A., Baltazar, E. B., Lugo, E. E. y Piñera, E. N. (2016). Procesos organizativos, turismo y conservación en la reserva de la biósfera Ría Lagartos, Yucatán. Estudios Sociales, 25(47), 164-187.

Ghimire, K. B. (1994). Parks and people: Livelihood issues in national parks management in Thailand and Madagascar. Development and Change, 25(1), 195-229.

Gómez, N. S. (2011). La planificación de los destinos turísticos mexicanos: una receta mil veces vanagloriada. Renovación y restructuración de destinos turísticos consolidados del litoral, Bloque temático 1: Principios y fundamentos de los procesos de renovación y reestructuración en el marco del ciclo de vida de los destinos turísticos (pp. 1-21). Alicante: Universidad de Alicante.

Guerrero Rodríguez, R. (2010). Ecoturismo mexicano: la promesa, la realidad y el futuro. Un análisis situacional mediante estudios de caso. El Periplo Sustentable, 18, 37-67.

Higham, J. (2007). Ecotourism: Competing and conflicting schools of thought. En J. Higham, Critical Issues in Ecotourism: Understanding a Complex Phenomenon (pp. 20-40). Oxford: Butterworth-Heinemann. 
Honey, M. (2002). Ecotourism and Certification: Setting Standards in Practice. Washington, D. C.: Island Press.

Honey, M. (2008). Ecotourism and Sustainable Development: Who Owns Paradise? Washington, D. C.: Island Press.

Hvenegaard, G. (1994). Ecotourism: A status report and conceptual framework. Journal of Tourism Studies, 5(2), 24-35.

Instituto Nacional de Estadística y Geografía. (2010). Censo de Población y Vivienda 2010. México: Autor.

International Union for the Conservation of Nature. (1994). Guidelines for Protected Area Management Categories. Gland y Cambridge, Reino Unido: International Union for the Conservation of Nature-World Monitoring Conservation Centre.

Karst, H. (2017). "This is a holy place of Ama Jomo": Buen vivir, indigenous voices and ecotourism development in a protected area of Bhutan. Journal of Sustainable Tourism, 25(6), 746-762.

Kenya National Bureau of Statitics. (2012). Statistical releases. Nairobi: Government of Kenya. Recuperado de https://www.knbs.or.ke/data-releases /

Laven, D. N., Wall-Reinius, S. y Fredman, P. (2015). New challenges for managing sustainable tourism in protected areas: An exploratory study of the European Landscape Convention in Sweden. Society \& Natural Resources, 28(10), 1126-1143.

Lawton, L. J. y Weaver, D. B. (2015). Using residents' perceptions research to inform planning and management for sustainable tourism: A study of the Gold Coast Schoolies Week, a contentious tourism event. Journal of Sustainable Tourism, 23(5), 660-682.

Magio, K. O., Velarde, M. V., Santillán, M. N. y Ríos, G. (2013). Ecotourism in developing countries: A critical analysis of the promise, the reality and the future. Journal of Emerging Trends in Economics and Management Sciences (JETEMS), 4(5), 481-486.

Marín, G., García, A. y Daltabuit, M. (coords.). (2012). Turismo, globalización y sociedades locales en la península de Yucatán, México (PASOS edita, 7). Tenerife: PASOS. Revista de Turismo y Patrimonio Cultural.

Morse, J. M. (2003). Principles of mixed methods and multimethod research design. En A. Tashakkori y C. Teddlie (eds.), Handbook of Mixed Methods in Social and Behavioral Research (pp. 189-208). Thousand Oaks: Sage.

Palomo, I., Montes, C., Martín-López, B., González, J. A., García-Llorente, M., Alcorlo, P. y Mora, M. R. G. (2014). Incorporating the social-ecological approach in protected areas in the Anthropocene. BioScience, 64(3), 181-191.

Patton, M. Q. (1990). Qualitative Evaluation and Research Methods (2a ed.). Newbury Park: Sage.

Picard, D. (2015). Making ecotourism sustainable: Refocusing on economic viability. Lessons learnt from the "Regional strategic action plan for coastal ecotourism development in the South Western Indian Ocean”. Journal of Sustainable Tourism, 23(6), 819-837.

Poudel, S. y Nyaupane, G. P. (2017). Understanding environmentally responsible behaviour of ecotourists: The reasoned action approach. Tourism Planning \& Development, 14(3), 337-352.

Primack, R. B. y Ros, J. (2002). Introducción a la biología de la conservación. Barcelona: Ariel. 
Siewe, S., Vadjunec, J. M. y Caniglia, B. (2017). The politics of land use in the Korup National Park. Land, 6(1), 7.

Toledo, V. M. (2005). Repensar la conservación: ¿Áreas naturales protegidas o estrategia biorregional? Gaceta Ecológica, 77, 67-83.

Unesco. (1995). Reservas de la biósfera: La estrategia de Sevilla y el marco estatutario de la red mundial. París: Autor.

Unesco. (2005). Biosphere Reserves Benefits and Opportunities, Man and the Biosphere Programme. Recuperado de http://portal.unesco.org [2016, 25 de noviembre].

Vargas del Río, D. y Brenner, L. (2013). Ecoturismo comunitario y conservación ambiental: la experiencia de La Ventanilla, Oaxaca, México. Estudios Sociales, 21(41), 31-63.

Weaver, D. (1998). Ecotourism in the Less Developed World. Wallingford: Cab International.

Weaver, D. (2006). Sustainable Tourism: Theory and Practice. Oxford: Elsevier Butterworth-Heinemann. 


\title{
Patrimonialización y turismo en Zozocolco de Hidalgo, Veracruz Etnicidad, CULtura, naturaleza y PUESTA EN VAlOR
}

\author{
Federico Gerardo Zúñiga Bravo \\ elfos_tolkien@yahoo.com.mx \\ Dirección de Etnología y Antropología Social \\ Instituto Nacional de Antropología e Historia
}

Se analiza el proceso de patrimonialización y puesta en valor de la identidad étnica de la población totonaca, así como de los elementos culturales y naturales que caracterizan a la cabecera municipal de Zozocolco de Hidalgo, a partir de su declaración como joya de Veracruz y pueblo mágico por los gobiernos estatal y federal. Esto contribuyó a la proyección y conformación de la zona -situada en la región geográfico-cultural del Totonacapan, en la porción que corresponde al estado de Veracruz- como un espacio patrimonial, propicio para el desarrollo de actividades y servicios de turismo cultural, ecoturismo y turismo étnico, además de la creación de festivales con el propósito de mantener una oferta más allá de los periodos vacacionales. A partir de este estudio, es posible develar el proceso de patrimonialización y turistificación de Zozocolco de Hidalgo -tras el logro de tales declaratorias- mediante un carácter cualitativo e interdisciplinario de la investigación y de los resultados del registro etnográfico. Asimismo, la aplicación del modelo de análisis antropológico de la conversión del lugar, a través de la mediación significativa del espacio turístico y el modelo de articulación espacial, puso de manifiesto que la etnicidad (identidad étnica), la cultura y la naturaleza adquieren nuevas valoraciones y significaciones que trascienden el ámbito comunitario.

Palabras clave: Totonacapan, joya de Veracruz, patrimonialización, pueblo mágico, turistificación.

\section{Patrimonialization and Tourism in Zozocolco de Hidalgo, Veracruz. Ethnicity, Culture, Nature and Putting in Value}

The present work analyzes the process of patrimonialization and putting in value of the ethnic identity of the totonaca indigenous population, as well as a series of cultural and natural elements that characterize the municipal headboard Zozocolco de Hidalgo, since its valuation as "Joya Veracruz" and "Pueblo Mágico", categories granted by the governments state and federal. This declarations contributed to the projection and configuration of Zozocolco -located in the geographical-cultural region of the Totonacapan, in the portion that corresponds to the state of Veracruz- as a patrimonial and target space to the development of activities and services of cultural tourism, ecotourism and ethnic tourism, as well as the creation of festivals with the intention of improving an offer beyond the official vacation periods. This study has revealed the process of patrimonialization and touristification of Zozocolco de Hidalgo-, after the obtaining of the above-mentioned declarations -, through the qualitative and interdisciplinary character of the investigation, and of the results obtained through the ethnographic record. Furthermore, the application of the Model of Anthropological Analysis of the Local Conversion across the Significant Mediation of the Tourist Space and of the Model of Spatial Articulation revealed that the ethnicity (ethnic identity), the culture and nature acquire new valuations and significances beyond the community area.

Keywords: Totonacapan, Joya de Veracruz, patrimonialization, Pueblo Mágico, touristification.

Fecha de recepción: 3 de octubre de 2017. Fecha de aceptación: 20 de noviembre de 2017

CÓMO CITAR: Zúñiga-Bravo, F. (2018). Patrimonialización y turismo en Zozocolco de Hidalgo, Veracruz Etnicidad, cultura, naturaleza y puesta en valor. Dimensiones Turisticas, 2(2), 79-101. https://doi.org/10.47557/OTSF9528 
E n México, como en otras latitudes de Latinoamérica, a partir de que ciertas expresiones culturales y tradiciones de los pueblos indígenas y campesinos han transitado por procesos de revitalización, revaloración, patrimonialización, folclorización y comercialización, es posible afirmar, con base en el caso que aquí se presenta, que tales procesos han incidido por igual en su conversión como recursos turísticos (turistificación) a través de su puesta en valor para diferentes tipos de turismo: cultural, étnico, rural, ecoturismo, etc., y para un turista que "como un consumidor cada vez más exigente, demanda calidad y autenticidad con relación a los lugares, culturas y ambientes que se le ofrecen" (Machuca, 2008, p. 59).

El objetivo de este trabajo es describir y explicar cómo las denominaciones joya de Veracruz y pueblo mágico, para el caso de Zozocolco de Hidalgo, en el estado de Veracruz, constituyen elementos de visibilidad para esta localidad y todas aquellas con estas categorías. ${ }^{1}$ Estos son ejemplos de patrimonialización que, más allá de la salvaguarda, conservación y difusión con fines educativos, representan para el mercado turístico el equivalente a una marca, una Etnicidad S. A., como refieren Comaroff y Comaroff (2011), con fines de promoción y comercialización en las que también se expresa una producción singular de lo auténtico a partir de la selección y valoración, en este caso, de la identidad étnica (etnicidad) de los totonacos y el patrimonio cultural y natural con el que se les identifica. ${ }^{2}$ Lo que influye en la construcción de discursos e imágenes que sirven de soporte para ese imaginario social y turístico cuyo referente se manifiesta en las imágenes e ideas presentes en los textos de promoción turística (folletos, trípticos, mapas) y medios electrónicos (páginas web) que funcionan como "esqueletos" de tal imaginario en tanto organizan las expectativas del potencial turista a partir del consumo anticipado de atractivos y destinos (Almirón, Troncoso y Lois, 2007). Esa marca-símbolo en la que los aspectos más visibles de la cultura y los grupos étnicos se ponen al servicio de la industria del espectáculo y del turismo (Oehmichen, 2013, p. 12). Se produce una reapropiación de los símbolos étnico-culturales para el consumo turístico.

\section{La PATRIMONIALIZACIÓN Y EL TURISMO}

Si bien existen diversos significados en torno a la patrimonialización (Kirshenblatt-Gimblett, 2001; Frigolé, 2014; Davallon, 2014), en este trabajo se define como el proceso administrativo por el cual una localidad, elemento cultural o natural es seleccionado, valorado, declarado y categorizado como patrimonio con el propósito de transformarlo en un bien o servicio que se oferta, en este caso, para el consumo turístico como si fuese una mercancía,

${ }^{1}$ Este artículo es resultado de la tesis de doctorado en Antropología: Patrimonio cultural, etnicidad y turismo. Procesos de patrimonialización, turistificación y mercantilización en el Totonacapan veracruzano, Universidad Nacional Autónoma de México-Facultad de Filosofía y Letras e Instituto de Investigaciones Antropológicas, México, 2016.

${ }^{2}$ Además de la lengua, la ceremonia ritual de los Voladores, el sitio arqueológico de El Tajín, y la vainilla (Vanilla planifolia), fruto de la orquídea, suelen ser los elementos más sobresalientes con los que comúnmente se caracteriza a los totonacos de la Costa. 
lo que conlleva señalar que el estatus patrimonial es dependiente de una intencionalidad y apropiación. En este caso, la intención de patrimonializar una población con determinadas características, un espacio urbano, paisaje, manifestación o práctica cultural implica fines de promoción y consumo en el mercado turístico. Ejemplo de ello es que, al asumir el discurso globalizador del turismo por parte de los Estados, gobiernos e instituciones -algunas globales, como la Organización para la Educación, la Ciencia y la Cultura (Unesco), y nacionales-, el objetivo en concreto es que, para atraer el turismo, se debe apostar por lo que distingue y hace único a lo local en el mercado de lo global, esto es, los elementos más sobresalientes con los que se identifica a una sociedad, como puede ser su patrimonio cultural (arquitectónico, histórico, arqueológico, monumental, inmaterial, natural, etc.). En síntesis, constituye una instrumentalización de la cultura por parte del Estado a través del turismo. ${ }^{3}$

En el caso aquí analizado también conviene apuntar que esta forma de patrimonializar un lugar -es decir, una población con determinadas características histórico-culturales y naturales- supone una suerte de política cosmética, ya que si bien se restauran y embellecen ciertos espacios, como suelen ser los centros históricos o los inmuebles más emblemáticos y significativos para la población local, con potencial turístico para figurar como atractivos, a la par implica que se oculten las necesidades y condiciones reales de vida de la gente (Hernández, 2009).

Con base en lo anterior, la función que ejerce la turistificación, o turistización (Lanfant, 1994), ${ }^{4}$ debe considerarse parte de la dinámica mercantil en la que se insertan la cultura, el patrimonio cultural-natural -la cultura y la naturaleza resignificadas bajo la etiqueta de patrimonio- y las identidades étnicas con fines de promoción turística mediante su puesta en valor. En el caso de México, esto se expresa en el programa federal Pueblos Mágicos, como se mostrará líneas más adelante.

\section{El turismo en México}

La importancia económica del turismo como estrategia de desarrollo en México radica en su aportación al producto interno bruto nacional. Esto le ha permitido situarse como el destino más importante de Latinoamérica y el décimo (con 29.1 millones de turistas) en el ámbito mundial, si se tiene en cuenta que de los 45 millones de turistas que recibe América

\footnotetext{
${ }^{3}$ Empero, conviene señalar que la patrimonialización no necesariamente implica que debe realizarse con fines de marketing y comercialización en el mercado del turismo. Funge también como un proceso de reivindicación de las identidades étnicas, del reconocimiento a los territorios donde se asientan los pueblos indígenas, lo que implica que la patrimonialización sea igualmente considerada como una estrategia de negociación con el Estado a través de movimientos etnopolíticos. Se vuelve un objeto de lucha política por parte de los pueblos indígenas para existir como ciudadanos.

${ }^{4}$ Aunque este concepto tiene su origen en las transformaciones espaciales que coincidieron con la expansión de turismo después de la Segunda Guerra Mundial, hasta nuestros días, generando con ello una turistificación de los lugares tradicionales a partir de su conversión en nuevos destinos turísticos, aunado a una fuerte presencia del turismo en todas sus escalas geográficas; también se entiende como el proceso por el cual se transforma y resignifica un bien histórico, cultural o natural en un producto valioso mediante la adquisición de ciertas características que permiten comercializarlo en el mercado turístico.
} 
Latina cada año, México capta entre 22 y 23 millones en promedio (Organización Mundial del Turismo, 2016).

Su posición dentro de los primeros lugares en el ranking mundial del turismo se debe a "la riqueza de elementos culturales y naturales que se traducen en un alto potencial de aprovechamiento turístico, expresado en los paisajes en zonas montañosas, tropicales, áridas, templadas y costeras, aunado a la atracción que despiertan los sitios arqueológicos y la arquitectura de los distintos periodos históricos del país, que en conjunto representan una singularidad geográfica apreciada y buscada tanto por el turista extranjero como por el nacional” (Propín y Sánchez, 2002, p. 386). Lo que ha generado un considerable impacto en la distribución espacial y la infraestructura turística en diversas regiones del país (Brenner y Aguilar, 2002), sumado a la diversificación de la oferta turística, donde las preferencias y el consumo también han variado con el propósito de que el turismo deje de concentrarse exclusivamente en destinos de sol y playa.

Esto ha influido en nuevas formas de valorar la cultura y la naturaleza como recursos que sustentan la oferta de atractivos, servicios, actividades e imágenes de promoción en el mercado turístico interno e internacional, si se considera que estos fungen como sostén de una simbología turística que remite al pasado y presente a través de: sitios arqueológicos e históricos, arquitectura colonial, museos, artesanías, tianguis, festividades y danzas tradicionales, balnearios, parques, paisajes naturales, playas, etc. (Castellanos, 2008). De ahí que el aprovechamiento de la diversidad étnico-cultural-natural y el patrimonio arqueológico, arquitectónico, histórico e inmaterial, presente en distintas regiones del país, se haya integrado al mercado del turismo cultural, el ecoturismo, el turismo étnico y el indígena (Morales, 2008), entre otras modalidades. Gracias a ello, México es uno de los diez destinos turísticos más visitados del mundo, actividad que constituye su segunda fuente de ingresos (Rosas Mantecón, 2006).

\section{El turismo cultural y el programa Pueblos Mágicos EXPRESIÓN DE LA POLÍTICA TURÍSTICA NACIONAL}

Dado que entre los diversos objetivos establecidos en el Acuerdo Nacional por el Turismo (Secretaría de Turismo, 2011) se busca incrementar la oferta cultural en los destinos turísticos e incorporar el valor de las poblaciones indígenas como componente de la identidad y diferenciación del turismo -entre otros-, la estrategia de diversificar la oferta turística nacional pone énfasis en las modalidades turísticas referidas líneas arriba. Con relación al fomento del turismo cultural, cabe destacar que representa una derrama económica de aproximadamente 184000 millones de pesos del mercado nacional (Secretaría de Turismo, 2016), cuyo incremento ha sido posible gracias que México es uno de los países ${ }^{5}$ con mayor número de sitios histórico-naturales y elementos culturales inscritos en la Lista de

${ }^{5}$ Ocupa el sexto lugar detrás de Italia, España, China, Alemania y Francia, y el primero en América Latina y el Caribe. 
Patrimonio Mundial. A los 34 elementos registrados en esta lista ${ }^{6}$ habría que agregar las ocho manifestaciones de carácter inmaterial ${ }^{7}$ que han sido consideradas en las Listas Representativas de Patrimonio Cultural Inmaterial. Además de 111 pueblos mágicos, 187 zonas arqueológicas abiertas al público ${ }^{8}$ y 1200 museos y galerías de arte, lo que contribuye a que esta oferta - distribuida en todo el territorio nacional- sea una de las más apreciadas por los visitantes internacionales (Secretaría de Turismo, 2016).

Por ello el Estado mexicano, a través de la Secretaría de Turismo, ha diseñado diversas estrategias para promover esta modalidad en distintas regiones del país mediante los llamados programas regionales. ${ }^{9}$ A estos se sumaría el programa turístico que hoy en día es considerado el más exitoso y el que mayor impulso ha tenido desde su creación, hace 16 años: Pueblos Mágicos.

Pueblos Mágicos representa la instrumentación de una política de turismo cultural que pretende ser integral para las localidades que en un diferente nivel de desarrollo organizan diversas acciones de carácter económico, social y ambiental, con el fin de impulsar la imagen urbana de las ciudades que cuentan, entre otras cosas, con un significativo patrimonio histórico, arquitectónico y monumental ${ }^{10}$ (Velázquez, 2013; Martínez y Figueroa, 2015). Aunado a que muchos de los sitios declarados con esta denominación tienen también un importante legado indígena y campesino. Fue diseñado y planeado por la Secretaría de Turismo y forma parte del Programa Nacional de Cultura -contenido en el eje 7 donde se aborda el vínculo entre cultura y turismo-, en el que intervienen los tres niveles de gobierno: federal, estatal y municipal, cuyo objetivo es dinamizar las economías locales mediante el impulso al turismo cultural, a través de:

otorgar un nombramiento mediante un proceso determinado que responde a una serie de requerimientos institucionales con el fin de reconocer la riqueza cultural e histórica de un lugar emblemático, legitimando simbólicamente un destino turístico y de esta manera potencializar el desarrollo y la activación del mercado mediante el patrimonio material e inmaterial generando fuentes de empleo y una mejor calidad de vida [Ortiz, 2013, p. 342].

Organismos internacionales como la Organización para la Cooperación y el Desarrollo Económicos y el Banco Interamericano de Desarrollo consideran este programa uno de los

${ }^{6}$ De los cuales cinco son bienes naturales, 28 culturales y uno mixto (natural-cultural).

7 1. Las fiestas indígenas dedicadas a los muertos (2008); 2. Lugares de memoria y tradiciones vivas de los otomíchichimecas de Tolimán: en torno al territorio sagrado de Peña de Bernal (2009); 3. La ceremonia ritual de los Voladores (2009); 4. La pirekua, canto de los p'urhépechas (2010); 5. Los Parachicos en la fiesta tradicional de enero de Chiapa de Corzo (2010); 6. La tradición gastronómica de Michoacán. Cocina tradicional mexicana, cultura comunitaria, ancestral y viva. El paradigma de Michoacán (2010); 7. El Mariachi. Música de cuerdas, canto y trompeta (2011); y 8. La charrería, tradición ecuestre de México (2016).

${ }^{8}$ De las aproximadamente 40000 registradas por el Instituto Nacional de Antropología e Historia en todo el país.

${ }^{9}$ Estos programas son: México Norte, Mundo Maya, Ruta de los Dioses, Tesoros Coloniales, En el Corazón de México, y Mar de Cortés-Barrancas del Cobre.

${ }^{10}$ Conviene señalar que a este tipo de patrimonio se agregan elementos del patrimonio cultural inmaterial, por ejemplo festividades religiosas y comunitarias, músicas, danzas y cocina tradicional, saberes tradicionales, entre otras manifestaciones inmateriales, así como el patrimonio arqueológico, con el objetivo de ampliar los atractivos y productos que sustenten la oferta turística del lugar. 
más exitosos debido a que, según ellos, ha logrado impulsar el crecimiento de comunidades y pueblos rurales, además de fomentar la conservación de los paisajes naturales y las tradiciones culturales locales, a la par de ser calificado como una adecuada estrategia de marketing para el crecimiento del mercado turístico interno al promover el turismo cultural (Velázquez, 2013). Sin embargo, casos como el de la población de Tequila, Jalisco (Hernández, 2009), demuestran que la obtención de tal categoría puede tender hacia la privatización del espacio público y el patrimonio local, así como a la homogeneización del paisaje urbano (Sassen, 2010) y rural, ${ }^{11}$ beneficiando solo a aquellos que invierten en el ramo turístico, y no a la mayoría de los habitantes, como se promueve en los objetivos del programa. Por ello cabe tener en cuenta lo siguiente:

En ocasiones, lo que los organismos encargados de la gestión del patrimonio deciden patrimonializar no coincide con lo que el pueblo se identifica o cree relevante y significativo, es decir, con lo que interpreta como patrimonio. El problema está en quién determina qué es patrimonio: es aquello que los políticos ponen en sus miradas (casi siempre influidos por condicionamientos, lógicamente, de rentabilidad política y partidista), lo que se declara legal y formalmente como patrimonio o lo que las gentes consideran que es su patrimonio [Jiménez de Madariaga, 2005, p. 27].

Respecto al Totonacapan veracruzano, desde que el gobierno estatal ha planteado que el turismo debe fungir como estrategia de desarrollo regional en la zona norte de Veracruz, las acciones gubernamentales y políticas turísticas y de desarrollo se han orientado a generar ventajas competitivas, por un lado, mediante el fomento de una mayor eficiencia productiva a partir de la creación de infraestructuras para el transporte y la comunicación, la formación de recursos humanos y la promoción para el aprovechamiento del uso del suelo a través de cambios jurídicos (Ortiz, 2009), y por otro lado, a través de la puesta en valor de la cultura, la naturaleza y las localidades por la vía de la patrimonialización. Ejemplo de ello son Papantla ${ }^{12}$ (2012) y Zozocolco de Hidalgo (2015).

\section{El fomento del turismo en el Totonacapan veracruzano}

Como ya se mencionó, parte de las estrategias que el Estado mexicano ha llevado a cabo con el propósito de impulsar el turismo como forma de desarrollo para el país ha sido la aplicación de políticas públicas y programas orientados a esta actividad, los cuales han adquirido ciertas especificidades para cada uno de los estados de la república. Aquí vale apuntar que la política pública es el eje preferencial para apoyar a determinados sectores socioeconómicos

\footnotetext{
${ }^{11}$ Esta homogeneización funciona como un sistema de señalización: subrayando los lugares donde opera la renovación y transformación del espacio urbano, y se podría agregar el rural, a partir de la identificación de los aspectos específicos de las ciudades y las comunidades, mediante una gestión adecuada de las peculiaridades y diferencias con el fin de obtener un paisaje homogeneizado, común, en función, en este caso, del turismo global. Esas peculiaridades y diferencias se refieren a aquellos elementos distintivos y singulares por los cuales son elegidos los pueblos mágicos.

${ }^{12}$ Papantla perdió la denominación de pueblo mágico en 2009, por incumplir criterios de orden y calidad. No obstante, la recuperó en 2012 tras llevar a cabo acciones de reordenamiento en el primer cuadro de la ciudad.
} 
a partir de estrategias concretas que cubran los objetivos propuestos marcados en el Plan Nacional de Desarrollo y en los planes estatales de Desarrollo, implementados al inicio de cada sexenio (Vázquez y Aguilar, 2011).

Esto ha permitido la diversificación no solo en cuanto a la segmentación de modalidades turísticas, sino también respecto a la ampliación de destinos, aprovechando la heterogeneidad que presenta, en este caso, el estado de Veracruz en términos geográficos, ambientales y socioculturales. Un primer paso ha consistido en la regionalización turística de la entidad con el fin de organizar territorialmente y poner en valor los recursos naturales y culturales de todas las regiones con determinadas características geográfico-culturales ${ }^{13}$ con el criterio de diversificar la oferta de productos, servicios y actividades vinculada con la promoción turística del estado como destino preferencial.

En el caso de la Región Totonaca (Totonacapan ${ }^{14}$ ), a partir de impulsar otras formas de hacer turismo (turismo cultural, étnico, de sol y playa, ecoturismo, etc.), el turismo cultural destaca con el objetivo de aprovechar el patrimonio cultural, material e inmaterial, y natural de la región mediante su conversión en recursos turísticos, así como el establecimiento de rutas o corredores turísticos - como la Ruta de la Vainilla o Ruta del Totonacapan-, la creación de festivales culturales-musicales -como el festival Cumbre Tajín (promocionado como el Festival de la Identidad)-, además del otorgamiento de distintivos que ayuden a sobresalir a los destinos turísticos más publicitados, por ejemplo, Papantla: "La ciudad que perfuma al mundo", "Déjate envolver por la magia de la capital cultural del Totonacapan”; y Zozocolco de Hidalgo: "El lugar de los cántaros del sol”, “Joya de Veracruz y pueblo mágico”.

Desde esta perspectiva, apreciar la regionalización turística del Totonacapan permite añadir también que este tipo de división regional de su territorio resulta conveniente para los promotores turísticos, pues el hecho de que se delimiten regiones culturalmente representativas con tal propósito contribuye, junto con el proceso de patrimonialización, a acondicionar y habilitar cierta organización territorial con objeto de poner en valor los distintos elementos vinculados con el territorio y las poblaciones que lo habitan, de manera que la inversión destinada a los proyectos turísticos cuente con una oferta diversificada que garantice su éxito (Machuca, 2008):

Entre las entidades mexicanas que cuentan con notables recursos geográficos y socioeconómicos para el desarrollo del turismo alternativo se considera al estado de Veracruz, pionero en este tipo de actividades; sin embargo, en la región del Totonacapan todavía se tiene un gran potencial para el desarrollo del ecoturismo, del turismo de aventura y del rural, que para los fines prácticos de este trabajo se engloban dentro del denominado turismo alternativo [Centro Promotor de Diseño, Universidad Nacional Autónoma de México-Instituto de Geografía y Secretaría de Economía, 2002, p. 6].

${ }^{13}$ De acuerdo a los criterios de la Secretaría de Turismo y Cultura del gobierno estatal, Veracruz se ha segmentado en diez regiones turística: 1.Huasteca alta, 2. Huasteca baja, 3. Totonaca, 4. Nautla, 5. Capital, 6. Sotavento, 7. Las Montañas, 8. Papaloapan, 9. Tuxtlas, 10. Olmeca.

${ }^{14}$ Cabe mencionar que el Totonacapan es una región geográfico-cultural compartida entre los estados de Puebla y Veracruz, conformada por 39 municipios, dos zonas geográficas (Sierra Madre Oriental y Llanura Costera del Golfo Norte) y cuatro subregiones o microrregiones (1. Sierra Norte de Puebla, 2. Llanura Costera, 3. Sierra de Papantla y 4. Tierras Bajas del Norte de Puebla). 
Como ha sucedido con los municipios de Papantla y Zozocolco de Hidalgo, ejemplos representativos de tales procesos:

El turismo significaría una importante generación de recursos económicos para los indígenas totonacas de la sierra, ya que el turismo tiene que ver con todo, las artesanías, productos agrícolas, sobre todo los productos naturistas.

Existen municipios como Coxquihui, Zozocolco y Mecatlán en donde se conservan varias danzas autóctonas, además de que recientemente en Coxquihui se descubrieron unas cavernas antiguas, mientras que en Zozocolco se han ubicado aguas termales en los límites con el estado de Puebla, además de las riquezas culturales, artísticas y naturales con las que cuentan [entrevista al diputado Loth Segura, del Partido Acción Nacional, por el Distrito VII de Papantla, Zozocolco de Hidalgo, 10 de agosto de 2010].

Con base en lo anterior, se debe considerar que la atracción y valoración de un lugar, localidad o región no solo se construye a partir de las expectativas y deseabilidades de la sociedad de origen de la que provienen los turistas mediante una colección de signos e imágenes que se incorporan a paisajes del campo o la ciudad, como diferentes de aquellos que se encuentran en la experiencia cotidiana del turista (Almirón, 2004), sino también a través de los discursos e imágenes que evocan ese destino (localidad o región turística) por medio de la elección de elementos étnico-culturales y naturales con los cuales es posible conformar una cartografía e imaginario turístico que remita al visitante a través de cierto tipo de experiencias con la finalidad de vivir la autenticidad del destino. Esto implica contar con una base discursiva o sumario creativo que oriente la imagen e información que se proyecta a través de palabras y representaciones visuales (Zorrilla, 2010).

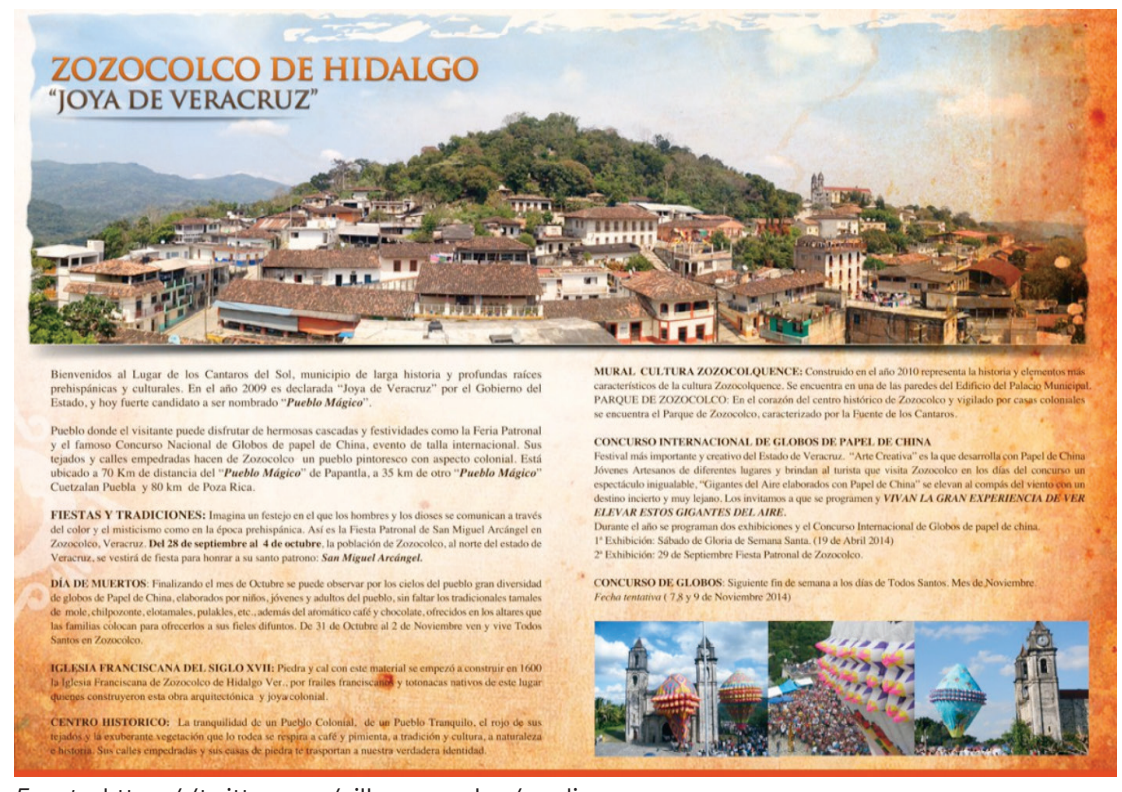

Fuente: https://twitter.com/villaszozocolco/media

FiguRa 1. Información turística sobre Zozocolco de Hidalgo, joya de Veracruz 
En el caso de Zozocolco de Hidalgo, esta dinámica se pudo constatar mediante la observación etnográfica y la aplicación de los dos modelos teórico-metodológicos señalados en líneas anteriores.

\section{Metodología y rasgos etnográficos de Zozocolco de Hidalgo}

Respecto a la metodología empleada en la investigación, el uso del registro etnográfico tuvo como objetivo hacer una "descripción densa" (Geertz, 1987) de los procesos de patrimonialización y turistificación con base en las percepciones y valoraciones de la gente de Zozocolco de Hidalgo (la perspectiva emic ${ }^{15}$ ) en su posición de promotores, anfitriones y receptores de turistas, tras haberse convertido en joya de Veracruz y pueblo mágico.

El propósito de hacer una descripción densa que, como recurso metodológico, tuvo un papel central en el proceso de investigación para el análisis de la patrimonialización y turistificación de Zozocolco de Hidalgo, tiene que ver con el papel del investigador -en este caso, el etnógrafo-, quien participa de la vida cotidiana de las personas durante un tiempo relativamente extenso, al observar lo que pasa, escuchar lo que se dice, preguntar cosas; o sea, recopilar todo tipo de datos accesibles para arrojar luz sobre los temas que ha elegido estudiar. De ahí la importancia de presentar, a continuación, algunos rasgos que distinguen a esta localidad y por los cuales fue elegida para conformarse como incipiente destino turístico.

Zozocolco de Hidalgo se localiza en la zona denominada como Sierra de Papantla, entre los paralelos $20^{\circ} 0^{\prime}$ y $20^{\circ} 10^{\prime}$ de latitud norte, los meridianos $97^{\circ} 30^{\prime}$ y $97^{\circ} 36^{\prime}$ de longitud oeste, y con una altitud entre 100 y $600 \mathrm{~m}$. Se encuentra asentado en tres cerros rodeados por una exuberante vegetación compuesta de bosque subtropical perennifolio en el que es posible hallar cedro, caoba, encino -cuyas maderas se utilizan en la construcción de casas y en la fabricación de muebles artesanales-, chaca, palo mulato, chote, chicozapote, plátano, hule criollo, chijol y acahuales, además de plantas comestibles como chayote, pápalo, quelite y calabaza.

Su fauna está conformada por una gran variedad de animales silvestres como conejos, mapaches, armadillos, tlacuaches y zorrillos; y aves como chachalacas, palomas, calandrias, codornices y tordos, así como reptiles e insectos. ${ }^{16}$ Posee una extensión de $69 \mathrm{~km}^{2}$-lo que representa $0.1 \%$ del territorio estatal del estado de Veracruz y $1 \%$ del territorio regional-, la cual en su mayoría presenta una topografía quebrada y atravesada por los ríos Tecuantepec y Apulco, limitando con la Sierra Norte de Puebla a la altura de las poblaciones de Tetelilla, Nauzontla y Huehuetla. Al norte colinda con el municipio de

${ }^{15}$ En antropología, la perspectiva emic corresponde a una visión del mundo que los participantes nativos aceptan como real, significativa o apropiada. Al llevar a cabo una investigación desde este enfoque, el investigador trata de adquirir un conocimiento de las categorías y reglas necesarias para pensar y actuar como un nativo, a fin de interpretar las percepciones, valoraciones y puntos de vista sobre un tema o pregunta en específico para tratar de indagar en la realidad del grupo social estudiado.

${ }^{16}$ La puesta en valor de esta biodiversidad es la que ha contribuido a la creación del Festival por la Cultura de los Hongos Silvestres, la Unidad de Manejo para la Conservación de la Vida Silvestre "El Jabalí” y el Centro Ecoturístico Cántaros del Sol. 
Coxquihui, al sur con el estado de Puebla, al este con el municipio de Espinal y al oeste con Huehuetla, Puebla.

Según datos del Censo de Población y Vivienda 2010, del Instituto Nacional de Estadística y Geografía (2010), el municipio de Zozocolco de Hidalgo está constituido por 30 localidades -categorizadas como rurales-y compuesto por una población total de 13434 habitantes: 6599 hombres y 6835 mujeres, de los cuales 77.18 \% son indígenas, es decir, 9623 son hablantes de lengua indígena: 4678 hombres y 4945 mujeres. De estos, 1487 son bilingües: 729 hombres y 758 mujeres, y 67 no hablan español: 16 hombres y 51 mujeres. Del total, 3221 personas: 1595 hombres y 1626 mujeres, residen en la cabecera municipal, siendo 1569 hablantes de lengua indígena: 752 hombres y 817 mujeres. ${ }^{17}$

La principal fuente de ingresos económicos son las actividades agrícolas, destacando el cultivo de café, pimienta, maíz, el comercio y la cría de ganado bovino. La producción agrícola se mantiene como actividad rectora que sustenta el desarrollo económico y social local. De acuerdo con el Sistema de Información Municipal de la Secretaría de Finanzas y Planeación del Gobierno del Estado de Veracruz (2011), a pesar de su creciente grado de urbanización, derivado de la introducción de servicios básicos (drenaje, luz, agua y pavimentación), educativos y de salud para la población local y del resto del municipio, maneja un alto grado de rezago social. Sin embargo, este grado de marginalidad parece contrastar con la riqueza natural y cultural local, la cual se ve reflejada en elementos de su cultura material e inmaterial: festividades religiosas y prácticas lúdicas, danzas, producción artesanal, vestido y cocina tradicionales, lengua, mitos y saberes indígenas (etnoconocimiento).

Ejemplo de ello es san Miguel Arcángel, figura del santoral católico, a quien se le identifica con esta localidad serrana, cuya fiesta se le dedica el 29 de septiembre y en la que se Ilevan a cabo numerosas actividades culturales, deportivas y comerciales que enmarcan la celebración religiosa. Entre las razones por las cuales esta festividad patronal se ha transformado en uno de los principales atractivos y recursos turísticos de Zozocolco de Hidalgo se encuentran los numerosos grupos de danza que participan en el atrio y en el interior de la iglesia, como los siguientes: Voladores (Kgosni), Quetzales, Tejoneros (Shkutis), Santiagueros, Negros Reales (Xatalhman), Toreadores y San Migueles, en honor al santo. Además de las vistosas ceras ornamentadas con flores y diversos motivos que se le ofrendan, y que son parte del sistema de cargos donde cada mayordomo tiene encomendado guardar al santo en su casa por varios días para después Ilevarlo a la iglesia en procesión, con el acompañamiento de los grupos de danza, música, las ceras labradas, gente de la localidad y de las comunidades cercanas.

Como parte del esfuerzo colectivo de las personas, las fiestas seculares y religiosas expresan el agradecimiento a los favores recibidos de san Miguel Arcángel: buenas cosechas, cuidado del pueblo, milagros concedidos, entre otras peticiones. Las fiestas de carácter religioso contribuyen a reafirmar el sentido de pertenencia e identificación con

${ }^{17}$ En este sentido, conviene destacar que el grueso de la población indígena se concentra en las comunidades, denominadas localmente como "rancherías", y que en el periodo de las festividades patronales son quienes presentan la mayoría de las danzas tradicionales que se promocionan como atractivos turísticos. 
la comunidad, así como a obtener reconocimiento y prestigio social a través de las mayordomías (sistema de cargos), ya que para los zozocolquenses la fiesta patronal y las ceras ornamentales son signo de identidad y orgullo.

Con relación a la festividad patronal, las ceras ornamentales y danzas se constituyen como elementos presentes en la identidad étnica del totonaco. La elaboración de las ceras y la presencia de los grupos de danza en la fiesta patronal es, para la gente mayor, parte de su cosmovisión del mundo y de la realidad cotidiana, expresión auténtica de la totonaqueidad que el turista vendría buscando en su afán de reconocerse a sí mismo en la otredad. Esto implica que como tradiciones locales hoy en día se inserten en el contexto global como forma de mantener su vigencia y revitalización, pero también como una oportunidad para ganar dinero a través de las transformaciones que el turismo ejerce sobre ellas al asignarles nuevos valores de uso y en diferentes espacios ajenos al contexto comunitario.

A ello hay que agregar las características de la localidad, representada por sus casas de teja roja y edificadas con piedra laja -mineral abundante en la zona-, sus calles empedradas hechas del mismo material y su iglesia franciscana en la que tiene su morada san Miguel Arcángel -santo patrono del pueblo y advocación del trueno y de la deidad mesoamericana Nattsun (Williams, 1993)-. En conjunto, la vigencia de rasgos culturales que moldean el paisaje, la arquitectura del lugar, aunado a su población de mayoría indígena (totonaca), hacen que Zozocolco de Hidalgo sea concebido en el imaginario de los foráneos como un "pueblo tradicional".

Estos elementos culturales y naturales constituyen una oportunidad para su puesta en valor como recursos turísticos con el fin de promover a Zozocolco como destino de turismo cultural, entre otras modalidades referidas con anterioridad, que por sus singulares características le otorgan cierto valor con objeto de atraer potenciales consumidores.

Como se mencionó líneas atrás, otro de los recursos metodológicos utilizados fue la aplicación del modelo de análisis antropológico de la conversión del lugar a través de la mediación significativa del espacio turístico (Nogués, 2007) y del modelo de articulación espacial (Hiernaux, 1989), los cuales contribuyeron a la recolección de información en campo y a la identificación de aquellos elementos que intervienen en la conformación de Zozocolco como destino de turismo cultural, resaltando con ello el carácter cualitativo e interdisciplinar de la investigación.

La aportación teórico-metodológica del modelo de análisis antropológico de la conversión del lugar a través de la mediación significativa del espacio turístico, en cuanto contribución de la antropología del turismo, facilitó la comprensión de los procesos de patrimonialización, turistificación y puesta en valor como elementos que intervienen en la estructura territorial del turismo, al considerar los aspectos socioculturales presentes en la dinámica territorial vinculada con la actividad turística. ${ }^{18}$ Para ello, la mediación del

\footnotetext{
${ }^{18} \mathrm{Si}$ se tiene en cuenta que el concepto de estructura territorial se refiere a identificar una serie de elementos físicos, estáticos o dinámicos, que posibilitan la implantación de esta actividad económica en el territorio, que incluye los recursos turísticos que definen los patrones de ocupación del espacio, la infraestructura o red de servicios que sostienen la demanda de visitantes y los flujos de bienes, personas e información alentados por el turismo desde diferentes sitios en el plano nacional e internacional.
} 
espacio turístico -derivada de tal modelo- consiste en definir al turismo como un proceso por el cual los lugares son convertidos en territorios turísticos a través de la aparición de espacios negociados mediante la estrategia metodológica de "dar valor y poner en valor". Esto significa que los lugares (territorios turísticos) adquieren valor simbólico, el cual también adquieren aquellos elementos culturales o naturales presentes en estos, que además habrán de adquirir valor económico y, por ende, de mercancía conforme a la demanda de los turistas a fin de que se constituyan como parte de la oferta de atractivos y servicios a consumir. Tras adecuarlo al contexto de estudio y a los aspectos identificados a través de la observación etnográfica en campo, el modelo es explicado por su autor, el antropólogo Antonio Nogués (2007), de la siguiente manera:

1) Las condiciones macrosociales impuestas por 1) la presencia física del turismo sobre un territorio turístico en forma de alojamientos (hoteles y urbanizaciones), restaurantes, empresas de ocio y transporte; lo cual se aprecia en Zozocolco de Hidalgo con el incremento de estos servicios (hoteles y restaurantes), sumado a la creación de eventos y festivales -como el Festival de Semana Santa, el Festival por la Cultura de los Hongos Silvestres (figura 2) o el Festival Internacional de Globos de Papel de China (figura 3)- que contribuyen a ampliar y mantener una oferta sostenida de servicios, atractivos y actividades a lo largo del año; 2) la presencia simbólica de los dispositivos de dominación ideológica que condicionan lo deseable, e institucional (gobiernos federal y estatal, ayuntamientos, medios de comunicación, asociaciones de empresarios, etc.), que condicionan lo factible; ejemplo de ello es el impulso que el ayuntamiento de Zozocolco ha dado al turismo como estrategia de desarrollo económico a través de las denominaciones de joya de Veracruz y pueblo mágico, los festivales antes mencionados y la constante promoción y difusión al que es considerado uno de sus principales recursos turísticos: la fiesta patronal dedicada a san Miguel Arcángel, que se realiza anualmente del 26 al 29 de septiembre, conformando con ello un imaginario sobre la localidad, cuya representación visual y simbólica remite a lo que significa -en términos étnicos- "ser totonaca" en la Sierra de Papantla.

2) Las posibilidades de lo microsocial plasmadas en los haceres y decires de la gente. Las percepciones, valoraciones y prácticas socioculturales expresadas por los actores sociales que se encuentran inmersos en la actividad turística, así como aquellos que visualizan los efectos de la patrimonialización, turistificación en ciertos aspectos del entorno natural y sociocultural presentes en su vida cotidiana. Las estrategias que estos mismo actores llevan a cabo, ya sea para apropiarse del turismo como una actividad que pueda redituarles beneficios económicos y sociales en el nivel individual y colectivo, o como forma de sobrellevar la presencia de agentes externos, los turistas, que alteran por un breve y determinado tiempo su ciclo de vida cotidiano a partir de las prácticas culturales (su equipaje cultural) propias que estos reproducen en el lugar de destino. 


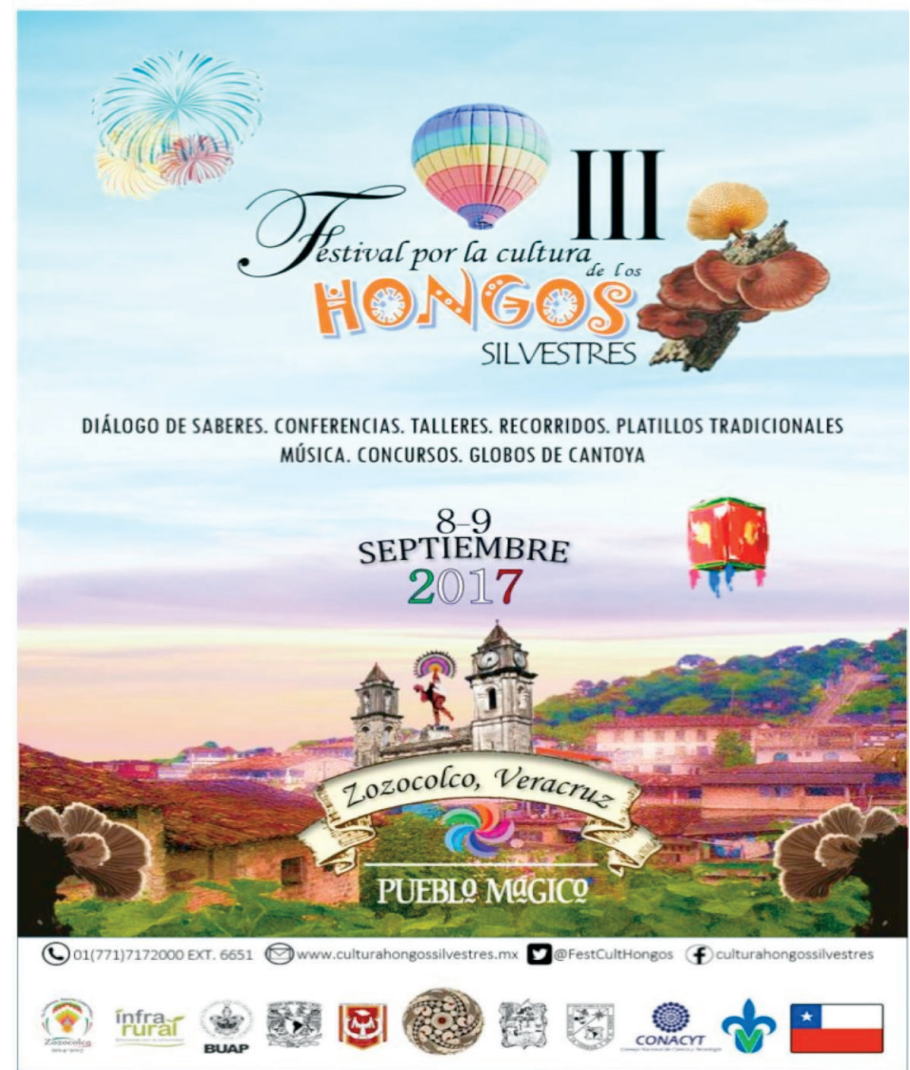

Fuente: https://www.facebook.com/culturahongossilvestres/ y

Figura 2. Cartel del Festival por la Cultura de los Hongos Silvestres

Por otro lado, al considerar por igual los aportes de la geografía del turismo, mediante la aplicación del modelo de articulación espacial fue posible identificar una serie de elementos que contribuyen en la estructura territorial del turismo en Zozocolco de Hidalgo:

1) La existencia y estructura de un núcleo, constituido por Zozocolco de Hidalgo, donde se concentran los principales recursos naturales y culturales para su puesta en valor como atractivos turísticos, y que influyeron en la obtención de las denominaciones joya de Veracruz y pueblo mágico.

2) Los flujos generados por tal presencia, los turistas nacionales e internacionales que si bien arriban a la región motivados principalmente por asistir al festival Cumbre Tajín en el municipio de Papantla -además de conocer la zona arqueológica de El Tajín, declarada Patrimonio Cultural de la Humanidad-, la relativa cercanía entre estos dos pueblos mágicos (Papantla y Zozocolco de Hidalgo) despierta su interés por desplazarse hacia este punto de la Sierra de Papantla para conocer los atractivos y actividades promocionados, en el contexto del desarrollo turístico regional. 
3) Los actores interesados en promover y consumir la oferta local de productos y servicios turísticos, es decir, los miembros de la sociedad local-regional que participan y fomentan tal actividad: gobiernos estatal y municipales -encargados fundamentalmente de la promoción y difusión de Zozocolco como destino turístico; instituciones responsables de impulsar la política social del país, como la Comisión Nacional para el Desarrollo de los Pueblos Indígenas, a través del Programa de Turismo Alternativo en Zonas Indígenas, entre otros organismos gubernamentales-, políticos y empresarios locales del ramo hotelero y restaurantero, agencias de viajes, consultorías para el diseño de proyectos ecoturísticos, promotores culturales, así como las comunidades campesinas e indígenas que buscan insertarse de igual forma en la actividad turística a través de proyectos de ecoturismo, turismo comunitario, agroturismo y turismo indígena.

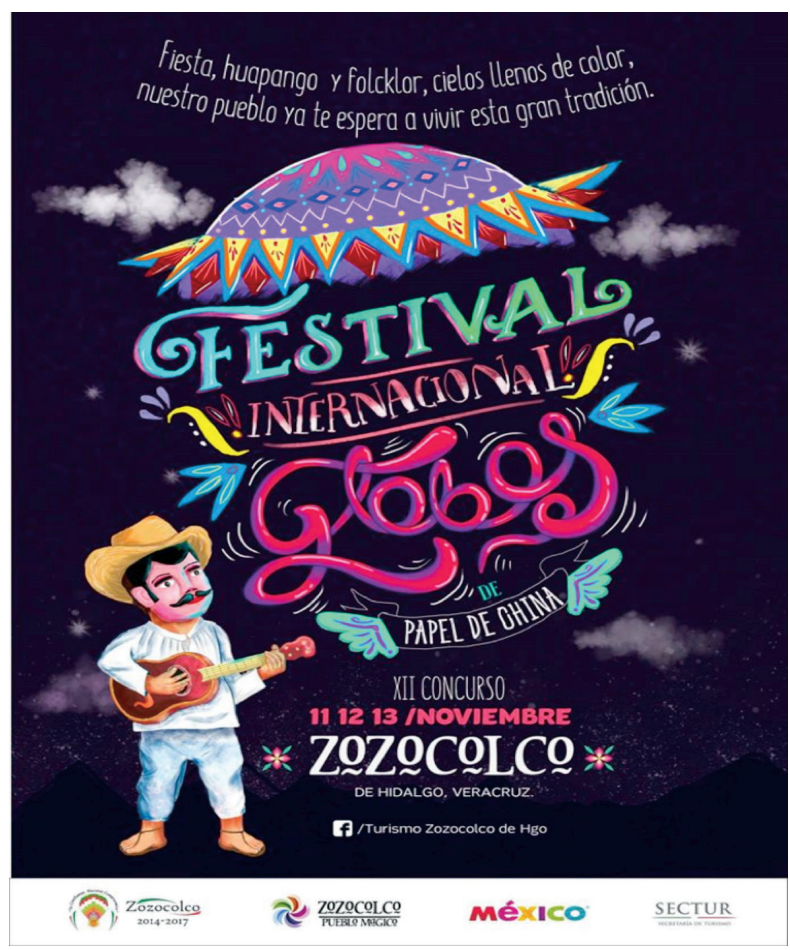

Fuente: https://www.facebook.com/turismo.zozocolcobely/

FIGURA 3. Cartel del Festival Internacional de Globos de Papel de China

En el caso de Zozocolco de Hidalgo, la relevancia del tema en cuanto a la patrimonialización y turistificación tras obtener las declaratorias de joya de Veracruz y pueblo mágico se debe a que, de acuerdo con las opiniones de algunos actores clave entrevistados, la mayoría de la población no fue tomada en cuenta para opinar si quería que la localidad fuese declarada pueblo mágico, ya que no se realizó ninguna consulta pública. El proceso de 


\section{F. G. Zúñiga Bravo}

patrimonialización obedeció, principalmente, a los intereses de funcionarios y políticos del ayuntamiento, muchos de los cuales son, a su vez, incipientes empresarios locales. Esto lleva a considerar que, en general, las autoridades encargadas del turismo suelen mercantilizar y comercializar la cultura local sin pedir la opinión de los habitantes (Greenwood, 1989).

\section{Patrimonialización y turistificación de Zozocolco de Hidalgo}

Como ya se ha señalado, el uso de los modelos propuestos en el apartado metodológico permitió reconocer los elementos que conforman la estructura territorial del turismo en Zozocolco de Hidalgo: recursos geográficos-físicos y culturales, canales espaciales de articulación, infraestructura de comunicaciones, bienes y servicios, y alcance geográfico, con los cuales fue posible elaborar una cartografía de la localidad en cuanto a su proyección como destino turístico de la región (según puede apreciarse en la figura 4), además de identificar a los actores clave a través de la observación participante y por medio de entrevistas a profundidad, con el objetivo de recopilar la perspectiva emic de los actores involucrados en los procesos de patrimonialización y turistificación. ${ }^{19}$

El proceso para la puesta en valor de la festividad patronal como uno de los principales recursos turísticos e imagen para la difusión de Zozocolco de Hidalgo en cuanto destino turístico -así como las tradiciones, cultura e identidad- ha tenido como principales promotores a funcionarios del ayuntamiento local desde hace aproximadamente 14 años, cuyo inicio se gesta en la administración del presidente municipal Antonio Grande Gutiérrez (2001-2004) y cobra mayor auge en la administración del presidente municipal, y posteriormente diputado del Distrito VII por el Partido Acción Nacional, Loth Melchisedec Segura Juárez (2008-2010).

Fue con este último que las campañas de difusión e información sobre los beneficios aportados por el turismo para el desarrollo económico y social de la municipalidad se intensificaron, dando como primer paso la obtención de la denominación joya de Veracruz para Zozocolco, otorgada por la Secretaría de Turismo, Cultura y Cinematografía del Estado de Veracruz en $2009,{ }^{20}$ cuyo propósito es proyectar a los lugares con potencial turístico con un enfoque social. Esta denominación ayudó a consolidar la promoción y difusión del municipio como destino turístico-cultural en poco tiempo. Así, bajo la administración del presidente municipal Alejandro García Rodríguez (2014-2017), en septiembre de 2015 Zozocolco de Hidalgo finalmente fue declarado pueblo mágico.

\footnotetext{
${ }^{19}$ Junto con la observación participante, me valí de la aplicación de entrevistas abiertas y semiestructuradas a funcionarios municipales y estatales, políticos locales, promotores culturales, antropólogos, arqueólogos, artesanos, danzantes, comerciantes, pescadores, campesinos, consultores de proyectos, entre otros actores sociales. Para ello, llevé a cabo alrededor de 30 entrevistas a profundidad con el propósito de conocer sus percepciones y valoraciones (la perspectiva emic) sobre su inserción en la actividad turística, aunado al interés por conocer su punto de vista en torno al turismo como forma de desarrollo para el Totonacapan, a través del aprovechamiento de la cultura y la identidad de las comunidades totonacas como el principal producto y atractivo turístico.

${ }^{20}$ Además de Zozocolco de Hidalgo, los municipios de Xico, Naolinco, La Antigua y Misantla recibieron el mismo año la designación de joyas de Veracruz.
} 


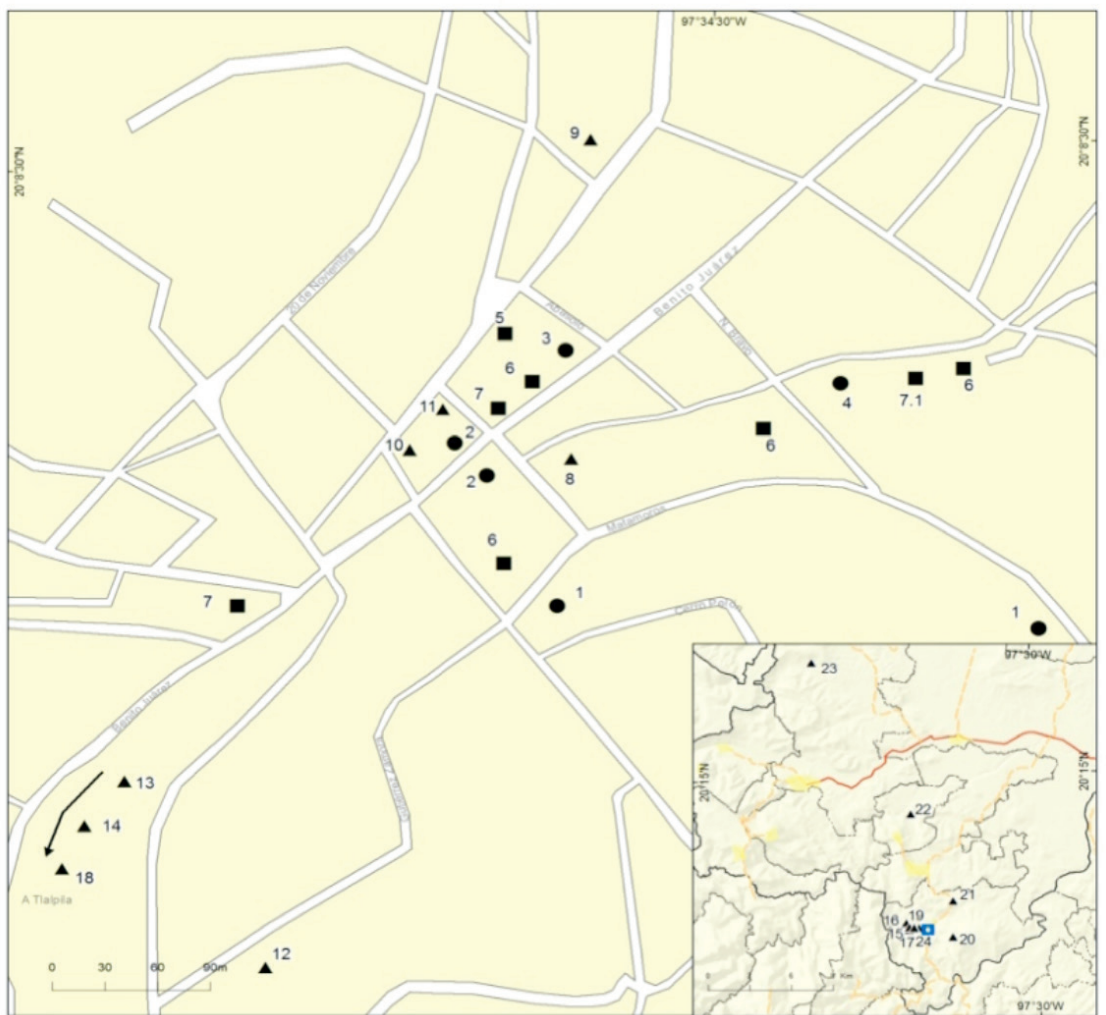

Rasgos, servicios e infraestructura

$\Delta$ Recurso

1. Terminal de autobuses

\section{Hotel}

3. Cajero automático

4. Parada de taxis

5. Palacio Municipal

6. Restaurante

7. Servicio médico

7.1 Medicina tradicional

8. Mercado municipal
9. Parroquia de San Migual de Arcánge
10. Juegos Infantiles
11. Parque municipal
12. Mirador
13. Poza Las Golondrinas (cascada)
14. Poza Los Cajetes
15. Poza del Diablo (cascada)
16. El Callejón (cascada)
17. Poza La Junta (cascada)

Infraestructura

18. Puente Caliche

19. Cerro Alto (cascada)

20. Proyecto ecoturístico Papan Real

21. Proyecto ecoturístico Cántaros del Sol

22. Proyecto ecoturístico Kuhuik

23. Proyecto ecoturístico Calixaxan

24. UMA El Jabají

\section{Rasgos geográficos}

----_ Límite municipal _ Vialidades _ Vía pavimentada -.. @ Ṕrea urbana

Fuente: Elaborado por Víctor Ríos Ramírez con base en el trabajo de campo.

Figura 4. Mapa de infraestructura, servicios y recursos turísticos del municipio de Zozocolco de Hidalgo

Conviene añadir que esta denominación fue impulsada durante el sexenio del gobernador Fidel Herrera Beltrán (2004-2010) en apoyo a aquellas localidades que buscaron integrarse al programa Pueblos Mágicos, pero que fueron rechazadas por no cubrir con la totalidad de los criterios solicitados por este. Como forma de paliar esta situación, en 2009 se creó el programa Joyas de Veracruz con la intención de darles un nombramiento 
especial a aquellos municipios y localidades que no rebasan los 60000 habitantes y cuentan con bellezas naturales y de valor histórico-cultural, a fin de proyectarlos como destinos turísticos e implementar obras de infraestructura para el mejoramiento de la imagen urbana. Es decir, otorgar un reconocimiento a aquellas poblaciones por su esfuerzo en la conservación de su patrimonio cultural, además de fomentar el cuidado y protección de sus recursos naturales.

Si bien el proceso de patrimonialización y turistificación de la localidad mediante este tipo de declaratorias -joya de Veracruz y pueblo mágico- implica una marca que garantiza el prestigio y la calidad de estos atractivos y servicios que se ofertan por la vía del turismo cultural, es también una forma de privatizar los espacios con alto valor sociocultural y natural, mediante la canalización de recursos públicos para beneficios privados (Hernández, 2009), similar a lo que ocurre con las declaratorias emitidas por la Unesco. Con ello se puede enfatizar que se busca que la selección, valoración y patrimonialización de los elementos que identifican a la población totonaca sean administrados y promovidos como recursos turísticos por parte de las autoridades locales, dado que, más allá de su papel como funcionarios públicos, son de los primeros empresarios locales que tratan de beneficiarse con ambas designaciones para la localidad.

Por ejemplo, la organización de la festividad patronal, de estar íntimamente ligada a las mayordomías y de ser una función exclusiva de estas, hoy en día se incluye la participación del ayuntamiento, el cual, si bien se encuentra más involucrado en la organización de las actividades que se realizan dentro de la Feria del Pueblo (permisos para el comercio y los juegos mecánicos y en los eventos culturales y deportivos), también influye en las decisiones respecto a la celebración religiosa al indicar el orden que debe seguir la procesión de las ceras por las principales calles del pueblo con el objetivo de que sean visibles especialmente para los visitantes. Esto lleva a señalar que el acceso diferencial a los beneficios del turismo altera las relaciones de poder, pues "aquellos que tienen intereses financieros en la industria del turismo son los que fomentan su desarrollo. [...] En consecuencia el desarrollo del turismo sirve de base para el surgimiento de conflictos de carácter estructural" (Boissevain, 2011, p. 42).

Esto se debe a que gran parte de la población de la cabecera y de las localidades que conforman el municipio, hasta ese momento no estaba bien informada sobre las posibilidades de hacer de Zozocolco un destino turístico, pese a que los funcionarios locales alegaban haber promovido campañas de difusión entre los pobladores. Si bien la mayoría de las personas no estaba al tanto, había opiniones a favor:

Aquí en Zozocolco somos muy celosos de nuestra cultura, principalmente la gente mayor. Aunque es una buena idea lo del turismo, porque los visitantes son gente que aprecia mucho lo nuestro y de alguna forma todos nos beneficiaríamos. Quizás por eso desde hace como tres años comenzó el impulso y prioridad a la cultura. Me gusta este presidente municipal que le ha dado interés a la cultura porque se estaba perdiendo, pues ya no era como antes. Ahora hasta tardeadas de huapango se están volviendo a hacer, además de que por eso estamos haciendo los talleres de danza con niños para rescatar la danza de Toreadores que se está perdiendo 
[entrevista al profesor Freddy Salas, maestro de primaria, danzante y promotor cultural, Zozocolco de Hidalgo, 23 de septiembre de 2010].

Mientras que otros parecían estar en contra:

El pueblo va a sufrir muchos cambios, nos van a quitar algunos valores. El beneficio no va a ser para los de aquí. Esos cambios van a traer droga también, pues ya se filtra con más facilidad. Los precios de las cosas van a subir porque con la llegada de los turistas todos van a querer vender más caro, por ejemplo el pan. Si antes con 20 pesos comprabas diez piezas porque te costaba dos pesos, ahora comprarás menos si lo suben de precio porque el pan que aquí se elabora todavía se coce en horno de leña y es un pan tradicional. Creo que el turismo tendrá sus ventajas y desventajas para el pueblo [entrevista a doña Natividad Salas, maestra jubilada y promotora cultural, Zozocolco de Hidalgo, 20 de septiembre de 2010].

Los testimonios citados coinciden con lo que Boissevain (2011) menciona respecto a que muchas comunidades se encuentran divididas en facciones pro y antiturísticas, derivando en el surgimiento de conflictos por quienes están a favor y en contra, lo cual, en el caso de Zozocolco, está ligado también a los partidos políticos gobernantes en turno, como el Partido Acción Nacional y ahora el Partido Revolucionario Institucional. Esto provoca la inconformidad en algunos sectores de la población que son apolíticos o militan en partidos ajenos a los que han gobernado el municipio, al argumentar que los únicos beneficiarios son quienes se encuentran afiliados a ellos, teniendo como resultado una gran diversidad de opiniones, a favor y en contra, sobre los proyectos emprendidos por el gobierno municipal para impulsar el turismo.

Por otro lado, con relación a la revitalización y resignificación de algunas tradiciones y prácticas culturales locales, algunos de los actores entrevistados consideraron que la llegada de visitantes podía ser una forma de dar a conocer sus tradiciones y costumbres, ya que muchas se estaban perdiendo, como las danzas de los Quetzales y los Toreadores, porque ya no se ejecutan como antes. $\mathrm{O}$ el caso de la manufactura de las ceras, dado que las constantes crisis económicas habían traído cambios en las mayordomías y en el proceso de elaboración de las ceras, como el costo de los materiales y la sustitución de los que comúnmente se utilizan, como la cera virgen de abeja, por otros.

Un ejemplo más es el de los globos de papel de china, práctica lúdica con la que se identifican los zococolquenses, ya que es uno de los medios más comunes de socialización entre niños y adultos, y que en la actualidad es considerada otro de los principales atractivos-recursos para atraer el turismo mediante la realización del Festival Internacional de Globos de Papel de China, como ya se refirió.

Aunque se argumenta que el origen de los globos de papel de china proviene del vecino estado de Puebla, en la Sierra Norte, el arraigo que tienen en esta zona del Totonacapan veracruzano no solo se constituye como un referente identitario, sino también como uno de los juegos tradicionales por excelencia, amén de ser una práctica relacionada con el culto a los muertos. Es costumbre que el $1^{\circ}$ y 2 de noviembre (Fiesta de Todos Santos), además de poner los tradicionales altares con las ofrendas, se elaboren globos de papel 
de china de menor tamaño que los que se exhiben en el festival -ya que algunos se llegan a realizar hasta con 4000 pliegos de papel- para elevarlos y recordar a los fieles difuntos.

Los orígenes del festival de globos de papel de china datan del año 2004, durante la administración municipal de José Luis Vallarta Figueroa (2004-2006). Por lo vistoso de los diseños y tamaño de los globos que se elaboran con miles de pliegos de papel, la idea fue organizar un concurso en el nivel regional. Sin embargo, la afluencia de espectadores y participantes redimensionó el evento para convertirlo en un festival de carácter nacional. Asimismo, la difusión y promoción del festival como parte de los atractivos de Zozocolco contribuyó a proyectarlo como festival internacional y hoy en día se concatena con otras festividades en la región que permiten mantener una oferta sostenida y permanente lo que resta del año -ya que una vez concluida la fiesta patronal de san Miguel Arcángel en Zozocolco, inicia la Feria Nacional del Café y el Huipil en el municipio de Cuetzalan, Puebla, otro de los destinos turísticos étnico-culturales y naturales consolidados desde hace años en la Sierra Norte de Puebla. ${ }^{21}$

En cuanto a algunos de los impactos o efectos negativos de la patrimonialización y turistificación referidos en la entrevista a la señora Natividad, estos comienzan ya a afectar a Zozocolco. Por ejemplo, un mes después de haber sido emitida la designación de pueblo mágico, hubo gran descontento de la gente local por la destrucción de una calzada construida en 1928, y que para muchos de los habitantes era de gran valor histórico, como se puede apreciar en el siguiente fragmento de una nota periodística donde se da cuenta de este hecho:

Gran indignación causó a los habitantes del recién nombrado Pueblo Mágico, la destrucción de una parte de la banqueta o calzada que data de 1928, esto para construir una barda donde colocarán una placa de Pueblo Mágico y así alimentar el ego del presidente municipal Alejandro García Rodríguez.

A un mes del nombramiento de Zozocolco como Pueblo Mágico, las autoridades no han emprendido absolutamente ninguna acción de mejora, lo que sí han hecho los empleados del Ayuntamiento desde ese día es andar celebrando en cantinas la denominación de ese lugar con la ya popular frase "Somos Pueblo Mágico".

En un recorrido, se logró obtener información del clamor de la mayoría de los habitantes de este pintoresco pueblo donde informaron que desde la llegada al poder de esta administración no se ha hecho absolutamente ninguna acción que haya mejorado su imagen urbana.

Por el contrario, dijeron, se ha descuidado el pueblo: se ha incrementado el ambulantaje al igual que el número de cantinas, no hay control de las lonas o publicidad de comercios, el problema de la basura sigue en crecimiento. $Y$ este hecho se pudo constatar por este corresponsal quien entrevistó a turistas que visitaban este pueblo y opinaron sobre la mala imagen de los vehículos oficiales del Ayuntamiento estacionados en la calle empedrada que conduce a la iglesia. ${ }^{22}$

${ }^{21}$ Ya que la distancia que separa a ambos municipios (Zozocolco de Hidalgo y Cuetzalan) es de aproximadamente 40 kilómetros, aunque el tiempo promedio es de hora y media debido a las malas condiciones de la carretera.

${ }^{22}$ Plumas Libres, octubre de 2015. Recuperado de http://www.plumaslibres.com.mx/2015/10/23pese-a-que-ya-espueblo-magico-alcalde-de-zozocolco-destruye-calzada-historica/ 
Por otra parte, cabe señalar que la mayoría de quienes participan y conforman esa imagen estereotipada y exotista de lo auténticamente totonaco: danzantes, artesanos, músicos, gente que participa en las procesiones y en la fiesta patronal, proviene de las comunidades pertenecientes al municipio, muchas de las cuales ni siquiera cuentan con servicios básicos como luz eléctrica, agua potable o pisos de cemento en sus viviendas, y padecen un alto grado de marginación, a pesar de que se han empezado a introducir algunos servicios en sus comunidades. Incluso, los únicos medios de transporte para quienes habitan en estas poblaciones son andar a pie, en camionetas de redila, a caballo o en mulas.

Muchas de estas personas participan por devoción y fe a san Miguel Arcángel, y son ellas quienes dan forma y vida a la festividad, "ellos son las que la sostienen" (entrevista a don Hilario Luna, Zozocolco de Hidalgo, 18 de agosto de 2010). En esto mismo coincide la nota periodística de la publicación Plumas Libres cuando refiere que: "Destacan los habitantes de este lugar que el mérito de esta denominación de Pueblo Mágico no es del actual Ayuntamiento, sino de cientos de danzantes, mayordomos, artesanos, y habitantes que han cuidado por años sus costumbres y tradiciones así como de los gobiernos que han aportado para que este pueblo se haya conservado y crecido". ${ }^{23}$

Esto es parte de las paradojas y contradicciones que encierran la patrimonialización y la turistificación cuando se pondera el valor económico más allá del valor, en este caso, simbólico-religioso-cultural que los propios depositarios confieren. Aunque es posible combinar ambas formas de valorar todo aquello relacionado con la cultura y la identidad étnica, como forma de generar procesos de revaloración y revitalización, salvaguarda y difusión, el valor mercantil no debería supeditar los significados que los propios depositarios otorgan.

\section{Conclusiones}

Los procesos de patrimonialización y turistificación de la localidad de Zozocolco de Hidalgo, descritos y analizados en este trabajo, mediante la obtención de las denominaciones joya de Veracruz y pueblo mágico, son un ejemplo de lo que Comaroff y Comaroff (2011) definen como una Etnicidad S. A., en la que a través de la marca, en este caso por medio de las categorías de joya de Veracruz y pueblo mágico, se crean mercancías simbólicas, a la par que se construye un discurso e imaginario visual que resalta lo étnico como algo exótico y auténtico. A esto habría que añadir la dicotomía entre tradiciones y prácticas culturales que persisten en un relativo aislamiento de las fuerzas del mercado y aquellas creadas específicamente para el mercado turístico en las que se reinventa y recrea lo étnico a fin de satisfacer las necesidades de tal mercado.

En el caso de Zozocolco de Hidalgo, la puesta en valor por la vía de la patrimonialización y la turistificación resulta un proceso ambivalente, si se considera que no solo ha

${ }^{23}$ Plumas Libres, octubre de 2015. Recuperado de http://www.plumaslibres.com.mx/2015/10/23pese-a-que-ya-espueblo-magico-alcalde-de-zozocolco-destruye-calzada-historica/ 
generado formas distintas de valorar la cultura, la etnicidad y la naturaleza, sino también de asignarles diferentes usos (sociales y mercantiles) y otorgarles nuevos significados. Es aquí donde surge la estrategia metodológica de "dar valor y poner en valor" mediante la conversión del lugar -Zozocolco de Hidalgo como joya de Veracruz y pueblo mágico- a través de condiciones macrosociales: la aparición de nuevos negocios, como restaurantes y hoteles, orientados a la prestación de servicios turísticos, aunado al impulso que los funcionarios del gobierno local han buscado mediante las declaratorias ya mencionadas; y microsociales: las opiniones vertidas por los entrevistados con relación a la turistificación de la cabecera municipal, de la festividad patronal, las ceras, las danzas y los globos de papel de china, sirven como ejemplo para tratar de demostrar que en la selección de determinados elementos que distinguen a las comunidades totonacas existe una correspondencia perfecta entre la patrimonialización y la mercantilización de lo auténtico, dado que la primera está subordinada a la segunda. Ambas son complementarias de una economía terciaria, una economía turística.

De ahí que la patrimonialización sea la base sobre la cual descansan diversas formas de mercantilización de lo auténtico (Frigolé, 2014); en este caso, de aquellos elementos vinculados con la etnicidad expresada por los totonacos a través de su identidad, su cultura material e inmaterial y el entorno natural que rodea a Zozocolco de Hidalgo.

El papel protagónico otorgado a la descripción etnográfica ha permitido mostrar la diversidad de opiniones de los actores involucrados (la perspectiva emic) en los procesos que inciden en la conversión significativa de Zozocolco de Hidalgo (la estructura territorial del turismo) como destino turístico y su articulación con el contexto turístico nacional por la vía de la patrimonialización y la turistificación, lo cual ha sido una forma de comprender las dinámicas locales inmersas en los procesos globales. En un momento en el que la coyuntura económica y política de México y del mundo parece profundizar los procesos de despojo y apropiación de los recursos de los territorios donde se asientan las comunidades indígenas-campesinas a través de proyectos mineros, eólicos, hidroeléctricos y turísticos, es importante dar cuenta de las estrategias con las cuales estas comunidades enfrentan los cambios y se adaptan a las nuevas dinámicas generadas por el capitalismo global, que busca mercantilizar todo aquello que esté a su alcance.

\section{Fuentes CONSUltadas}

Almirón, A. (2004). Turismo y espacio. Aportes para otra geografía del turismo. GEOUSP-Espaco e Tempo, 16, 167-180.

Almirón, A., Troncoso, C. y Lois, C. (2007). Promoción turística y cartografía. La Argentina turística en los mapas de la Secretaría de Turismo de la Nación (1996-2004). Investigaciones Geográficas, Boletín del Instituto de Geografía, UNAM, 62, 138-154.

Boissevain, J. (coord.). (2011). Lidiar con turistas. Reacciones europeas al turismo de masas. Barcelona: Ediciones Bellaterra. 
Brenner, L. y Aguilar, A. (2002). La planeación de centros turísticos sustentables. ¿Estrategia prometedora para impulsar el desarrollo rural o ilusión sin perspectivas? El ejemplo de Bahías de Huatulco, Oaxaca. En E. Barragán (comp.), Gente del campo. Patrimonios y dinámicas rurales en México (pp. 397-430). Zamora: El Colegio de Michoacán.

Castellanos, A. (2008). Turismo, identidades y exclusión. Una mirada desde Oaxaca. En A. Castellanos y J. A. Machuca (comps.), Turismo, identidades y exclusión (pp. 143181). México: Universidad Autónoma Metropolitana-Iztapalapa/Juan Pablos.

Centro Promotor de Diseño, Universidad Nacional Autónoma de México-Instituto de Geografía y Secretaría de Economía. (2002). Diagnóstico para identificar el potencial natural, socioeconómico y cultural para el establecimiento de circuitos de Turismo Alternativo. México. Recuperado de http://www.contactopyme.gob.mx/cpyme/ estudios/docs/B-turismo_Indice.doc

Comaroff, J. y Comaroff, J. (2011). Etnicidad S. A. Madrid: Katz Editores.

Davallon, J. (2014). A propos des régimes de patrimonialisation: enjeux et questions. Recuperado de https://halshs.archives-ouvertes.fr/halshs-01123906/document

Frigolé, J. (2014). Retóricas de la autenticidad en el capitalismo avanzado. ÉNDOXA: Serie Filosóficas, 33, 37-60.

Geertz, C. (1987). Descripción densa: hacia una teoría interpretativa de la cultura. En La interpretación de las culturas (pp. 19-40). Barcelona: Gedisa.

Greenwood, D. (1989). La cultura al peso: perspectiva antropológica del turismo en tanto proceso de mercantilización cultural. En V. Smith (comp.), Anfitriones e invitados. Antropología del turismo (pp. 257-279). Madrid: Endymion.

Hernández, J. J. (2009). Tequila: centro mágico, pueblo tradicional. ¿Patrimonialización o privatización? Andamios, 6(12), 41-67.

Hiernaux, D. (1989). El espacio reticular del turismo en México. Geografía y Desarrollo, 2(3), 31-39.

Instituto Nacional de Estadística y Geografía. (2010). Censo de Población y Vivienda 2010. México: Autor.

Jiménez de Madariaga, C. (2005). Patrimonio etnológico e instrumentalización política. En X. C. Sierra y X. Pereiro (coords.), Patrimonio cultural: politizaciones y mercantilizaciones, X Congreso de Antropología (pp. 25-36). Sevilla: Fundación El Monte/ Asociación Andaluza de Antropología/Federación de Asociaciones de Antropología del Estado Español.

Kirshenblatt-Gimblett, B. (2001). La cultura de les destinacions: teoritizar el patimoni. $R e-$ vista d'Etnologia de Catalunya, 19, 44-61.

Lanfant, M. F. (1994). Identité, mémoire, patrimoine et touristification. Sociology, 7(4), $397-$ 412.

Machuca, J. A. (2008). Estrategias turísticas y segregación socioterritorial en regiones indígenas. En A. Castellanos y J. A. Machuca (comps.), Turismo, identidades y exclusión (pp. 51-96). México: Universidad Autónoma Metropolitana-Iztapalapa/Juan Pablos.

Martínez, A. y Figueroa, R. (coords.). (2015). Pueblos mágicos: la política mexicana de turismo cultural, conjunción de iniciativas para el desarrollo y fortalecimiento de la identidad nacional. México: Universidad Autónoma Metropolitana-Lerma.

Morales, M. (2008). ¿Etnoturismo o turismo indígena? Teoría y Praxis, 5, 123-136. 
Nogués, A. (2007). Quizás una cuestión de topología social: Moebius, la interculturalidad y los residentes europeos en Alicante. Revista Valenciana d'Etnologia, 2, 33-58.

Oehmichen, C. (coord.). (2013). Enfoques antropológicos sobre el turismo contemporáneo. México: Universidad Nacional Autónoma de México-Instituto de Investigaciones Antropológicas.

Organización Mundial del Turismo. (2016). Programa de estadísticas y cuentas satélite de turismo. Madrid: Autor.

Ortiz, M. E. (2013). Pueblos mágicos: análisis de la dinámica cultural y económica. En M. Reyes y J. Linares (coords.), Economía y cultura (pp. 341-368). México: Universidad Autónoma de la Ciudad de México-Facultad de Economía/Universidad Nacional Autónoma de México.

Ortiz, T. (2009). Bordando paradigmas para el desarrollo. Metodología para abordar el turismo rural desde el sujeto social (Docencia y Metodología). México: Universidad Autónoma Metropolitana/Universidad Latina.

Propin, E. y Sánchez, A. (2002). Estructura regional del turismo en México. Ería, 59, 386394.

Rosas Mantecón, A. (2006). Turismo cultural en México: ¿Un modelo alternativo? Caderno CRH, 19(48), 499-506.

Sassen, S. (2010). Formatos espaciales y dinámicas subyacentes. En F. Muñoz, Urbanalización. Paisajes comunes, lugares globales (pp. 7-9). Barcelona: Gustavo Gilli.

Secretaría de Turismo. (2011). Acuerdo Nacional por el Turismo. México: Autor.

Secretaría de Turismo. (2016). El turismo cultural en México representa una derrama económica por más de 184 mmdp del mercado nacional [Boletín de prensa]. México: Autor.

Sistema de Información Municipal. (2011). Cuadernillos municipales. Zozocolco de Hidalgo. Veracruz: Gobierno del Estado de Veracruz-Secretaría de Finanzas y Planeación.

Vázquez, V. y Aguilar, M. (2011). Organización territorial del turismo alternativo en la zona media del estado de San Luis Potosí, México: retos y perspectivas. Revista Geográfica de América Central, 2(47), 1-15.

Velázquez, M. A. (2013). Turismo y los símbolos de la identidad mexicana. El caso de pueblos mágicos. En. E. Méndez y M. A. Velázquez (coords.), Turismo e imaginarios (pp. 53-78). México: El Colegio de Sonora.

Williams, R. (1993). Diversos nombres de la deidad Tajín. La Palabra y el Hombre, 87, 5-12. Zorrilla, A. (2010). El tiempo y el espacio del turismo cultural (Intersecciones). México: Consejo Nacional para la Cultura y las Artes/Instituto Mexiquense de Cultura. 


\title{
¿Peregrinación, turismo o turismo religioso? \\ La reinterpretación del Santuario del Señor del Cerrito, Estado de MÉxico
}

\author{
Víctor Manuel Mora Torres \\ Universidad Autónoma del Estado de México \\ victor.mora.torres@gmail.com
}

El presente artículo tiene como objetivo analizar la dinámica social del turismo religioso con respecto a las diferentes interpretaciones que se tienen de la visita al Santuario del Señor del Cerrito, ubicado al norte del Estado de México. El estudio es de corte cualitativo basado en el método etnográfico. Para recabar la información de campo se utilizaron el diario de campo y las entrevistas semiestructuradas a los visitantes. De manera general, se reconocen dos interpretaciones en torno al santuario: como un espacio sagrado y como un espacio recreativo. Se concluye señalando la relación del turismo religioso con la reinterpretación de los espacios sagrados en espacios recreativos.

Palabras clave: Señor del Cerrito, turismo religioso, peregrinación, santuario, interpretación.

\section{Pilgrimage, Tourism or Religious Tourism? Reinterpretation of Sanctuary of the Lord of the Hill, State of Mexico}

The aim of this article is to analyze the social dynamics of religious tourism with regard to different interpretations of the visit to the Sanctuary of the Lord of the Hill, located in the north of the State of Mexico. The study is qualitative, based on the ethnographic method; the field notes and semi-structured interviews to the visitors were used to collect field information. In general, two interpretations are recognized around the sanctuary: as a sacred space and as a recreational space. It concludes by pointing out the relationship of religious tourism with the reinterpretation of sacred spaces within recreational spaces.

Keywords: Lord of the Hill, religious tourism, pilgrimage, sanctuary, interpretation.

Fecha de recepción: 6 de octubre de 2017. Fecha de aceptación: 27 de noviembre de 2017

CÓMO CITAR: Mora, V. M. (2018). ¿Peregrinación, turismo o turismo religioso? La reinterpretación del Santuario del Señor del Cerrito, Estado de México. Dimensiones Turísticas, 2(2), 103-122. https://doi.org/10.47557/QDMV6468 
U na de las formas de movilidad humana más antiguas que perdura hasta nuestros días es la peregrinación. Dentro de las prácticas más comunes en casi todas las religiones se encuentra la visita a espacios considerados como más sagrados o saludables que el entorno de la vida cotidiana (Margry, 2008). Como todo viaje, la peregrinación puede variar en magnitud y distancia, yendo desde desplazamientos cortos hacia las afueras del lugar de residencia hasta viajes de varios días hacia el extranjero. Debido a su naturaleza, la peregrinación es frecuentemente relacionada con el turismo, puesto que ambos implican una salida del lugar de residencia hacia un entorno cualitativamente diferente. Si bien algunos autores consideran a las peregrinaciones como el antecedente directo del turismo (Esteve, 2002; Collins-Kreiner y Gatrell, 2006), el surgimiento del turismo en su forma convencional casi siempre ha sido asociado con la industrialización y las nuevas condiciones laborales que prevalecen desde el siglo xIx (Osorio, 2010).

El origen del turismo y la peregrinación brinda una perspectiva diferente para su comparación en contraste con las similitudes visibles entre estas formas de viaje. Desde la perspectiva de las motivaciones y significados del viaje, el turismo y la peregrinación se contraponen, puesto que ambos se encuentran ligados a conceptos diferentes que orientan la visita: lo sagrado (para la peregrinación) y lo recreativo (para el turismo). En la literatura turística sobre el tema, el peregrino es visualizado como un individuo que se desplaza para estar en contacto con algún tipo de orden sobrenatural, mientras que el turista suele buscar el placer y la relajación (Smith, 1992) en un ámbito diferente al entorno cotidiano.

La relación del turismo con la peregrinación ha sido estudiada en la investigación turística, tal y como lo dejan ver las revisiones llevadas a cabo por Olsen y Timothy (2006), Sharpley (2009) y Tobón y Tobón (2013). Esta relación está generalmente representada por el concepto de turismo religioso, siendo un término más general que engloba manifestaciones tanto del turismo como de la peregrinación. Los trabajos sobre el tema se han concentrado tanto en reflexiones teóricas sobre el significado del turismo y la peregrinación, como en el análisis de patrones de viaje en lugares específicos donde convergen estos dos tipos de movilidades. Lo anterior debido a que "los lugares sagrados se han transformado en puntos de encuentro de visitantes, movidos por la peregrinación, la búsqueda de experiencias religiosas, apreciación del lugar como espacio en sí y su significado cultural; así como por la curiosidad hacia lo sagrado" (Cànoves, 2006, p.68).

En el contexto mexicano, existe un gran número de santuarios que se destacan por la variedad de manifestaciones religiosas que albergan, las cuales constituyen un rico patrimonio cultural que atrae la atención de diferentes visitantes. Gran parte de ellos se interesan en conocer dichos destinos al margen del culto y la adoración, les interesa sobre todo ponerse en contacto con realidades diferentes a las que viven en su entorno cotidiano y que resultan novedosas. Esto es recurrente sobre todo en santuarios donde el catolicismo tradicional se mezcla con los cultos prehispánicos, dando lugar a tradiciones con valor cultural significativo. Muchos de estos sitios pasan desapercibidos en los estudios sobre turismo religioso, debido a que no presentan una gran afluencia de visitantes, si se comparan con otros santuarios como la Basílica de Guadalupe (Carmona, 2012) o la catedral de 
San Juan de los Lagos (Puebla, 2011). Sin embargo, representan un escenario fértil para el análisis de las convergencias entre el turismo y la peregrinación en un mismo sitio.

En tal sentido el presente artículo tiene como objetivo analizar la dinámica social del turismo religioso con respecto a las diferentes interpretaciones que se tiene de la visita hacia los santuarios. En este caso se estudia el Santuario del Señor del Cerrito, ubicado en Jiquipilco, al norte del Estado de México. Este es un lugar de gran valor histórico y cultural ubicado en la cima de una montaña, al que acuden desde tiempos coloniales peregrinaciones de las etnias mazahua y otomí (De la Cruz, 2010). También, a lo largo de todo el año pero principalmente durante sus festividades, el santuario es visitado por un sinnúmero de individuos que no arriban en peregrinación. De esta manera, poco a poco al Santuario del Señor del Cerrito se le ha reconocido como un espacio receptor de personas cuyas motivaciones van más allá de las religiosas tradicionales; razón por la que se le considera un objeto de estudio relevante para el análisis del turismo religioso en lugares considerados como sagrados en primera instancia. El artículo se organiza en cuatro apartados. En el primero se da cuenta de las principales investigaciones que tiene como objeto de estudio la relación entre turismo y peregrinación como una forma de expresión del turismo religioso. En el segundo, se presenta el referente teórico, retomando la noción de centro y las interpretaciones que este puede tener con respecto al turismo y a la peregrinación, asimismo se refieren las consideraciones metodológicas. En el tercero, se detallan los principales hallazgos del trabajo de campo con respecto a las diferentes actividades que se realizan durante la visita hacia el Santuario del Señor del Cerrito. En el cuarto apartado se presenta el análisis de las interpretaciones del santuario en el contexto del turismo religioso con base en los hallazgos del trabajo de campo. Asimismo, se incluyen algunas conclusiones sobre el redimensionamiento del concepto de turismo religioso y la reinterpretación de los espacios sagrados en espacios recreativos.

\section{Breve acercamiento al turismo Religioso}

Puesto que hasta antes de la década de los 70s del siglo pasado predominaba una escasa relación y tratamiento comparativo entre el turismo y la peregrinación en la producción científica internacional, se considera esta fecha como el inicio del abordaje de ambas formas de movilidad de manera conjunta, especialmente en la literatura turística (CoIlins-Kreiner, 2010). Ciertamente tanto el turismo como la peregrinación habían sido estudiadas anteriormente desde diferentes disciplinas, por lo que poseen una vasta tradición científica que explica sus supuestos principales tanto en la investigación en idioma inglés como en español. No obstante, para el caso de esta investigación, interesa conocer las aportaciones científicas que se han hecho sobre estos dos tipos de desplazamiento en conjunto, lo que permite analizar al turismo religioso como una intersección de ambos.

Las propuestas teóricas enmarcadas en la sociología y la antropología, las cuales en su mayoría retoman el carácter sagrado y recreativo de la peregrinación y el turismo respectivamente para establecer convergencias entre ellos, fueron los primeros abordajes 
conjuntos del turismo y la peregrinación. Destacan las propuestas de MacCannell (1973), Graburn (1977) y Cohen (1979). De acuerdo con MacCannell (1973) la conexión entre los viajes turísticos y las peregrinaciones religiosas no solo se refiere a similitudes de organización, puesto que el motivo detrás de una peregrinación es similar al de un viaje turístico: ambos son búsquedas de experiencias auténticas. Los turistas se encuentran en una constante búsqueda de autenticidad, siendo esta una versión moderna del interés universal por lo sagrado. Así el turista se convierte en un peregrino moderno que busca autenticidad en otros "tiempos" y "lugares" fuera de la vida cotidiana.

En una analogía similar, Graburn (1977) afirma que las vacaciones son el equivalente moderno para las sociedades seculares de las festividades anuales para las sociedades religiosas tradicionales. En su propuesta, se contrasta el estado de trabajo ordinario/obligatorio vivido "en casa" y el estado sagrado no-ordinario/voluntario "fuera de casa". El periodo profano es la vida cotidiana, lo ordinario e inevitable; mientras que el tiempo de vacaciones y el turismo es donde la vida es más "real” que la vida real, una vida que vale la pena vivir. Por otro lado, Cohen (1979) propone una tipología fenomenológica que explica las diferentes experiencias turísticas con base en el lugar y significado del turismo en la vida del hombre moderno. Las cinco experiencias que propone son la recreativa, la de distracción, la experiencial, la experimental y la existencial, las cuales representan una serie de combinaciones que van del turismo (recreativa) a la peregrinación (existencial).

Ya que las aportaciones teóricas de esta primera etapa han servido de base para la realización de estudios empíricos posteriores, actualmente continúan considerándose como pilares fundamentales de la llamada "sociología del turismo", dada su generalidad y capacidad explicativa. La década de los 90s aportó nuevos acercamientos hacia el vínculo turismo-peregrinación, en cuanto a la investigación en turismo se refiere. En 1992, se publicó el volumen 19 del Annals of Tourism Research, dedicado en parte al estudio de esta temática. Los trabajos de Smith (1992), Rinschede (1992), Nolan y Nolan (1992), Cohen (1992) y Eade (1992) destacan por sus aportes teóricos. Smith (1992) propone un continuo en el que sitúa a la peregrinación en un extremo y al turismo en el otro, atribuyendo un carácter sagrado a la primera y secular al segundo. "Entre las extremidades subyacen diversas combinaciones entre lo sagrado y lo secular, con un área central comúnmente denominada turismo religioso. Dicha posición refleja las múltiples y cambiantes motivaciones del viajero, cuyos intereses y actividades pueden moverse del turista al peregrino y viceversa" (Smith, 1992, p. 4).

Una tipología de turismo y usos turísticos de los sitios de peregrinación, enfocándose en las características y patrones de viaje de los turistas motivados religiosamente, es la principal aportación de Rinschede (1992). Desde esta lógica existen básicamente dos formas de turismo religioso: "el de corto plazo, que se caracteriza por excursiones a centros de peregrinación o conferencias religiosas cercanas; y el de largo plazo, refiriéndose a visitas de varios días o semanas a sitios de peregrinación o conferencias religiosas nacionales e internacionales" (Rinschede, 1992, p. 51). Por otra parte, el estudio de Nolan y Nolan (1992) se interesa por los sitios religiosos desde una perspectiva turística, estableciendo 
tres tipos de santuarios, acorde al potencial que tienen para atraer visitantes distintos a los peregrinos tradicionales. El primero de ellos se refiere a los santuarios con un fuerte énfasis en la devoción religiosa, pero con pocas características para atraer turistas seculares; el segundo abarca los santuarios que funcionan como centros de devoción y atractivos turísticos, debido a una combinación de características históricas, artísticas y escénicas; mientras que el tercero comprende aquellos lugares donde los festivales religiosos son la principal atracción.

En la década de los 90s se inicia con el estudio de casos específicos para abordar el vínculo turismo-peregrinación. Como ejemplo se tienen el análisis de Cohen (1992) sobre cuatro tipos de templos budistas en Tailandia retomando los postulados teóricos de Turner y Turner (1978). El estudio señala que el peregrino tiende a convertirse en un "peregrino turista" cuando el templo se encuentra más alejado de su hogar, lo que contraviene la idea sobre el aumento del carácter religioso al visitar un templo excéntrico al entorno cotidiano. Asimismo, Eade (1992) aborda el caso de Lourdes, Francia, observando que los peregrinos participan en actividades típicamente turísticas, se visten como turistas, hacen compras similares, y no pueden ser diferenciados de sus contrapartes turísticas en la manera en cómo se relajan de noche. Las propuestas de esta segunda etapa muestran un mayor vínculo entre la teoría y la realidad. Se deja ver que los esquemas y tipologías son aplicables solo en determinados casos puesto que es poco probable construir una teoría general que explique la relación del turismo y la peregrinación debido a lo multifacético del fenómeno.

En un tercer momento de la investigación sobre el tema, surgen estudios empíricos que destacan la existencia de dos grandes grupos de visitantes: los primeros con una motivación de viaje eminentemente religiosa y/o espiritual y los segundos cuyas diversas motivaciones son diferentes a la primera. Entre ellos se puede referir la escala de Collins Kreiner y Kliot (2000), que destaca la creciente convergencia de la peregrinación tradicional y el turismo en sitios sagrados de Tierra Santa; y el estudio de Sharpley y Sundaram (2005) sobre las motivaciones y experiencias de los turistas occidentales que visitan el Sri Aurobindo Ashram en India, identificando a los turistas permanentes y a los visitantes temporales como principales grupos de visitantes. Otros estudios de este tipo son el de Colllins-Kreiner y Gatrell (2006), sobre la experiencia de los visitantes que arriban a los Jardines Bahá'i en Haifa, Israel; y el de Williams, Francis, Robbins y Annis (2006), sobre la experiencia de los visitantes con respecto a la catedral de Gales.

Posteriormente se aprecia una diversificación en la investigación sobre turismo religioso mediante el abordaje de la relación entre turismo y peregrinación desde diferentes disciplinas. Las obras Tourism, Religion and Spiritual Journeys, editado por Timothy y Olsen (2006) y Religious Tourism and Pilgrimage Management: An International Perspective, de Raj y Morphet (2007) son prueba de ello. En la primera, se da cuenta de los principales paradigmas, conceptos y prácticas existentes relacionados a la peregrinación y otras formas de viajes religiosos, desde perspectivas como la naturaleza, creación y gestión de lugares sagrados; la dicotomía turista-peregrino, la economía del turismo religioso y las implicaciones educativas del turismo religioso. En la segunda, se abordan puntos clave en 
estudios de caso contemporáneos sobre la peregrinación religiosa relacionada con destinos turísticos y nuevas formas de peregrinación; sus bases teóricas provienen del turismo, los eventos, la economía, la sociología, la psicología y la teoría cultural, así como diferentes tradiciones culturales y filosóficas de Oriente y Occidente.

Los estudios en español sobre turismo religioso se desarrollan principalmente en España y México a partir del nuevo milenio. Las investigaciones incorporan elementos conceptuales de la economía y la administración para explicar realidades del turismo religioso o proponer el desarrollo de productos turísticos. Se resalta la visión de lugares sagrados como recursos susceptibles de aprovechamiento para la generación de ingresos. Este tipo de investigaciones puede incluir aquellas que muestran los beneficios económicos de las peregrinaciones y el turismo para las comunidades que albergan a los santuarios, como la de Puebla (2011), sobre San Juan de los Lagos, México; estudios que analizan la satisfacción de los visitantes, como el de Millán, Morales y Pérez (2010) con respecto a las rutas del Camino de Santiago; o bien aquellos que enfatizan el potencial turístico del patrimonio religioso, como el de Cànoves y Blanco (2011).De igual manera, la investigación en idioma español se ha caracterizado por la realización de trabajos mayoritariamente empíricos, dejando en segundo término la generación de marcos teóricos y conceptuales para el turismo religioso. Los artículos de Cànoves (2006), Maak (2009) y Hruleva, Blanco y Cànoves (2013), que "abordan el aprovechamiento de diferentes sitios y rutas religiosas en Europa como parte de proyectos de desarrollo turístico que generen beneficios económicos a las comunidades" (Mora, Serrano y Osorio, 2017, p. 94) que habitan estos sitios, son ejemplo de ello. Cebrián y García (2014) presentan el "diseño de una ruta de santuarios al sureste de España aplicando los criterios de centralidad y significado de las visitas religiosas" (Mora, Serrano y Osorio, 2017, p. 96), mientras que Lorenzo y Ramón (2011) estudian "la fiesta en honor al Santísimo Misterio de los Corporales, en Lluxent, España para una posterior puesta en valor de su ruta” (Mora, Serrano y Osorio, 2017, p. 96). En México, Fernández (2012) revisa la actual relación entre Iglesia, Estado y sociedad con respecto al santuario de la Virgen de Talpa. Jalisco.

Tal y como lo deja ver este breve acercamiento, el estudio del turismo religioso, entendido como el análisis de las convergencias entre el turismo y la peregrinación, ha evolucionado desde propuestas generales y teóricas hasta el abordaje de casos específicos y el diseño de productos turísticos en los que se involucran rutas y santuarios. Se han incorporado elementos de diversas disciplinas al análisis de realidades tan variadas como las mismas manifestaciones religiosas. No obstante, existe aún una carencia de conocimiento con respecto a cómo se presenta la relación del turismo con la peregrinación en lugares inicialmente considerados como santuarios, pero que actualmente muestran indicios de actividad turística. Al respecto en el siguiente apartado se realiza una reflexión sobre cómo algunos postulados teóricos del turismo religioso permiten la comprensión de dicha relación. 


\section{Turismo religioso ¿entre el turismo y La PeRegrinación?}

Dentro de los aspectos abordados en la investigación sobre turismo y peregrinación se encuentran las coincidencias y diferencias entre el peregrino y el turista. Dichos tipos de viajeros son diferentes con respecto a las motivaciones de su desplazamiento: a los primeros los mueven profundas convicciones religiosas y espirituales, mientras que los segundos viajan por placer, educación, curiosidad, altruismo o la relajación (Olsen y Timothy, 2006). Las características asociadas a estos tipos de viajeros también son diferentes El peregrino tiende a ser pío, humilde y sensible con la cultura receptora, en contraste con el turista, quién parece ser hedonista y cada vez más exigente en términos de servicios, necesidades y deseos en el destino (de Sousa, 1993; Gupta, 1999). Esta visión de turista y peregrino tiene sus bases en los significados tradicionales asociados al turismo y a la peregrinación como formas de viaje.

De acuerdo con Margry (2008), la peregrinación es un complejo de comportamientos y rituales en el dominio de lo sagrado y lo trascendente, en el que la religión y las personas religiosas se muestran en una forma poderosa y colectiva. La finalidad del viaje es la búsqueda de un encuentro trascendental con un objeto de culto específico, con el propósito de adquirir beneficios espirituales, emocionales o de curación física. Asimismo, la peregrinación puede ser "una experiencia social de movimiento y transición en la que los individuos voluntariamente abandonan las estructuras y patrones de la vida social normal y emprenden un viaje extraordinario por un paisaje sacro" (Turner y Turner en Shadow y Rodríguez, 1994, p. 28). Turner y Turner (1978), indican que en la peregrinación se percibe una sensación liberadora de comunalidad, universalismo y fraternidad entre quienes viajan, cuyas relaciones son igualitarias, no diferenciadas, directas, no racionales y existenciales.

El turismo, en cambio, es una consecuencia de las civilizaciones industriales, "un fenómeno social derivado de otro fenómeno social: el tiempo libre institucionalizado" (Boullón, 1983: 89). En la ruptura del tiempo de trabajo para dar paso al tiempo libre es donde gran parte de la investigación sobre turismo ubica este fenómeno, asumiendo que se aprovecha dicho periodo de tiempo para viajar. No obstante, para que un viaje se considere como turístico debe cumplir con otras características. Para Osorio (2005), el viaje turístico, además de realizarse fuera del tiempo de trabajo (en el llamado tiempo libre), debe llevarse a cabo fuera del entorno cotidiano y tener al ocio como principal motivador. El ocio turístico, entendido como lo realizado durante el tiempo libre, conlleva una serie de actividades elegidas libremente que implican un escape de la cotidianidad (Lanquar, 1985; Azevedo y Gomes, 2013). Este, junto con la recreación, son los motivos principales por los que los individuos emprenden un viaje turístico.

Sin embargo, ya que en la actualidad muchos santuarios no son lugares exclusivos de culto sino también espacios de visita, resulta complicado separar las motivaciones de los visitantes, donde se mezclan los auténticos peregrinos, que visitan el lugar movidos por la fe; los turistas, que aprovechan la visita para acercarse al lugar religioso; y los turistas que visitan el lugar con una motivación patrimonial y cultural, al margen del hecho religioso (Cànoves y Blanco, 2011). Puesto que "las dicotomías rígidas entre la peregrinación y el 
turismo o los peregrinos y los turistas ya no parecen defendibles por mucho tiempo" (Badone y Roseman, 2004:2), algunos investigadores destacan la necesidad de conciliar la otrora polaridad del turismo con la peregrinación mediante fundamentos teóricos que expliquen su coexistencia en sitios religiosos (Badone y Roseman, 2004, Collins-Kreiner, 2010).

Al respecto, el concepto de turismo religioso propuesto por Smith (1992) resulta útil para cumplir con dicho propósito. De acuerdo con la autora, el turismo religioso es una posición que refleja las motivaciones múltiples y cambiantes del viajero, cuyos intereses y actividades se mueven de las del turista al peregrino y viceversa, incluso sin ser conscientes del cambio. Es decir, el turismo religioso pasa a ser un espacio teórico de coexistencia entre el turismo y la peregrinación, en lugar de una más de las modalidades turísticas asociada con el consumo de productos culturales-religiosos. El turismo religioso ocupa un espacio único en el imaginario de los viajes religiosos y seculares, lo algunos investigadores denominan como "tercer espacio". Al percibir a los lugares religiosos como un "tercer espacio", los investigadores tienen la posibilidad de deconstruir las prácticas sociales de los turistas en los sitios religiosos, evitando las nociones simplificadas de "viajero religioso" o "vacacionista" como peregrino y turista respectivamente. Este enfoque revisado para el turismo religioso, basado en parte en el concepto de "tercer espacio" reconoce, tanto implícita como explícitamente el carácter interdependiente de los dos actores y la construcción social de un sitio que es a la vez sagrado y secular (Collins-Kreiner y Gatrell, 2006).

Para explicar las diferentes interpretaciones que se puede dar al espacio, en este artículo se retoma la propuesta de Cohen (1979), la cual forma parte de la formulación de su tipología sobre la experiencia turística. De acuerdo con el autor, el elemento principal que permite dicha interpretación es la dirección del viaje. El lugar y el significado del turismo en la vida del hombre moderno se derivan de su visión total del mundo y dependen especialmente de la cuestión de si se adhiere o no a un "centro", y de la localización de este "centro" en relación con la sociedad en la que vive. El centro representa el nexo carismático de una sociedad con sus valores morales supremos y fundamentales, y que no es necesariamente central geográficamente en la vida de una comunidad.

Generalmente las religiones tienen centros sagrados que las personas desean visitar, ya que para el hombre religioso el espacio no es uniforme. Los diferentes lugares pueden considerarse como espacios sagrados o espacios no sagrados (Eliade, 1998). El espacio sagrado puede considerarse como un lugar donde se manifiesta una realidad que no pertenece a este mundo en objetos que forman parte del mundo natural o profano, siendo este estado la "realidad por excelencia" (Eliade, 1998). Los objetos que poseen el carácter sagrado dentro de la realidad son consideradas como superiores en deidad y poder con respecto a las cosas profanas, un medio ideal y trascendente que se opone al mundo material (Durkheim, 2000). En muchas sociedades, la necesidad de estar en contacto con el centro origina ciertos desplazamientos hacia el espacio sagrado.

Puesto que el centro no necesariamente se ubica dentro del espacio de residencia de los creyentes, su localización externa orienta a la peregrinación como un viaje sagrado de ascensión espiritual (Turner, 1973). En el caso de la peregrinación tradicional, el centro 
está localizado dentro del "mundo" del peregrino, pero más allá de las fronteras de su espacio de vida inmediato; esta contingencia se afirma sobre una separación entre el espacio de vida limitado y su "mundo": la imagen de este último es más extensa y abarca un gran número de espacios de las comunidades individuales o de las sociedades. La peregrinación es esencialmente un movimiento de la periferia profana hacia el centro religioso o “cosmos" religioso (Cohen, 1979). Lo profano, refiriéndose al entorno cotidiano que se percibe como ajeno al santuario, es considerado un lugar que desgasta al ser humano y a la sociedad.

En cambio, desde una perspectiva turística, se asume que el centro del hombre moderno se localiza dentro de los confines de su sociedad, es decir, él se "alineará" con los valores fundamentales del lugar donde reside. Dicha conformidad puede generar tensiones e insatisfacciones que el individuo aliviará a través del turismo, el cual es una forma de entrada temporal a un centro, pero en relación con la biografía individual, su plan de vida y aspiraciones, permanece en un significado periférico. El turismo solo es funcional mientras no se convierta en algo central dentro del plan de vida y aspiraciones del individuo, en tanto regule sus tensiones e insatisfacciones, refrescándolo y restaurándolo, sin destruir su motivación para desempeñar las tareas de la vida cotidiana. El turismo masivo moderno es asumido sobre un desarrollo diferente al de la peregrinación: el abandono gradual de la imagen sagrada y tradicional del cosmos, y el despertar del interés por la cultura, vida social y entorno natural de otros (Cohen, 1979).

Las peregrinaciones y el turismo moderno, se asumen en concepciones sociales diferentes del espacio y visiones contrarias referentes al tipo de destinos que vale la pena visitar y de su localización en el espacio socialmente construido; de ahí que implican movimientos en direcciones opuestas: en la peregrinación de la periferia (que en este caso sería el lugar de residencia del peregrino) hacia el centro de su cultura (el santuario a visitar), y en el turismo moderno, del centro cultural (su lugar de residencia, el ámbito de la vida cotidiana) hacia la periferia (en este caso, el destino religioso). Sin embargo, ante la presencia simultánea de actividades comúnmente asociadas al turismo y a la peregrinación en diferentes santuarios, se hace necesario conocer cuál es la interpretación que les individuos asignan al espacio visitado, lo que explicaría el sentido de dichas actividades y la coexistencia del turismo con la peregrinación en un mismo sitio.

En el presente artículo se abordan las interpretaciones que, desde la perspectiva de la visita, se generan entorno al Santuario del Señor del Cerrito, lugar ubicado en una comunidad rural perteneciente al Estado de México. El análisis se centra en la peregrinación que parte de San Pedro Cholula, en Ocoyacac, Estado de México, hacia el santuario para asistir a la Fiesta del Señor del Cerrito, realizada el 3 de mayo de cada año. En consonancia con el enfoque interpretativo del referente teórico, el estudio es de corte cualitativo, y se apoya en el método etnográfico. Para obtener la información de campo necesaria, el investigador participó en la peregrinación en su edición 2014. Se llevó a cabo observación directa y participante, la información obtenida se registró en un diario de campo. Asimismo, se aplicaron 20 entrevistas semi-estructuradas a personas que participaron en el viaje. 
Posteriormente se procedió a realizar un análisis de contenido de la información obtenida, de manera que pudieran reconocerse tendencias generales sobre las interpretaciones en torno al espacio visitado con base en el referente teórico. A continuación se exponen los principales hallazgos del trabajo de campo.

\section{La visita al Santuario del Señor del Cerrito}

El Cerrito de Tepexpan es una elevación de 3009 metros, localizado en la comunidad de Santa Cruz Tepexpan, perteneciente al municipio de Jiquipilco, al norte del Estado de México. En la cima, se ubica un santuario de estilo barroco en su interior y neoclásico en su exterior, el santuario resguarda la imagen de un cristo conocido como el Señor del Cerrito. Se refiere que "el Santuario del Cerro de Tepexpan es el segundo más visitado en la región del Valle de Toluca, después del Santuario del Señor de Chalma (Hernández, 2013:1)”, debido a las peregrinaciones mayoritariamente indígenas, que tradicionalmente acuden a las diferentes celebraciones. Principalmente dos grupos indígenas son los que visitan desde antaño el Cerrito de Tepexpan: los mazahuas y los otomíes. Estos grupos han habitado, desde tiempos ancestrales, el territorio de diversos municipios que forman parte del actual Estado de México (Barrientos, 2004a). De ahí que el Cerrito de Tepexpan sea un punto geográfico sobresaliente que los mazahuas y otomíes han significado a partir de sus prácticas ceremoniales (Barrientos, 2004b).

Las principales festividades en ocasión de las cuales se llevan a cabo peregrinaciones hacia el santuario son la del 3 de mayo, en honor al Señor del Cerrito, y la del 15 de octubre, en honor a Santa Teresa de Jesús (De la Cruz, 2010). El viaje puede durar desde dos hasta siete días dependiendo del lugar de origen de las peregrinaciones. Algunos municipios de donde provienen las peregrinaciones son Almoloya de Juárez, Temascalcingo, Almoloya del Río, Ixtlahuaca, Ocoyoacac, Huixquilucan, Lerma y Santiago Tianguistenco, ubicados en el Estado de México (Hernández, 2013). Quienes participan en las peregrinaciones juegan un papel clave en la realización de las festividades, ya que la mayoría de quienes participan en la celebración son personas ajenas a Santa Cruz Tepexpan.

La organización de cada peregrinación está a cargo de la mayordomía. Esta podría definirse como un grupo de personas originarias de una misma localidad, a quienes se les encomienda la planeación y correcto desarrollo de la peregrinación durante la ida, la estancia en el santuario y el regreso. Los mayordomos son los organizadores y coordinadores de la peregrinación, destacan por su buena reputación ante la comunidad de feligreses católicos, siendo llamados por el resto de los viajeros y por los otros mayordomos como "compadritos" y "comadritas". La mayordomía de la peregrinación de San Pedro se renueva cada tres años, siendo el santuario del Señor del Cerrito el lugar donde los nuevos mayordomos adquieren el compromiso organizar y coordinar la peregrinación. Entre las labores de los mayordomos se encuentran: conseguir el transporte de apoyo durante el recorrido, gestionar los lugares de hospedaje, invitar con anticipación a los miembros de la 
comunidad católica a participar en la peregrinación, cuidar a los miembros de la peregrinación mientras van caminando, coordinar el tráfico cuando la peregrinación viaja por carretera, en los lugares de pernocta deben vigilar que haya orden durante la noche, y durante el viaje proveer de alimentos y bebidas a todos los participantes del viaje.

Existen seis objetos sagrados que son fundamentales en la peregrinación. Los más importantes son las réplicas en miniatura de San Pedro y la del Señor del Cerrito. Los otros cuatro objetos sagrados son: una alcancía, que es un recipiente donde se guarda la limosna o dinero aportado por los creyentes; una charola o bandeja que se utiliza para servir comida y/o bebidas; una campana y un petate, tapete pequeño elaborado con palma. Los objetos pueden ser cargados por personas de la comunidad. En el camino rumbo al santuario, los visitantes realizan algunas paradas, las cuales implican periodos de tiempo dedicados al descanso y la convivencia. Los lugares donde la peregrinación realiza las paradas han sido definidos desde tiempo atrás y no hay descansos en zonas diferentes a las tradicionales. Los puntos específicos en donde se hacen las paradas, particularmente cuando la peregrinación camina por campo abierto, se identifican por una pequeña construcción de color blanco y una cruz a lado.

La última parada antes de llegar al santuario es de suma importancia, pues en este lugar se lleva a cabo el cambio de mayordomía. Los mayordomos salientes hacen entrega a los nuevos mayordomos de los objetos sagrados de la peregrinación. A las 7 de la mañana del 3 de mayo, se lleva a cabo la ceremonia religiosa de bienvenida a las peregrinaciones en la iglesia del Cerrito, donde los mayordomos entrantes se oficializan en el cargo, haciendo un juramento para cumplir a cabalidad la misión que se les ha encomendado.

A lo largo del trayecto los viajeros cuentan historias y creencias relacionadas con los santos, se dice, por ejemplo, que el Señor del Cerrito ayuda a algunos miembros de la comunidad a recuperar la salud. En caso de que los visitantes se comporten inapropiadamente en el Cerrito son castigados. Al respecto hay un relato acerca de una pareja de peregrinos que tuvo un acto pasional cerca del santuario, por lo que fueron convertidos en una roca, imagen que representa a "Los Compadres". Durante el viaje, se da muestra de fe al tratar de no quejarse por el esfuerzo físico que hace, se cree que las personas que se quejan se cansan más rápido, pueden caer o encontrarse con animales peligrosos en el camino. Quienes visitan el santuario por primera vez deben entrar de rodillas hasta el altar, y de no seguir la costumbre pueden sufrir "mal de montaña" (náuseas y dolor de cabeza).

Al llegar al pie del Cerrito, las personas inician el ascenso para alcanzar la cima, que es donde se encuentra el santuario y la imagen del Señor del Cerrito. Esta parte es visualizada como la más retadora de todo el trayecto al ser un camino inclinado en razón de la elevación del terreno. Al ascender al santuario, las personas tienen por costumbre hacerse “limpias" para aliviar el cansancio, esto es, se frotan todo el cuerpo con ramas de plantas o árboles y una pequeña piedra, sobre todo en las partes donde sienten mayor molestia física. Esta actividad se lleva a cabo frente a las cruces o árboles que son muy significativos y se encuentran a lo largo del camino. No todos los que visitan el santuario participan en las "limpias", algunas personas solo se detienen para observar el paisaje o apreciar 
los rituales. Otras prefieren apresurar el paso para llegar antes que aquellas que caminan lentamente.

Alcanzada la cima, los viajeros ingresan al santuario para estar en presencia del Cristo. Como muestra de sacrificio y agradecimiento, algunos de ellos apoyados en sus rodillas recorren el espacio que va desde la entrada hasta el altar. Durante el 3 de mayo se celebran ceremonias religiosas en honor al Cristo. En el interior del santuario destacan las ofrendas al Señor del Cerrito, entre las principales se encuentran veladoras, listones, ramas de árbol, semillas y prendas de vestir. Una vez fuera del templo, los visitantes buscan un lugar donde comer. Una vez elegida el área, se reúnen para hacer una fogata y calentar sus alimentos, también pueden pedir de favor que les permitan calentarlos en las cocinas que hay para tal fin. Otra opción es comprar sus alimentos y bebidas en los puestos establecidos en la explanada; la oferta aproximada es de 25 locales y puestos.

El tiempo de comida es también un tiempo de convivencia. El consumo de bebidas alcohólicas, principalmente entre jóvenes y adultos jóvenes, está estrechamente relacionado con la recreación y el disfrute de la ocasión. Para recordar la experiencia, algunas personas compran determinados objetos, estos pueden estar ligados al aspecto religioso, como los rosarios, cuadros o imágenes de santos, crucifijos, entre otros; o ser artesanías como los juguetes de madera, bordados y cestería. Gran parte de los visitantes compra fotografías que dan evidencia de los diferentes momentos de su experiencia de viaje.

Las danzas que se presentan en la explanada frente a la iglesia atraen la atención de gran parte de los asistentes, quienes se congregan alrededor de los danzantes para apreciar y tomar fotografías. En el caso de la peregrinación de San Pedro Cholula, la danza tradicional del pueblo (Danza de los Arrieros) acude al santuario el día de la fiesta del 3 de mayo como parte de los rituales en honor al santo. La indumentaria y pasos son elementos visuales muy atractivos que es posible que no puedan observarse en otras fiestas religiosas. De igual manera, quienes visitan el santuario en ocasión de la festividad se muestran atraídos por el paisaje natural que rodea al templo, especialmente por la vista desde la cima del valle de Ixtlahuaca. Las caminatas por los senderos cercanos al santuario para conocer la capilla de Santa Teresa o el manantial que se encuentra en la cima son recurrentes.

Las actividades mencionadas muestran una naturaleza bivalente del santuario, no solo como un lugar de manifestaciones religiosas sino también como un espacio donde se llevan a cabo actividades más cercanas al turismo. Es a partir de las peregrinaciones tradicionales que parece surgir el turismo, y con ello, una reinterpretación del santuario a partir de la visita. A continuación se describen las principales interpretaciones que se entretejen entorno al Santuario del Señor del Cerrito.

\section{Interpretaciones del Santuario del Señor del Cerrito a partir de la visita}

Si se considera que a partir de las peregrinaciones tradicionales surge la actividad turística en el Santuario del Señor del Cerrito, es posible reconocer diversas interpretaciones del santuario a partir de los significados preponderantes que pueden asignar los mismos 
visitantes a sus actividades durante la visita. En este sentido, se aprecia la coexistencia de dos formas principales de interpretar el santuario: el viaje como búsqueda de lo sagrado y el viaje como búsqueda de recreación.

\subsection{El santuario como espacio sagrado}

Esta interpretación es predominante entre los visitantes asiduos y de mayor edad, asociados a la noción de peregrino tradicional. Estos individuos participan en la peregrinación hacia el santuario con motivo de la fiesta del Señor del Cerrito desde hace varios años. Suelen estar familiarizados con las actividades de la región de donde proceden y con las tradiciones de la religión católica propias de la comunidad. A partir de esta interpretación, el Santuario del Señor del Cerrito no es un lugar más de adoración a Cristo, sino que representa el "centro del mundo", un espacio que alberga una deidad de suma importancia para mantener las condiciones de la vida cotidiana de manera propicia. El cerro, en cuya cima se ubica el santuario, no es más un accidente geográfico, puesto que forma parte de la deidad en sí, siendo una prolongación tangible del poder divino: por eta razón el Cristo es denominado Señor del Cerrito y en algunos cánticos es denominado "Señor de la Montaña". El paisaje del cerro es impregnado con el carácter mágico/milagroso atribuido al Cristo.

Durante el ascenso al santuario, los peregrinos enfatizan el significado del cerro como una extensión del Señor del Cerrito. Lo acontecido en ese espacio sagrado es observado por él, por lo que las conductas inapropiadas son castigadas. Asimismo reconocen que determinados elementos del paisaje poseen un significado especial, en la medida en que les recuerdan el poder y omnipresencia del Cristo en el territorio del cerro; la roca de "Los Compadres" es quizá el ejemplo más representativo. Al ascender por el camino, los peregrinos asumen una actitud de respeto y reverencia, ya que esto significa la penitencia inherente al contacto con lo sagrado, por tanto no se debe renegar a pesar de la fatiga o de cualquier otra dificultad que se les presente a lo largo del camino pedregoso. La naturaleza misma puede obrar en contra de quien contraviene al ser sagrado, ya que de acuerdo con la creencia, a quienes lo hacen les puede aparecer serpientes o sufrir accidentes. El "mal de montaña" se le considera una desgracia que padece el peregrino, cuya conducta ha sido inapropiada, relacionando al castigo con el espacio donde se encuentra el santuario.

Paradójicamente, el carácter milagroso del cerro también está presente en ciertos elementos del paisaje que son benéficos o protegen a quienes terminan el recorrido hasta el santuario, sin quejarse. Cuando el individuo se frota con hojas y piedras del camino para aliviar su molestar, entra en contacto con la divinidad, quien lo renueva con su poder para que pueda continuar ascendiendo hasta llegar a la cima. Las "limpias" se llevan a cabo en puntos clave del ascenso (parajes, cruces y árboles, entre otros) a los que los peregrinos les asignan un significado especial desde hace muchos años; estos puntos no se han cambiado y continúan respetándose como paradas oficiales, en donde se realizan los rituales propios de la peregrinación. Dentro de las peticiones que los peregrinos dirigen al Señor del Cerrito se encuentran aquellas relacionadas con la lluvia y el logro de las cosechas, ofrecen a la deidad elementos del paisaje natural, como ramas de árbol, semillas y el 
esfuerzo de todos aquellos que suben a visitarlo. El paralelismo entre la cruz, como símbolo de Cristo y del Señor del Cerrito, con los árboles y los parajes, apoya la interpretación del santuario como un espacio sagrado, en el que la deidad y el lugar visitado se fusionan en un entorno mágico que orienta la vida caótica de la cotidianidad.

Es de destacar que el cambio de mayordomía en las inmediaciones del Cerrito se significa en este sentido. La mayordomía es un grupo de personas que, de alguna manera, da continuidad al viaje de peregrinación. Dada su connotación religiosa, es necesario que el cambio sea "oficializado" ante la divinidad representada por el entorno. Para tal fin, previo a la llegada al santuario, se hace una pausa en un paraje del cerro, ahí cada mayordomo saliente entrega, a sus contrapartes entrantes, uno de los objetos sagrados. Al entregarse las imágenes de San Pedro y el Señor del Cerrito (santo patrono de la comunidad y santo que se visita, respectivamente), se reafirma de manera simbólica el vínculo entre el espacio sagrado y la vida cotidiana. Es evidente que la mayordomía solo adquiere el estatus correspondiente para llevar a cabo sus labores en el entorno visitado, no se puede llevar a cabo un nombramiento de este tipo en el lugar de residencia, considerado como profano.

Para quien que visita el santuario interpretándolo como un lugar sagrado, es decir, como el centro que orienta su vida cotidiana, la vista del valle de Ixtlahuaca que aprecia desde la cima del cerro es muestra de la magnificencia y bondad de la divinidad. Es posible apreciar desde la cima varias de las comunidades de donde provienen los peregrinos, lo que reafirma la percepción del Cerrito como centro del mundo. Esta noción de centro del mundo define la trascendencia de la visita al santuario para poder continuar el resto del año en el entorno de la vida cotidiana: se espera que este periodo corto fuera de casa pueda tener efectos positivos en el lugar de residencia que aseguren la salud y el sustento.

\subsection{El santuario como espacio recreativo}

Esta interpretación del espacio es común entre los participantes más jóvenes de la peregrinación e incluso en personas que acuden a la festividad pero no viajan en peregrinación. Quienes asumen esta interpretación suelen interesarse en el viaje por comentarios o invitaciones hechos por personas que anteriormente han visitado el lugar. Dado que estos individuos consideran al entorno de su vida cotidiana como el centro que orientan sus actividades, no prevalece en ellos la visión del santuario como "centro del mundo". El interés por la visita surge a partir de las diferencias que muestra el espacio donde se sitúa el santuario con respecto al de su vida cotidiana. El acudir al santuario implica el contacto con los centros y formas de vida de otras personas, lo cual permite la restauración y/o renovación del individuo para reincorporarse a la realidad constrictiva del entorno cotidiano. Las personas que asumen esta interpretación del santuario suelen estar familiarizadas con los entornos urbanos en su lugar de residencia.

Esta idea cobra sentido a la luz de algunos hallazgos del trabajo de campo, los cuales pueden ser interpretados desde esta lógica. Por ejemplo, la mayordomía, además de ser un grupo de carácter religioso que perpetúa la tradición de la peregrinación, es también 
la organizadora de los aspectos operativos del viaje, principalmente del transporte y el hospedaje. La previsión de estas cuestiones es necesaria puesto que se está entrando en contacto con un entorno "desconocido", en donde hay que asegurar los lugares de descanso, los medios en los que se viajará y las rutas que se seguirán para evitar contratiempos y la insatisfacción del viaje. Se pretende evitar cualquier situación que genere conflicto con respecto al desplazamiento y estancia en el santuario, ya que desde esta interpretación la finalidad de la visita es aliviar las tensiones cotidianas.

Las pausas que se hacen a lo largo de la ruta no solo tienen una finalidad ritual, sino que también propician momentos de convivencia que favorecen el surgimiento o fortalecimiento de las relaciones sociales entre peregrinos. Las conversaciones entre viajeros giran en torno a diferentes situaciones de la vida cotidiana, contribuyendo al desahogo de las tensiones. Dado que este tiempo es diferente al que se experimenta en el lugar de residencia (pues no están sujetos a la dinámica habitual), están en posibilidad de conocer mejor "al otro" con quien viajan. La apreciación del paisaje natural alrededor de las paradas, les permite valorar la tranquilidad de un espacio diferente al cotidiano. Asimismo, se presta atención a las leyendas y creencias relacionadas con el Cristo, las cuales no son asumidas como ciertas o necesarias para el correcto desarrollo del viaje, sino como elementos culturales de interés. Resulta de interés el conocer diversas formas de pensar y concebir el mundo gracias a la tradición oral, pues esto permite la renovación y distracción inherente a la visita.

En este sentido es que estas personas contemplan, e incluso participan, de la festividad y de la peregrinación. Pero sus acciones son interpretadas como manifestaciones culturales externas a ellos, pues desconocen (o no comparten) el significado sagrado que entrañan para los peregrinos más tradicionales. Así, las "limpias”, ofrendas y danzas no representan una forma de comunicación con lo sagrado, sino que despiertan la curiosidad de los visitantes, quienes en su mayoría observan y fotografían lo que para ellos es extraño y novedoso, y en algunos casos se interesan por participar. Esto mismo sucede con la arquitectura del santuario o la vista que se tiene del valle desde la cima del cerro, puesto que se asocia más con elementos que les recuerde su visita al Cerrito, en el sentido de que posiblemente no los puedan encontrar en sus viajes a otros sitios semejantes. Se puede decir que la visita en general tiene un carácter exótico, incluso con respecto a los alimentos y bebidas que se consumen durante el viaje. El degustar ciertos platillos y bebidas propios del contexto contribuye a enriquecer la experiencia cultural de los visitantes.

Puesto que la peregrinación representa una entrada temporal hacia otra realidad, las personas que asumen esta interpretación se relajan y realizan actividades que en su entorno cotidiano no llevarían a cabo de la misma manera. Esto explica por qué durante el viaje y estancia en el santuario es común el consumo de bebidas alcohólicas. Esto forma parte del matiz recreativo del viaje, pese a que en un inicio el desplazamiento era de carácter meramente religioso. Igualmente, al tratarse de una entrada temporal a otra realidad, se busca llevar al entorno cotidiano algún(os) objeto(s) que permitan recordar, en el futuro, la visita al santuario. Algunos de ellos son los recuerdos religiosos, artesanías y fotografías. 
El surgimiento de la actividad comercial durante los días de fiesta responde a los requerimientos de los "nuevos peregrinos", quienes muestran una faceta que se acerca cada vez más al turismo.

Se expresa como positiva la experiencia adquirida al acudir al Santuario del Señor del Cerrito en días de fiesta, en una valoración general sobre la visita. En esta interpretación el visitante puede separar con claridad la visita al Cristo, que le puede representar la parte religiosa del viaje, sin dejar de disfrutar del recorrido por el cerro y de otras actividades con fines recreativos. Por lo que se deduce que la peregrinación y el Santuario del Señor del Cerrito en conjunto con los paisajes del campo, arquitectura religiosa, danzas coloridas, artesanías y alimentos y bebidas tradicionales, hacen de este lugar un espacio recreativo que contribuye por una parte a aliviar las presiones de la vida cotidiana, favoreciendo la reincorporación y alineación del visitante a su entorno una vez que finaliza el viaje, y por otra parte impulsa el desarrollo de actividades comerciales y de servicios propios del turismo.

\section{Conclusiones}

El análisis de la relación entre turismo y peregrinación como un acercamiento entre estas dos formas de viaje no es solo una tendencia en la investigación turística, más bien responde a una realidad presente en muchos espacios considerados como religiosos en un primer momento. Desde hace varios años, se ha presenciado la irrupción del turismo en esferas de la sociedad que habían permanecido aisladas de este fenómeno, como en el caso de las peregrinaciones tradicionales hacia los lugares de culto. Esta ruptura de esferas en otro tiempo claramente definidas da lugar a dinámicas sociales, las cuales no son uniformes sino que tienen peculiaridades con respecto al contexto donde se desarrollan.

En este trabajo se ha pretendido mostrar como el reconocimiento de las diferentes interpretaciones asignadas al espacio permiten comprender la dinámica del turismo religioso en el contexto específico del Santuario del Señor del Cerrito. Si se entiende al turismo religioso como un punto de encuentro entre el turismo y la peregrinación, que se manifiesta en la experiencia de viaje de las personas, entonces es posible comprender como la peregrinación tradicional ha dado lugar al surgimiento del turismo, visible no solo en la oferta de servicios en el santuario sino más bien en la actitud recreativa que asume una parte de los visitantes, ya sea que viajen en peregrinación o no. Así, el santuario ha sido resignificado de acuerdo con una interpretación turística. Asimismo, se aprecia un estrecho vínculo entre el espacio visitado y el de lugar de residencia en ambas interpretaciones pues, a diferencia de otros tipos de viajes, en ambos casos se espera obtener beneficios visibles en la cotidianidad una vez concluida la visita. De ahí que estas formas de concebir al santuario pertenezcan a una sola forma de viajar: el turismo religioso.

En ambas interpretaciones del santuario se reconoce la necesidad de renovar o volver a crear ciertas condiciones en el lugar de residencia mediante la visita, por lo que podría considerarse a la "re-creación", el renovarse, como el elemento unificador y significado primordial que orienta al turismo religioso. En el caso de la interpretación del santuario como 
espacio sagrado, se pretende asegurar principalmente la salud y el sustento mediante la intervención de la divinidad, ya que estas cuestiones escapan a las capacidades humanas. En la interpretación del santuario como espacio recreativo se busca la renovación anímica al entrar en contacto con una realidad que es novedosa e interesante en relación con su lugar de residencia. Es así que la "re-creación", el "volver a crearse", es el fin último de la visita en el turismo religioso, y por tanto el significado primordial que orienta las actividades en el santuario.

El reconocer la existencia de por lo menos dos interpretaciones principales que se entretejen en torno al santuario en el marco del turismo religioso, brinda información importante sobre la dinámica social de esta modalidad, lo cual puede permitir mejorar su gestión en un futuro. Se destaca que para que el santuario pueda seguir considerándose un espacio recreativo es necesario que al mismo tiempo sea interpretado (por otras personas) como un espacio sagrado. El atractivo turístico del espacio que circunda al Santuario del Señor del Cerrito es su carácter mágico, apreciado como cualitativamente diferente a las realidades de donde provienen algunos visitantes. En el futuro se deben de tomar acciones encaminadas a la preservación de ambas interpretaciones, delimitando los espacios donde se lleven a cabo determinadas actividades, fomentando la participación y/o apreciación respetuosa de los rituales y dando a conocer el significado sagrado de lo que observan quienes no asumen una interpretación religiosa. El turismo religioso es una modalidad que permite el enriquecimiento personal en dos vías: por una parte se enriquece el conocimiento de la persona a través de la puesta en contacto con otras formas de vida diferentes a las que le son familiares, y por el otro, se favorece la preservación del patrimonio cultural religioso a través de incentivos económicos derivados de la actividad turística.

Para concluir, se reafirma que el turismo no es un concepto más general que englobe a la peregrinación, así como la incompatibilidad del turismo en su forma convencional con lo que aquí se entiende por turismo religioso. Desde la perspectiva de reinterpretación de los santuarios, el turismo religioso no es una nueva tendencia de los viajes turísticos que se centran en el patrimonio religioso (de hecho es cuestionable su novedad), sino que más bien representa la evolución de la peregrinación como fenómeno social, y por consiguiente, de algunos santuarios. Aquí se propone entender al turismo religioso como un concepto más abarcador, en el que es posible ubicar las diferentes reinterpretaciones de la peregrinación que han surgido (y que continuarán surgiendo) a partir de la intersección de los significados religiosos y recreativos. En ese sentido, la investigación en diferentes lugares debe continuar con la finalidad de mejorar la comprensión sobre la evolución de los santuarios hacia destinos de turismo religioso gracias a la reinterpretación que los visitantes hacen de los mismos. 


\section{REFERENCIAS}

Azevedo, J. y Gomes, C. (2013). El ocio y el turismo en los artículos publicados en revistas académicas de turismo. Estudios y Perspectivas en Turismo, 22 (5), pp. 875-892.

Badone, E. y Roseman, S. (eds.) (2004). Intersecting Journeys. The Anthropology of Pilgrimage and Tourism. Illionois, Estados Unidos: University of Illionois Press.

Barrientos, G. (2004a). El Cerrito Tepexpan: sustentador de vida. Un santuario indígena en el Valle de Ixtlahuaca. En J. Broda y C. Good (eds.), Historia y vida ceremonial en las comunidades mesoamericanas: los ritos agrícolas (pp. 351-372). Ciudad de México, México: Ediciones de la Universidad Nacional Autónoma de México.

Barrientos, G. (2004b). Otomíes. Pueblos indígenas del México Contemporáneo. Ciudad de México, México: Comisión Nacional para el Desarrollo de los Pueblos Indígenas.

Boullón, R. (1983). Las actividades turísticas y recreacionales: el hombre como protagonista. Ciudad de México, México: Trillas.

Cànoves, G. (2006). Turismo religioso en Montserrat: Montaña de fe, montaña de turismo. Cuadernos de Turismo, 18, pp. 63-76.

Cànoves, G. y Blanco, A. (2011). Turismo religioso en España: ¿La gallina de los huevos de oro? Una vieja tradición, versus un turismo emergente. Cuadernos de Turismo, (27) pp. 115-131.

Carmona, C. (2012). Fiesta del 12 de diciembre como principal detonador del turismo religioso en la Basilica de Guadalupe (Tesis de Licenciatura en Turismo). Universidad Autónoma del Estado de México. México, Toluca, Estado de México, México.

Cebrián, A. y García, R. (2014). Del turismo religioso a las peregrinaciones permanentes: Diversificación turística en el sureste español. CULTUR, (2), pp. 3-30.

Cohen, E. (1979). A phenomenology of tourism experience. Sociology, (132) , pp. 179-201.

Cohen, E. (1992). Pilgrimage centres: Concentric and excentric. Annals of Tourism Research, 19 (1), pp. 33-50.

Collins-Kreiner, N. (2010). Researching pilgrimage: Continuity and Transformations. Annals of Tourism Research, 37 (2), pp. 440-456.

Collins-Kreiner, N. y J.D. Gatrell, (2006). Tourism, heritage and pilgrimage: The case of Haifa's Baha'i gardens. Journal of Heritage Tourism, 1(1), pp. 32-50.

Collins-Kreiner, N. y N. Kliot, (2000). Pilgrimage tourism in the holy land: The behavioral characteristics of Christian pilgrims. GeoJournal, 501 (2,) pp. 55-67.

De la Cruz Clemente, P.S. (2010).Rituales agrícolas y de petición de Iluvia entre los otopanes en el Santuario del Señor del Cerrito, Estado de México (Tesis de Licenciatura en Historia). Universidad Autónoma del Estado de México, Toluca, Estado de México, México.

De Sousa, D. (1993). Tourism and pilgrimage: Tourist as Pilgrims? Contours, 6 (2), pp.4-8.

Durkheim, E. (2000). Las formas elementales de la vida religiosa. Ciudad de México, México: Colofón.

Eade, J. (1992). Pilgrimage and tourism at Lourdes, France. Annals of Tourism Research, 19 (1), pp. 18-32.

Eliade, M. (1998). Lo sagrado y lo profano. Barcelona, España: Paidós.

Esteve, R. (2002). Turismo y religión. Aproximación a la historia del turismo religioso. Málaga, España: Universidad de Málaga. 
Fernández, A.M. (2012). La Virgen de Talpa: religiosidad, turismo y sociedad. Política y Cultura, (38), pp. 29-48.

Graburn, N. (1977). Tourism: the sacred journey. En V. Smith (ed.), Hosts and guests: The anthropology of tourism (pp. 17-31). Filadelfia, Estados Unidos: University of Pennsylvania Press.

Gupta, V. (1999). Sustainable tourism: learning from Indian religious tradition. International Journey of Contemporary Hospitality Management, (2/3), pp.91-95.

Hernández González, M.I. (2013) La festividad del 3 de mayo en el Cerrito de Santa Cruz Tepexpan. Recuperado el 21 de marzo de 2014 de http://deas.inah.gob.mx/lafestividad-del-3-de-mayo-en-el-cerrito-de-santa-cruz-tepexpan/.

Hruleva, M., A. Blanco y G. Cànoves (2013). Monasterios en la ciudad de Sofía. Potencialidades del viaje de peregrinación y desarrollo turístico. Cuadernos de Turismo, (32), pp. 155-169.

Lanquar, R. (1985). Sociologie de tourisme et des voyages. París, Francia: Universitaires de France.

Lorenzo, L. y Ramón, F. (2011). La ruta de los sagrados corporales de Llutxent (Valencia) como una nueva expresión del turismo religioso en España. Estudios y Perspectivas en Turismo, 20 (4), pp. 960-971.

Maak, K. (2009). El Camino de Santiago como posible motor turístico en zonas rurales de escasos recursos: el caso de Brandeburgo. Cuadernos de Turismo, 23, pp. 149-171.

MacCanell, D. (1973). Staged authenticity: Arrangements of social space in tourist settings. American Journal of Sociology, (793), pp. 589-603.

Margry, P. J. (2008). Shrines and Pilgrimage in the Modern World. New Itineraries into the Sacred. Amsterdam, Países Bajos: Amsterdam University

Millán, M.G., E. Morales y L.M. Pérez (2010). Turismo religioso: estudio del Camino de Santiago. Gestión Turística, (13), pp. 9-37.

Mora, V. M., Serrano. R.C. y Osorio, M. (2017). El vínculo turismo-peregrinación. Un acercamiento desde la producción científica en inglés y en español. Estudios y Perspectivas en Turismo (1), pp. 86-106.

Nolan, M.L y S. Nolan (1992). Religious sites as tourism attractions in Europe. Annals of Tourism Research, 19 (1), pp. 68-78.

Olsen, D.H. y D.J Timothy (2006). Tourism and religious journeys. En D.J Timothy y D.H OIsen (eds.), Tourism, Religions and Spiritual Journeys (pp. 1-21). Nueva York, Estados Unidos: Routledge.

Osorio, M. (2005). El análisis del turismo desde la perspectiva de los sistemas funcionales. (Tesis de Doctorado en Ciencias Sociales). Universidad Iberoamericana. Ciudad de México, México.

Osorio, M. (2010). Turismo masivo y alternativo. Distinciones de la sociedad moderna/ posmoderna. Convergencia, 17 (52), pp. 235-259.

Puebla, J.J. (2011). Turismo religioso, el caso de San Juan de los Lagos. En R. Martínez (ed.), Turismo espiritual. Una alternativa de desarrollo para las poblaciones (pp. 63-76). Guadalajara, México: Universidad de Guadalajara,.

Raj, R. y N.D. Morphet (eds.) (2007). Religious Tourism and Pilgrimage Management: An International Perspective. Oxfordshire, Reino Unido: CABI. 
Rinschede, G. (1992). Forms of religious tourism. Annals of Tourism Research, 19 (1), pp. 51-67.

Shadow, R. y Rodríguez, M. (1994). La peregrinación religiosa en América Latina: enfoques y perspectivas. En C. Garma Navarro y R. Shadow (eds.) Las peregrinaciones religiosas: una aproximación (pp. 15-38). Ciudad de México, México: Universidad Autónoma Metropolitana.

Sharpley, R. (2009). Tourism, Religion and Spirituality. En T. Jamal y M. Robinson (eds.), The Sage Handbook of Tourism (pp. 237-253). Londres, Reino Unido: SAGE Publications.

Sharpley, R. y P. Sundaram (2005). Tourism: A sacred journey? The case of ashram tourism, India. International Journal of Tourism Research, 7, pp. 161-171.

Smith, V. (1992). Introduction: The quest in guest. Annals of Tourism Research, 19 (1), pp. 1-17.

Timothy, D.J. y D.H. Olsen (eds.) (2006). Tourism, Religion and Spiritual Journeys. Nueva York, Estados Unidos: Routledge.

Tobón, S.M. y N. Tobón (2013). Turismo religioso: fenómeno social y económico. Anuario Turismo y Sociedad, 14, pp. 237-249.

Turner, V. (1973). The center out there: Pilgrim's goal. History of Religions, (123), pp. 191230.

Turner, V. y Turner E. (1978). Image and Pilgrimage in Christian Culture: Anthropological Perspectives. Nueva York, Estados Unidos: Columbia University Press.

Williams, E., Francis, L., Robbins, M. y Annis, J. (2006). Visitor Experiences of St. David's Cathedral: The Two Worlds of Pilgrims and Secular Tourists. Documento presentado en The Tourism: The Spiritual Dimension Conference, Oxford, Reino Unido. 


\title{
Más de tres décadas de investigación turística en México: Algunas reflexiones
}

\author{
More than three decades of tourism research in Mexico: Some reflections
}

\author{
Daniel Hiernaux-Nicolas \\ Facultad de Ciencias Políticas y Sociales \\ Universidad Autónoma de Querétaro \\ danielhiernaux@gmail.com
}

$\mathrm{D}$ ice el tango que "veinte años no son nada"; pero también un sabio refrán recuerda que "no es lo mismo Los tres mosqueteros que veinte años después"; y cuando estamos hablando de 40 años, la situación se torna aún más escabrosa. Nuestra intención en este texto es hacer un poco de historia sobre la investigación turística en México, desde una perspectiva sui géneris: la propia. Ello implica carencias pero a la vez vivencias particulares, posiblemente también una cierta dificultad para tomar una posición de investigador "neutral" frente a lo vivido. A pesar de eso, se considera que la oportunidad de escribir este texto debía ser aprovechada para verter aquellos comentarios que derivan de esa experiencia personal.

Cabe aclarar que varios investigadores se han dedicado al rescate de la trayectoria histórica del turismo en México (particularmente Jiménez, 1993); estos trabajos son esenciales porque dan cuenta pormenorizada de la evolución del mismo, y dan luces sobre la investigación del turismo a partir de las fuentes que analizan en sus obras. En este sentido, ambas formas de atender la investigación turística pueden sumarse para ofrecer una visión más integral.

\section{Un poco de historia}

Todas las voces autorizadas coinciden en señalar que los inicios de la investigación turística en México fueron complicados. No es para menos: el modelo turístico que se propuso desde la esfera pública y el capital no fue concebido como un proyecto nacional sino como una oportunidad para insertar una nueva modernidad muy "americana” en el México aún bastante tradicional de los años cincuenta.

Fue esencialmente, como lo demostraron más adelante varios investigadores, una manera de expandir la esfera de acumulación, ofreciendo al capital nuevos campos de desarrollo (todos los servicios susceptibles de ser prestados al turista) y, a la vez, nuevos espacios para desarrollarse. Usamos "nuevos espacios" ya que, con sendas excepciones, se trató de impulsar el turismo en ámbitos territoriales nuevos, solo ocupados por escasa población local, con frecuencia incapaz de reaccionar frente a ese modelo innovador pero al mismo tiempo perverso para sus intereses. 
Desde la visión analítica de las ciencias sociales, era evidente que este modelo iba a generar conflictos, desposesión, nueva pobreza, aun si se pregonaba que iba a inducir riqueza nacional y local, por la generación de empleos, la captación de divisas y el desarrollo regional, trilogía de objetivos que constituyen, todavía en el discurso actual, la esencia de la maná turística.

Quien pretendía realizar investigación sobre el turismo en esos tiempos pretéritos se topaba con la escasez de materiales académicos: recordamos, con mucha admiración para quienes llevaron a cabo semejante esfuerzo en ese entonces, las obras de Eugenio MacDonald (1981), Octavio Moreno Toscano (1971), y algunos trabajos extremadamente críticos de Francisco Gomezjara (1974), quien no dudó en analizar, con una posición marxista radical (desde la tradición trostkista), la transformación de la Costa Grande de Guerrero, tanto por la intromisión de la Colgate-Palmolive en el ámbito agrícola (por la producción de palma de coco cuyo aceite era esencial para la elaboración de sus productos), como por los efectos drásticos que estaban provocando el crecimiento álgido de Acapulco.

Con excepción de este conjunto de trabajos, la producción académica nacional era exigua, toda vez que a las editoriales o bien no les interesaba el tema o preferían publicar materiales para mercado amplio, es decir, libros de texto esencialmente, dirigidos a las escuelas de turismo que empezaron a proliferar a la par del crecimiento de la actividad. Con la mención necesaria de que las mismas mostraban un perfil "utilitario", esto es, que estaban destinadas a formar a los empleados de nivel bajo y medio bajo que podían operar las empresas turísticas fueran nacionales o transnacionales. Desde su creación, por Decreto Presidencial en 1978, el Colegio Nacional de Educación Profesional Técnica (Conalep) se planteó formar mandos medios para el turismo, sin mucho éxito, porque los puestos correspondientes no se reclutaban en ese modelo educativo.

Vale la pena evidenciar una "anomalía" sustancial en lo antes subrayado: la editorial Trillas, gracias a la iniciativa y a la inclinación por el tema de un editor de nacionalidad salvadoreña refugiado en México, dio espacio a la publicación de varios libros del mayor interés: obras de Roberto Boullón, Miguel Ángel Acerenza, Manuel Rodríguez Woog, Sergio Molina y Fabio Cárdenas, entre otros (véanse las fuentes consultadas al final), quienes pueden considerarse como los primeros investigadores profesionales con un tinte académico muy fuerte y dedicados intensamente a la investigación turística.

A la par, como si fueran materiales subversivos que esconder de las autoridades, se podía acceder eventualmente a las obras de Valene Smith (1992) y Dean MacCannell (1976) desde Estados Unidos, así como de Julio Aramberri (1983), Mario Gaviria (1974) y Rafael Esteve Secall (1983) desde España. La circulación de las obras francófonas resultó más compleja por el idioma no tan difundido como el inglés en esa época. La mayoría de estos textos se podía tener solo en fotocopias por la falta de circulación de obras internacionales en México, situación que duró hasta bien avanzada la década de los ochenta. 


\section{El contexto universitario y los inicios difíciles de la investigación en turismo}

Para un sano desarrollo de la investigación académica, un contexto universitario positivo es una variable clave. Sin embargo, me he referido hasta ahora al periodo de fines de los setenta e inicios de los ochenta, cuando el estructuralo-marxismo de cuño althusseriano tenía un peso inaudito en América Latina, y me atrevería a afirmar particularmente en nuestro país, en gran medida por la fuerte presencia de las editoriales mexicanas, entre ellas Siglo XXI, formada después de la renuncia forzada de Arnaldo Orfila Reynal de la dirección del Fondo de Cultura Económica por haber tenido la "osadía” de publicar la obra de Oscar Lewis que evidenciaba las fallas del modelo mexicano y la pobreza de buena parte de la población.

Un libro como Los conceptos fundamentales del materialismo histórico, de la chilena Marta Harnecker, publicado por primera vez por Siglo XXI en 1968, tuvo un destacado éxito entre los jóvenes. El turismo no se consideraba como un tema de importancia; antes bien, se puede aseverar que era un tema prohibido, porque la investigación marxista debía orientarse -según los dogmas vigentes entonces- a analizar la producción más que la reproducción de la fuerza de trabajo, así como el proletariado (y apenas el sub o lumpen proletariado) y obvio que no o casi nunca las clases medias y menos los capitalistas. Una excepción notable: Francisco Gomezjara tuvo la audacia de introducirse al tema, ya que le interesaban definitivamente los procesos que afectaban al estado de Guerrero y su capital económica, Acapulco, y no podía eludir la presencia del turismo (véase Gomezjara, 1974); sin embargo, fue un caso muy específico y no cundió mucho su ejemplo.

En semejante contexto y desde las ciencias sociales, estudiar el turismo era como colocarse fuera de la norma, marginarse de la corriente o las corrientes dominantes y, en buena medida, marginarse personalmente. Pocos se atrevieron, aun si algunos investigadores mostraron incidentalmente interés en la cuestión del ocio, turismo y tiempo libre, como Juan Manuel Ramírez Saiz o María Teresa Rodríguez, ambos adscritos a la Universidad Autónoma Metropolitana en su campus de Xochimilco. Vale destacar la obra de Ana García sobre Cancún, pionera de los estudios geográficos sobre el turismo, y crítica del megadesarrollo que estudió (García, 1979); sin embargo, esta dedicación al terreno de nuestro interés no sobrevivió a la llamada de otros temas, por lo que sus publicaciones al respecto fueron escasas.

Del otro lado del muro, para llamarlo de alguna manera, en las escuelas de turismo más consolidadas de universidades públicas, como en la actual Facultad de Turismo de la Universidad Autónoma del Estado de México o en el Instituto Politécnico Nacional, se empezó a sentir la necesidad de abrir líneas de investigación sobre turismo. Empero, la tarea no fue fácil, ya que los programas de estudio no eran muy adecuados para formar investigadores, por lo que fue esencialmente cuando se abrieron posgrados especializados o por iniciativas individuales que empezó a florecer la investigación.

En las universidades privadas la situación fue aún más difícil, toda vez que su principal actividad era la formación de jóvenes de clases acomodadas para tomar el mando de empresas turísticas. No obstante, en 1986-1987 en la Universidad Anáhuac, quizás la más

elitista en ese momento, se dio una iniciativa del rector para impulsar la investigación, 
circunstancia que se enfrentó a una férrea resistencia de los profesores, por lo que la propuesta abortó, en buena medida también por el fallecimiento de su promotor.

No se puede pasar por alto el papel que cumplió el Centro Internacional de Capacitación Turística de la Organización de los Estados Americanos (Cicatur), que preparó contingentes de jóvenes latinoamericanos con una visión menos rígida del turismo que la que propiciaban las instituciones mexicanas. ${ }^{1}$ Profesores como Fabio Cárdenas (colombiano), Roberto Boullón (argentino), Miguel Ángel Acerenza (uruguayo), entre otros, fueron pilares de la formación impartida y todos autores de libros que marcaron a centenares de estudiantes.

Entre quienes se formaron en este contexto privilegiado, mencionaré particularmente a Manuel Rodríguez Woog (1957-2015), y a Sergio Molina Espinosa (1953-2016), chileno instalado en México, quienes fueron las piezas clave de una incipiente investigación crítica del turismo. Vale aclarar que su formación como licenciados en Turismo provocó que, a diferencia de algunos cientistas sociales como Valene Smith, que provenía de la antropología y la geografía, ellos defendieran el turismo sin por eso dejar de cuestionar la manera en que este se desarrollaba en México y por doquier: la crítica central se fue orientando al modelo de turismo de masas que había sido enarbolado por las autoridades del país como “la vía mexicana al turismo" siguiendo entonces el modelo de desarrollo turístico español, todavía lejos de ser vapuleado, como se puede notar hoy en día. Ambos autores, y quienes configuraron con ellos el grupo Nuevo Tiempo Libre, no solo se ubicaron en una posición crítica de las realizaciones en materia de turismo en México, sino que a la vez emprendieron la compleja tarea de repensar el turismo como fenómeno social desde diversos enfoques. Tal perspectiva de conceptualización desde las ciencias sociales o desde la teoría de los sistemas, en boga en esa época, ha dejado profundas huellas en la investigación mexicana del turismo, aun en la actualidad.

También es pertinente señalar el rol del Instituto Mexicano de Investigaciones Turísticas (IмІт), que fue creado el 5 de diciembre de 1962 e inaugurado por el expresidente de la República licenciado Miguel Alemán Valdés, quien fungía entonces como presidente del Consejo Nacional de Turismo (en esa época no existía aún la Secretaría de Turismo). Se propuso para realizar "una investigación técnica integral del fenómeno turístico [...] puntos de apoyo para la planeación y programación de las actividades turísticas de un país” (IMIт, $\mathrm{s} / \mathrm{f}, \mathrm{s} / \mathrm{p}$ ), subrayando que el ıмıт es considerado como "una institución universitaria y técnica" (Iмıт, s/f, s/p). Su función fue "impulsar el desarrollo técnico de la industria turística en México" (ıміт, s/f, s/p), lo que sitúa su posición precisa frente a la investigación: ofrecer datos, estudios técnicos, asesorías, formación de recursos humanos y divulgación por medio de una investigación claramente aplicada. Si bien se trató de una institución dedicada a la investigación aplicada, no es menos cierto que fue la precuela de la organización de una reflexión sobre el turismo, que después tomará su propio despegue desde la academia.

1'El Cicatur nació el 8 de marzo de 1973 de un acuerdo entre el gobierno mexicano y la Organización de los Estados Americanos; se inauguró el 16 de mayo de 1974 bajo la dirección del arquitecto Roberto Boullón hasta 1979 cuando lo reemplazó Miguel Ángel Acerenza. 
Cabe apuntar que Manuel Rodríguez Woog y Eugenio MacDonald trabajaron en sus respectivas épocas en el ıмıт e iniciaron investigaciones aplicadas que marcaron no solo la actividad del sector público sino que apoyaron la consolidación de la investigación académica.

\section{El quiebre y la consolidación}

Se puede ubicar el quiebre de esta situación incipiente y el comienzo de una nueva "era" para la investigación turística hacia la mitad de los años ochenta. Tres eventos académicos abrieron la puerta a impulsar el interés hacia la investigación turística y otorgarle una visibilidad muy necesaria. El primero, organizado por quien escribe este trabajo, se celebró en la Universidad Autónoma Metropolitana, Unidad Xochimilco, en 1985, y dio voz al equipo de Nuevo Tiempo Libre y otros investigadores no asociados permanentemente a la investigación en turismo. Se tuvo la suerte de que las ponencias pudieran ser editadas por la misma universidad (Hiernaux, 1989).

Poco después, la Universidad Anáhuac coordinó otro evento de resonancia limitada pero significativo de que se sentía la necesidad de analizar el tema a detalle. Las memorias del encuentro muestran cierto avance en la discusión del modelo turístico, aunque todavía limitado. El Primer Seminario Internacional, realizado en 1987, organizado y celebrado en la Universidad de Guadalajara, evidenció no solo la solidez de la institución y de la formación que imparte en turismo, sino también el éxito de esa primera convocatoria de gran magnitud. Salvador Gómez Nieves fue una pieza clave de este suceso. Lo notable es que la convocatoria atrajo la atención tanto de los profesores dedicados a la enseñanza del turismo, como de profesionales en ejercicio e investigadores de ciencias sociales no orientados con permanencia al estudio del turismo, en breve, una reunión ecuménica de enorme éxito. Si bien muchas ponencias formaban parte de lo que podemos llamar la investigación aplicada descriptiva, no es menos cierto que el impacto de la reunión fue muy relevante, y se puede afirmar que fue fundamental para la consolidación de una corriente de análisis del tema en el ámbito universitario mexicano.

El fortalecimiento de la investigación en turismo en nuestro país se debe a varios factores. La reducción del peso del estructuralo-marxismo en las orientaciones académicas fue un detonador importante, y el efecto de la caída del muro de Berlín, ciertamente, pero además una mayor apertura internacional de la investigación y el conocimiento de nuevas experiencias y desde tiempo atrás, dieron impulso a una visión mucho menos limitada de los procesos de sociedad.

Lo que ocurrió en los estudios turísticos fue entonces también el reflejo de un mayor interés por el individuo, por las dimensiones subjetivas del ser humano, con la emergencia de temas nuevos, por ejemplo los imaginarios, y de los trabajos cualitativos. La fuerte presión de los estudios culturales llegó también al turismo, aun si se reconoce con Carlos Reynoso (2000) que no todo es valioso en ellos.

Otro factor quizás menos evidente a primera vista fue la diseminación de destinos turísticos como efecto de la demanda del capital de nuevos espacios de acumulación y 
por las mismas políticas públicas. Los megadesarrollos, como se llegaron a llamar durante el sexenio delamadrista (1982-1988); posteriormente la voluntad del Estado mexicano de tomar cierta distancia en su intervención en el impulso de los grande proyectos (Cancún, Ixtapa, Los Cabos, Loreto y Huatulco), y la promoción de localidades menores a través del Programa Pueblos Mágicos han propiciado el interés por los estudios turísticos en no pocos centros de investigación (en turismo u otras áreas) ubicados en provincia.

De esta consolidación dan fe varias dimensiones. En primer lugar, signo inequívoco de producción académica es la proliferación de artículos y libros sobre el tema, y no únicamente los libros de texto de administración de puestos y demás de corte administrativo, sino también obras que recogen los hallazgos de las investigaciones terminadas, así como libros colectivos que reflejan la formación de relaciones más estrechas entre investigadores del tema. Varios artículos recientes han mostrado lo anterior en México (Monterrubio, 2016; Osorio y Korstanje, 2017, entre otros).

A la vez, la realización de eventos y la edición de memorias en línea o impresas y libros con selección de textos abonaron a la misma valorización de los estudios turísticos. Dicho en términos de estudios de mercado: los estudios turísticos se han vuelto no solo un campo en consolidación (no se puede afirmar aún que está plenamente consolidado), sino además uno "competitivo" frente a otros campos de estudio y "rentable" para los investigadores que buscan también reconocimiento a su labor y los consabidos apoyos para la misma a través de financiamientos a la investigación y la inserción en el Sistema Nacional de Investigadores.

\section{Los retos actuales}

La consolidación de los estudios del turismo representa un gran avance pero no está exento de retos que refieren a dimensiones muy distintas entre sí. A continuación se propondrá una breve síntesis de lo que se vislumbran como los aspectos principales que ponen en riesgo los estudios turísticos en el futuro.

El primero, y no el menor, es el fuerte componente de estudios aplicados con escaso andamiaje teórico y métodos no muy actualizados que se pueden encontrar sobre todo en las memorias de los eventos: para muchos estudiosos del tema, desarrollar estudios aplicados no es nada negativo. Este no es un problema solo de los estudios turísticos: la geografía humana, por ejemplo, mantuvo un fuerte debate al respecto, con autores a favor de una geografía totalmente aplicada (al servicio del Estado y de las empresas), como refleja la conocida obra de Phliponneau (1966), y otros, como Pierre George, que defendían una geografía crítica y comprometida con la sociedad (George, 1966).

De hecho, el desarrollo tecnológico actual, con la profusa disponibilidad de información dentro de lo que se ha llamado Big Data, además de la disponibilidad de métodos cada vez más sofisticados y tecnificados de análisis, incita a no pocos investigadores a refugiarse en el uso de los datos cuantitativos y la apabullante capacidad existente de análisis con métodos especializados. Asimismo, con el fuerte amorío entre, por una parte, 
las instituciones de tutela (y fiscalización) de las instituciones de educación superior y de investigación, y por la otra, la corriente técnica-cuantitativa, es evidente que esta tendencia se mantendrá y, aún más, se consolidará, salvo que se dé un giro radical en las políticas nacionales de investigación.

Otro reto o amenaza es el mismo carácter glamoroso del turismo. ¿Cómo resistir a la tentación de estudiar el turismo si este ha logrado un prestigio creciente que se refleja en el interés que le han prestado destacados académicos como Marc Augé, Zygmunt Bauman, John Urry y otros? Esto es, en esencia, uno de los resultados más siniestros del llamado posmodernismo, el cual incuba generaciones completas de personas que toman el tema a la ligera y lo usan como pretexto de viaje y de una escritura light. Carlos Reynoso ya había llamada la atención sobre este problema en su Apogeo y decadencia de los estudios culturales, una visión antropológica, del que se recuperan de la cuarta de forros estas palabras que se adecúan a la perfección con ciertas tendencias perversas de los estudios turísticos, que comparten -vale precisarlo- con otras disciplinas. El texto habla de "inconsistencias flagrantes" cuando señala:

las contradicciones entre sus gestos antidisciplinarios y sus pretensiones interdisciplinarias, entre su actitud intransigente y su prolija codificación de su ortodoxia, entre la anunciada riqueza de sus recursos metodológicos y su notoria improductividad teórica, encubierta por el despliegue de una jerga complicada [Reynoso, 2000, cuarta de forros].

Para no ser tildado de exagerado, se precisa que es una tendencia que solo se empieza a notar en los estudios turísticos, pero que puede extenderse. Va entonces la reflexión anterior como llamada de atención.

Lo que se acaba de expresar debe además ser ubicado en su contexto: la carencia todavía sensible, aunque menor que en los ochenta, de un marco conceptual sobre el turismo o quizás la falta de voluntad para ceñirse a un marco particular -lo cual exige más esfuerzo- también ha dado como resultado que muchos investigadores que se insertan en el turismo como campo de investigación ignoran los avances considerables realizados para conceptualizar el turismo o prefieren ignorarlos para llegar directamente a su tema particular y limitado, lo cual puede engendrar puntos de partida erróneos.

Para ilustrar lo anterior se tomará solo un ejemplo de una situación crítica actual, la llamada turismofobia. Este concepto está generalmente mal empleado porque confunde el proceso -el turismo- con su aplicación, la cual se reconoce que dista de ser óptima. Se puede elegir también la metáfora del rechazo al automóvil, tendencia a la cual las jóvenes generaciones se asocian con energía. ¿Es el coche el que debe ser criticado o el uso que se hace de él (uso individual mayormente para un solo pasajero)? ¿Su consumo energético o la dominancia de los intereses petroleros que inhiben lo más posible el empleo de combustibles alternativos? Si un coche se sube a la banqueta y mata alguien, no se le pone en la cárcel, sino al conductor que hace mal uso del vehículo. Si el turismo está mal empleado, por ejemplo para vomitar miles de turistas en la Rambla de Barcelona desde cruceros-ciudades o para rentar pisos sin discriminación y control para alojar turistas, ¿quién es el responsable? ¿El turista o los operadores del turismo? 
Este es un simple ejemplo de la falta de un andamiaje conceptual adecuado, o de la voluntad de discutirlo abiertamente. Al igual cuando la Organización Mundial del Turismo define que las personas que se movilizan a otro lugar por razón de negocios son turistas, podemos observar, como bien lo ha hecho Miguel Ángel Acerenza, que los datos que nos ofrecen las instancias internacionales y nacionales/locales de turismo no son referencias certeras.

Sin embargo, la mayoría de los investigadores que se quieren adscribir al tema glamoroso de los estudios turísticos prefieren eludir las discusiones conceptuales -que, ciertamente, pueden ser interminables y cansadas- y ceñirse a lo obvio y usual.

Otra tendencia tampoco exclusiva de los estudios turísticos es el tema disciplinario/ interdisciplinario/transdisciplinario. Se ha gastado ya mucha tinta al respecto; vale agregar algo que nos parece fundamental: es imperativo partir del reconocimiento de que los estudios turísticos son un campo de estudio, un objeto de investigación efectivamente con muchas facetas interesantes, pero no una disciplina. Por ende, bienvenidos todos los aportes que provienen de disciplinas ajenas al tema pero que, por un motivo u otro, se han percatado de la importancia del asunto en un mundo en perpetuo movimiento. Sin embargo, es preciso adecuar los conceptos y posiblemente las metodologías de estas disciplinas para enfrentar la especificidad del turismo en cualquiera de sus manifestaciones.

No se puede analizar el turismo como si fuera la industria siderúrgica, por ejemplo; de allá que, en primera instancia, el término de industria turística no refiere al turismo en su totalidad, sino exclusivamente a las componentes del proceso turístico que son apropiados por agentes económicos que los ejercen para la ganancia. De nuevo estamos frente a una sinécdoque, para emplear una figura retórica convencional: tomar la parte como el todo. Vale señalar que su uso ha sido muy benéfico para impulsar el "sector" turismo (otra expresión que merecería una mayor atención conceptual), toda vez que implica a un conjunto de actividades productivas muy distintas entre sí (de la línea de aviación al paseo en lancha, por ejemplo) como si fueran encubiertas en una entidad única, una "industria".

\section{Injerencia estatal}

En México, el Estado ha mostrado una pronta presencia en el turismo: tanto que ciertos políticos han intervenido en algunas actividades para su enriquecimiento personal; sin embargo, lo más importante es la existencia temprana de un cuerpo de políticos-técnicos que se ha formado para definir, poner en práctica y evaluar las políticas del Estado y, en parte, conducir las actividades turísticas hacia un grado de consolidación que no exhiben otros entornos de América Latina.

Estas personas han contribuido a que se crearan un marco legal, normas de operación, planes de desarrollo a escala nacional desde fechas tempranas, además de instituciones perdurables a pesar de altibajos en la concepción de la prioridad del turismo en las más altas esferas del poder. 
Por ello, los funcionarios del turismo consideran que su forma particular de concebir la actividad, de orientarla, de pautar su desarrollo son indiscutiblemente las referencias de partida para cualquier acción o reflexión sobre el tema.

Esto ha provocado que los funcionarios del turismo, a lo largo del tiempo, hayan desarrollo posiciones generalmente cerradas con respecto a la crítica. Más aún, al ver extenderse un vasto campo de investigación en ocasiones crítica, han sentido la necesidad de ejercer un cierto control sobre el mismo. La no invitación de académicos a los foros oficiales, la no aceptación de la crítica a lo que consideran como un paradigma de gestión del turismo, la creación de estructuras de investigación paralelas a las que se construyen (con dificultad) desde los medios académicos, son algunos aspectos de esta injerencia que merece nuestra reflexión desde la academia.

\section{Reflexiones finales}

Los estudios del turismo en México han llegado a una mayor madurez, y no podemos más que felicitarnos por este avance considerable, aun si ha tomado varias décadas. Sería riesgoso ver solamente el vaso llenándose y no reflexionar sobre los diversos aspectos que se presentan como amenazas y de las cuales hemos hecho una rápida e incompleta reseña en las páginas anteriores. Por ende, esta nota de investigación propone, como cierre, unas muy breves consideraciones en torno a algunos puntos que nos parecen centrales para impulsar y consolidar la investigación del turismo.

Por un lado, la identidad del campo de estudio requiere fomentarse de manera más intensa. Participar en eventos de otras disciplinas con mesas temáticas, ofrecer publicaciones de calidad no solo en revistas de nuestro medio sino en el vasto abanico de disciplinas de las humanidades y las ciencias sociales, evidenciar la calidad de nuestro trabajo, son asignaturas pendientes. Para ello, es imperativo un trabajo conceptual serio y permanente. El andamiaje conceptual que dará seriedad al campo de los estudios del turismo está lejos de haber sido plenamente construido. Podemos pensar en la metáfora de que todavía usamos tablas colocadas sobre botes de pintura en vez de un andamio profesional, con los riesgos de accidente que ello implica. Si bien la prueba/error es indispensable, la solidez de nuestro sustrato conceptual resulta una necesidad imperiosa.

Así pues, con estas bases conceptuales se podrán realizar estudios verdaderamente analíticos que trasciendan las fronteras de las descripciones reiteradas de datos, hechos y constataciones superficiales. Solo así, impulsando la calidad, podremos alcanzar una posición interesante entre las ramas de las ciencias que nos otorgue una visibilidad positiva en el medio académico.

A poco más de tres décadas del inicio declarado de la investigación turística mexicana, asumimos que hemos avanzado, pero que todavía una larga ruta nos espera, a la manera de un viaje turístico o de un peregrinaje como el de Santiago de Compostela: la ruta está trazada, el final es una meta, pero también el viaje en sí es una experiencia humana de altísimo valor. 


\section{Fuentes consultadas}

Aramberri, J. (1983). El paraíso... ¿perdido? Sobre algunas teorías del turismo. Estudios Turísticos, 80, 73-95.

Boullón, R., Molina, S. y Rodríguez Woog, M. (1984). Un nuevo tiempo libre: tres enfoques teórico prácticos. México: Trillas.

Esteve Secall, R. (1983). Turismo ¿democratización o imperialismo? Málaga: Universidad de Málaga.

García de Fuentes, A. (1979). Cancún, turismo y desarrollo regional. México: Universidad Nacional Autónoma de México.

Gaviria, M. (dir.). (1974). España a gogo, turismo chárter y neocolonialismo del espacio. Madrid: Turner Ediciones.

George, P. (1966). La geografía activa. Barcelona: Ariel.

Gomezjara, F. (1974). Acapulco: despojo y turismo. Problemas del Desarrollo, 5(19), 126147.

Hiernaux, D. (comp.). (1989). Teoría y praxis del espacio turístico. México: Universidad Autónoma Metropolitana-Xochimilco.

Hiernaux, D. (2000). Los nuevos derroteros de la investigación turística. En N. Monterroso y L. Zizumbo (coords.), Investigación turística (pp. 163-176). Toluca: Universidad Autónoma del Estado de México.

Hiernaux, D. (comp.). (2015). Turismo, sociedad y territorio: Una lectura crítica. Querétaro: Universidad Autónoma de Querétaro.

IMIт. (s/f). Instituto Mexicano de Investigaciones Turísticas. Antecedentes, organización interna, función técnica y experiencias generales del mismo. México: Autor. Recuperado de http://cedocvirtual.sectur.gob.mx/janium/Documentos/2009/000567.pdf [2018, 23 de enero].

Jiménez M., A. J. (1993). Turismo. Estructura y desarrollo. México: McGraw-Hill.

Kadt, E. de (1979). Turismo: ¿pasaporte al desarrollo? Madrid: Endymion.

MacCannell, D. (1976). The Tourist: A New Theory of the Leisure Class. Londres: Macmillan.

MacDonald Escobedo, E. (1981). Turismo: una recapitulación. Historiografía de los conceptos pronunciados por gobernantes mexicanos desde 1823. México: Bodoni.

Molina, S. (1988). Conceptualización del turismo. México: Ediciones Nuevo Tiempo Libre.

Monterrubio, C. (2016). Necesidades de la investigación turística en México. Reflexiones en el marco de la investigación internacional. Dimensiones Turísticas, 1(1), 31-52.

Moreno Toscano, O. (1971). El turismo como factor político en las relaciones internacionales. Foro Internacional, XII, 1(45), 66-94.

Nieto, J. A. (1975). Turismo: ¿democratización o imperialismo? Revista de Estudios Sociales, 14-15.

Osorio, M. y Korstanje, M. (2017). Reflexiones en torno a la situación de la investigación turística. Dimensiones Turísticas, 1(1), 13-30.

Phliponneau, M. (1966). Geografía aplicada. Barcelona: Ariel.

Reynoso, C. (2000). Apogeo y decadencia de los estudios culturales, una visión antropológica. Buenos Aires: Gedisa.

Smith, V. (comp.). (1992). Anfitriones e invitados. Madrid: Endymion.

Turner, L. y Ash, J. (1991). La horda dorada. Madrid: Endymion. 
González Damián, A. (2017)

\section{Construcción social de la experiencia turística. Una cooproducción de turistas y de anfitriones basada en hechos reales}

España: Bubok publishing

Rodrigo Espinoza Sánchez y Rosa María Chávez Dagostino

Centro Universitario de la Costa

Universidad de Guadalajara

rodrigoe@cuc.udg.mx, rosac@cuc.udg.mx

E I autor del libro la Construcción social de la experiencia turística. Una coproducción de turistas y anfitriones basada en hechos reales es un excelente académico, compañero y amigo: Alfonso González Damián, cuya preocupación por los diferentes abordajes de los estudios turísticos lo han conducido a explorar diversidad de temas de este fenómeno, en el que engrana una complejidad sistémica que orienta el desarrollo estructural de esta obra, la cual parte de ciertos supuestos teórico-metodológicos y de hechos reales que ayudan a comprender la gestación y concreción de la experiencia turística.

En la introducción el autor señala que después de la Segunda Guerra Mundial, el turismo tomó un papel preponderante en el desarrollo económico de los países y, por ende, este fenómeno empezó a ser estudiado por los oferentes con el objeto de crear productos turísticos que satisficieran los requerimientos del turista y que su experiencia fuera exitosa. Luego argumenta González Damián que han proliferado estudios que se enfocan desde la perspectiva del turista en la obtención de la experiencia única, mientras que desde el ángulo de la anfitrionía no se ha abordado como debiera; por tanto, su consideración es que el estudio de esta experiencia turística se ha parcelado y se ha obviado la otredad que participa en la creación del producto para que la experiencia tenga lugar, ya que esta se da a través del construccionismo social. El contenido de la obra está fundamentado en casi dos centenares de referencias y se estructura en seis capítulos en los que se analizan otros abordajes al estudio de la experiencia turística.

El primer capítulo, "Realidad social, construccionismo y turismo", parte de un cuestionamiento central acerca del propio construccionismo, que en sí mismo encierra una gran discusión, la cual motiva el cuestionamiento acerca de si el construccionismo es una teoría, un paradigma o una moda. Para dar respuesta, el autor recurre a diversos estudios y ofrece elementos que permiten identificar y diferenciar aspectos teórico-conceptuales que están implícitos en la intersubjetividad e interpersonalidad de los hechos sociales que se 
estudian; sin embargo, llega a la conclusión de que existen diferencias desde su concepción epistémica, ya que este construccionismo aglutina teorías y métodos que coinciden en su fundamentación epistémica, lo que puede ser considerado desde dos posturas, según los teóricos, una fuerte y otra débil. En la primera: 1) el conocimiento no es un mundo que depende de un observador; 2) el conocimiento no representa tal mundo; 3) el conocimiento se refiere a la experiencia individual más que al mundo; 4) no hay una realidad extra-experiencia racionalmente. Por tanto, la verdad de ese conocimiento reside en lo que los seres humanos construyen. La segunda postura es opuesta, si bien el conocimiento del mundo natural es accesible para el ser humano, entonces existe como tal, mientras que el conocimiento de lo social es inaccesible, por tanto, debe ser construido. Ante estas posturas el autor argumenta que el construccionismo es aquel cuyas bases se gestan en lo colectivo y no en el individualismo ni el realismo o el racionalismo, ya que estas posturas son inadecuadas para su aprehensión. Por tanto, el conocimiento turístico es producto de un proceso dialéctico en el cual se fusiona el elemento objetivo, constituido por las relaciones sociales de los sujetos, y uno subjetivo, que es la interpretación de los símbolos, internalización de los roles y la formación de identidades individuales. En este sentido, se apela a la reflexión para la generación del conocimiento, desde la postura construccionista con sustento epistemológico.

En el segundo capítulo, "La experiencia turística en la literatura académica”, se analiza la complejidad de entender la experiencia turística y se "da un paseo" que muestra cómo se ha manejado la integración de productos turísticos según los recursos que posee el territorio en el cual se suscita la experiencia, pero a la vez, hace reflexionar ante tal perspectiva, ya que en ocasiones, la experiencia turística auténtica no se genera por los recursos considerados como atractivos, sino por lo que el turista va a realizar y no sólo a ver. Muestra así la evolución del manejo del mercado turístico desde la oferta, cada día más especializada, para dar respuesta a una demanda muy selectiva. Hace referencia también, a que en ese devenir evolutivo el turista concentra su atención en una inmersión, ya no solo de lo que va a hacer, sino que ahora quiere sentir además de ver y hacer; es decir, dónde experimentar vivencias, por lo que la industria tiene que redoblar esfuerzos y ofrecerlas. En este capítulo, se abordan los modos de la experiencia turística y como se representan. Cierra con una reflexión acerca de lo que el autor denomina paisaje turístico y cosificación de la comunidad anfitriona, e invita a una nueva concepción de experiencia turística desde una perspectiva más interpersonal y humana.

En el tercer capítulo, "Hacia una teoría construccionista de la experiencia turística”, se identifican los esfuerzos que se han hecho desde el siglo pasado por entender desde otra óptica la experiencia turística, que era vista desde la perspectiva de la economía; sin embargo, el autor cuestiona cómo se puede diferenciar la experiencia de un viaje turístico de un viaje cualquiera. Considera que la industria solo hace la distinción de turista para fines mercadológicos y el gobierno para fines estadísticos. Esto trae ciertas confusiones, ya que si solo se considera al turista se está dejando de lado al que hace posible dicha experiencia como resultado de la acción del colectivo denominado anfitriones. Para complejizar este construccionismo de la 
experiencia turística se hace referencia a marcos en los cuales se da la experiencia, pero a la vez se determina y explican ciertas dimensiones que competen al binomio turista y anfitrión, como construcción colectiva.

El cuarto capítulo, “Construcción colectiva de la experiencia turística”, presenta un estudio de caso de Cozumel, y enfatiza los soportes teórico referenciales importantes para indicar el significado que tienen los marcos en la construcción colectiva de la experiencia turística. El autor trata de contrastar la teoría y la práctica con experiencias turísticas en el contexto de la isla de Cozumel, pero a la vez plantea una metodología basada en los cuatro marcos primarios de todo viaje turístico: a) Planeación del viaje, b) Planeación hacia y desde el destino, c) Estancia en el destino y d) Experiencia posviaje; donde el trabajo empírico pueda abarcar a toda la experiencia a través de la observación participante y no participante, y establece que la concreción de la experiencia turística, a pesar de estar concebida dentro de marcos tipificados de la industria del turismo, depende de una interpretación de la anfitrionía.

El quinto capítulo, "Transformación de las experiencias del viajero como turista ante la presencia de tecnología”, vuelve a retomar la experiencia del turista como un constructo colectivo, esto lo enfatiza al decir que dicha experiencia se construye porque es un hecho social en el que interviene tanto el turista como la comunidad anfitriona. A la vez, hace una aproximación empírica a la experiencia turística en los recorridos subacuáticos de la isla en Cozumel, México, a través de los marcos de la experiencia turística en los referidos recorridos, en tanto plantea un modelo conceptual de la intervención de la tecnología en estos marcos de la experiencia turística, que se sustenta en dos vertientes: 1) una relacionada al uso intensivo de la tecnología para beneficio del desarrollo del turismo, y 2) los efectos de los desarrollos tecnológicos en el turismo, sin embargo, señala que el sector turismo no ha quedado rezagado del uso de las tecnologías. El capítulo cierra con reflexiones sobre nuevas líneas de investigación que posibiliten aproximaciones cualitativas construccionistas para entender lo que sucede con las interacciones entre anfitriones y turista cuando interviene la tecnología.

El sexto y último capítulo, "Límites y posibilidades del concepto de experiencia turística colectivamente construido", enfatiza que el construccionismo colectivo puede sentar bases sólidas para el estudio del turismo y específicamente de la experiencia turística, toda vez que este se sustenta en las relaciones interpersonales que se dan entre turista y comunidad anfitriona. Refiere que en los capítulos precedentes de la obra están los planteamientos teóricos para su aplicación, y en este capítulo se encuentran algunas limitantes de la experiencia turística socialmente construida. Finalmente, los hallazgos presentados en el libro y las líneas de investigación que deja el autor, plasmadas como inquietudes para proseguir la investigación, son un reto para la indagación y profundización de su interpretación desde los variados enfoques teóricos y metodológicos. 


\section{RESEÑA \\ XI Congreso Internacional de la AMIT "30 Años de Investigación Turística en México"}

\author{
Irma Magaña Carrillo \\ Universidad de Colima \\ Maribel Osorio García \\ Universidad Autónoma del \\ Estado de México
}

E I congreso anual de la Academia Mexicana de Investigación Turística (AMIT) es un evento esperado con interés no solo por los miembros de esta asociación, sino también por estudiantes de licenciatura y posgrado de las diferentes carreras de turismo y áreas afines del país. EI XI Congreso Internacional de la Aмıт: “30 Años de Investigación Turística en México” se llevó a cabo del 27 al 29 de septiembre de 2017, el cual se realizó conjuntamente con la Universidad de Guadalajara, en el Centro Universitario de Ciencias Económico Administrativas (CUCEA).

La celebración del trigésimo aniversario del estudio científico del turismo en México se desarrolló con la participación de especialistas de diversas generaciones, propiciando el diálogo e intercambio de ideas, conocimientos y avances de investigaciones entre los académicos con el tema central de los adelantos del turismo en materia científica.

Este congreso dio muestra de una efervescencia de inquietudes para formar grupos, redes y nuevas oportunidades de colaboración con miras al futuro. Se constituye así en un espacio de encuentro donde entablar un diálogo entre actores de diferentes disciplinas y perspectivas de análisis, con objeto de reflexionar sobre los cambios, las condiciones y oportunidades para hacer investigación, y los espacios

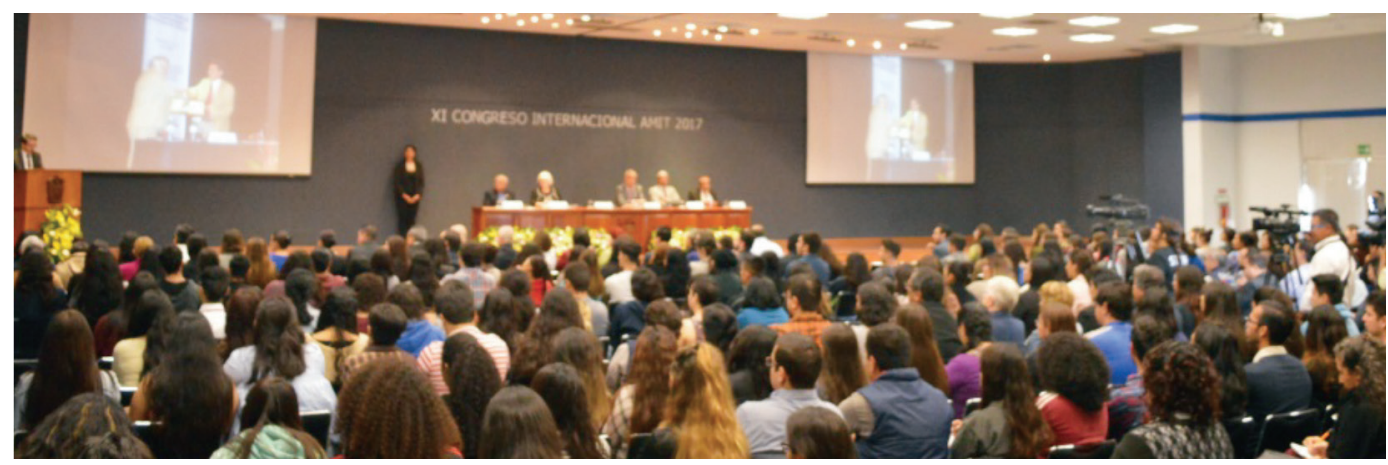

CÓMO CITAR: Magaña, I. y Osorio-García, M. (2018). Reseña del XI Congreso Internacional de la AMIT «30 Años de Investigación Turística en México». Dimensiones Turísticas, 2(2), 137-143. https://doi.org/10.47557/NSSM7220 

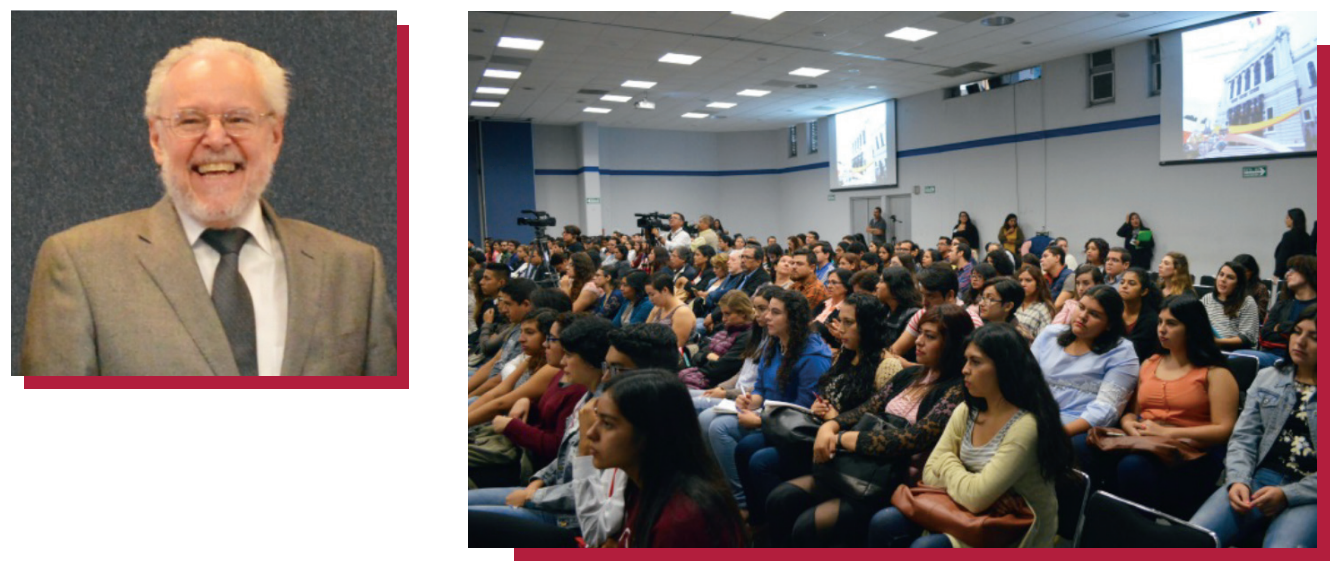

para establecer relaciones de colaboración entre los diversos participantes que son parte de la formación, diseño, ejecución, financiamiento, publicación y reconocimiento de los resultados de investigación en turismo.

El evento dio inicio con el curso pre-Congreso “El estudio científico de la sociedad”, impartido por el doctor Fernando Miguel Leal Carretero, destacado investigador de la Universidad de Guadalajara. Posteriormente, el 27 de septiembre se realizó la inauguración oficial del Congreso, con la participación de autoridades universitarias, gubernamentales y la presencia de la doctora Nora L. Bringas Rábago, actual presidenta de la AMIT. Durante la ceremonia se destacó la importancia y los beneficios que el turismo ha traído para el desarrollo del país, tanto en el ámbito económico como en el cultural, principalmente.

La inauguración fue enmarcada con dos interesantes eventos magistrales. Se abrió con una conferencia titulada “Las ciencias sociales ¿disciplinas o áreas de estudio?”, a cargo del doctor Leal Carretero, quien hizo una reflexión-análisis para clarificar la naturaleza del turismo como objeto de estudio y su riqueza multidisciplinaria.

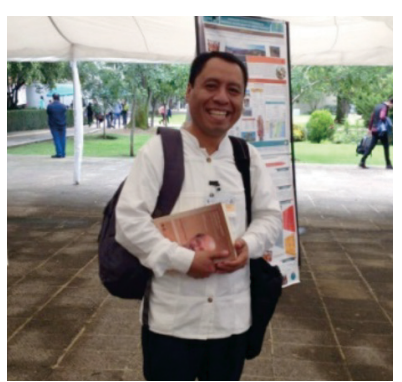

Después se desarrolló el panel "Investigación de la gastronomía: miradas multidisciplinarias", coordinado por la maestra Angélica Guerra Ávalos, y contó con la participación de Ricardo J. Ávila Palafox (Centro Universitario de Ciencias Sociales y Humanidades-Universidad de Guadalajara), Claudia Rocío Magaña González (Centro Universitario del Sur-Universidad de Guadalajara), Lourdes Flores López (Centro de Investigación y Asistencia en Tecnología y Diseño del Estado de Jalisco-Consejo Nacional de Ciencia y Tecnología), Nora L. Bringas Rábago (El Colegio de la Frontera Norte) y Marco Antonio Covarrubias Castro (Universidad del Claustro de Sor Juana). Sin duda, un panel interesante en el que cada uno de los participantes mostró su nivel de conocimiento en el área y coincidieron en que la gastronomía es un activo inseparable, figurando en muchas ocasiones como el principal motivo para regresar a un lugar.

El mismo día, en la explanada del auditorio central del CUCEA se expusieron los carteles participantes en el Congreso, que fueron alrededor de 20 sobre diversas temáticas. 


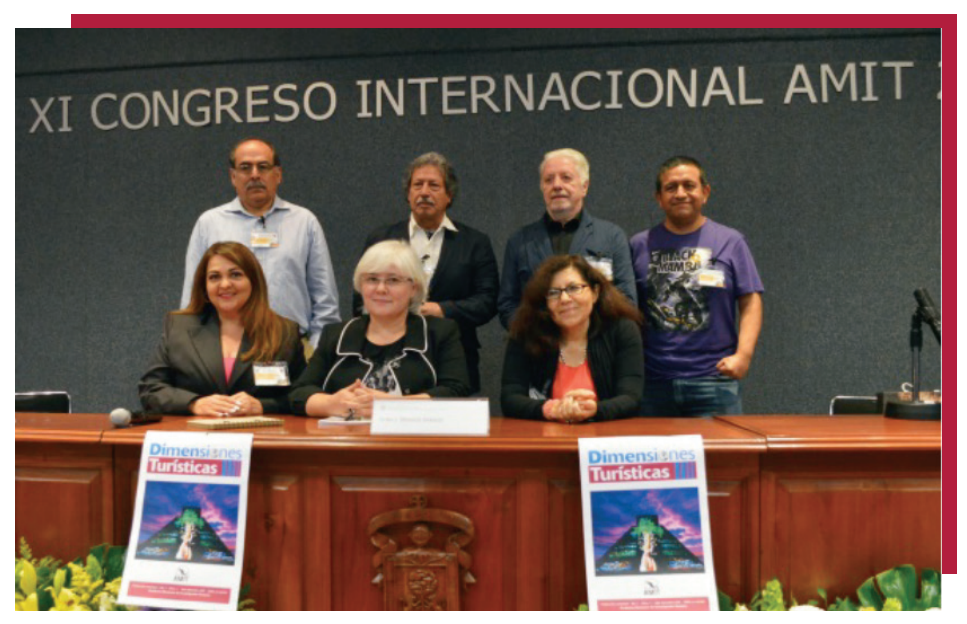

Uno de los momentos más emotivos y relevantes durante el Congreso Amit 2017 lo constituyó la presentación del primer número de la revista Dimensiones Turísticas, uno de los proyectos estratégicos que el actual Consejo de la AMIT se propuso concretar al inicio de su gestión. Esta revista tiene la intención de convertirse en un producto académico sobresaliente y viene a llenar un espacio importante de difusión entre quienes hacen investigación y generan nuevo conocimiento en el campo del turismo. Se reconoció que el camino no es fácil para llegar a ser una revista de calidad y posicionarse como una de las mejores en su género, pero se cuenta con el esfuerzo conjunto de los miembros de la academia para alcanzar el estatus que se exige en estos casos y poder ingresar en los más prestigiados índices de impacto nacionales e internacionales.

Por la tarde del miércoles 28 y el jueves 29 de septiembre se inició la presentación de 139 ponencias en 24 mesas de trabajo que versaron sobre epistemología; capacitación y competitividad; educación y tecnologías de la información; gestión de conocimiento turístico; empleo turístico; planificación de destinos; evaluación de impactos en destinos turísticos; producción del espacio turístico; percepciones sociales; gestión territorial; turismo, sustentabilidad y cambio climático; cultura e identidad; y patrimonio turístico, entre otros. Adicionalmente hubo tres mesas temáticas: La formación de investigadores en los posgrados de turismo en México; Turismo y centros históricos: ¿oportunidades o amenazas?; y Reflexión desde la atractividad territorial de Jalisco como destino turístico, de inversiones y capital humano. En total participaron 170 expositores de 35 universidades nacionales de diferentes puntos cardinales del país y de cuatro universidades extranjeras (Argentina, Brasil, Colombia y Ecuador). Los resultados, propuestas y experiencias generados durante el encuentro reflejan el avance de la investigación turística en México, pero también en Latinoamérica.

Asimismo, durante el segundo día del Congreso se realizó un panel con el tema: "30 años de investigación turística en México”, en el cual fungió como moderador el doctor Basilio Verduzco Chávez (CUCEA-Universidad de Guadalajara) y participaron los doctores Daniel Hiernaux-Nicolas (Universidad Autónoma de Querétaro), Alfonso Jiménez Martínez 
(Universidad Autónoma de Guadalajara), Felipe Cuamea Velázquez (Universidad Autónoma de Baja California), Salvador Gómez Nieves (CuCEA-Universidad de Guadalajara) y Carlos Rogelio Virgen Aguilar (Centro Universitario de la Costa-Universidad de Guadalajara). Los panelistas vertieron sus experiencias y dificultades en el camino hacia un trabajo investigativo para estudiar el turismo mexicano que a la fecha ha dado frutos, enfatizando la necesidad de seguir en esa vía para asegurar el desarrollo del conocimiento del turismo.

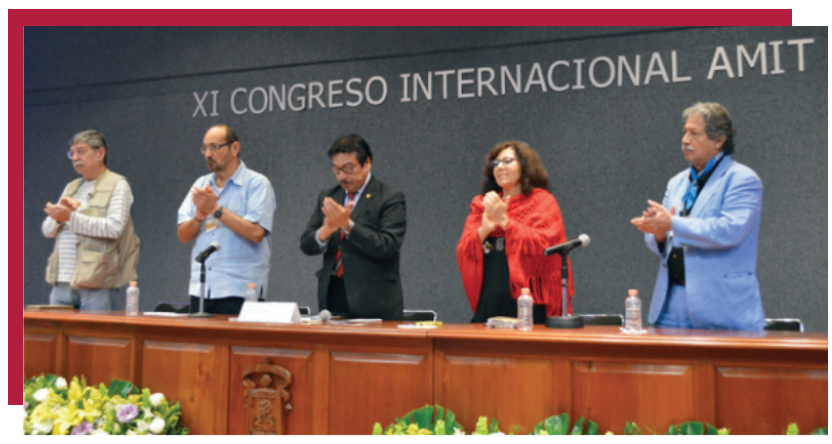

Dentro de las actividades que se llevaron a cabo, hubo dos homenajes post mórtem. El primero para el doctor Sergio Molina Espinoza, cuyo moderador fue el doctor Tomás de Jesús Cuevas Contreras, de la Universidad Autónoma de Ciudad Juárez. Los participantes en este foro fueron la doctora Noemí Wallingre (Universidad Nacional de Quilmes, Argentina), el maestro Jorge Trujillo Rincón (Universidad Autónoma de Chiapas), el doctor Marcelino Castillo Néchar (Universidad Autónoma del Estado de México), el maestro Fernando Mandri Bellot (Integra Tourism for Good), el doctor Roger Bergeret Muñoz (Universidad Autónoma de Guerrero), el doctor Carlos Virgen Aguilar (Centro Universitario de la Costa-Universidad de Guadalajara) y la doctora Maribel Osorio García (Universidad Autónoma del Estado de México). Todos ellos expresaron su relación personal con el maestro Sergio Molina, destacando su calidad humana y resaltando la trascendencia de sus investigaciones y sus valiosos aportes a la investigación turística en México.

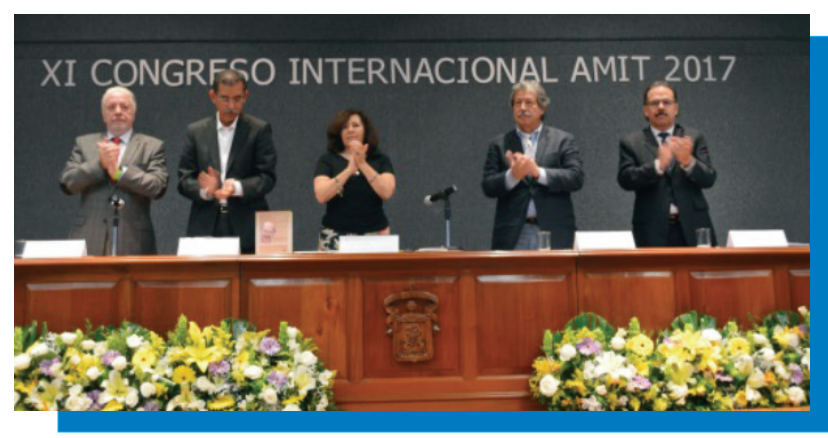

El segundo homenaje fue para el licenciado Manuel Rodríguez Woog, el cual moderó la doctora Maribel Osorio García (Universidad Autónoma del Estado de México) y en el que participaron los doctores Felipe Cuamea Velázquez (Universidad Autónoma de Baja California), Daniel Hiernaux-Nicolas (Universidad Autónoma de Querétaro), Alfonso de Jesús Jiménez (Universidad Autónoma de Guadalajara) y el maestro José de Jesús Quiñónez Ramírez (Instituto de Competitividad Turística-Secretaría de Turismo). Los participantes también compartieron con el público asistente la calidad humana del homenajeado y su importante trayectoria y aportaciones a la investigación del turismo. Vale la pena destacar que estos dos personajes fueron pioneros en el estudio del turismo en México. 
En el marco del Congreso también se presentaron los siguientes libros: Desarrollo de destinos turísticos consolidados: una visión desde la sustentabilidad y la resiliencia (2017), de A. Montaño Armendáriz, A. Ivanova Boncheva y R. Serrano Castro (coords.); Guía introductoria a la dimensión temática del sistema turístico, Acapulco (2017), de A. J. Jiménez Martínez, D. D. Ortiz Guzmán, M. Velarde Valdez y R. J. Bergeret Muñoz; Experiencias de turismo rural en Quintana Roo (2017), de J. F. Domínguez Estrada; Herramientas conceptuales y metodológicas para la gestión turística (2016), de J. G. Ruiz Andrade; e Internacionalización de los servicios de salud. Turismo médico en México y Jalisco (2016), de J. Guzmán Flores.

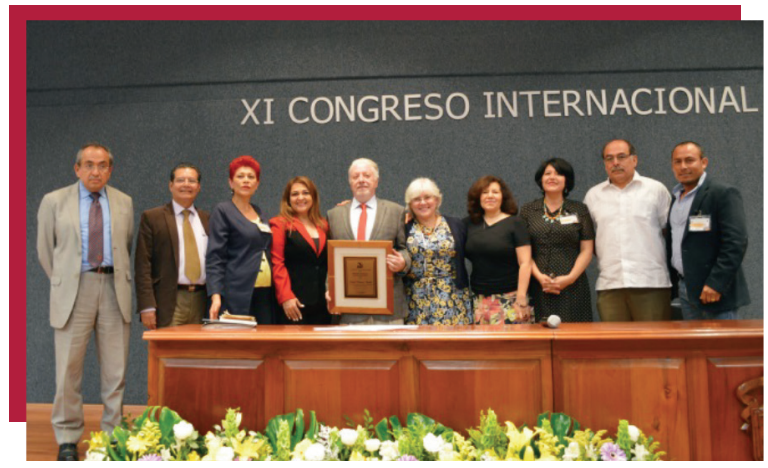

Finalmente, con la intención de reconocer los esfuerzos realizados por estudiantes y miembros de la comunidad científica del turismo, la AmIT otorgó el Premio Nacional a la Trayectoria de Investigación Turística 2017, el cual se entrega anualmente a un investigador, considerando su trayectoria y contribución al conocimiento científico del turismo; y el Premio Nacional a la Mejor Tesis de Posgrado 2016 en dos categorías: Maestría y Doctorado.

El Premio Nacional a la Trayectoria de Investigación Turística 2017 fue otorgado al doctor Daniel Hiernaux-Nicolas (Universidad Autónoma de Querétaro), tras la deliberación realizada por el Comité Evaluador, conformado por los doctores José Fernando Vera Rebollo y Raquel Huete Nieves (Univer-

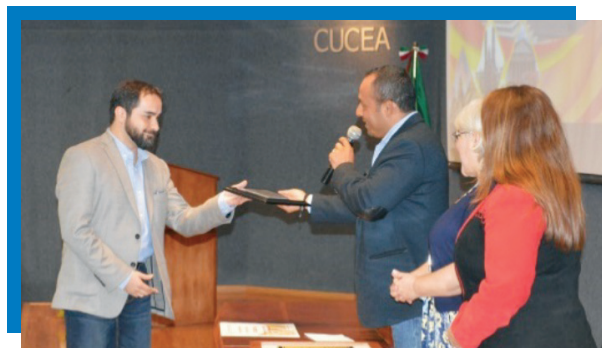

Dr. Federico Gerardo Zúñiga Bravo, Premio Nacional a la Mejor Tesis de Posgrado 2016, categoría Doctorado.

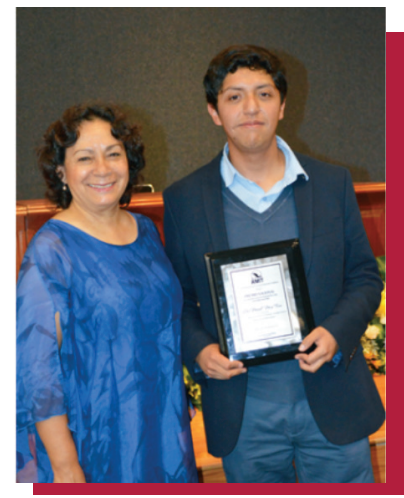

Mtro. Víctor Manuel Mora Torres, Premio Nacional a la Mejor Tesis de Posgrado 2016, categoría Maestría, y su directora, Dra. Rocio Serrano Barquin. paña),Agutín Santana Talavera (Universidad de La Laguna, España), Basilio Chávez Verduzco (CUCEA-Universidad de Guadalajara) y Maribel Osorio García (Universidad Autónoma del Estado de México). Asimismo, el Premio Nacional a la Mejor Tesis de Posgrado 2016, categoría Maestría, fue entregado a Víctor Manuel Mora Torres por su trabajo intitulado Turismo religioso en el Cerrito 


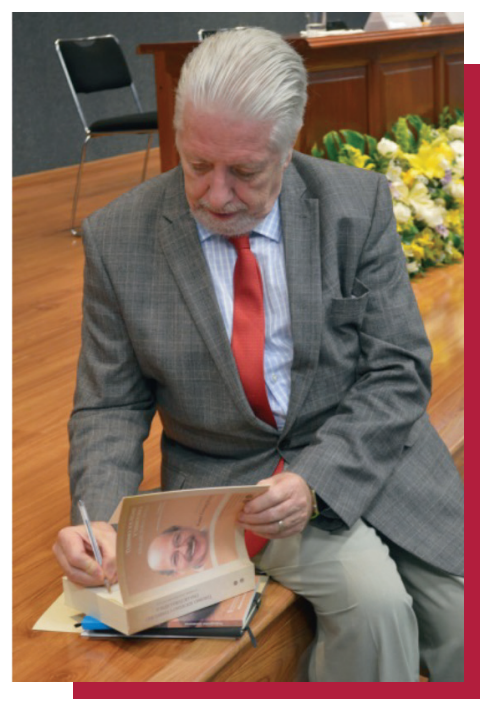

Dr. Daniel Hiernaux-Nicolas, Premio Nacional a la Trayectoria de Investigación Turística 2017.

de Tepexpan: un análisis desde el enfoque de la desdiferenciación, mientras que el de categoría Doctorado fue para Federico Gerardo Zúñiga Bravo, de la Universidad Nacional Autónoma de México, por su investigación Patrimonio cultural, etnicidad y turismo. Procesos de patrimonialización, turistificación y mercantilización en el Totonacapan veracruzano.

La última conferencia magistral, "El turismo del siglo xIX: cerrar/abrir puertas para su estudio" estuvo a cargo del recién galardonado, doctor Daniel Hiernaux-Nicolas, en la cual trasladó a los asistentes a los orígenes de la investigación turística y planteó sus vicisitudes, retos, logros y fracasos, develando un camino largo y sinuoso del quehacer investigativo en materia de turismo. El conferencista destacó la relevancia de investigaciones que marcaron interesantes aportes al campo del conocimiento del turismo y principalmente a la actividad turística.

El 29 de septiembre este magno evento llegó a su fin, su realización fue una buena oportunidad para ampliar los nexos entre la investigación turística y otras miradas científicas sobre el turismo y sus manifestaciones. Un aspecto que estuvo presente a lo largo del Congreso fue la necesidad de mantener vigente la relación entre la docencia, la investigación y la publicación de resultados. Como producto de este puente se destacó la trascendencia de la aparición de la revista Dimensiones Turísticas, la presentación de libros, el reconocimiento a la trayectoria en investigación turística y a las tesis de posgrado, y el intercambio de resultados de investigación.

Otro aspecto que prevaleció durante todo el Congreso fue la necesidad de fortalecer un modelo de colaboración intergeneracional para mantener viva la memoria de quienes han contribuido con su conocimiento al desarrollo de la investigación turística de México, de ahí la relevancia de reconocer sus aportaciones. Esto resulta significativo porque recupera la experiencia y muestra una visión del futuro que se quiere construir para la investigación turística. Igualmente se resaltó la importancia de reconocer el papel de los jóvenes como creadores del conocimiento en un contexto mediado por lo tecnológico, en lo social, ambiental, cultural y político, situación que estuvo fuera del alcance de quienes hacían investigación hace 30 años y que seguramente en el futuro cercano potenciará más el análisis del turismo como objeto de estudio.

Todo este trabajo académico estuvo aderezado por actividades socioculturales organizadas por los anfitriones. El primer día se brindó un coctel de bienvenida en el Museo de Artes de Zapopan y un video mapping en Plaza de las Américas, ambos por parte de la Dirección de Turismo de Zapopan, Jalisco. El segundo día se ofreció un recorrido nocturno en el Tapatío Tour por Guadalajara y Zapopan, bajo el auspicio de la Secretaría de Turismo del 


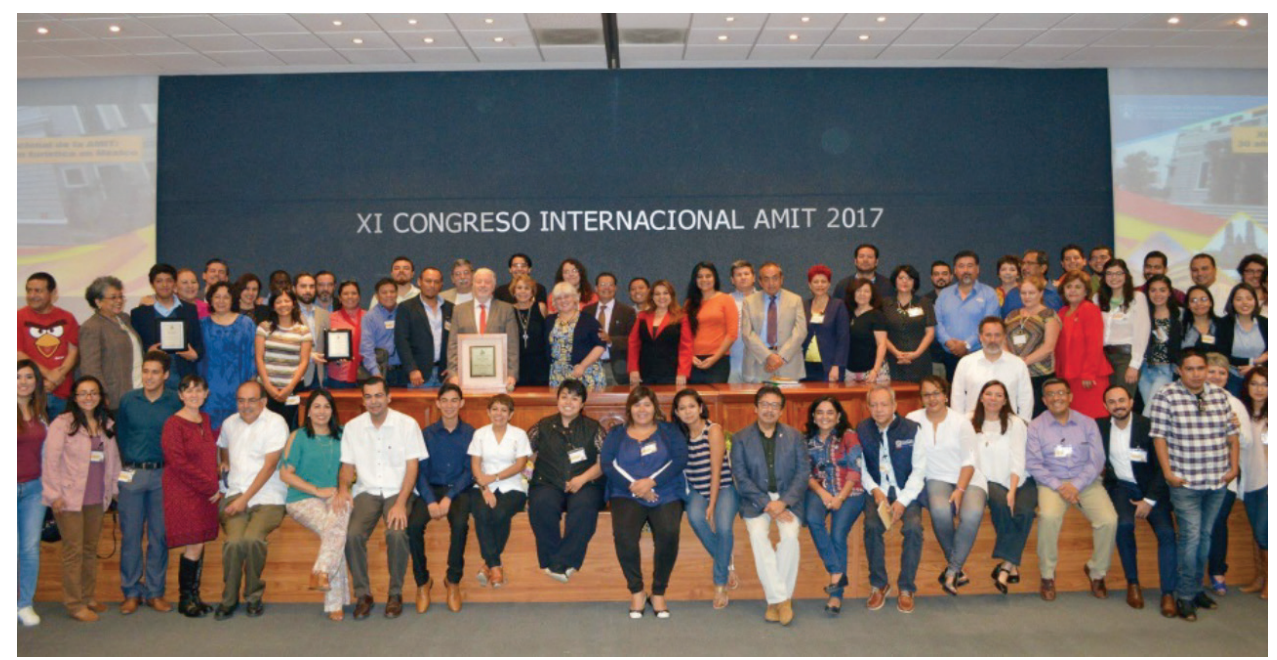

Estado de Jalisco. Para la clausura se realizó una cena de gala mexicana en el restaurante El Patio, tradicional sitio en Tlaquepaque, Jalisco, ofrecida por la Oficina de Visitantes y Convenciones de Guadalajara.

Por otra parte, se informó que el Congreso Amı 2018 se llevará a cabo en Cancún, Quintana Roo, con el auspicio de la Universidad del Caribe, gracias a la disposición de su rectora, la doctora Ana Pricila Sosa Ferreira. Por último, se efectuó la clausura de este notable encuentro, donde estuvieron presentes miembros del Consejo de la AMIT y autoridades de la Universidad de Guadalajara.

Cabe mencionar que el XII Congreso de la AMIT se celebrará de manera conjunta con el VII Congreso Latinoamericano de Investigación Turística (CLAIT) y con el XVI Seminario de Turismo y Sustentabilidad de la Universidad del Caribe, por lo que la AMIT, desde el cierre del Congreso 2017, ya se encuentra trabajando arduamente para la versión 2018, en espera de reunir especialistas de todo el continente para analizar el turismo desde diferentes perspectivas, con miras a generar una discusión creativa que permita avanzar en el entendimiento y comprensión del turismo como objeto de estudio. 


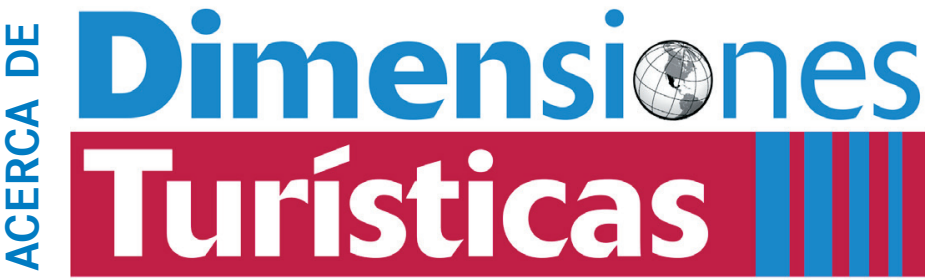

\section{POLÍTICAS}

\section{Enfoque y alcance}

Dimensiones Turísticas es una publicación científica, digital y de distribución gratuita que publica y difunde trabajos originales de investigación que abordan temáticas turísticas en México y en otros contextos internacionales. Dimensiones Turísticas se especializa en el estudio de los distintos procesos sociales, culturales, económicos, políticos, ambientales y territoriales vinculados con la actividad turística a través de investigaciones analíticas, críticas y reflexivas desde una perspectiva inter y multidisciplinaria con el propósito de difundir los principales hallazgos de investigación tanto entre la comunidad académica, como con el sector gubernamental, empresarial y la sociedad en su conjunto.

Su objetivo es constituirse en un espacio que permita exponer nuevos enfoques, teorías, metodologías, estudios, experiencias y hallazgos de investigación que posibiliten avanzar en la construcción y difusión del conocimiento acerca del turismo, así como contribuir al enriquecimiento de debates actuales sobre la investigación turística.

\section{Políticas de sección}

Dimensiones Turísticas publica textos inéditos de carácter científico que analicen teorías, metodologías o procesos sociales, culturales, económicos, administrativos, políticos, ambientales y territoriales vinculados con la actividad turística desde una perspectiva inter y multidisciplinaria. Se publicarán tres tipos de trabajos: artículos, notas críticas y reseñas bibliográficas.

Artículo: Se refiere a trabajos originales que expongan los principales hallazgos teóricos, empíricos o metodológicos de investigaciones concluidas o en curso que analicen desde distintas disciplinas procesos vinculados a la actividad turística.

Notas críticas: Es una reflexión académica sobre temas actuales o avances de investigación.

Reseña: Es un texto breve que refiere o analiza publicaciones en formato físico o electrónico recientes que aborden temáticas de turismo o de investigación. El Comité editorial será el responsable de sugerir los libros a reseñar. 


\section{Proceso de evaluación por pares}

Los trabajos académicos serán sometidos a un proceso de evaluación anónima por pares. Las notas críticas serán sometidas al mismo proceso de evaluación que los artículos. Las publicaciones reseñadas no deberán tener una fecha de publicación mayor a dos años anteriores al año de envío de la propuesta.

Debido al proceso editorial anónimo, los datos de autores/as como adscripción, currículo sucinto, dirección electrónica y postal figurarán en una hoja aparte. Los trabajos serán sometidos a la revisión de un comité de expertos para avalar la calidad científica y deberán enviarse en su versión final y completa, ya que no se permitirán modificaciones posteriores una vez iniciado el proceso de evaluación.

El proceso para la revisión blindada de artículos es el siguiente:

Recepción del manuscrito y aviso de recepción al autor en un plazo no mayor a 72 horas. Posteriormente, inicia el proceso que consta de las siguientes fases:

1. Primera fase: Envío de la propuesta al Comité editorial para realizar una pre-evaluación de la calidad del manuscrito, la pertinencia temática y la conformidad de las normas editoriales. El manuscrito podrá ser aceptado o rechazado por el Comité, que basa su decisión en criterios de calidad académica, aportación al campo científico y a la temática y normatividad. Si el manuscrito es aceptado, pasa a la segunda fase; en caso contrario, se envía un aviso de rechazo al/la autor/a.

2. Segunda fase: en caso de que el pre-dictamen sea favorable, el manuscrito anónimo se enviará a dos evaluadores/as externos/as, con especialidad en la línea de investigación, temática o materia de la propuesta. En caso de contar con dictámenes contradictorios, el manuscrito se envía a un tercer evaluador/a, también especialista, cuya decisión será determinante para el dictamen final.

Los dictámenes podrán tener los siguientes resultados:

1. Dictamen positivo: indica un resultado favorable; el manuscrito puede ser evaluado como:
a) Publicar sin cambios;
b) Publicar cuando se hayan cumplido con modificaciones menores;
c) Publicar una vez que se haya efectuado una revisión a fondo.

2. No publicable: El manuscrito se rechaza de forma definitiva.

En caso de que el dictamen final solicite cambios o modificaciones, los/as autores/as disponen de cuatro semanas para incorporarlos y volver someter el manuscrito para su revisión. La revisión la realiza el Comité editorial. Si los cambios se incorporan adecuadamente, el manuscrito se acepta finalmente; si se considera que no se han hecho las modificaciones requeridas se pedirá a los/las autores/as que revisen su propuesta y se contará con un 
plazo no mayor a dos semanas para incorporar los cambios solicitados. Si los cambios se incorporan, será aceptado para su publicación; si los cambios no se incorporan en este segundo periodo, el manuscrito se rechaza.

Para que las propuestas sean enviadas al Comité editorial deberán cumplir con las normas editoriales de AмIт (APA 6). En caso contrario, serán devueltas a los/las autores/as para que ajusten sus propuestas a las Directrices.

Una vez aceptado el trabajo para su publicación, los/as autores/as conceden a la Dimensiones Turísticas los derechos de los artículos publicados, conservando sus derechos morales conforme lo establece la Ley de derechos de autor

\section{Frecuencia de publicación}

Dimensiones Turísticas es una publicación semestral. Se publica en junio y diciembre La convocatoria para recepción de trabajos se mantiene abierta durante todo el año.

\section{Política de acceso abierto}

Dimensiones Turísticas brinda un acceso abierto y gratuito al contenido de sus investigaciones con la finalidad de difundir y garantizar un intercambio amplio y directo del conocimiento generado.

Dimensiones Turísticas no cobra cuotas por el envío, gestión o publicación de los trabajos enviados a evaluar.

\section{Derechos de los/las autores/as}

Los/las autores/as serán responsables únicos de las ideas, afirmaciones y opiniones expresadas en su texto, por lo que la revista no asume responsabilidad alguna en este sentido. Los/las autores/as conserva/n sus derechos morales conforme lo establece la Ley de derechos de autor. Dimensiones Turísticas autoriza la reproducción de su material a través de medios magnéticos, electrónicos y de reprografía siempre y cuando no se alteren los contenidos, sea sin fines de lucro y se cite la fuente completa.

\section{DIRECTRICES PARA AUTORES/AS}

Los trabajos serán sometidos a evaluación por un comité de expertos. Todas las propuestas pasarán por un proceso editorial que se desarrollará en varias fases, por lo que es necesario que la presentación de los manuscritos siga una serie de normas que faciliten la edición y eviten el retraso de la publicación.

1. Los trabajos que se envíen a Dimensiones Turísticas para su publicación deberán ser originales y académicos, no haber sido publicados en otros medios impresos, ni electrónicos. Tampoco deberán haber sido sometidos de manera simultánea a otras 
revistas u órganos editoriales. Deberán atender de manera estricta la presente guía para autores.

2. Los trabajos deberán enviarse en su versión final y completa, ya que no se admitirán modificaciones posteriores una vez iniciado el proceso de evaluación.

3. Dimensiones Turísticas publicará tres tipos de trabajos: artículos, notas críticas y reseñas bibliográficas.

4. Todos los trabajos serán revisados para verificar que se ajusten estrictamente a la presente guía para autores. En caso contrario se remitirán a los/las autores/ as para que realicen los ajustes correspondientes. Una vez establecido que el trabajo cumple con los requisitos solicitados por la revista, será enviado a dos árbitros, quienes determinarán en forma anónima:

a) Dictamen positivo: indica un resultado favorable; el manuscrito puede ser evaluado:

- Publicar sin cambios;

- Publicar cuando se hayan cumplido con modificaciones menores;

- Publicar una vez que se haya efectuado una revisión a fondo.

b) No publicable: El manuscrito se rechaza de forma definitiva.

5. En caso de discrepancia entre ambos resultados, el texto será enviado a un tercer árbitro, cuyo dictamen será determinante para decidir si se acepta o no. Los resultados del proceso de evaluación serán inapelables en todos los casos.

6. Los trabajos enviados por académicos/as adscritos/as a alguna institución serán sometidos a consideración de árbitros externos a la misma.

7. Los dictámenes serán enviados a los/las autores/as oportunamente.

8. Los trabajos enviados deberán estar escritos de manera clara, sencilla y bien estructurada, omitiendo la redacción en primera persona, ya sea en singular o plural (yo o nosotros).

9. Los párrafos adoptarán el estilo de párrafo moderno (sin sangría).

10. Los trabajos podrán estar escritos en español o en inglés.

\section{Requisitos para los artículos}

1. Todos los trabajos deberán estar escritos en el programa Word 2011 o anterior, en hojas tamaño carta, en una sola faz, a espacio y medio y con márgenes de tres centímetros. Tipo de letra Times New Roman de 12 puntos.

2. La extensión mínima del artículo será de 20 cuartillas y la máxima de 30 cuartillas tamaño carta, a espacio y medio, incluyendo resumen, cuadros, gráficos y figuras (mapas, ilustraciones, diagramas, fotografías) y bibliografía.

3. En la primera página deberá aparecer el título del trabajo (redactado en alta y bajas, en negritas y en español e inglés), que deberá ser breve y referir claramente 
el contenido. Enseguida se incluirá un resumen en español e inglés (abstract) con una extensión máxima de 600 caracteres, en el que se destaque el objetivo, la relevancia del análisis, el método utilizado, los principales resultados o hallazgos más relevantes. Es responsabilidad del autor proveer una traducción correcta del resumen. Asimismo, se requieren cinco palabras clave en español e inglés (key words). Se sugiere que estas palabras sean: una geográfica, dos disciplinarles y dos temáticas, con su respectiva traducción al inglés o español que permitan identificar el contenido del artículo. Enseguida se presenta el texto principal y las referencias.

4. El texto deberá organizarse como sigue (los títulos de secciones son indicativos, las propuestas pueden llevar otro título, pero respetar los contenidos):

a) Título

b) Resumen (español e inglés) y palabras clave en ambos idiomas

c) Introducción

d) Cuerpo del trabajo: antecedentes, metodología, resultados, discusión y/o hallazgos.

e) Conclusiones

f) Bibliografía

5. Los títulos o subtítulos deberán diferenciarse entre sí, para ello se recomienda el uso del sistema decimal progresivo, cuidando que la numeración de los subtemas o secciones no sea excesiva o mayor a dos órdenes (2., 2.1, 2.1.1, 2.1.2).

6. Las siglas y acrónimos deberán ser claramente definidos en su primer uso en el texto.

7. No se aceptan abreviaturas.

8. Todas las referencias a material previamente publicado y a fuentes estadísticas deberán estar identificadas en el texto utilizando el sistema de citas autor y fecha de APA 6, anotando entre paréntesis el primer apellido del autor/a o autores, seguido del año de publicación y página(s) de referencia precedida(s) por las letras p. o pp. Por ejemplo: (Hiernaux, 2010, p. 63) o (Hiernaux y Osorio, 2015, pp. 231-235).

9. Las notas de pie de página deberán ser las estrictamente necesarias, estar numeradas sucesivamente en números arábigos y estar situadas a pié de página. Se utilizarán sólo para hacer comentarios puntuales o aclaraciones del autor y no para referencias bibliográficas. Deberán presentarse con letra Times New Roman de 9 puntos evitando anexos o apéndices.

10. Los cuadros, tablas y gráficos deberán incluir información estadística concisa, en formato de hoja de cálculo, preferiblemente en Microsoft Excel. Igualmente deberán colocarse en formato editable en el lugar propuesto en el documento, con el título colocado en la parte superior del objeto, con tipología Times New Roman 10 puntos y con su respectiva fuente de referencia colocada en la parte inferior. 
11. Las figuras deberán respaldarse en un archivo aparte, en formato de imagen jpeg (.jpg) o tiff (.tif) con una resolución de 300 dpi y preferentemente en color y un archivo por cada objeto. También deberán colocarse en formato editable en el lugar propuesto en el documento, con el título colocado en la parte superior de la figura, con tipología Times New Roman 10 puntos y con su respectiva fuente de referencia colocada en la parte inferior.

12. Tanto los cuadros, tablas, gráficos y demás figuras serán numerados con el sistema arábigo (cuadro 1, 2, 3, etc.). Las fotografías son consideradas como figuras (figura 1, 2, 3, etcétera). Estas últimas deberán manejarse en formato JPG a 300 dpi como mínimo y deberán especificar como pie de foto, el autor y el año en que fueron tomadas, con tipología Times New Roman 10 puntos y con su respectiva fuente de referencia, colocada en la parte inferior.

13. Cada archivo debe ir titulado en primer lugar por el tipo de objeto, su número consecutivo y la página en que queda ubicado (graf1p8.jpg; mapa1p15.tif; fig 1p12. jpg; fig2p16.xls; etcétera). En el cuerpo del texto deberá incluirse cada objeto en el lugar correspondiente en formato editable.

14. La bibliografía se incluirá al final del artículo ordenada alfabéticamente por autor, incluyendo exclusivamente las obras citadas en el cuerpo del texto como libros, capítulos de libros, artículos en revistas digital o impreso, notas periodísticas, archivos de Internet, películas, entre otros.

\section{Requisitos para las notas críticas}

1. Las notas críticas son reflexiones sobre temas de actualidad o avances de investigación. Deberán tener una extensión mínima de ocho cuartillas tamaño carta y un máximo de diez, a espacio y medio, en Times New Roman de 12 puntos, con márgenes de tres centímetros.

2. Las notas críticas serán seleccionadas por el Comité Editorial de la revista considerando su calidad, originalidad en el análisis, actualidad y pertinencia temática.

3. Las notas críticas deberán atender las mismas indicaciones con respecto al título (bilingüe), así como para citar referencias y bibliografía.

\section{Requisitos para las reseñas bibliográficas}

1. Las reseñas deben referirse a libros relevantes publicados dentro de los dos años anteriores a la fecha de publicación de la revista y su extensión máxima deberá ser de cuatro páginas tamaño carta, a espacio y medio, en Times New Roman de 12 puntos, con márgenes de tres centímetros en todos los lados. 
2. La reseña deberá contener la referencia completa de la obra (formato APA 6), seguida de los comentarios de quien hace la reseña y los datos de identificación (nombre y apellidos, adscripción institucional y correo electrónico).

3. Las reseñas deberán atender las mismas indicaciones con respecto al título (bilingüe), así como para citar referencias y bibliografía.

Normas para citar las referencias bibliográficas

Las referencias a fuentes consultadas deberán incluirse al final en orden alfabético, sin distinguir el tipo de fuente y en formato APA 6.

\section{Artículos y publicaciones periódicas impresas}

Apellido, A. A., Apellido, B. B. y Apellido, C. C. (Año). Título del artículo (en redondas). Nombre de la revista (en cursivas), volumen(en cursivas)(número), pp.-pp.

Ejemplo:

Bertoncello, R. (2002). Turismo y territorio otras prácticas, otras miradas. Aportes y Transferencias, 6(2), 29-50.

\section{Artículo y publicaciones digitales o electrónicas}

Apellido, A. A., Apellido, B. B. y Apellido, C. C. (Año). Título del artículo (en redondas). Nombre de la revista (en cursivas), volumen(en cursivas)(número), pp.-pp. Recuperado de www.direcciónelectrónica.com

Ejemplo:

Valcuende del Río, J. M. (2012). Turismo y poblaciones indígenas: Espacios, tiempos y recursos. Scripta Nova. Revista Electrónica de Geografía y Ciencias Sociales, XVI(410), 2855. Recuperado de http://www.raco.cat/index.php/ScriptaNova/issue/view/18634

\section{Artículo con DoI}

Apellido, A. A., Apellido, B. B. y Apellido, C. C. (Año). Título del artículo (en redondas). Nombre de la revista (en cursivas), volumen(en cursivas)(número), pp.-pp. Dol: XXX-YYYY Ejemplo:

Valcuende del Río, J. M. (2012). Turismo y poblaciones indígenas: Espacios, tiempos y recursos. Scripta Nova. Revista Electrónica de Geografía y Ciencias Sociales, XVI(410), 28-55. DOI: $1138-9788$

\section{Libros}

Apellido, A. A. (Año). Título (en cursivas). Ciudad, País: Editorial.

Ejemplos:

Santana, A. (1997). Antropología y Turismo. ¿Nuevas hordas, viejas culturas? Barcelona, España: Ariel. 
Casez, G. (1992a). Fondements pour une géographie du tourisme et des loisirs. París, Francia: Bréal Editions.

Casez, G. (1992b). Tourisme et tiers-monde, un bilan controversé. París, Francia: L'Harmattan (Tome II).

\section{Libros con editor, compilador o coordinador:}

Apellido, A. A. (Ed.). (Año). Título (en cursivas). Ciudad, País: Editorial.

Ejemplo:

Vera Rebollo, J. F. (coord.). (2011). Análisis territorial del turismo y planificación de destinos turísticos. Valencia, España: Tirant Lo Blanch.

\section{Versión electrónica o digital de libro impreso:}

Apellido, A. A. (Año). Título (en cursivas). Editorial. Recuperado de www.direcciónelectrónica.com

Ejemplo:

Ascanio, A. (2013). Economía del turismo [e-book]. Ediciones de la U.

\section{Capítulo de libro:}

Apellido, A. A. y Apellido, B. B. (Año). Título del capítulo (en redondas). En A. A. Apellido (Ed.), Título del libro (en cursivas) (pp. nn-nn). Ciudad, País: Editorial.

Ejemplos:

Luka, N. (2011). Del espacio al lugar y al paisaje cultural: segundas residencias a orillas de ríos y lagos en Canadá central. En T. Mazón, R. Huete y A. Mantecón (eds.), Construir una nueva vida. Los espacios del turismo y la migración residencial (pp. 2146). Santander, España: Milrazones.

Salvat, J., Meritxell, S. y Olmos, P. (1998). Evaluación del potencial turístico: las montañas de Prades. En J. Oliveras y S. Antón (eds.), Turismo y planificación del territorio en la España de fin de siglo (pp. 107-115). Tarragona, España: Universitat Rovira I Virgili.

\section{Videos, grabaciones y otros soportes digitales:}

Apellido, A. A. (Productor) y Apellido, B. B. (Director). (Año). Título (en cursivas) [Película cinematográfica]. País de origen: Estudio.

Ejemplo:

Secretaría de Turismo de México (2015). Compendio estadístico del turismo en México 2016 [disco compacto]. México: Sectur.

\section{Videos, podcast y otras fuentes en línea:}

Apellido, A. A. (día, mes, año). Nombre del programa o evento (en cursivas) [Tipo de archivo]. Recuperado de www.direcciónelectrónica.com 
Ejemplo:

Boehm, P. (26 de noviembre de 2014). La entrevista de Herta Müller en Hay Festival Cartagena 2013 [Audio en podcast]. Recuperado de http://programas.cooperativa.cl/ unanuevamanana/

\section{Páginas web}

Apellido, A. A. (Año). Título de la página web (en cursivas). Recuperado de www.direcciónelectrónica.com

Ejemplo:

Instituto Nacional de Estadística y Geografía (INEGI) (2014). Cuenta Satélite del Turismo (CST) de México. Recuperado de http://www.beta.inegi.org.mx/app/biblioteca/ficha. html?upc=702825060640

\section{Simposios y conferencias}

Apellido, A. y Apellido, B. (mes, año). Título de la presentación (en redondas). En A. Apellido del Presidente/organizador del Congreso (Presidencia), Título del simposio (en cursivas). Simposio dirigido por Nombre de la Institución Organizadora, Lugar.

Ejemplo:

Ibáñez, R. (noviembre, 2013). Retos en materia de turismo y sustentabilidad en pequeñas localidades costeras de Baja California Sur (BCs). En 7mo. Congreso Internacional de la Academia Mexicana de Investigación Turística. Academia Mexicana de Investigación Turística y Universidad Autónoma de Chiapas, San Cristóbal de Las Casas, Chiapas, México.

\section{Tesis}

Apellido, A. (Año). Título de la tesis (en cursivas) (Tesis de [grado]). Nombre de la Institución, lugar de presentación.

Ejemplo:

Gaxiola Aldama, R. (2010). Turismo sexual masculino y las prácticas sociales de uso del espacio urbano en la ciudad de Tijuana (Tesis de doctorado en Ciencias Sociales con especialidad en Estudios Regionales). El Colegio de la Frontera Norte, Tijuana, Baja California, México.

\section{Comunicaciones personales y entrevistas}

Si bien las comunicaciones personales (correos, cartas privadas, memorandos, entrevistas telefónicas) deberán aparecer referidas en el cuerpo del texto según lo sugerido por las normas APA 6, no se incluyen en las referencias bibliográficas, por no considerarse fuentes consultables. 


\section{ENVÍos}

Los trabajos podrán enviarse atendiendo cualquiera de las dos opciones:

1. Enviar el archivo digital del trabajo a la dirección: amit.dimentur@gmail.com, asegurándose de eliminar las referencias de autoría y filiación.

2. Subir el archivo digital del trabajo directamente en el siguiente enlace: https://dimensionesturisticas.amiturismo.org/envio-de-archivos/

\section{Información adicional}

1. Para asegurar el anonimato, además del texto completo del artículo o reseña, es necesario enviar en hoja independiente o capturar directamente en el siguiente enlace https://dimensionesturisticas.amiturismo.org/envio-de-archivos/

- Tipo de colaboración

- Título de la colaboración.

- Nombre completo del/la autor/a.

- Correo electrónico del/la autor/a.

- Institución y dependencia de adscripción.

- Dirección postal

- País

2. Currículo abreviado de el/la autor/a o autores/as (máximo 600 caracteres), que incluya el último grado académico y la institución donde obtuvo el grado, ocupación actual, líneas de investigación y título de los últimos tres trabajos publicados.

Lista de comprobación de preparación de envíos

Como parte del proceso de envío se requiere que los autores indiquen que el mismo cumple puntualmente con las siguientes características:

1. Que la propuesta no ha sido publicada previamente, ni se ha enviado simultáneamente a otra revista.

2. Que el fichero enviado está en formato Microsoft Word.

3. Que se han añadido direcciones web para las referencias donde sea posible.

4. Tipografía Times New Roman a 12 puntos para el texto y de 10 para títulos de cuadros, gráficas y figuras y para notas de pie de página el tamaño es 9.

5. Texto interlineado a espacio y medio.

6. Que el texto cumple con los requisitos bibliográficos y de estilo indicados en la presente Guía para autores. 
Los trabajos que no cumplan con estas indicaciones pueden ser devueltos al/la autor/a, quien podrá enviar de nuevo su manuscrito siempre y cuando cumpla con los puntos solicitados.

Aviso de derechos de autor

- Los/as autores/as conceden a Dimensiones Turísticas el permiso para que su material se difunda en la revista y medios magnéticos, electrónicos y fotográficos. Los derechos de autor de los artículos publicados en Dimensiones Turísticas son cedidos a la Academia Mexicana de Investigación Turística, A.C. (AMIT) tras la aceptación del original para que éste se publique y distribuya en versión electrónica; asimismo, los/las autores/as conserva(n) sus derechos morales conforme lo establece la Ley de derechos de autor.

- El/la autor/a principal recibirá una forma de Declaración de originalidad y cesión de derechos de autor que deberá firmar y remitir a Dimensiones Turísticas (amit.dimentur@gmail.com) conjuntamente con la versión final del trabajo. Será su responsabilidad obtener la firma y consentimiento de los/las demás autores/as si los hubiere.

- Por otra parte, los/as autores/as podrán usar el material de su artículo en otros trabajos o libros publicados por ellos mismos, con la condición de citar a Dimensiones Turísticas como la fuente original de los textos.

- Es responsabilidad de los/las autores/as obtener por escrito la autorización correspondiente para todo aquel material que forme parte de su artículo (Vg. fotografías o mapas satelitales) y que se encuentre protegido por la Ley de derechos de autor.

\section{Declaración de privacidad}

Los nombres y direcciones de correos administrados por Dimensiones Turísticas se usarán exclusivamente para los fines declarados por la revista y no estarán disponibles para ningún otro propósito u otra persona.

\section{OTROS}

\section{Declaración de ética}

Dimensiones Turísticas suscribe el código de conducta del cope (Committee on Publication Ethics), que adopta las siguientes recomendaciones de la Guía de buenas prácticas revisada y aprobada por el COPE en 2011: 
- La dirección de la revista y demás miembros del equipo editorial son responsables de garantizar un proceso de evaluación anónimo entre autores y evaluadores. La información sobre el manuscrito se mantendrá en estricta confidencialidad y sólo se informará a autores/as responsables de la propuesta y al equipo editorial.

- La dirección de la revista mantendrá anónima la identidad de los/as evaluadores/as.

- Dimensiones Turísticas se compromete a elegir evaluadores/as calificados/as según la temática y con capacidad probada para evaluar de forma ética y profesional, evitando conflictos de intereses.

- Dimensiones Turísticas cuidará la calidad académica y ética de la comunicación con los/las evaluadores/as, cualquier falta, descortesía o mala conducta de un/a dictaminador/a será revisada y la revista se compromete a no recurrir a evaluadores / as que realicen tales prácticas.

- Las propuestas serán sometidas a dictamen considerando su contenido intelectual, sin sesgos ni discriminación de edad, género, creencias políticas o religiosas y respetando la libertad de expresión.

- Las decisiones editoriales de aceptación o rechazo estarán basadas en la importancia, originalidad y claridad del manuscrito, en la validez del estudio científico y en su vínculo con la línea editorial de la revista. El/la directora/a sólo podrán revocar propuestas o contribuciones en caso de que se identifiquen problemas serios con las mismas, como plagio, faltas éticas, entre otras, aunque estuvieran previamente aprobadas para su publicación.

- En caso de ser necesario y estar comprobado, Dimensiones Turísticas puede hacer públicas cuestiones de mala conducta vinculadas a la investigación y a las propuestas incluyendo prácticas de plagio y duplicidad por parte de los/as autores/as.

- La dirección de la revista y el Consejo editorial recomiendan a sus revisores/as el uso de software para detectar plagios (Turnitin, Paper Rater, Viper, entre otros).

En cuanto a los/las evaluadores/as, éstos deberán comprometerse a lo siguiente:

Revisar las propuestas de forma confidencial y no utilizar la información de la revisión para otros fines distintos a la evaluación del trabajo.

- Informar a la dirección de la revista en caso de existir algún conflicto de cualquier tipo (de interés o vinculado con la metodología, contenidos o procedimientos de la investigación, los/las evaluadores/as deberán informar a la dirección).

- Informar a la dirección de la revista cuestiones de mala ética vinculadas a la investigación y a las propuestas incluyendo prácticas de plagio y duplicidad por parte de los/as autores/as.

En cuanto a los/las autores/as, éstos deberán comprometerse a lo siguiente:

- Las propuestas son responsabilidad de quien sustenta la autoría; los/las autores/ as se comprometen a someter obras académicas inéditas y originales elaboradas 
por ellos mismos. Las propuestas no deberán ser sometidas a otros procedimientos editoriales ni haber sido objeto de plagio, falsificación o manipulación.

- Todo material no producido por quien sustenta la autoría, deberá estar claramente citado de acuerdo a las normas de Dimensiones Turísticas.

- Los/las autores/as tienen la obligación de no incurrir en falsificación de participación de autoría, por lo que deberán equilibrar su participación a fin de que no aparezcan autorías o colaboraciones fantasmas.

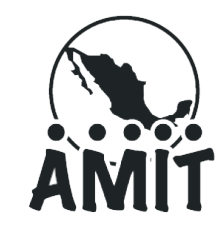

